\title{
Assessment of Ecosystem Services based on \\ Multiple Criteria and Group Decision Making
}

Marina Segura Maroto

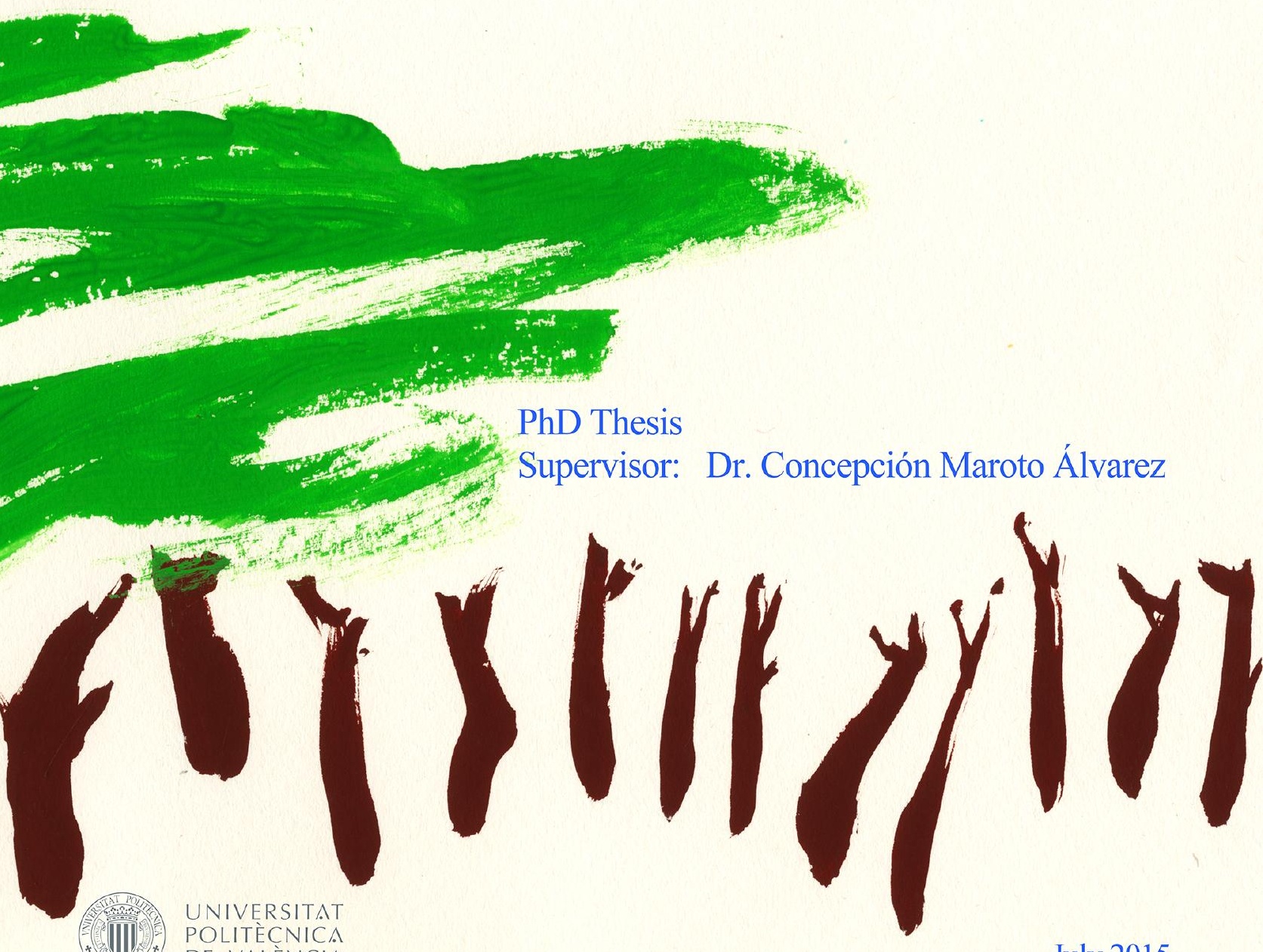

July 2015 




\section{Universitat Politècnica de València Department of Applied Statistics and Operational Research, and Quality}

\section{Assessment of Ecosystem Services based on Multiple Criteria and Group Decision Making}

Marina Segura Maroto

Supervisor:

Dr. Concepción Maroto Álvarez

\section{PhD in Statistics and Optimisation}

July 2015 

To my parents and my brother

"Your future is created by what you do today, not tomorrow" Robert Kiyosaki 



\section{Acknowledgements}

First of all, I acknowledge the Ministry of Education for the support received through the scholarship of Training Plan of University Teaching (AP2010-2134) for developing my doctoral thesis, as well as the support from the Ministry of Economy and Competitiveness through the research project "Multiple Criteria and Group Decision Making integrated into Sustainable Management”, ref. ECO2011-27369.

I would like to thank Dr Concepción Maroto for the patient guidance, encouragement and advice she has provided throughout my time as a PhD student. I have been extremely lucky to have her continued support during the ups and downs of this research.

I would also like to thank the other co-authors of the published articles: Dr Concepción Ginestar, Mr Duncan Ray, Dr Valerie Belton, Dr Baldomero Segura, Mr Juan Uriol, without whose expertise and lessons this work would have been more difficult. I would also like to add my thankfulness with Dr Valerie Belton and Mr Duncan Ray for allowing me to work with them and to live a useful and wonderful experience in the Department Management Science-University of Strathclyde (Glasgow, United Kingdom) and in the Centre for Ecology, Society and Biosecurity-Forest Research (Roslin, United Kingdom). The stays with Dr Belton have been supported by Minister of Economy and Competitiveness (2014) and the Ministry of Education (2015). My stays in Roslin were funded by the European Cooperation in Science and Technology (COST) Actions, COST action FP0804 Forest Management Decision Support Systems (FORSYS) for the first one in 2012 and COST Action FP1207 Orchestrating ForestRelated Policy Analysis in Europe (ORCHESTRA) for the second stay, in 2015.

This research would have not been possible without the involvement of staff from Department of Natural Resources Management (Generalitat Valenciana), specially $\mathrm{Mr}$ José Luis Pérez Sopena, as well as the time and expert' judgments from all of the stakeholders involved in the workshop and in surveys which have been carried out. The collaboration of the directors, staff and stakeholders of the natural parks from Valencian Community have been very important. I am indebted to them for their collaboration in this research for improving management of natural resources in Valencian region, in 
particular to Mr Antonio J. Cases and Mrs Gema del Amo from Serra Espadà natural park.

I must express my gratitude to the members of the Department of Applied Statistics and Operational Research, and Quality. In particular, I would like to mention the director, Dr Ana Isabel Sanchez, and the director of the Centre for Quality and Change Management, Dr Andres Carrion.

I also thank Dr Carmen Lloret (Fine Arts Professor) for her beautiful interpretation of the ecosystem services for the manuscript cover, by merging art and science.

Finally, thanks a lot to Mr M. Dogan and Mr Stephen Kennedy for their valuable help with the English proofreading and Mrs Mercé Palmer for the Valencian translation from the Office for the Dissemination and Standardisation of Valencian. 


\section{Contents}

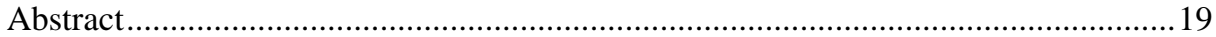

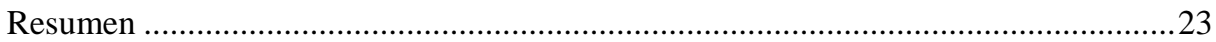

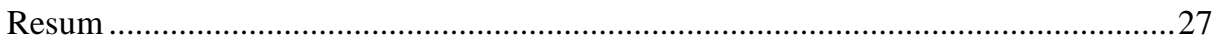

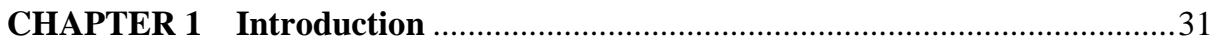

CHAPTER 2 Decision Support Systems for Forest Management: a comparative

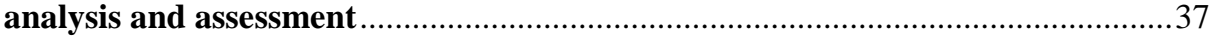

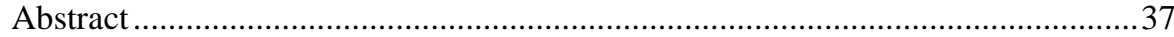

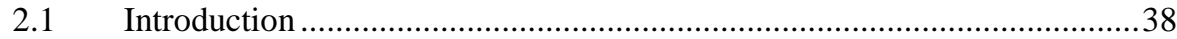

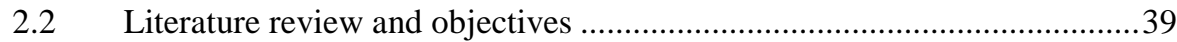

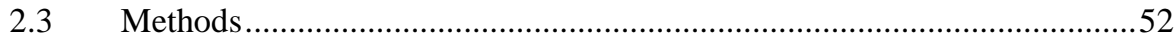

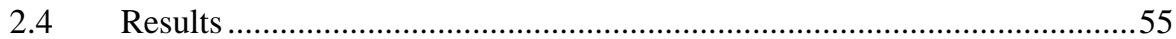

2.4.1 Distribution of forest problems by dimension ................................55

2.4.2 Distribution of forest problems by models and methods ...................59

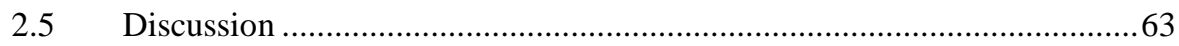

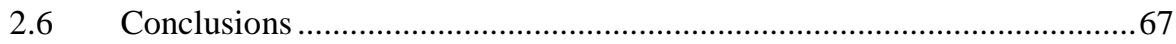

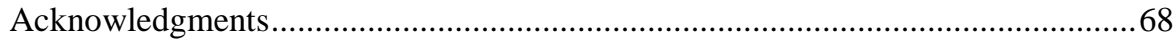

CHAPTER 3 Sustainable Forest Management in a Mediterranean region: Social

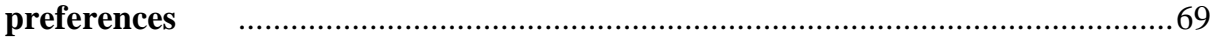

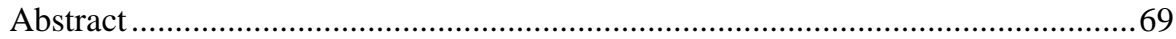

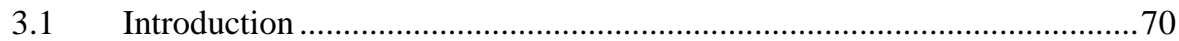

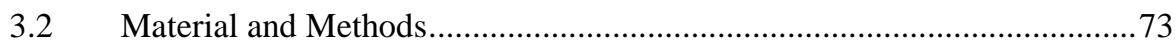

3.2.1 The Analytic Hierarchy Process and Goal Programming models .....73

3.2.2 Experts, stakeholders, workshop and surveys.................................74

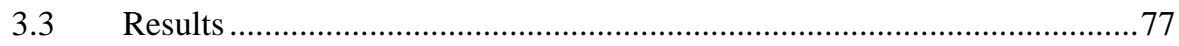

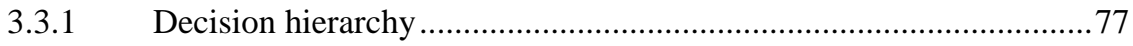

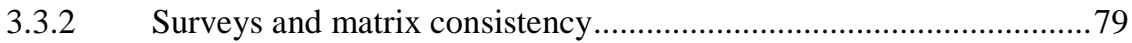

3.3.3 Preferences of stakeholder about criteria and objectives ...................81 


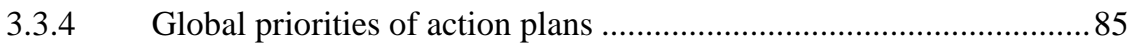

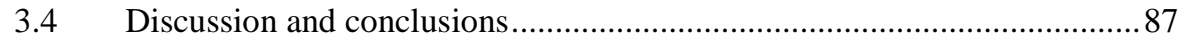

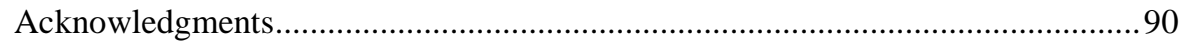

CHAPTER 4 A New Collaborative Methodology for Assessment and Management of Ecosystem Services............................................................... 91

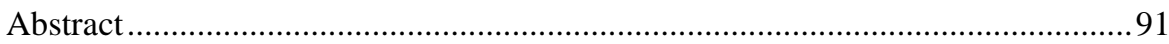

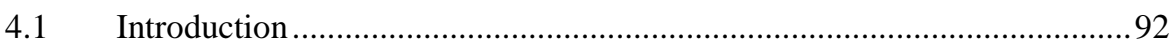

4.2 Methodological approach...................................................................96

4.3 A collaborative process to manage and assess Ecosystem Services...........98

4.3.1 Decision makers, technical staff and other stakeholders ..................98

4.3.2 Performance measures for Ecosystem Services and elicitation of

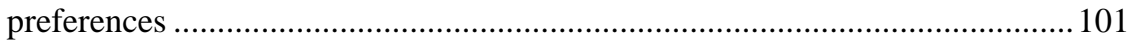

4.3.3 Determining new indicators for assessing Ecosystem Services.......102

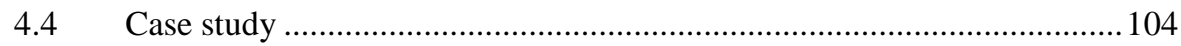

4.4.1 Natural park network in the Valencian Community ........................ 104

4.4.2 Network survey, data analysis and results .................................... 105

4.4.3 Main Ecosystem Services hierarchy and preferences elicitation .....108

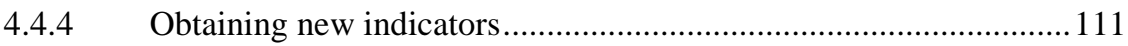

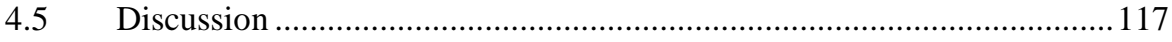

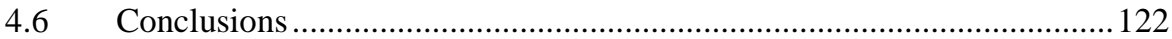

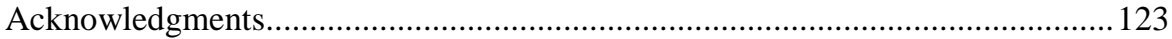

CHAPTER 5 Valuing Ecosystem Services through Multiple Criteria Decision

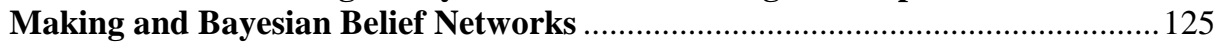

5.1 Multiple Criteria Decision Making ......................................................... 125

5.2 Bayesian Belief Networks ................................................................. 128

5.3 Multiple Criteria Decision Making and Bayesian Belief Networks: a

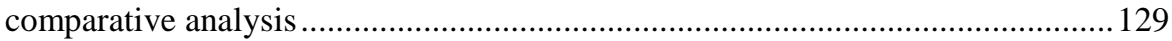

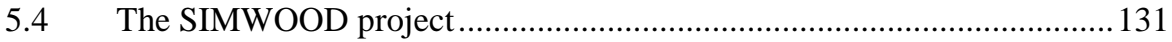

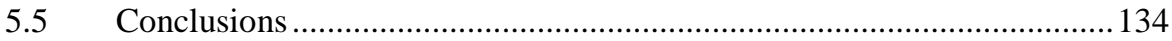

CHAPTER 6 General discussion of results .....................................................137 
CHAPTER 7 Conclusions 145

References 151

Annexes 173

Annex I Glossary of abbreviations. 175

Annex II Questionnaire for the survey carried out to elicit the stakeholders' preferences about criteria and objectives for sustainable and participatory management of the forests of the Valencian Community 181

Annex III Questionnaire for the survey carried out amongst forest experts to quantify the contribution of the action lines to different objectives for forest management in the Valencian Community 191

Annex IV Goal Programming models to aggregate stakeholders' preferences from comparison matrices and to obtain weights of criteria

Annex V Questionnaire for the survey to identify the preferences for Ecosystem Services in the natural park network of the Valencian Community

Annex VI Questionnaire for the survey carried out amongst stakeholders to obtain the weights of the criteria for collaborative management and valuation of ecosystem services of the Serra d'Espadà natural park 



\section{List of Tables}

Table 2-1. Literature review of Decision Support Systems for forest management ....40

Table 2-2. Literature review of optimisation methods for forest management

Table 2-3. Literature review of MCDM techniques and economical models for forest

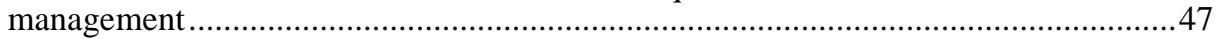

Table 2-4. Literature review of statistical methods for forest management.................50

Table 2-5. Models and Methods in Forest Management DSS classified by approaches

Table 2-6. Contingency table of problems by temporal scale and objective dimensions

Table 2-7. Contingency table of problems by decision making dimension and products \& services

Table 2-8. Distribution of DSS by temporal scale of problems and methods in cases and percentage 60

Table 2-9. Contingency table of problems by temporal scale dimension and economic models

Table 2-10. Contingency table of problems only products dimension and information systems.

Table 3-1. Distribution of questionnaires among stakeholder groups (first survey) and the expert group (second survey)

Table 3-2. Global priorities of action plans by stakeholder groups and public budget 86

Table 4-1. Evaluation table of alternatives based on the Ecosystem Services.... 102

Table 4-2. Preferences for Ecosystem Services by functions and group of stakeholders in percentage obtained by AHP method

Table 4-3. Evaluation table for five zones of the Serra d'Espadà natural park 112

Table 4-4. Preferences functions and parameters for Ecosystem Services indicators 113

Table 5-1. Comparative analysis of BBN and MCDM methods 130 



\section{List of Figures}

Figure 2-1. Forest management problems identified in country reports (Borges et al., 2014) classified by goods and services 56

Figure 2-2. Significant relations between features of problems solved by DSS, shown by links between items, obtained through contingency tables with 5\% statistical significance

Figure 2-3. Significant relations between methods (rectangles) and features of problems (ellipses) solved by DSS shown by links between items, obtained through contingency tables with $5 \%$ statistical significance

Figure 3-1. Flow-chart of process to obtain stakeholders' preferences and to prioritise action plans

Figure 3-2. Decision hierarchy for strategic management of Mediterranean forests ... 78

Figure 3-3. Priorities of social, economic and environmental criteria in sustainable management of Valencian forest by stakeholder groups

Figure 3-4. Priorities of social objectives of Valencian forest by stakeholder groups.82

Figure 3-5. Priorities of environmental objectives of Valencian forest by stakeholder groups

Figure 3-6. Priorities of economic objectives of Valencian forest by stakeholder groups

Figure 3-7. Priorities of environmental objectives when varying the control parameter in the extended Goal Programming model

Figure 4-1. Methodology for implementing collaborative management and assessment Ecosystem Services. 100

Figure 4-2. Percentage of decision makers, technical staff and other stakeholders by importance degree assigned to Ecosystem Services in the natural park network ......107

Figure 4-3. Ecosystem Services hierarchy of Serra d'Espadà natural park 109

Figure 4-4. Ecosystem Services preferences (\%) by stakeholder groups in the Serra d’Espadà natural park

Figure 4-5. Visual classification of territory (Zones) by main categories of ESS in the Serra d'Espadà natural park 115

Figure 4-6. Global index by zones in the Serra d'Espadà natural park. D-Sight software 116

Figure 4-7. Global Visual Analysis for the Serra d'Espadà natural park. D-Sight software 


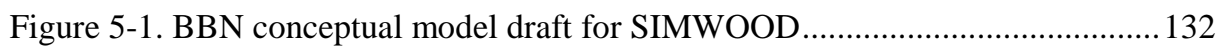

Figure 5-2. Decision hierarchy based on ecosystem services for SIMWOOD ...........133 


\section{List of Illustrations}

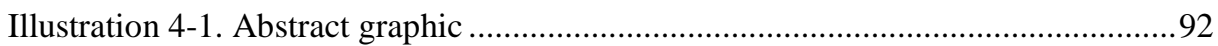





\section{Abstract}

Multiple Criteria and Group Decision Making are powerful techniques for dealing with strategic decision problems from both public and private sectors. These approaches are essential when addressing issues related to the management of natural resources, forests in particular. Strategic forest planning has evolved from regulating the flow of industrial timber resources to its current focus on sustainable forest management. Nevertheless, many Ecosystem Services (ESS) are free and can disappear due to a lack of economic incentive to preserve them.

The main objectives of this research are the following. First, to analyse the models and methods in Decision Support Systems (DSS) for forest management, taking into account the important features which allow forestry related problems to be categorized. Second, to define strategic criteria for the sustainable management of Mediterranean forests, as well as to elicit and aggregate the stakeholders' preferences. Third, to propose a robust methodology to implement collaborative management focused on ESS and to develop indicators for the main functions of ESS.

The methodology is based principally on a workshop and surveys to elicit the decision makers', experts' and other stakeholders' preferences. Several techniques were then used to aggregate individual judgements and determine social preferences, in particular, Analytic Hierarchy Process (AHP) and Goal Programming (GP). In addition, a PROMETHEE based method has been developed to provide indicators of the ESS, classified into provisioning, maintenance and direct to citizens services.

The analysis of DSS for forest management has shown that the best choice of approach to solve a given problem depend on its nature, which can be characterized by the temporal scale (strategic, tactical, operational), spatial context, spatial scale (stand, forest/landscape, regional/national), number of decision makers or stakeholders, objectives (single, multiple) and finally goods and services involved. Simulation methods are related to the spatial context and spatial scale, as well as the number of people involved in taking a decision, more commonly being used on a smaller spatial scale, as well as when there is a single decision maker. On the contrary, there have been 
no significant relationships between optimisation and statistical methods and problem characteristics.

With respect to the latest trends, the new generation of evolutionary algorithms gain importance when faced with Integer Programming (IP) solvers, but they require tuning parameters to be competitive and their values are dependent on instance data. Regarding statistical methods there is a need to develop and integrate spatial models in Geographic Information Systems (GIS) tools, which will be a requirement to tackle spatial problems and also to involve stakeholders in participatory processes.

The problems focused on forest products are mainly managed from a technical point of view, while those involving goods and services are related less to expert knowledge than to stakeholder preferences. Approximately $73 \%$ of problems have multiple objectives, nevertheless nowadays only $40 \%$ of them are solved using Multiple Criteria Decision Making (MCDM) techniques. These data show a strong need and also a great opportunity to improve the capabilities of DSS in this regard. Additionally, the majority of DSS are focused on market products, alone or together with services and a few dealing only with services, and especially with non-market services. It has been confirmed that forest DSS are mainly focused on technical and market economic objectives rather than social and environmental ones.

One of the most vulnerable ecosystems is the Mediterranean forest, according to the Intergovernmental Panel on Climate Change (2007). Valencian forest is a good example of the Mediterranean forest, which provides low wood productivity and also non-wood services. A decision hierarchy for strategic management of Valencian forests has been developed by involving experts during the design phase. This was later validated in consultation with the stakeholders in a workshop and provides the base from which to obtain the social preferences. The results show greater importance for environmental and social criteria and lesser relevance for economic criteria, valid for both public and private Mediterranean forests. This result is the same regardless of which preference aggregation technique was used and takes into account the preferences of the majority of the stakeholders and also the minority opinions furthest from the consensus. New products and services such as rural tourism, renewable energies, landscape, hydrological regulation and erosion control, biodiversity and climate change mitigation are relevant. 
This research also proposes a robust methodology to implement collaborative management focused on ESS provided by protected areas and aggregated indicators for their main functions. Decision makers, technical staff and other stakeholders are included in the process from the beginning, by identifying ESS and eliciting preferences using the AHP method. Qualitative and quantitative data are then integrated into a PROMETHEE based method in order to obtain indicators for provisioning, maintenance and direct to citizens services. This methodology, which has been applied in a forest natural park, provides a tool for exploiting available technical and social data in a continuous process, as well as graphical results, which are easy to understand. This approach also overcomes the difficulties found in prioritising management objectives in a multiple criteria context with limited resources and facilitates consensus between all of the people involved. The new indicators define an innovative approach to assessing the ESS from the supply perspective and provide basic information to help establish payment systems for environmental services and compensation for natural disasters.

Finally, a comparative analysis between MCDM and Bayesian Belief Networks (BBN) is also included, pointing out the strengths and weaknesses of both approaches and their great potential for assessing ESS by using them in a hybrid methodology. One of the main strengths of BBN is that expert knowledge can be combined with empirical data, turning it into a useful method for environmental issues as is the case with MCDM. Both approaches allow the integration of qualitative and quantitative data, but availability of reliable data can represent an important challenge in both methodologies. New technologies to capture data will provide an opportunity to overcome this weakness, as well as a challenge to develop new models and methods that are really effective for assessing and managing ESS. 



\section{Resumen}

Las técnicas multicriterio y de decisión en grupo son métodos potentes para abordar problemas estratégicos de toma de decisiones, tanto en el sector público como en el privado. Este enfoque es esencial cuando se tratan temas relacionados con la gestión de los recursos naturales, en particular los bosques. La planificación forestal estratégica ha evolucionado de controlar el flujo de la madera con fines industriales a la actual planificación forestal sostenible. Sin embargo, muchos servicios del ecosistema son públicos y pueden desaparecer debido a la falta de incentivos económicos para su conservación.

Los principales objetivos de esta investigación son los siguientes. En primer lugar, analizar los modelos y los métodos de los sistemas de ayuda a la toma de decisiones para gestión forestal, teniendo en cuenta las características relevantes que permiten clasificar los problemas forestales. En segundo lugar, definir los criterios estratégicos para la gestión forestal sostenible del bosque mediterráneo, así como obtener y agregar las preferencias de los decisores y otras partes interesadas. En tercer lugar, proponer una metodología robusta para implementar una gestión colaborativa centrada en los servicios del ecosistema y desarrollar indicadores para las principales funciones de estos servicios.

La metodología se fundamenta principalmente en una jornada de trabajo con decisores, expertos y otros grupos de personas interesadas, así como en encuestas a todos ellos. Después se han utilizado varias técnicas para agregar las preferencias individuales y determinar las preferencias de los distintos grupos sociales, en particular el proceso analítico jerárquico y la programación por metas. Adicionalmente, se ha desarrollado un método basado en PROMETHEE que permite obtener indicadores de los servicios del ecosistema, clasificados en servicios de producción, mantenimiento y directos a los ciudadanos.

El análisis de los sistemas de ayuda a la toma de decisiones para gestión forestal ha puesto de manifiesto que los mejores enfoques para resolver los problemas forestales dependen de su naturaleza, caracterizada por la escala temporal (estratégicos, tácticos, 
operativos), el contexto espacial, la escala espacial (rodal, monte/paisaje, regional/nacional), el número de decisores o personas interesadas, el número de objetivos (uno, varios) y por último los bienes y servicios involucrados. Los métodos de simulación están relacionados con el contexto y escala espacial, así como con el número de personas que intervienen en la toma de decisiones, siendo más utilizados en las escalas espaciales más pequeñas y en el caso de un único decisor. Por el contrario, no se han encontrado relaciones significativas entre los métodos de optimización y los estadísticos con las características de los problemas.

Con respecto a las últimas tendencias, la nueva generación de algoritmos evolutivos gana importancia frente a la programación entera, sin embargo se necesita calibrar el valor de sus parámetros para ser algoritmos competitivos y además su valor depende de los datos concretos. En cuanto a los métodos estadísticos es necesario desarrollar e integrar modelos espaciales en los sistemas de información geográfica, que serán necesarios para abordar problemas espaciales y también para involucrar a las partes interesadas en los procesos participativos.

Los problemas centrados en los productos forestales se gestionan principalmente desde un punto de vista técnico, mientras que los que consideran bienes y servicios están menos relacionados con el conocimiento de los expertos que con las preferencias de las partes interesadas. Aproximadamente el $73 \%$ de los problemas de gestión forestal tienen varios objetivos, sin embargo sólo el $40 \%$ se resuelven mediante técnicas de toma de decisiones multicriterio. Estos datos muestran una fuerte necesidad y también una gran oportunidad para mejorar las prestaciones de los sistemas de ayuda a la toma de decisiones en este aspecto. Además, la mayoría de estos sistemas se centran en productos de mercado, solos o junto con servicios y sólo unos pocos abordan únicamente servicios y en especial los servicios públicos sin precio mercado. Se ha confirmado que los sistemas de ayuda a la toma de decisiones tienen en cuenta principalmente objetivos técnicos y económicos más que medioambientales.

Uno de los ecosistemas más vulnerables es el bosque mediterráneo, según los expertos sobre el cambio climático (Intergovernmental Panel on Climate Change, 2007). El bosque valenciano es un buen ejemplo, que tiene una baja productividad respecto a la madera y proporciona otros servicios diferentes. Se ha desarrollado una jerarquía de decisión para la gestión estratégica de los bosques valencianos involucrando a expertos en la fase de diseño. Este modelo fue validado posteriormente por las partes interesadas 
en una jornada organizada con esta finalidad y ha sido la base para obtener las preferencias sociales. Los resultados ponen de manifiesto la mayor importancia de los criterios medioambientales y sociales y la menor relevancia de los económicos, tanto para el monte mediterráneo público como privado. Este resultado es independiente del método de agregación utilizado y tiene en cuenta tanto las preferencias de la mayoría como de la minoría más alejada del consenso. Son relevantes los nuevos productos y servicios tales como el turismo rural, las energías renovables, el paisaje, la regulación hidrológica y el control de la erosión, la biodiversidad y la mitigación del cambio climático.

Esta investigación también propone una metodología robusta para implementar una gestión colaborativa centrada en los servicios del ecosistema que proporcionan las áreas protegidas e indicadores agregados para sus principales funciones. Los responsables de las decisiones, el personal técnico y otras personas interesadas han participado desde el inicio del proceso, identificando los servicios del ecosistema y proporcionado sus preferencias mediante la técnica del proceso analítico jerárquico. Después se integran los datos cualitativos y cuantitativos en un método basado en PROMETHEE con la finalidad de obtener indicadores para los servicios de producción, mantenimiento y directos a los ciudadanos. Esta metodología, que se ha aplicado en un parque natural, facilita la explotación de los datos técnicos y sociales en un proceso continuo y proporciona resultados gráficos muy fáciles de entender. Este enfoque también permite superar las dificultades que surgen al priorizar los objetivos de gestión en un contexto multicriterio con recursos limitados y facilita el consenso entre todas las personas involucradas. Los nuevos indicadores representan un enfoque innovador para la valoración de los servicios del ecosistema desde el punto de vista de la oferta y proporcionan información básica para establecer sistemas de pagos por servicios ambientales y compensaciones por desastres naturales.

Por último, se ha realizado un análisis comparado entre las técnicas multicriterio y las redes bayesianas, destacando las fortalezas y debilidades de ambos enfoques y su gran potencial en la valoración de los servicios del ecosistema mediante la utilización de ambos mediante una metodología híbrida. Una de las principales fortalezas de las redes bayesianas es la combinación de conocimiento de expertos con datos empíricos, que las convierten en un método útil en temas medioambientales, al igual que ocurre con las técnicas multicriterio. Ambos enfoques también permiten la integración de datos 
cualitativos y cuantitativos, sin embargo la disponibilidad de datos fiables puede representar un reto importante en ambas técnicas. Las nuevas metodologías de obtención de datos pueden representar una oportunidad para superar esta debilidad, así como un reto para desarrollar nuevos modelos y métodos que sean realmente efectivos para la valoración y gestión de los servicios de los ecosistemas. 


\section{Resum}

Les tècniques multicriteri i de decisió en grup són mètodes potents per a abordar problemes estratègics de presa de decisions, tant en el sector públic com en el privat. Aquest enfocament és essencial quan es tracten temes relacionats amb la gestió dels recursos naturals, en particular els boscos. La planificació forestal estratègica ha evolucionat de controlar el flux de la fusta amb finalitats industrials a l'actual planificació forestal sostenible. No obstant això, molts serveis de l'ecosistema són públics i poden desaparèixer a causa de la falta d'incentius econòmics per a conservarlos.

Els principals objectius d’aquesta recerca són els següents. En primer lloc, analitzar els models i els mètodes dels sistemes d'ajuda a la presa de decisions per a gestió forestal, tenint en compte les característiques rellevants que permeten classificar els problemes forestals. En segon lloc, definir els criteris estratègics per a la gestió forestal sostenible del bosc mediterrani, com també obtenir i agregar les preferències dels decisors i altres parts interessades. En tercer lloc, proposar una metodologia robusta per a implementar una gestió col·laborativa centrada en els serveis de l'ecosistema i desenvolupar indicadors per a les principals funcions d'aquests serveis.

La metodologia es fonamenta principalment en una jornada de treball amb decisors, experts i altres grups de persones interessades, i també en enquestes a tots ells. Després s'han utilitzat diverses tècniques per a afegir-hi les preferències individuals i determinar les preferències dels diferents grups socials, en particular el procés analític jeràrquic i la programació per metes. Addicionalment, s’ha desenvolupat un mètode basat en PROMETHEE que permet obtenir indicadors dels serveis de l'ecosistema, classificats en serveis de producció, manteniment i directes als ciutadans.

L'anàlisi dels sistemes d'ajuda a la presa de decisions per a la gestió forestal ha posat de manifest que els millors enfocaments per a resoldre els problemes forestals depenen de la naturalesa d'aquests problemes, caracteritzada per l'escala temporal (estratègics, tàctics, operatius), el context espacial, l'escala espacial (rodal, muntanya/paisatge, regional/nacional), el nombre de decisors o persones interessades, el nombre d'objectius 
(un, diversos) i, finalment, els béns i serveis involucrats. Els mètodes de simulació estan relacionats amb el context i l'escala espacial, com també amb el nombre de persones que intervenen en la presa de decisions, i són més utilitzats en les escales espacials més petites i en el cas d'un únic decisor. Per contra, no s'han trobat relacions significatives entre els mètodes d’optimització i els estadístics amb les característiques dels problemes.

Pel que fa a les últimes tendències, la nova generació d'algorismes evolutius guanya importància enfront de la programació sencera. No obstant això, cal calibrar-ne el valor dels paràmetres per a ser algorismes competitius i, a més, el valor depèn de les dades concretes. Quant als mètodes estadístics, cal desenvolupar i integrar models espacials en els sistemes d'informació geogràfica, que seran necessaris per a abordar problemes espacials i també per a involucrar les parts interessades en els processos participatius.

Els problemes centrats en els productes forestals es gestionen principalment des d'un punt de vista tècnic, mentre que els que es consideren béns i serveis estan menys relacionats amb el coneixement dels experts que amb les preferències de les parts interessades. Aproximadament el 73\% dels problemes de gestió forestal tenen diversos objectius, però només el $40 \%$ es resolen mitjançant tècniques de presa de decisions multicriteri. Aquestes dades mostren una forta necessitat i també una gran oportunitat per a millorar les prestacions dels sistemes d'ajuda a la presa de decisions en aquest aspecte. A més, la majoria d'aquests sistemes se centren en productes amb preu de mercat, sols o juntament amb serveis, i només uns pocs aborden únicament serveis i, especialment, els serveis públics sense preu comprat. S’ha confirmat que els sistemes d'ajuda a la presa de decisions tenen en compte principalment objectius tècnics i econòmics més que mediambientals.

Un dels ecosistemes més vulnerables és el bosc mediterrani, segons els experts sobre el canvi climàtic (Intergovernmental Panel on Climate Change, 2007). El bosc valencià n’és un bon exemple, ja que té una baixa productivitat respecte a la fusta i proporciona altres serveis diferents. S’ha desenvolupat una jerarquia de decisió per a la gestió estratègica dels boscos valencians involucrant experts en la fase de disseny. Aquest model ha sigut validat posteriorment per les parts interessades en una jornada organitzada amb aquesta finalitat $i$ ha sigut la base per a obtenir les preferències socials. Els resultats posen de manifest la major importància dels criteris mediambientals i socials i la menor rellevància dels econòmics, tant per a la muntanya mediterrània 
pública com privada. Aquest resultat és independent del mètode d'agregació utilitzat i té en compte tant les preferències de la majoria com de la minoria més allunyada del consens. Són rellevants els nous productes i serveis, com ara el turisme rural, les energies renovables, el paisatge, la regulació hidrològica i el control de l'erosió, la biodiversitat i la mitigació del canvi climàtic.

Aquesta recerca també proposa una metodologia robusta per a implementar una gestió col-laborativa centrada en els serveis de l'ecosistema que proporcionen les àrees protegides i indicadors agregats per a les seues funcions principals. Els responsables de les decisions, el personal tècnic i altres persones interessades hi han participat des de l'inici del procés, identificant els serveis de l'ecosistema i proporcionant les seues preferències mitjançant la tècnica del procés analític jeràrquic. Després s’integren les dades qualitatives i quantitatives en un mètode basat en PROMETHEE amb la finalitat d'obtenir indicadors per als serveis de producció, manteniment i directes als ciutadans. Aquesta metodologia, que s'ha aplicat en un parc natural, facilita l'explotació de les dades tècniques i socials en un procés continu i proporciona resultats gràfics molt fàcils d'entendre. Aquest enfocament també permet superar les dificultats que sorgeixen a l'hora de prioritzar els objectius de gestió en un context multicriteri amb recursos limitats i facilita el consens entre totes les persones involucrades. Els nous indicadors representen un enfocament innovador per a la valoració dels serveis de l'ecosistema des del punt de vista de l'oferta i proporcionen informació bàsica per a establir sistemes de pagaments per serveis ambientals i compensacions per desastres naturals.

Finalment, s'ha dut a terme una anàlisi comparada entre les tècniques multicriteri i les xarxes bayesianes, destacant les fortaleses i febleses de tots dos enfocaments i el seu gran potencial en la valoració dels serveis de l’ecosistema a través de la utilització de tots dos mitjançant una metodologia híbrida. Una de les principals fortaleses de les xarxes bayesianes és la combinació de coneixement d'experts amb dades empíriques, que les converteixen en un mètode útil en temes mediambientals, igual que ocorre amb les tècniques multicriteri. Tots dos enfocaments també permeten la integració de dades qualitatives i quantitatives, tot i que la disponibilitat de dades fiables pot representar un repte important en les dues tècniques. Les noves metodologies d'obtenció de dades poden representar una oportunitat per a superar aquesta feblesa, i també un repte per a desenvolupar nous models i mètodes que siguen realment efectius per a la valoració i la gestió dels serveis dels ecosistemes. 



\section{CHAPTER 1}

\section{Introduction}

Millennium Ecosystem Assessment (MEA) (2003) defines Ecosystem Services (ESS) as "the benefits that people obtain from ecosystems". The MEA classifies ESS into four categories: provisioning services (e.g. forest products), supporting services (e.g. soil formation), regulating services (e.g. water cycle, biodiversity) and cultural services (e.g. recreation). The vast majority of ESS are free, that is, they can be characterised as nonmarket services.

Forests are the most important terrestrial ecosystems on Earth and their management has environmental, economic, administrative, legal and social aspects. The large number of issues relating to forest management, such as fauna, flora, recreation, water, forest resources, etc. make the development of forest plans a complex process. Consequently, Decision Support Systems (DSS) are essential tools for practitioners involved in these decision making problems.

Forest management and planning have mainly focused on market products, especially timber. Forest DSS have been developed and applied mainly in North America, Latin America, Scandinavia, Australia and New Zealand, that is, in countries with highly productive forests in timber resources (Ananda and Herath, 2009). On the contrary, Mediterranean forests have low wood productivity and profitability, being one of the most vulnerable ecosystems, according to the Intergovernmental Panel on Climate Change (2007). Nevertheless, Mediterranean forests provide many other basic goods 
and services for human well-being, which have a high value for society, such as water, soil formation (erosion mitigation), biodiversity, recreation, etc.

According to Martell et al. (1998) strategic forest planning has evolved from regulating the flow of industrial timber resources to its current focus on Sustainable Forest Management (SFM). As the use of forests is oriented to multiple objectives, its management needs to know what is wanted from the forest, often involving numerous stakeholders, such as owners, people connected with tourism, recreation services or nature conservation, as well as forestry companies (Kangas et al., 2008). Nowadays, economic, social and environmental criteria should be taken into account in almost all strategic forest decisions.

The applications of Multiple Criteria Decision Making (MCDM) techniques focus on the conflicts among criteria and the conflicts between stakeholders with different opinions and priorities (Belton and Stewart, 2002). The multifunctional character of forest and natural landscapes makes the use of multiple criteria approaches necessary to solve forest problems. Likewise, these techniques can integrate the views of different groups of stakeholders.

In practice, MCDM methods have been implemented to inform forest decision problems and public participation and they will continue to be essential in forest and environmental management (Kangas and Kangas, 2005; Diaz-Balteiro and Romero, 2008). Decision making and public opinion appears as one of the relevant themes for future research in natural resource management (Petrokofsky et al., 2010). Nevertheless, several reviews (Mendoza and Martins, 2006; Ananda and Herath, 2009) and an extensive analysis of the literature to date show a lack of empirical research referring to Mediterranean forests.

Management objectives are one of the key issues, which are not always known or, in some cases, can only be elicited through prior analysis (Schmoldt et al., 2001). This is the case in sustainable management of Mediterranean forest, so explicitly specifying all relevant objectives and quantifying their importance in its strategic and sustainable management are very interesting contributions towards developing public policies according to social preferences in Europe.

Referring to protected areas, traditional methods of management define a legal framework, such as national park, natural monument or protected landscape, among 
others. Primary and secondary objectives are defined for each category of a protected area without providing tools or guidelines to weight their relevance in a specific context and without considering the value of ESS globally. In fact, the traditional management of protected areas has been focused only on the objectives of conservation and recreation.

Emerging paradigm also includes social and economic objectives, as well as the integration of different groups of stakeholders in collaborative management of protected areas. Collaborative management of public goods, such as some ESS, is essential to offer transparency of the decision making process. Public participation is already part of European public policies and those of the region of Valencia (PATFOR, 2011). Collaborative decision making leads to decisions which are socially more acceptable, because each group member can take other points of view into account in their preferences that might not have been considered if they had not shared information with others.

The management of protected areas requires the identification of market and non-market services that are provided to society, as well as an assessment of them to inform the state of the ESS. Valuation techniques such as Cost-Benefit Analysis (CBA) may be used to evaluate and make decisions based on market services (Sijtsma et al., 2013), however, this is not the case for non-market ESS. Traditional methods of ESS valuation such as benefit transfer or Contingent Valuation (CV) are the most widely used tools to assess non-market services. A complete review of economic valuation methods is presented in Ruiz (2014), as well as an application to several wetlands, located in the South of Valencian Community, protected as natural parks. In particular, this author used the travel cost method to assess recreation and CV for other aspects related to nonuse value of environmental services from wetlands.

Finally, a recent approach to dealing with ESS modelling is Bayesian Belief Networks $(\mathrm{BBN})$, whose applications in ESS have been presented in a recent review by Landuyt et al. (2013). BBN have been applied to assessing genetic resources, water and climate regulation, fresh water and food provision, recreation and pest and wildfire prevention. Due to the multidisciplinary character of ESS it is interesting to compare this approach with MCDM and explore the potential for combining them in order to enhance the assessment of ESS and, in the end, the decision making for their maintenance and improvement. 
The main objectives of this research are the following:

1. To assess the models and methods in DSS for forest management, taking into account the important features used to categorize forestry related problems.

2. To define the strategic criteria for sustainable management of Mediterranean forests to prioritise the action plans of public administration, as well as to elicit and aggregate the stakeholders' preferences, using several methods with the aim of increasing the objectivity and robustness of the results.

3. To develop a multicriteria methodology to implement collaborative and global ESS management, which is capable of integrating available data in order to select and rank projects in protected areas.

4. To develop new indicators based on the main functions of ecosystems to classify the territory inside protected areas, in particular according to their contribution to the maintenance services and direct services to citizen.

5. To compare the MCDM methodology with BBN, one of the most used in ESS modelling.

According to the regulation of the Universitat Politècnica de Valencia for a $\mathrm{PhD}$ as a compendium of publications, after this introduction the remaining manuscript is organised as follows:

Chapter 2 provides an extensive literature review of the DSS, models and methods which have been used to solve problems related to forest management, as well as a DSS assessment from the perspective of what problems should be dealt with and what models and methods should be applied. A literature review analysed the models and methods including MCDM, optimisation, economic models and statistical methods. The second part of this chapter is based on the DSS for SFM which are currently being used in 19 European countries, two North Americans countries, two South American countries, two African countries and an Asian country. 26 country reports written by 94 authors, experts on this topic, have been reviewed (Borges et al., 2014). In addition, the media semantic wiki developed by the FORSYS project (COST, 2012) has also been reviewed to include additional information to allow detailed analysis of the problems and methods described by the country reports. The content of this chapter has been published in Computers and Electronics in Agriculture as an article entitled "Decision Support 
Systems for Forest Management: a comparative analysis and assessment”, 101, pp 5567. February, 2014. DOI: http://dx.doi.org/10.1016/j.compag.2013.12.005.

Chapter 3 is a contribution which has been published in the open access journal Forest Systems, entitled "Sustainable Forest Management in a Mediterranean region: Social preferences”, 22(3) pp 546-558. December, 2013. DOI: http://dx.doi.org/10.5424/fs/ 2013223-4135. This chapter contributes a model for sustainable regional planning of Mediterranean forests, using a multiple criteria and group decision methodology with a participative process including all stakeholder groups. It has been developed for the forests in the Valencian region, defining and taking into account social, environmental and economic criteria. In this empirical research action plans have also been prioritised based on the preferences of several groups of stakeholders. Analytic Hierarchy Process (AHP) and Goal Programming (GP) have been used to determine the aggregated preferences of stakeholders, as well as to prioritise action plans of regional government.

Chapter 4 proposes a new methodology to manage protected areas based on their main ESS, grouped by functions (provisioning, maintenance and direct to citizens), considered as the objectives in the management process and it is therefore the basis for assessing them. This methodology merges two MCDM techniques, AHP and the Preference Ranking Organisation METhod for Enrichment Evaluations (PROMETHEE), incorporating all relevant points of view by involving decision makers and other stakeholders in the process. In addition, it provides a graphical tool that allows areas to be classified according to ESS indicators and has been applied in a case study in a forest natural park (Serra d' Espadà), located in Valencian Community, Spain. This contribution has been published in the open access journal Forest as an article entitled "A New Collaborative Methodology for Assessment and Management of Ecosystem Services”, 6(5), pp 1696-1720. May, 2015. DOI: http://dx.doi.org/10.3390/f6051696.

Chapter 5 includes a comparative analysis between MCDM and BBN, pointing out the strengths and weaknesses of both approaches and their potential for assessing ESS by using them in a hybrid methodology. The general discussion of results is presented in Chapter 6 and conclusions in Chapter 7. Finally, references and annexes are at the end of the manuscript. 
Supplementary materials are presented in annexes, which are organised as follows:

- Annex I is the glossary of abbreviations of the manuscript: acronyms of DSS and acronyms of models and methods.

- Annex II shows the questionnaire for the survey carried out to elicit the stakeholders' preferences about criteria and objectives for sustainable and participatory management of the forests of the Valencian Community.

- Annex III presents the questionnaire for the survey carried out amongst forest experts to quantify the contribution of the action lines to different objectives for forest management in the Valencian Community.

- Annex IV summarises the GP models to aggregate stakeholders' preferences from comparison matrices and to obtain weights of criteria.

- Annex V shows the questionnaire for the survey to identify the preferences for ESS in the natural park network of the Valencian Community.

- Finally, Annex VI provides the questionnaire for the survey carried out amongst stakeholders to obtain the weights of the criteria for collaborative management and valuation of ESS of the Serra d'Espadà natural park. 


\title{
CHAPTER 2
}

\section{Decision Support Systems for Forest}

\section{Management: a comparative analysis and assessment}

Segura, M., Ray, D., \& Maroto, C. (2014)

Computers and Electronics in Agriculture, 101, 55-67. http://doi.org/10.1016/j. compag.2013.12.005

\begin{abstract}
Decision Support Systems (DSS) are essential tools for forest management practitioners to help take account of the many environmental, economic, administrative, legal and social aspects in forest management. The most appropriate techniques to solve a particular instance usually depend on the characteristics of the decision problem. Thus, the objective of this chapter is to evaluate the models and methods that have been used in developing DSS for forest management, taking into account all important features to categorize the forest problems. It is interesting to know the appropriate methods to answer specific problems, as well as the strengths and drawbacks of each method. We
\end{abstract}


have also pointed out new approaches to deal with the newest trends and issues. The problem nature has been related to the temporal scale, spatial context, spatial scale, number of objectives and decision makers or stakeholders and goods and services involved. Some of these problem dimensions are inter-related, and we also found a significant relationship between various methods and problem dimensions, all of which have been analysed using contingency tables.

The results showed that $63 \%$ of forest DSS use simulation modeling methods and these are particularly related to the spatial context and spatial scale and the number of people involved in taking a decision. The analysis showed how closely Multiple Criteria Decision Making (MCDM) is linked to problem types involving the consideration of the number of objectives, also with the goods and services. On the other hand, there was no significant relationship between optimisation and statistical methods and problem dimensions, although they have been applied to approximately $60 \%$ and $16 \%$ of problems solved by DSS for forest management, respectively. Metaheuristics and spatial statistical methods are promising new approaches to deal with certain problem formulations and data sources. Nine out of ten DSS used an associated information system (Database and/or Geographic Information System - GIS), but the availability and quality of data continue to be an important constraining issue, and one that could cause considerable difficulty in implementing DSS in practice. Finally, the majority of DSS do not include environmental and social values and focus largely on market economic values. The results suggest a strong need to improve the capabilities of DSS in this regard, developing and applying MCDM models and incorporating them in the design of DSS for forest management in coming years.

\subsection{Introduction}

Forest management planning encompasses environmental, economic, administrative, legal and social aspects. The large number of issues relating to forest management, such as fauna, flora, recreation, water, forest resources, etc. make the development of forest plans a complex process. Consequently, Decision Support Systems (DSS) are essential tools for practitioners involved in complex decision making problems, such as those which arise in forest management and forest planning. DSS have been defined by Holsapple (2008, p.22) as “computer based systems that represent and process 
knowledge in ways that allow the user to take decisions that are more productive, agile, innovative and reputable', and Muys et al. (2010, p.87) considered DSS as “tools providing support to solve ill-structured decision problems by integrating a user interface, simulation tools, expert rules, stakeholder preferences, database management and optimisation algorithms', This chapter aims to assess the use of different models and methods in DSS for decision making in forestry, to gain some insight into which methods have been used in different applications, and to see where novel methods have emerged. The study supports the work of the European Cooperation in Science and Technology (COST) Action in demonstrating to new DSS developers how solutions have been found to different types of problems. Consequently, the literature review is comprised of two parts. Firstly, we review the recent literature on DSS relating to forest management planning, secondly we undertake and report an analysis of the literature in relation to the problem types addressed by different models and methods.

\subsection{Literature review and objectives}

An extensive literature review has uncovered a large number of published articles in recent years which use DSS to inform decision making in forestry. Table 2-1 shows how simulation and statistical methods have been applied to evaluate wind damage and pest management. Simulation is commonly used in growth models, and wildfire and landscape management. In focussing on Multiple Criteria Decision Making (MCDM) methods, we found the Analytic Hierarchy Process (AHP), Simple Multi-Attribute Rating Technique (SMART), and ELimination and Choice Expressing REality (ELECTRE) have all been integrated in DSS to solve problems, e.g. to indicate weights and to rank scenarios. The Preference Ranking Organisation METhod for Enrichment Evaluations (PROMETHEE) has been integrated in the LANdscape-scale, succession and DISturbance (LANDIS) DSS and applied to manage public forests in the USA with a consideration of forest products and Ecosystem Services (ESS) (Shang et al., 2012). Database and/or Geographic Information System (GIS) also appear in many DSS alone or together with techniques, such as simulation, MCDM, Linear Programming (LP), statistical analysis and Cost-Benefit Analysis (CBA).

It is also necessary to understand and evaluate which models and methods are available for solving main forest management problems and therefore provide guidance to 
developers on promising methods to improve the decision making by using DSS. Several recent reviews have explored areas such as spatial forest planning (Baskent and Keles, 2005; Weintraub and Murray, 2006), group decision making (Martins and Borges, 2007) and MCDM applications in forestry (Mendoza and Martins, 2006; DiazBalteiro and Romero, 2008). D’Amours et al. (2008) described supply chain planning problems related to the forest products industry. Seidl et al. (2011) reviewed statistical models to deal with pest control and forest damage due to wind or wildfire. Hildebrandt and Knoke (2011) addressed techniques for financial decision making under uncertainty.

Table 2-1. Literature review of Decision Support Systems for forest management

\begin{tabular}{|c|c|c|c|}
\hline DSS & Problems/Uses & Methods & Reference \\
\hline 4S Tool ${ }^{\mathrm{a}}$ & $\begin{array}{l}\text { Internet-based DSS to inform forest } \\
\text { management for private forest owners. }\end{array}$ & $\begin{array}{l}\text { Database and } \\
\text { GIS }^{\mathrm{q}}\end{array}$ & $\begin{array}{l}\text { Kirilenko et } \\
\text { al., } 2007\end{array}$ \\
\hline EMDS $^{b}$ & $\begin{array}{l}\text { Environmental analysis and planning at } \\
\text { user-defined spatial scale from landscapes } \\
\text { to continents. } \\
\text { Evaluation of management priorities. }\end{array}$ & $\begin{array}{l}\text { GIS }^{\mathrm{q}}, \mathrm{AHP}^{\mathrm{r}} \text { and } \\
\text { SMART }^{\mathrm{s}}\end{array}$ & $\begin{array}{l}\text { Reynolds, } \\
2005 \text {; } \\
\text { Gärtner et al., } \\
2008\end{array}$ \\
\hline ESC $^{\mathrm{c}}$ & $\begin{array}{l}\text { Informs decision on tree species choice for } \\
\text { given site conditions. }\end{array}$ & Delphi and $\mathrm{RA}^{\mathrm{t}}$ & $\begin{array}{l}\text { Pyatt, et al., } \\
2001\end{array}$ \\
\hline ESDSS $^{\mathrm{d}}$ & $\begin{array}{l}\text { Supports estimation of regional eco- } \\
\text { security and decisions about environmental } \\
\text { protection and land use. }\end{array}$ & $\begin{array}{l}\text { AHP }{ }^{\mathrm{r}} \text {, Delphi } \\
\text { and } \\
\text { GIS }^{\mathrm{q}}\end{array}$ & $\begin{array}{l}\text { Xiaodan et } \\
\text { al., } 2010\end{array}$ \\
\hline FORESTAR $^{\mathrm{e}}$ & $\begin{array}{l}\text { Selects harvesting targets (landscape level) } \\
\text { and determines cutting intensity and cycle } \\
\text { (stand level). }\end{array}$ & $\begin{array}{l}\text { Simulation and } \\
\text { GIS }^{q}\end{array}$ & $\begin{array}{l}\text { Shao et al., } \\
\text { 2005; Dai et } \\
\text { al., } 2006\end{array}$ \\
\hline ForestGALES ${ }^{\mathrm{f}}$ & $\begin{array}{l}\text { Informs decisions on management to } \\
\text { reduce wind damage. }\end{array}$ & $\begin{array}{l}\text { Risk model, } \text { RA }^{\mathrm{t}} \\
\text { and windflow } \\
\text { model }\end{array}$ & $\begin{array}{l}\text { Gardiner and } \\
\text { Quine, 2000; } \\
\text { Cucchi et al., } \\
2005\end{array}$ \\
\hline FTM $^{\mathrm{g}}$ & $\begin{array}{l}\text { Models and analyses tree growth, forest } \\
\text { operations, economy, biodiversity and } \\
\text { nutrient balances. }\end{array}$ & $\begin{array}{l}\text { Simulation and } \\
\text { GIS }^{q}\end{array}$ & $\begin{array}{l}\text { Andersson et } \\
\text { al., } 2005\end{array}$ \\
\hline GeoeSIMAe-HWIND ${ }^{\mathrm{h}}$ & $\begin{array}{l}\text { Assessing the short and long term risk of } \\
\text { wind damage in boreal forests (stand and } \\
\text { regional level). }\end{array}$ & Simulation & $\begin{array}{l}\text { Zeng et al., } \\
2007 a\end{array}$ \\
\hline
\end{tabular}


Table 2 1. Literature review of Decision Support Systems for forest management (cont.)

\begin{tabular}{|c|c|c|c|}
\hline DSS & Problems/Uses & Methods & Reference \\
\hline IA-SDSS ${ }^{\mathrm{i}}$ & $\begin{array}{l}\text { Supports land-use planning and local } \\
\text { forestry development with consideration } \\
\text { of carbon sequestration. }\end{array}$ & $\begin{array}{l}\text { Integrate } \\
\text { EMDS }^{\mathrm{b}}, \mathrm{CBA}^{\mathrm{u}} \\
\text { and } \mathrm{AHP}^{\mathrm{r}}\end{array}$ & $\begin{array}{l}\text { Wang et al., } \\
2010\end{array}$ \\
\hline LANDIS $^{\mathrm{j}}$ & $\begin{array}{l}\text { Simulates forest landscape (fire, wind, } \\
\text { harvesting and insects). }\end{array}$ & Simulation & $\begin{array}{l}\text { Shang et al., } \\
2012\end{array}$ \\
\hline LMS $^{\mathrm{k}}$ & $\begin{array}{l}\text { Landscape changes integrating landscape- } \\
\text { level spatial information, stand-level } \\
\text { inventory data, growth models. SFM } \\
\text { evaluation in private land-management. }\end{array}$ & $\begin{array}{l}\text { Simulation and } \\
\text { GIS }^{q}\end{array}$ & $\begin{array}{l}\text { Reynolds, } \\
2005\end{array}$ \\
\hline NED & $\begin{array}{l}\text { Project level planning and decision making } \\
\text { processes. From small private holdings to } \\
\text { cooperative management across multiple } \\
\text { ownerships. }\end{array}$ & $\begin{array}{l}\text { Simulation } \\
\text { (growth, yield } \\
\text { and wildlife), } \\
\text { Database and } \\
\text { GIS }^{q}\end{array}$ & $\begin{array}{l}\text { Reynolds, } \\
2005\end{array}$ \\
\hline $\mathrm{SDSS}^{\mathrm{l}}$ & $\begin{array}{l}\text { Elaborates silvicultural scenarios, } \\
\text { assessment of indicators and comparison } \\
\text { of the scenarios }\left(\mathrm{MCDM}^{\mathrm{p}}\right)\end{array}$ & 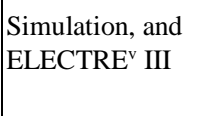 & $\begin{array}{l}\text { Pauwels et } \\
\text { al., } 2007\end{array}$ \\
\hline SprayAdvisor & Decisions for herbicide spray programs. & $\begin{array}{l}\text { Experiment } \\
\text { design and } \\
\text { statistical } \\
\text { analysis }\end{array}$ & $\begin{array}{l}\text { Thompson et } \\
\text { al., } 2010\end{array}$ \\
\hline Woodstock ${ }^{\mathrm{m}}$ & $\begin{array}{l}\text { Pest management decisions on use } \\
\text { biological insecticides, rescheduling of } \\
\text { harvest and forest restructuring. }\end{array}$ & $\begin{array}{l}\text { Simulation and } \\
\operatorname{LP}^{x}\end{array}$ & $\begin{array}{l}\text { Iqbal et al., } \\
2012\end{array}$ \\
\hline WRR-DSS ${ }^{\mathrm{n}}$ & $\begin{array}{l}\text { Decisions for effective fire management } \\
\text { planning. }\end{array}$ & $\begin{array}{l}\text { MCDM }^{\mathrm{P}} \text { and } \\
\text { Fuzzy set theory }\end{array}$ & $\begin{array}{l}\text { Kaloudis et } \\
\text { al., } 2008\end{array}$ \\
\hline
\end{tabular}

Acronyms of DSS: a- 4S Tool: Forest Stand Software Support System, b- EMDS: Ecosystem Management Decision Support System, c- ESC: Ecological Site Classification, d- ESDSS: Eco-Security assessment Decision Support System, e- FORESTAR: Forest Operation and Restoration for Enhancing Services in a Temperate Asian Region, f- ForestGALES: Geographic Analysis of the Losses and Effects of Storms in Forestry, g-FTM: The Forest Time Machine, $h$ - Geo-SIMA-HWIND: Forest growth SIMA and wind damage HWIND models integrated into GIS, i- IA-SDSS: Integrated Assessment framework and a Spatial Decision Support System, j- LANDIS: LANdscape-scale, succession and DISturbance model, $k$ - LMS: Landscape Management System, l- SDSS: Silvicultural Decision Support System, m- Woodstock: Remsoft Spatial Planning System, $n$ - WRR-DSS: Wildfire Risk Reduction DSS.

Acronyms of Models and Methods: o- SFM: Sustainable Forest Management, $p$ - MCDM: Multiple Criteria Decision Making, q- GIS: Geographic Information System, $r$ - AHP: Analytic Hierarchy Process, s- SMART: Simple Multi-Attribute Rating Technique, t- RA: Regression Analysis, u- CBA: Cost-Benefit Analysis, vELECTRE: ELimination and Choice Expressing Reality, $x$ - LP: Linear Programming. 
A selection of recent articles that focus on forest management planning using optimisation methods is presented in Table 2-2. LP and Integer Programming (IP) have been used to solve strategic and tactical problems, mainly maximizing the Net Present Value (NPV) and carbon sequestration, volume of harvested timber, but also with other objective functions, e.g. minimizing the outer perimeter of old forests in the landscape (Öhman and Wikström, 2008). The main set of decision variables are the area of each treatment unit managed by each alternative and the binary variables that indicate if a stand is assigned to a treatment schedule. IP has also been applied to solve forest industry problems, such as truck routing (Rey et al., 2009). Dynamic Programming (DP) was used in decisions related to fire risk and harvest policies with the objective to maximize the timber NPV (Spring et al., 2008).

Due to the difficulty in obtaining the optimal solution in mathematical models with a large number of integer variables, heuristic techniques have been developed as an alternative method to obtain good solutions with lesser computation times, although this approach does not guarantee optimal solutions. Thus, there is an increasing interest in applying metaheuristic methods to solve optimisation problems in forestry, e.g. Genetic Algorithms (GA), Tabu Search (TS) and Simulated Annealing (SA). SA has been used to consider the impact of climate change uncertainty in forest management (Eriksson et al., 2012) and multi-objective forest planning that maximizes total utility (Kurttila et al., 2009). These three metaheuristics were also applied with forest growth and wind damage models and GIS (Zeng et al., 2007a). Other metaheuristic algorithms, such as Ant Colony Optimisation (ACO) and Particle Swarm Optimisation (PSO) have also been applied to risk management of wind damage and management of uneven-sized stands, respectively. 
Table 2-2. Literature review of optimisation methods for forest management

\begin{tabular}{|c|c|c|c|c|c|c|c|c|c|}
\hline 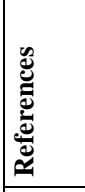 & 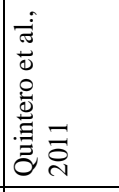 & 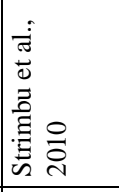 & 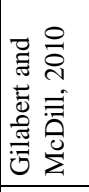 & 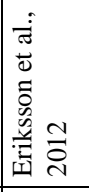 & 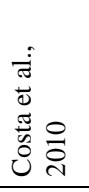 & 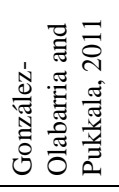 & 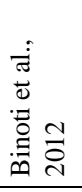 & 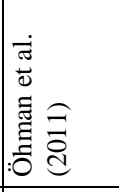 & 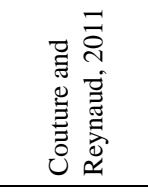 \\
\hline 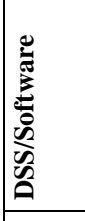 & & 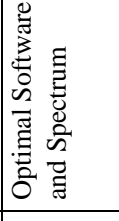 & & 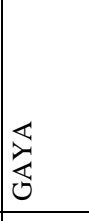 & & $\sum_{\Sigma}^{\circ}$ & 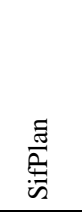 & 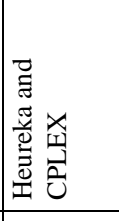 & \\
\hline 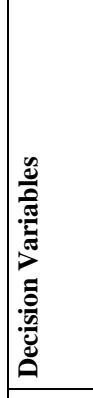 & 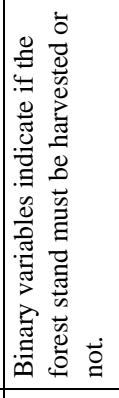 & 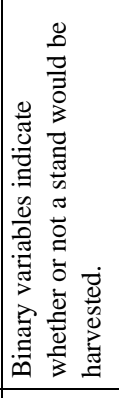 & 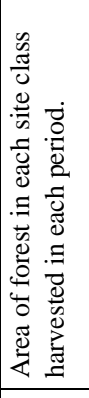 & 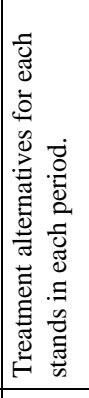 & 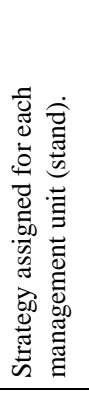 & 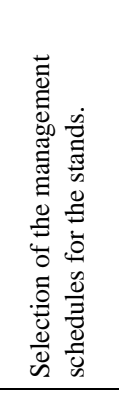 & 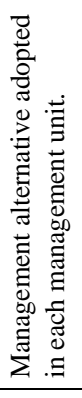 & 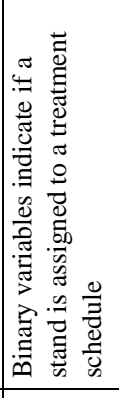 & 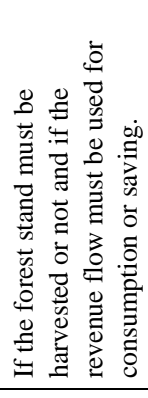 \\
\hline 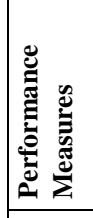 & 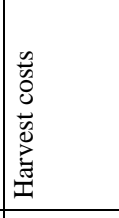 & 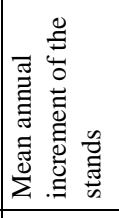 & 忿 & 竞 & $\begin{array}{l}\text { 召 } \\
\text { 足 }\end{array}$ & 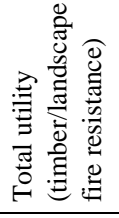 & 竞 & 竞 & 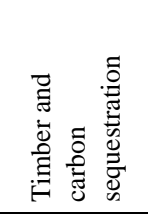 \\
\hline 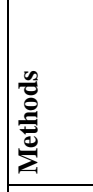 & 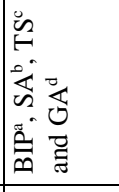 & 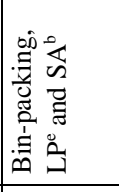 & $\stackrel{9}{9}$ & 苔 & 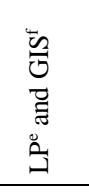 & 盛 & 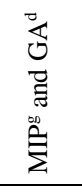 & 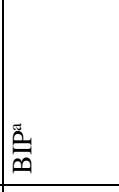 & 苚 \\
\hline 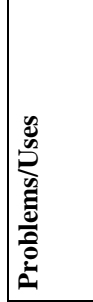 & 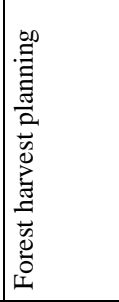 & 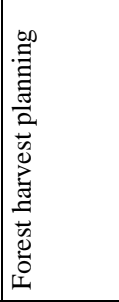 & 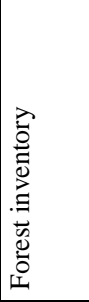 & 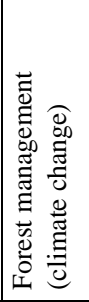 & 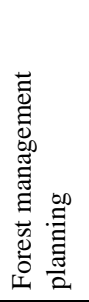 & 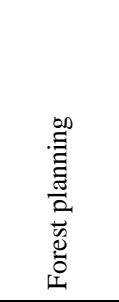 & 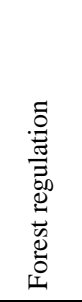 & 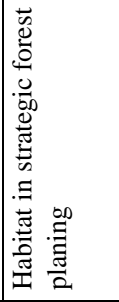 & 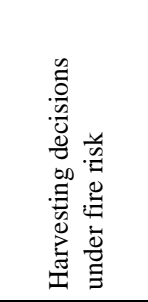 \\
\hline
\end{tabular}


Table 2-2. Literature review of optimisation methods for forest management (cont.)

\begin{tabular}{|c|c|c|c|c|c|c|c|c|}
\hline 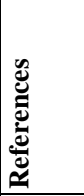 & 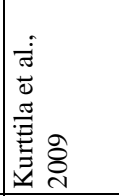 & 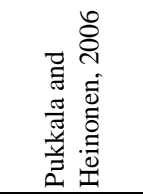 & 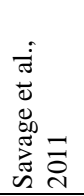 & 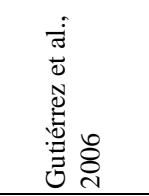 & 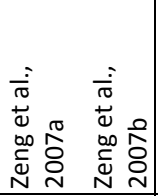 & 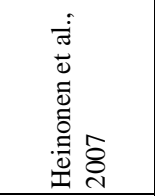 & 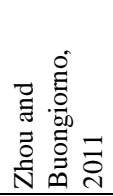 & 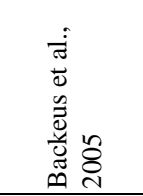 \\
\hline 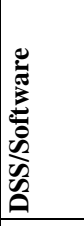 & & $\begin{array}{l}2 \\
n \\
z \\
0 \\
\Sigma\end{array}$ & 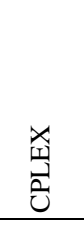 & 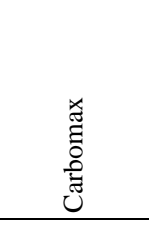 & 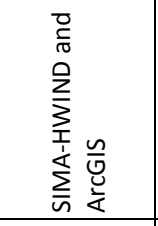 & $\begin{array}{l}D \\
n \\
z_{2} \\
\Sigma\end{array}$ & & \\
\hline 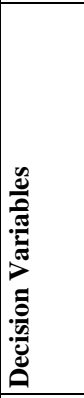 & 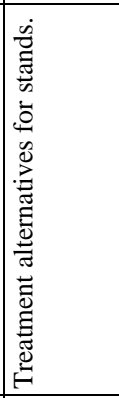 & 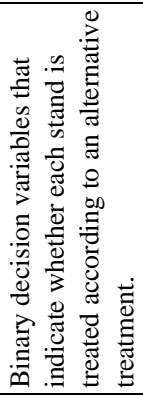 & 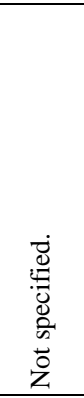 & 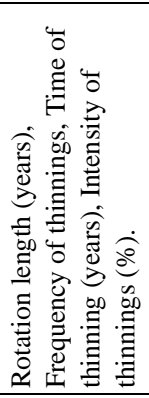 & 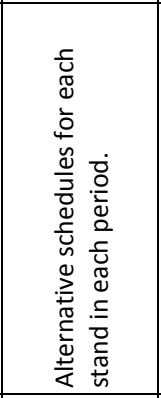 & 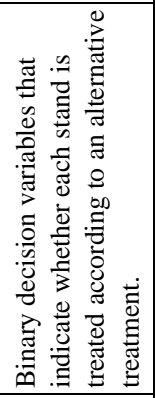 & 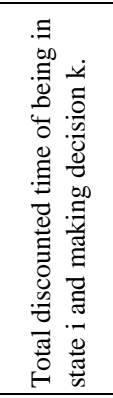 & 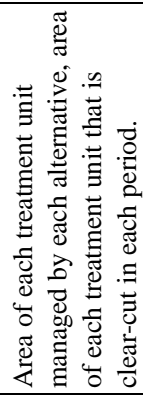 \\
\hline 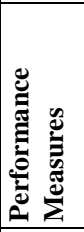 & 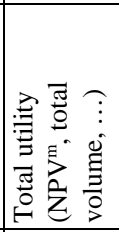 & 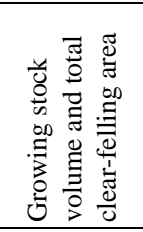 & 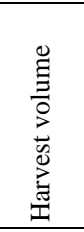 & 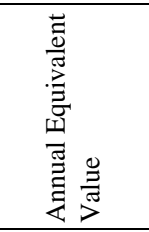 & 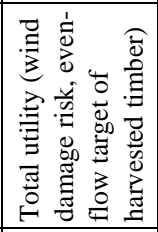 & 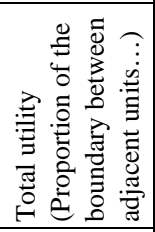 & $\begin{array}{l}\text { 要 } \\
\text { ב }\end{array}$ & 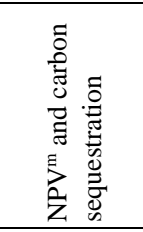 \\
\hline 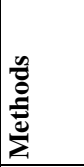 & 岕 & 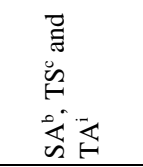 & 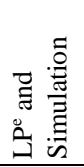 & త্ড & 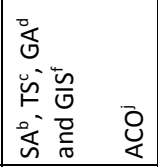 & $\mathbb{E}$ & 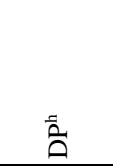 & 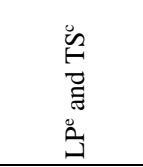 \\
\hline 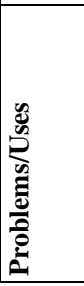 & 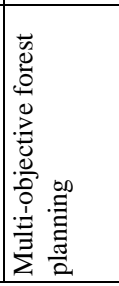 & 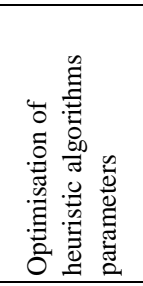 & 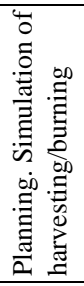 & 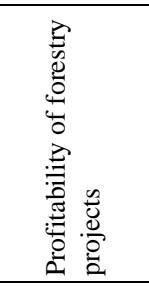 & 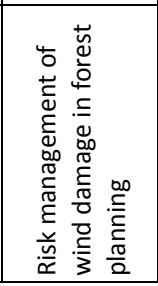 & 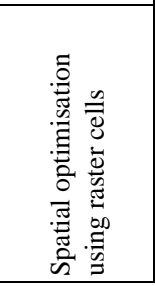 & 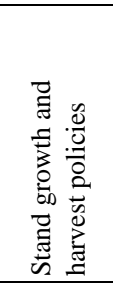 & 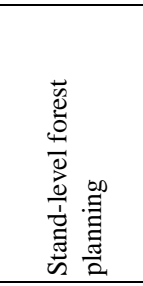 \\
\hline
\end{tabular}


Table 2-2. Literature review of optimisation methods for forest management (cont.)

\begin{tabular}{|c|c|c|c|c|c|c|c|}
\hline 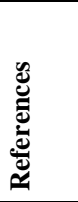 & 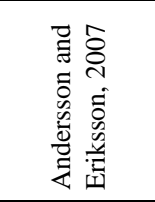 & 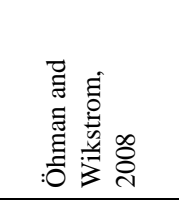 & 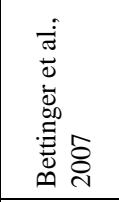 & 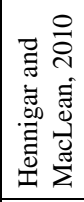 & 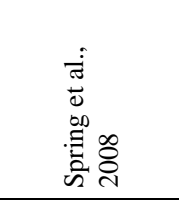 & 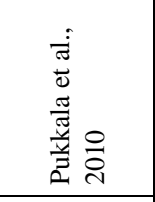 & 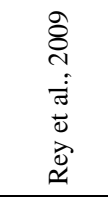 \\
\hline 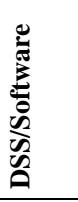 & 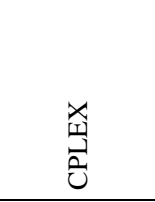 & & & $\begin{array}{l}\frac{5}{2} \\
0 \\
0 \\
0 \\
0 \\
0 \\
3\end{array}$ & 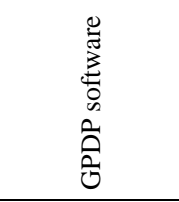 & & 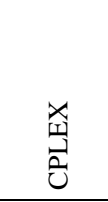 \\
\hline 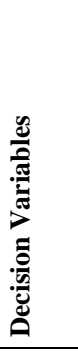 & 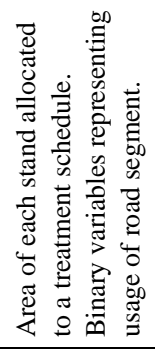 & 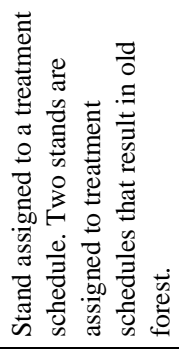 & 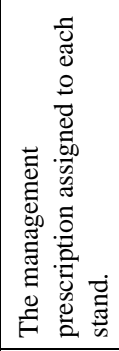 & 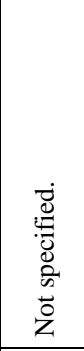 & 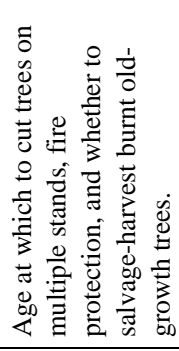 & 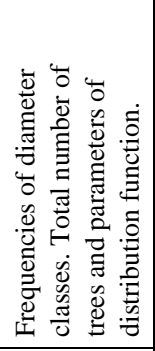 & 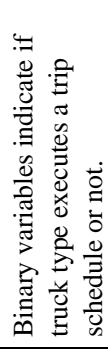 \\
\hline 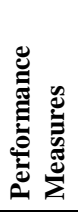 & 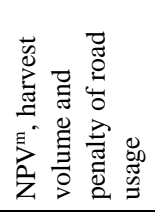 & 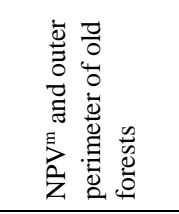 & 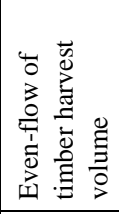 & 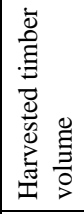 & 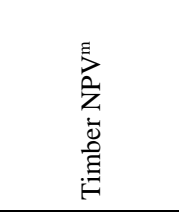 & $\frac{1}{2}$ & 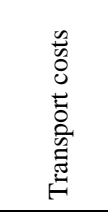 \\
\hline 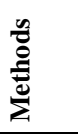 & 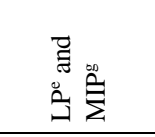 & $\stackrel{\text { Do }}{\sum}$ & $\stackrel{\breve{n}}{\leftrightarrow}$ & ردّ & 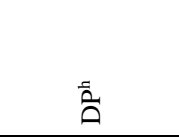 & $\begin{array}{l}\text { D̈ } \\
\text { n }\end{array}$ & $\vec{\beta}$ \\
\hline 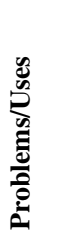 & 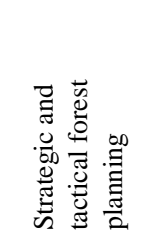 & 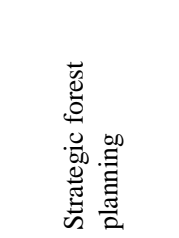 & 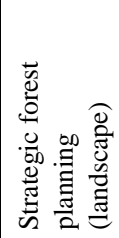 & 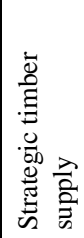 & 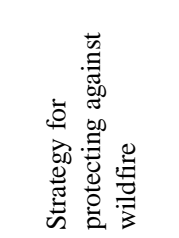 & 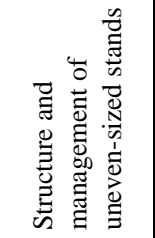 & 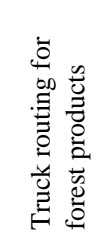 \\
\hline
\end{tabular}

Acronyms of Models and Methods: a- BIP: Binary Integer Programming, b- SA: Simulated Annealing algorithms, c- TS: Tabu Search, d- GA: Genetic Algorithms, e- LP: Linear Programming, f- GIS: Geographic Information System, g- MIP: Mix Integer Programming, $h$ - DP: Dynamic Programming, $i$ TA: Threshold Accepting, j- ACO: Ant Colony Optimisation, $k$ - PSO: Particle Swarm Optimisation, l-IP: Integer Programming, $m-N P V$ : Net Present Value

Acronyms of DSS: $n$ - Woodstock: Remsoft Spatial Planning System 
When there are a number of alternatives or courses of action, MCDM can play a very useful role (Belton and Stewart, 2002). As can be seen in Table 2-3 the combination of MCDM with other techniques, e.g. Strengths, Weaknesses, Opportunities and Threats (SWOT) analysis, and GIS has increased the functionality of the approach and its applicability in forest management. The main applications are the selection and agreement of forest plans. AHP is widely used, in particular when stakeholders are involved in the decision making process and with the aim to evaluate management alternatives. Likewise, Goal Programing (GP) and voting techniques are also useful in participatory processes to elicit stakeholder preferences in forest planning. CBA is the traditional technique in investment project decisions, with the goal of obtaining the future flows of benefits and costs adjusted for the time-bound changing value of money, a common approach uses NPV. However, many environmental goods and services are not traded directly in the market and so it is difficult to determine their value. CBA is mainly applied to market forest products and to make decisions on the use of forestland. The concept of willingness-to-pay has spread in the valuation of goods and services untested in the market, e.g. Contingent Valuation (CV).

Traditional statistical methods, such as ANalysis Of Variance (ANOVA), Bayesian analysis and Regression Analysis (RA) are the most widely used techniques (Table 24). In response to the increasing use of GIS and due to the characteristics of the data provided in forestry, spatial statistics have emerged for the analysis of this type of data (Newton et al., 2012). Simulation models, such as Monte Carlo Simulation Method (MCSM), and Growth Models (GM) are useful complementary tools to other statistical techniques (Loudermilk et al., 2011). To a lesser extent, other statistical methods have been applied to forestry problems, such as correlation analysis, Principal Components Analysis (PCA), and a General Linear Model (GLM) among others. Tables 2-2, 2-3 and 2-4 also present information about DSS and commercial software used in cited papers. Examples of DSS are Heureka, MONSU, Monte and GAYA that are included in the assessment presented in this research. Finally, there is a lack of systematic studies that analyse to what extent DSS in forest management are supported by specific models and methods, and the relationship between the different types of problems and the approaches dealing with them. This analysis will guide DSS developments in order to better fit the requirements of practitioners. 
Table 2-3. Literature review of MCDM techniques and economical models for forest management

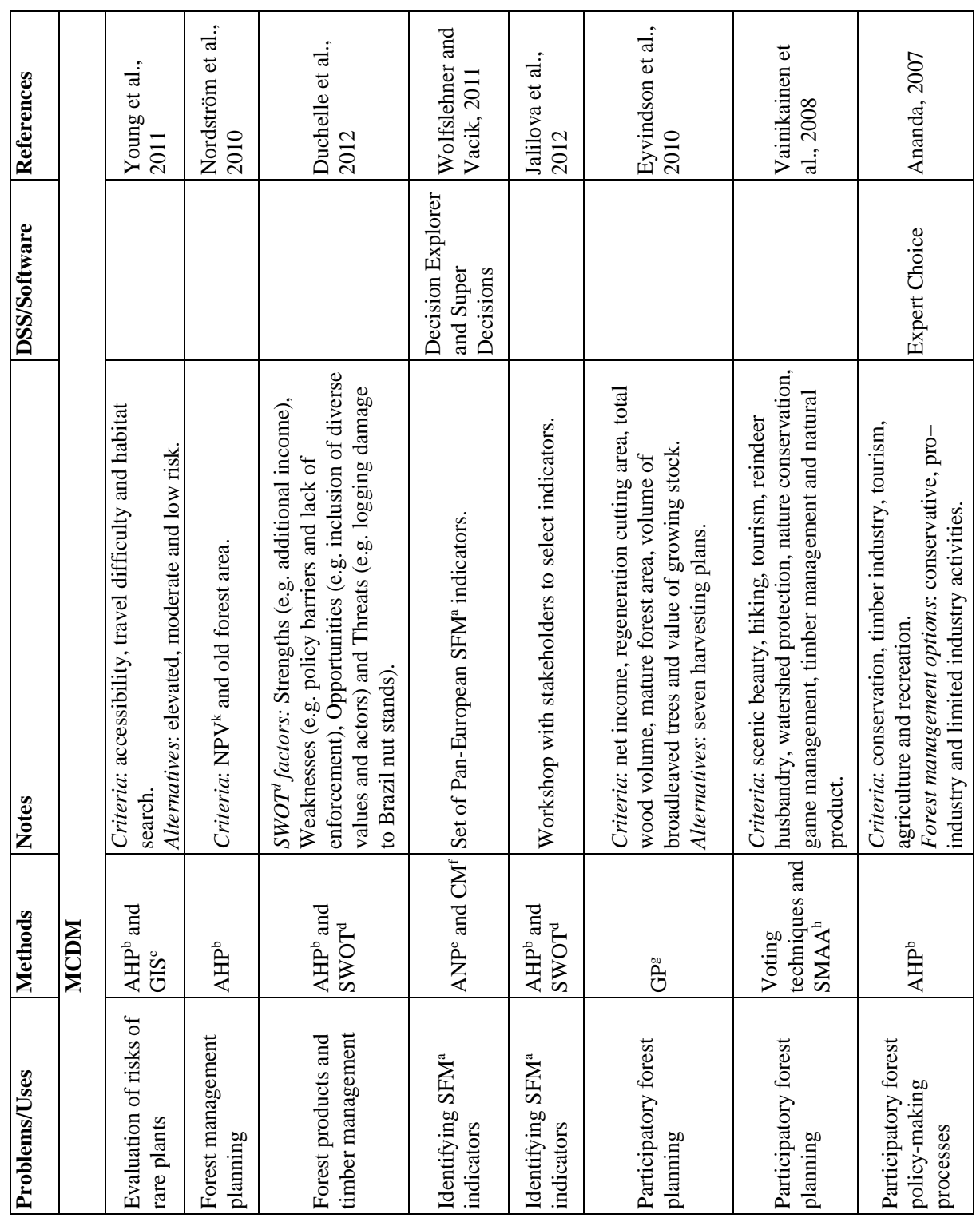


Table 2-3. Literature review of MCDM techniques and economical models for forest management (cont.)

\begin{tabular}{|c|c|c|c|c|c|c|c|c|}
\hline 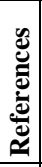 & 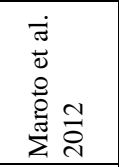 & 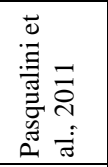 & 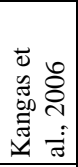 & 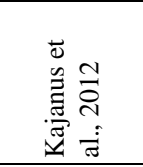 & 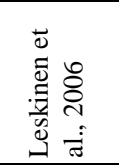 & \multirow{5}{*}{ 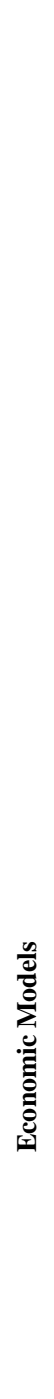 } & 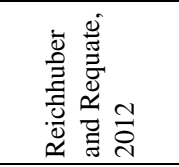 & 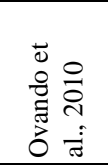 \\
\hline 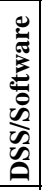 & 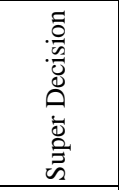 & $\begin{array}{l}0 \\
0\end{array}$ & & & & & & \\
\hline 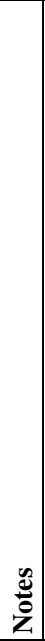 & 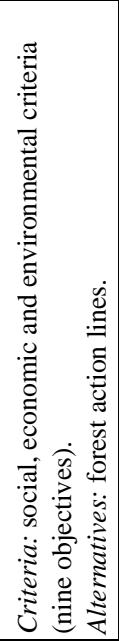 & 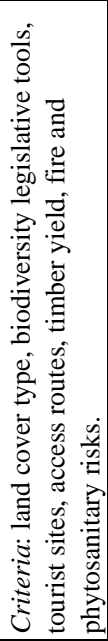 & 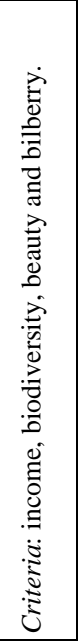 & 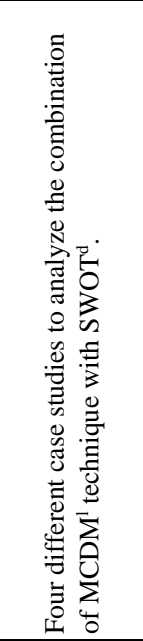 & 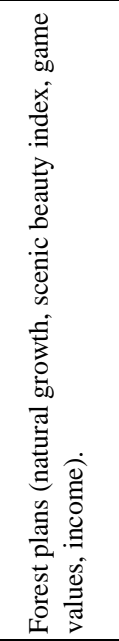 & & 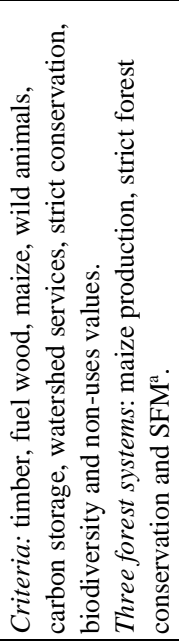 & 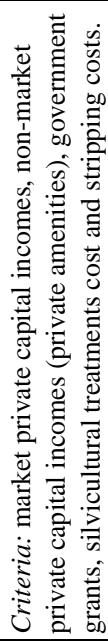 \\
\hline 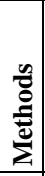 & 产 & 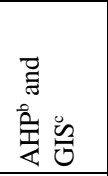 & $\sum_{\infty}^{\infty}$ & 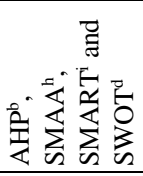 & 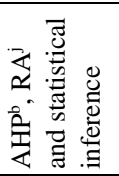 & & 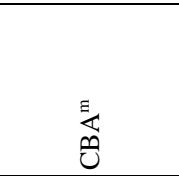 & 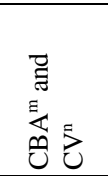 \\
\hline 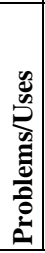 & 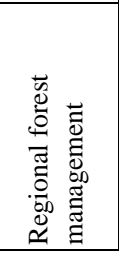 & 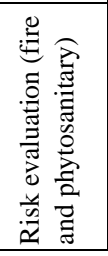 & 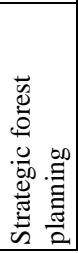 & 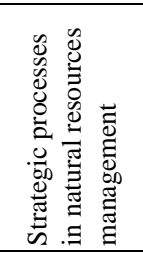 & 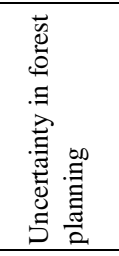 & & 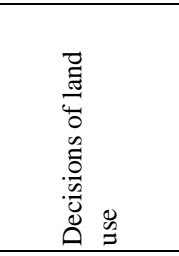 & 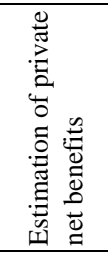 \\
\hline
\end{tabular}


Table 2-3. Literature review of MCDM techniques and economical models for forest management (cont.)

\begin{tabular}{|c|c|c|c|c|}
\hline 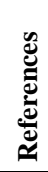 & 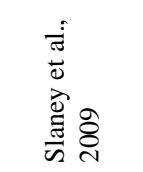 & 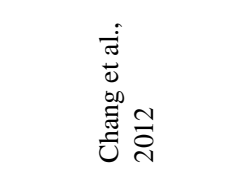 & 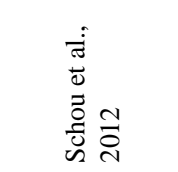 & 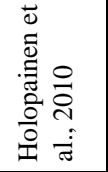 \\
\hline 旁 & 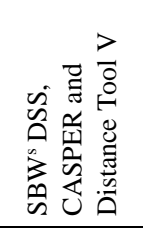 & $\begin{array}{l}n \\
n \\
n \\
n \\
n\end{array}$ & $\frac{\text { 茔 }}{\sum^{\pi}}$ & 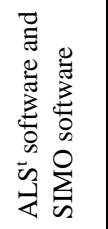 \\
\hline$\frac{\mathscr{y}}{0}$ & 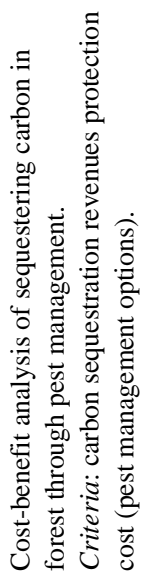 & 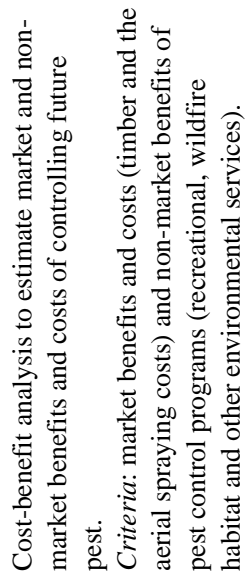 & 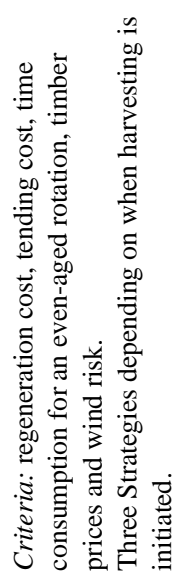 & 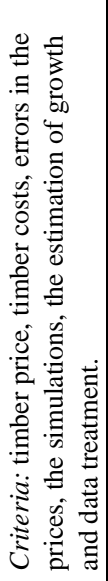 \\
\hline 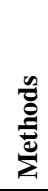 & 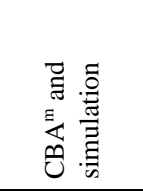 & 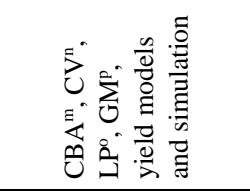 & 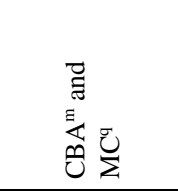 & 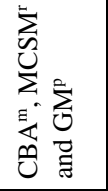 \\
\hline 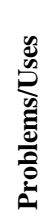 & 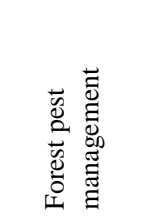 & 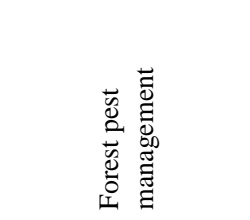 & 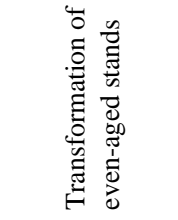 & 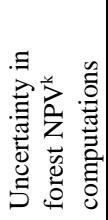 \\
\hline
\end{tabular}

Acronyms of Models and Methods: a- SFM: Sustainable Forest Management, $b$ - AHP: Analytic Hierarchy Process, c- GIS: Geographic Information System, d-SWOT: Strengths, Weaknesses, Opportunities and Threats, e-ANP: Analytic Network Process, f-CM: Cognitive Mapping, g-GP: Goal Programing, $h$ - SMAA: Stochastic Multicriteria Acceptability Analysis, i- SMART: Simple Multi-Attribute Rating Technique, j- RA: Regression Analysis, k- NPV: Net Present Value, l-MCDM: Multiple Criteria Decision Making m- CBA: Cost-Benefit Analysis, $n$ - CV: Contingent Valuation, o- LP: Linear Programming, $p$ - GM: Growth Model, q- MC: Markov Chain, r-MCSM: Monte Carlo Simulation Method.

Acronyms of DSS: s- SBW: Spruce Budworm, t- ALS: Airborne Laser Scanning 
Table 2-4. Literature review of statistical methods for forest management

\begin{tabular}{|c|c|c|c|c|c|c|c|c|}
\hline 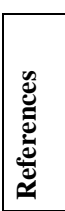 & 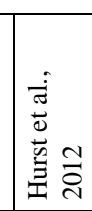 & 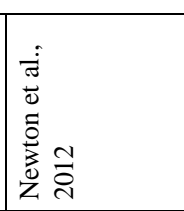 & 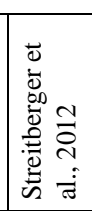 & 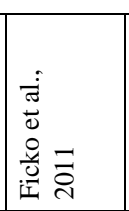 & 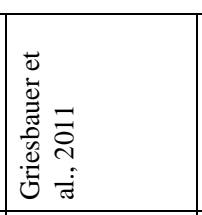 & 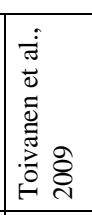 & 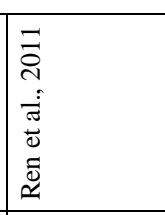 & 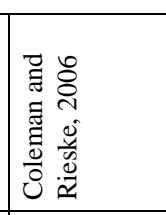 \\
\hline t & & & & 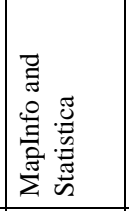 & 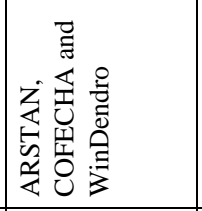 & $\begin{array}{l}\omega \\
0 \\
\omega\end{array}$ & 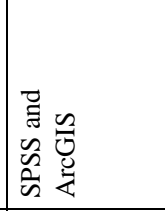 & $\begin{array}{l}\text { 帒 } \\
\omega\end{array}$ \\
\hline 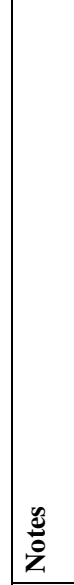 & 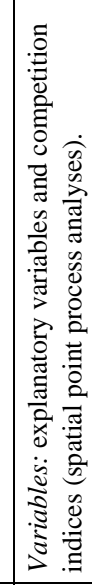 & 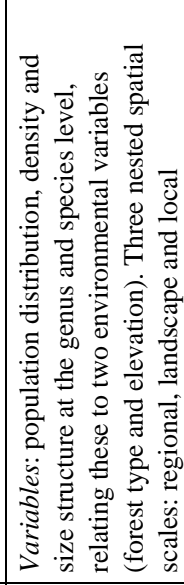 & 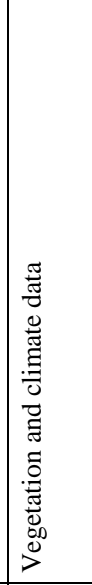 & 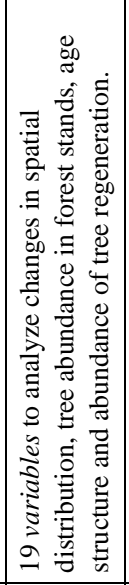 & 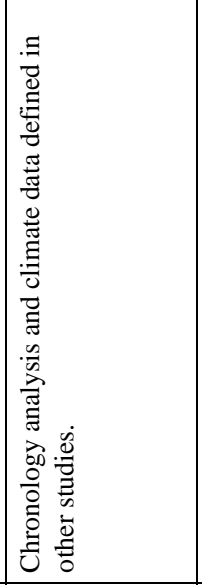 & 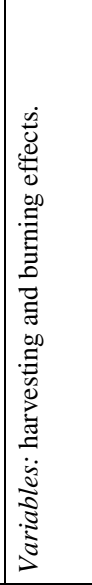 & 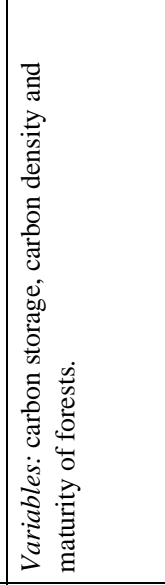 & 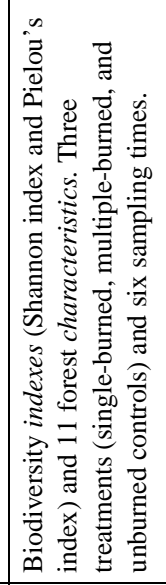 \\
\hline 童 & 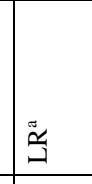 & 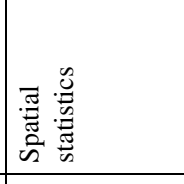 & 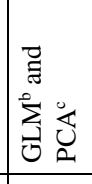 & 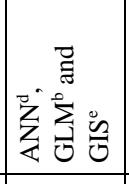 & 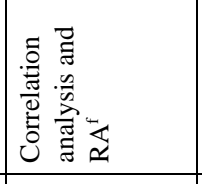 & $\begin{array}{l}3 \\
0 \\
0 \\
0 \\
0 \\
4\end{array}$ & 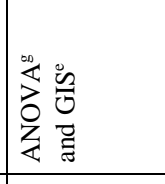 & 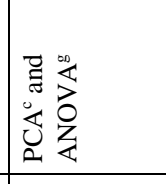 \\
\hline 造 & 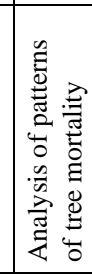 & 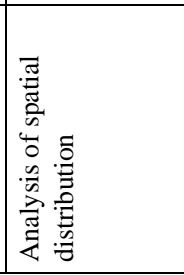 & 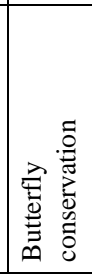 & 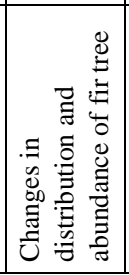 & 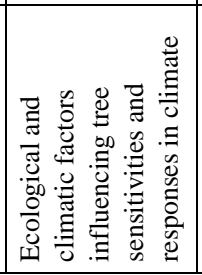 & 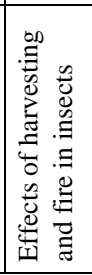 & 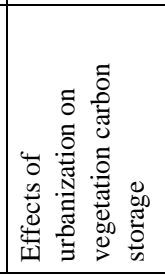 & 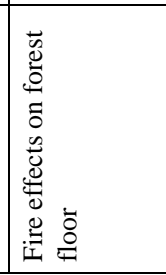 \\
\hline
\end{tabular}


Table 2-4. Literature review of statistical methods for forest management (cont.)

\begin{tabular}{|c|c|c|c|c|c|}
\hline 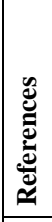 & 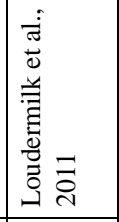 & 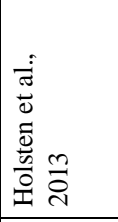 & 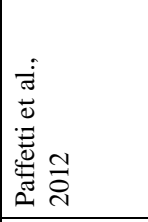 & 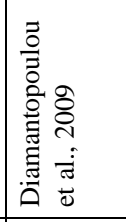 & 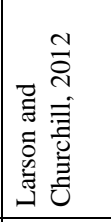 \\
\hline 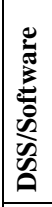 & 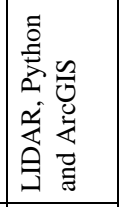 & 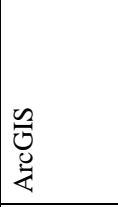 & 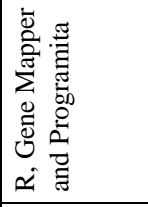 & $\begin{array}{l}w \\
\omega \\
\omega\end{array}$ & \\
\hline 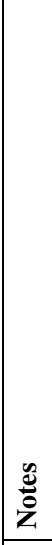 & 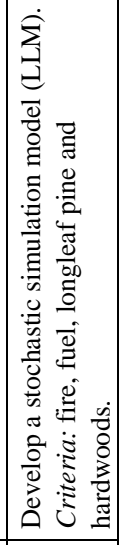 & 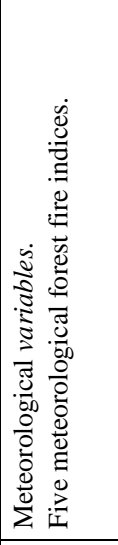 & 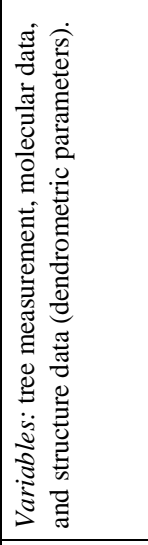 & 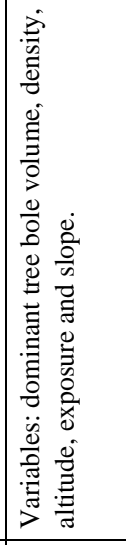 & \\
\hline 竞 & 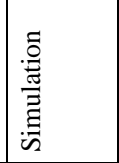 & 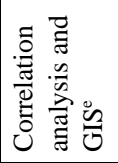 & 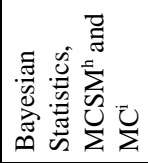 & $\sum_{⿺ 辶}^{\circ}$ & 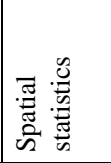 \\
\hline 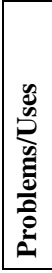 & 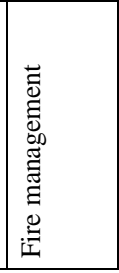 & 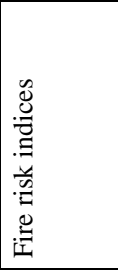 & 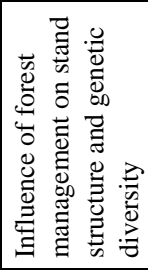 & 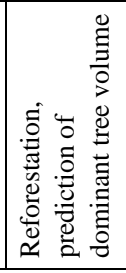 & 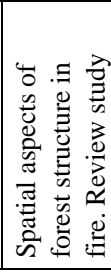 \\
\hline
\end{tabular}

Acronyms of Models and Methods: a- LR: Logistic Regression, $b$ - GLM: Generalized linear model, c- PCA: Principal Components Analysis, d- ANN: Artificial Neural Network, e- GIS: Geographic Information System, f- RA: Regression Analysis, g-ANOVA: ANalysis Of Variance, $h$ - MCSM: Monte Carlo Simulation Method, i- MC: Markov Chain 
The objectives of the study were to analyse and assess the models and methods in DSS for forest management, taking into account the important features used to categorize forestry related problems. It is useful to know the appropriate methods used to answer specific problems, as well as the strengths, weaknesses and drawbacks in each case. We were also interested in new methods used to answer specific problem types. Such applications could show innovation in tackling particular problems and be useful to design and apply DSS for forest management in coming years. The following sections of the chapter report an analysis of the link between particular methods and common problem types, and this is laid out in a classical format with a description of the method used to carry out the research, followed by the main results obtained, discussion and conclusions. Acronyms of DSS and methods appear in Annex I.

\subsection{Methods}

We describe an assessment of methods used in DSS for Sustainable Forest Management (SFM). The framework of the analysis is provided by the COST action FP0804 Forest Management Decision Support Systems, FORSYS (COST, 2012). The main objective of this European project was to develop information standards and guidelines for the development, testing, evaluation and application of DSS for multifunctional and sustainable forest management. In particular, Working Group 2 reviewed, assessed, and recommended models and methods for developing DSS tools. The COST Action developed a typology to enable the classification of the wide range of problems solved by forest management DSS. This typology takes into account various dimensions or features of forest management problems. In particular, the country report protocol for the classification of problems solved by DSS considers the following problem dimensions and categories:

1. Temporal scale: long term (strategic), medium term (tactical) and short term (operational).

2. Spatial context: non-spatial and spatial context (with and without neighborhood interrelations).

3. Spatial scale: stand level, forest/landscape level and regional/national level. 
4. Number of decision makers: single decision maker and more than one decision maker/stakeholder.

5. Number of objectives: single objective and multiple objectives.

6. Goods and services: market non-wood products, market wood products, nonmarket services and market services.

Each participating country developed a report on the design and use of computer-based tools and forest management DSS. All country reports (26) written by 94 authors, experts on this topic, have been reviewed (Borges et al., 2014). In addition, the media semantic wiki developed by the FORSYS project has also been revised to include additional information to allow detailed analysis of the problems and methods described by the country reports (COST, 2012). The COST Action was primarily focused on European countries and consequently there were more reports from Europe (19) however, there were several reports from other continents, including: North America (2), South America (2), Africa (2) and Asia (1). Additionally, a semantic wiki constructed by the COST Action includes DSS developed in Belgium, Latvia and Lithuania, but they do not appear in any of the country reports. All DSS analysed are included in Borges et al. (2014). The validity and wide representativeness of the input data used in our assessment are supported by the number of countries and authors who provided this information and their well-known expertise in forest management.

The methods used by DSS for forest management have been classified in six groups in accordance with the techniques of decision making: Multiple Criteria Decision Making, Optimisation, Simulation, Economic models, Statistical methods and Information systems (Table 2-5). We consider in the MCDM group continuous and discrete multiple criteria techniques. Group decision making and voting techniques have been included in this group, because they are more frequent in relation to MCDM, although they can be applied to problems with a single objective.

Grouping the different methods was necessary for an appropriate application of the statistical analysis, with the exception of the information system group which is divided in Database (Database Management System -DBM- and Relational Database Management System -RDMS) and GIS subgroups. Forest management problems were analysed using two categories in the spatial context, number of decision makers and objectives, while temporal scale, spatial scale and goods and services have three 
categories. In the latter case, due to the large number of possible combinations of both market and non-market products (wood and non-wood) and services, the problems have been classified into three categories for statistical purposes, referring to 'only products', 'only services' and 'goods and services'. Combining all the categories inside each problem dimension, 136 problem types were identified, 24 of which do not have an associated DSS, and were therefore taken out of the analysis.

Table 2-5. Models and Methods in Forest Management DSS classified by approaches

\begin{tabular}{|c|c|}
\hline \multicolumn{2}{|r|}{ Models and Methods } \\
\hline $\begin{array}{l}\text { Multiple Criteria Decision } \\
\text { Making }\end{array}$ & $\begin{array}{l}\text { Analytic Hierarchy Process (AHP), Goal Programming (GP), Multi-Attribute } \\
\text { Value (MAV), Multi-Attribute Utility Theory (MAUT), Multi-Attribute } \\
\text { Function, Multi-Criteria Analysis (MCA), Preference Ranking Organisation } \\
\text { Methods for Enrichment Evaluations (PROMETHEE), Simple Multi- } \\
\text { Attribute Rating Technique (SMART), Stochastic Multicriteria Acceptability } \\
\text { Analysis (SMAA), Group Decision Making and Voting Techniques }\end{array}$ \\
\hline Optimisation models & $\begin{array}{l}\text { Dynamic Programming (DP), Graph Theory, Heuristics, Linear Programming } \\
\text { (LP), Mathematical Programming (MP), Mix Integer Programming (MIP), } \\
\text { Non-Linear Programming (NLP) and Optimisation (without specific methods) }\end{array}$ \\
\hline Simulation models & $\begin{array}{l}\text { Dynamic Modeling, Growth Models (GM), Monte Carlo Simulation Method } \\
\text { (MCSM), Simulation Models (without specific methods), Risk Model and } \\
\text { Yield Models }\end{array}$ \\
\hline Statistical methods & $\begin{array}{l}\text { Bayesian Method, Data Mining, Fuzzy/Neural System, Least Squared } \\
\text { Method, Logistic Regression (LR), Multivariate Model, Regression Analysis } \\
\text { (RA), Statistical Models (without specific techniques), Stochastic Models and } \\
\text { ANalysis Of VAriance (ANOVA) }\end{array}$ \\
\hline Economic models & $\begin{array}{l}\text { Cost-Benefit Analysis (CBA), Gap Model, Economic Accounting, Economic } \\
\text { Models and Strengths, Weaknesses, Opportunities and Threats analysis } \\
\text { (SWOT) }\end{array}$ \\
\hline Information Systems & $\begin{array}{l}\text { Database Management System (DBMS), Relational Database Management } \\
\text { System (RDBMS) and Geographic Information System (GIS) }\end{array}$ \\
\hline
\end{tabular}


Firstly, a descriptive analysis of the data has been made to describe the distribution of DSS by problem types and approaches. Secondly, contingency tables have been used to study the relationships among problem dimensions and between the problem dimension and approaches to solve forest problems. Each problem dimension was considered as a categorical variable to classify a forest management problem. Contingency tables were used to contrast the relationships between problem dimensions, using Pearson chisquared $\left(\mathrm{X}^{2}\right)$ test. This involves a statistical inference procedure that measures the divergence between an observed and a theoretical distribution when the variables are not related, and indicating to what extent there are differences between the two due to chance using a hypotheses test. We tested the null hypothesis -that there is no association between two categorical variables- through the analysis of data in a contingency table (Moore, 1995). For example, it is possible that the temporal scale and the number of objectives of a decision problem are related. This allows us to examine whether an increasing number of objectives are more frequently assessed as a strategic problem than an operational problem. In our study we accept the statistical significance when $\mathrm{P}$ value is less than 0.05 .

\subsection{Results}

\subsubsection{Distribution of forest problems by dimension}

From the analysis of DSS in the goods and services dimension, we see that 93\% of DSS help solve problems related to market wood products. The percentage of the DSS developed to manage market and non-market services is $24 \%$. Due to a high number of combinations of the four elements of this problem dimension, Figure 2-1 shows only principal cases found in the country reports. Approximately one third of the total DSS (32\%) focus on market wood products, not including other capabilities for different goods and services. The second largest group is DSS that consider all products and services, including market as well as non-market (21\%) benefits. Other important DSS are those developed for market wood products and non-market services (18\%) and market non-wood products as well as market wood products (10\%). All other mixes are grouped in the category “'Other”' (Figure 2-1). Finally, it is remarkable that only a small percentage (5\%) of DSS have been developed to address ‘non-market services’. 


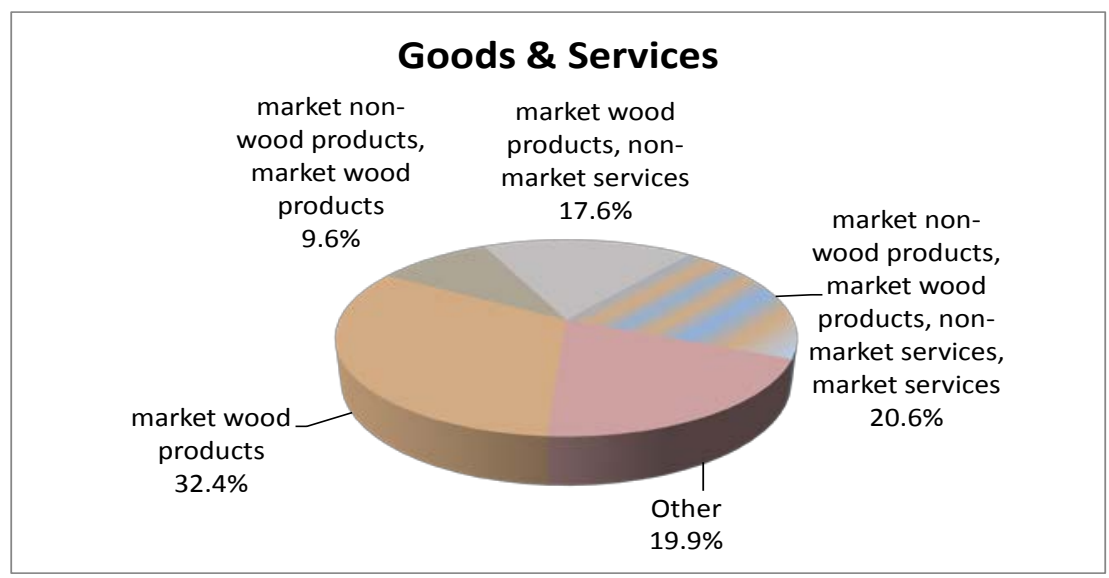

Figure 2-1. Forest management problems identified in country reports (Borges et al., 2014) classified by goods and services

The characteristics of forest problems have been classified using the six problem dimensions, defined by the FORSYS project: temporal scale, spatial context, spatial scale, number of decision makers, number of objectives and finally, goods and services. A statistical analysis using contingency tables shows significant differences among the distribution of problems inside each problem dimension, classified by one another, when both are considered as categorical variables.

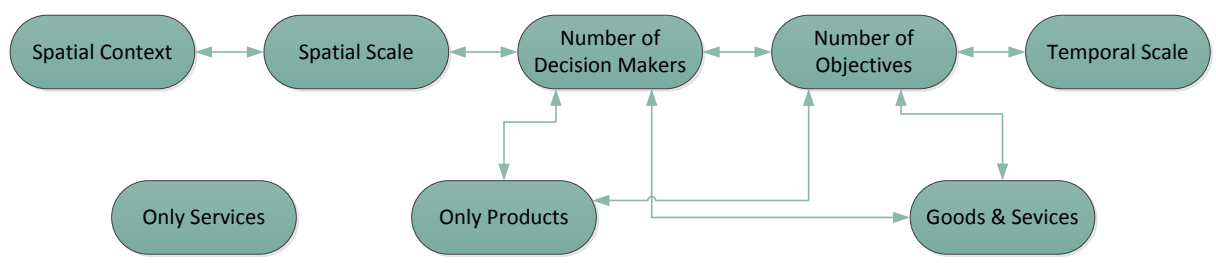

Figure 2-2. Significant relations between features of problems solved by DSS, shown by links between items, obtained through contingency tables with $5 \%$ statistical significance

To summarize the main results, Figure 2-2 shows links reflecting a significant relation between two problem dimensions. It can be seen that all problem features are related to others, except those problems that are focused only on services (approximately 5\%). 
The spatial context and the scale present a link, meaning that if the problem has a regional, forest or stand level, this situation affects the proportion of spatial or nonspatial problems.

Here we present the relation between temporal scale and number of objectives of forest problems (Table 2-6). The majority of issues assessed by the DSS described in the country reports are strategic issues (43\%), followed by tactical (33\%) and operational problems (24\%). Some cases consider two types of the three (4\%), which are short term and medium term or medium term and long term. In contrast, problems with multiple objectives represent $73 \%$ of the total, the remaining problems have a single objective. Nevertheless, Pearson Chi-Square test showed significant differences between proportions inside the categories of temporal scale and number of objectives. Indeed, one third or more of all the operational and tactical problems addressed by DSS involve a single objective, dropping to $15 \%$ for strategic problems. In other words, the importance of multiple objectives is higher in long term problems (85\%) than in medium term (67\%) and short term problems (62\%) (Table 2-6).

Table 2-6. Contingency table of problems by temporal scale and objective dimensions

\begin{tabular}{|l|l|c|c|c|}
\hline \multicolumn{2}{|c|}{ Temporal Scale } & \multicolumn{2}{c|}{ Objective Dimension } & \multirow{2}{*}{ Total } \\
\cline { 2 - 5 } & Multiple objectives Single objective & \\
\hline \multirow{2}{*}{ Long term (strategic) } & Count/(\% Temporal Scale) & $44 /(84.6 \%)$ & $8 /(15.4 \%)$ & $52 /(100.0 \%)$ \\
\cline { 2 - 5 } & $\%$ Objective Dimension & $50.0 \%$ & $25.0 \%$ & $43.3 \%$ \\
\hline \multirow{2}{*}{ Medium term (tactical) } & Count/(\% Temporal Scale) & $26 /(66.7 \%)$ & $13 /(33.3 \%)$ & $39 /(100.0 \%)$ \\
\cline { 2 - 5 } & $\%$ Objective Dimension & $29.5 \%$ & $40.6 \%$ & $32.5 \%$ \\
\hline \multirow{2}{*}{ Short term (operational) } & Count/(\% Temporal Scale) & $18 /(62.1 \%)$ & $11 /(37.9 \%)$ & $29 /(100.0 \%)$ \\
\cline { 2 - 5 } & $\%$ Objective Dimension & $20.5 \%$ & $34.4 \%$ & $24.2 \%$ \\
\hline Total & Count/(\% Temporal Scale) & $88 /(73.3 \%)$ & $32(26.7 \%)$ & $120 /(100.0 \%)$ \\
\hline
\end{tabular}

The number of objectives is related to the number of people involved in taking a decision. The problems have been divided into two groups in accordance with the number of decision makers. The percentage with more than one decision maker/stakeholder is $44 \%$, whereas this number is $56 \%$ for problems with a single decision maker. Nevertheless, these global percentages do not reflect the fact that a single decision maker addresses problems with a single objective more frequently (81\%). In contrast, 89\% of multiple objectives decisions are taken in problems involving more than one decision maker/stakeholder. 
The number of decision makers is also related to the spatial scale, approximately half were forest/landscape problems, one third stand level and the remaining $17 \%$ regional/national problems. As the spatial scale of the problem addressed by the DSS increases, then frequently more than one decision maker or group of stakeholders are involved in the decision making process. In contrast, stand level decisions are made by a single decision maker more frequently (69\% of problems). This percentage decreases to $56 \%$ for forest or landscape problems. Nevertheless, more than one decision maker or group of stakeholders are more frequently involved when regional problems are addressed. In this case, a single decision maker only occurs in $30 \%$ of the DSS problems described.

Another expected relation among dimensions of forest problems is the difference between the percentage of cases classified by spatial scale and spatial context. Taking the context into account most of the problems are spatial (72\%), 38\% with neighborhood interrelations and $30 \%$ without. No information exists for the remaining spatial problems. The percentage of non-spatial problems is $22 \%$, and the percentage of spatial problems varies from $60 \%$ in regional problems to $87 \%$ in forest/landscape problems. The highest proportion of non-spatial cases appears in regional forest problems (40\%).

Problems that can be solved by a DSS only dedicated to products represent on average $43 \%$ of cases. Differences are seen when we analyse the performance by the number of decision makers involved. The previous proportion rises up to $57 \%$ when there is a single decision maker. In the case of more than one decision maker or stakeholder this value is only $26 \%$. A negative relation appears when the problems involve both products and services. In this case two out of three problems with more than one decision maker have products and services and this proportion is lower with a single decision maker (Table 2-7).

There is a strong relationship between the percentage of problems involving only products and the number of objectives. When the problem has a single objective a high proportion of these (78\%) correspond to DSS with a capability focused only on products. Nevertheless, this percentage is $31 \%$ in multiple objective cases. A similar situation links the number of objectives, single or multiple, to products and services, but in the opposite way. A small number of problems with a single objective (16\%) are focused on products and services, while this occurs in two out of three cases in multiple objective problems. 
Table 2-7. Contingency table of problems by decision making dimension and products \& services

\begin{tabular}{|l|l|c|c|c|}
\hline \multicolumn{2}{|c|}{ Decision Making Dimension } & Products \& Services & \multirow{2}{*}{ Total } \\
\cline { 2 - 4 } & No & Yes & \\
\hline \multirow{2}{*}{$\begin{array}{l}\text { More than one decision } \\
\text { maker/stakeholder }\end{array}$} & $\begin{array}{l}\text { Count/(\% Decision Making } \\
\text { Dimension) }\end{array}$ & $17 /(32.1 \%)$ & $36 /(67.9 \%)$ & $53 /(100.0 \%)$ \\
\cline { 2 - 4 } & $\%$ Products \& Services & $29.8 \%$ & $57.1 \%$ & $44.2 \%$ \\
\hline \multirow{3}{*}{ Single decision maker } & $\begin{array}{l}\text { Count/(\% Decision Making } \\
\text { Dimension) }\end{array}$ & $40 /(59.7 \%)$ & $27 /(40.3 \%)$ & $67 /(100.0 \%)$ \\
\cline { 2 - 5 } \% Products \& Services & $70.2 \%$ & $42.9 \%$ & $55.8 \%$ \\
\hline \multirow{2}{*}{ Total } & $\begin{array}{l}\text { Count/(\% Decision Making } \\
\text { Dimension) }\end{array}$ & $57 /(47.5 \%)$ & $63 /(47.5 \%)$ & $120 /(100.0 \%)$ \\
\hline
\end{tabular}

\subsubsection{Distribution of forest problems by models and methods}

In decision making the most appropriate method to solve a particular problem usually depends on its relevant characteristics. Relations among methods and problems characteristics have also been analysed using contingency tables. Links shown in Figure 2-3 represent significant relations between the methods and the problem dimensions (with a $\mathrm{P}$ value less than 0.05 ).

The frequency table (Table 2-8) classifies the number of problems divided into a temporal scale dimension and methods to solve them. For example, 6 of the 29 short term problems (operational), have been solved by a DSS that uses MCDM.

Overall, in long term problems MCDM, economic models and information systems are the methods more commonly used than any other temporal scale. In the medium term, DSS use more optimisation and simulation methods, and in short term more problems are associated with statistical methods. 


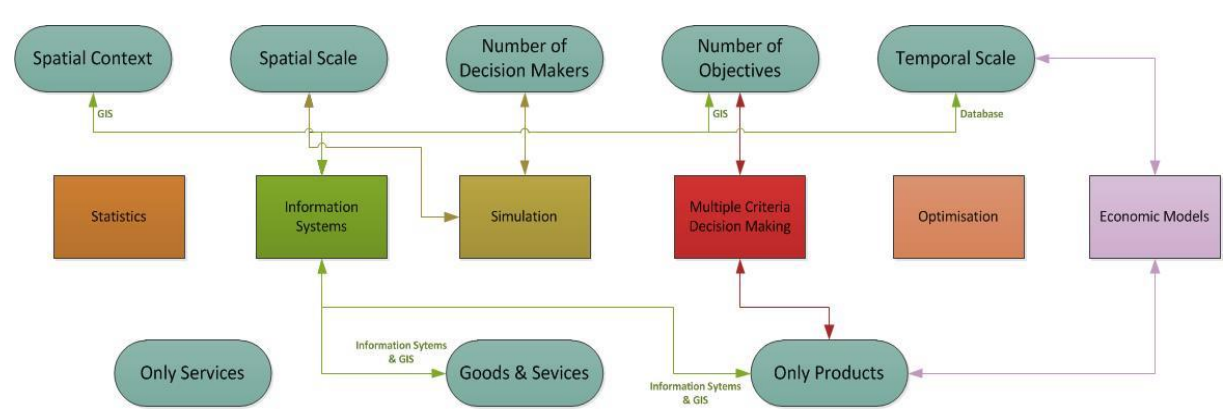

Figure 2-3. Significant relations between methods (rectangles) and features of problems (ellipses) solved by DSS shown by links between items, obtained through contingency tables with $5 \%$ statistical significance

Table 2-8. Distribution of DSS by temporal scale of problems and methods in cases and percentage

\begin{tabular}{|c|c|c|c|c|c|c|c|}
\hline Problems & MCDMa $^{\mathrm{a}}$ & OPT $^{b}$ & SIM $^{\mathrm{c}}$ & $\begin{array}{l}\text { Econ. } \\
\text { Models }^{\mathrm{d}}\end{array}$ & $\begin{array}{c}\text { Stat. } \\
\text { Methods }\end{array}$ & $\begin{array}{c}\text { Infor. } \\
\text { Systems }^{\mathrm{f}}\end{array}$ & $\begin{array}{c}\text { Total } \\
\text { problems }\end{array}$ \\
\hline Strategic & 19 & 32 & 35 & 20 & 6 & 49 & 52 \\
\hline Tactical & 13 & 25 & 27 & 10 & 5 & 35 & 39 \\
\hline Operational & 6 & 14 & 14 & 3 & 8 & 24 & 29 \\
\hline Total & 38 & 71 & 76 & 33 & 19 & 108 & 120 \\
\hline Percentage \% & 31.7 & 59.2 & 63.2 & 27.5 & 15.8 & 90.0 & \\
\hline
\end{tabular}

Acronyms of Models and Methods: a- MCDM: Multiple Criteria Decision Making, b- OPT: Optimisation, c-SIM: Simulation, d-Econ. Models: Economics Models, e-Stat. Methods: Statistics Methods, $f$ - Infor. System: Information Systems 
Information systems are more frequently used in DSS problems with a longer planning horizon. Globally, they appear in $90 \%$ of the DSS described in the country reports, but there are significant differences when taking the temporal scale into account. They are used more frequently in medium and long term problems than in short term problems (82\%).

As can be expected, economic models are most commonly used in DSS involving long term decisions. The percentage of DSS using economic models is $10 \%$ for operational problems, increasing to $26 \%$, and $38 \%$ in tactical and strategic problems respectively.

MCDM techniques are related to the number of objectives of forest problems and to those involving only products. Firstly, as can be expected almost all problems solved by MCDM are in the group of multiple objectives problem types. However, the percentage of problems with multiple objectives solved by MCDM is only $40 \%$. The percentage of problems solved by MCDM reduces to 19\% when the problem type relates only to forest products. In all other different cases this percentage rises to $41 \%$.

Simulation models are more commonly used to solve problems on a smaller spatial scale, mostly at the forest level, which represents $58 \%$ of the total and $33 \%$ at stand level. From the spatial scale perspective, the percentage of the regional/national problems using simulation models is $35 \%$, and this value increases to $64 \%$ at the stand level and to $72 \%$ at the forest level.

Simulation models are also related to the number of decision makers or stakeholders involved in the forest problem. Problems in which a single decision maker uses simulation models make up $72 \%$ of cases and this percentage decreases (53\%) in problems with more than one decision maker. We can say that two out of three problems solved by simulation models have a single decision maker and the remaining third has more than one decision maker or stakeholder.

Economic models are more frequently used in long term problems (61\%) than in the medium term (30\%) and short term (9\%) timescale (Table 2-9). On the other hand, 38\% of all long term problems use economic models, and this percentage decreases in shorter term planning horizons to $26 \%$ in the medium term and $10 \%$ in the short term. The global percentage of problems solved by a DSS which include economic models is $27 \%$. However, some significant differences occur if taking into account whether the problem 
considers only products, where the proportion using economic models is higher for problems focused on products (Table 2-9).

Table 2-9. Contingency table of problems by temporal scale dimension and economic models

\begin{tabular}{|l|l|c|c|c|}
\hline \multicolumn{2}{|c}{ Temporal Scale } & Economic models & \multirow{2}{*}{ Total } \\
\cline { 2 - 5 } & Nount/(\% Temporal Scale) & $32 /(61.5 \%)$ & $20 /(38.5 \%)$ & $52 /(100.0 \%)$ \\
\cline { 2 - 5 } Long term (strategic) & $\%$ Economic models & $36.8 \%$ & $60.6 \%$ & $43.3 \%$ \\
\hline \multirow{3}{*}{ Medium term (tactical) } & Count/(\% Temporal Scale) & $29 /(74.4 \%)$ & $10 /(25.6 \%)$ & $39 /(100.0 \%)$ \\
\cline { 2 - 5 } & $\%$ Economic models & $33.3 \%$ & $30.3 \%$ & $32.5 \%$ \\
\hline \multirow{2}{*}{$\begin{array}{l}\text { Short term } \\
\text { (operational) }\end{array}$} & Count/(\% Temporal Scale) & $26 /(89.7 \%)$ & $3 /(10.3 \%)$ & $29 /(100.0 \%)$ \\
\cline { 2 - 5 } & $\%$ Economic models & $29.9 \%$ & $9.1 \%$ & $24.2 \%$ \\
\hline Total & Count/(\% Temporal Scale) & $87 /(72.5 \%)$ & $33(27.5 \%)$ & $120 /(100.0 \%)$ \\
\hline
\end{tabular}

Almost $80 \%$ of the total problems solved by a DSS have a database. Considering the planning horizon the results are the following: $86 \%$ of long term problems have a database, $82 \%$ addressing medium term and 62\% in addressing short term problems. $47 \%$ of the problems that have a database are long term problems, decreasing to $34 \%$ for medium term and the remaining $19 \%$ for short term problems.

Unsurprisingly, a DSS linked to a GIS addresses mainly spatial problems (86\%). Even so, $37 \%$ of non-spatial problems use GIS in their associated DSS. The problems are divided into spatial with neighborhood interrelations and spatial with no neighborhood interrelations, $69 \%$ of the first category have GIS tools and 65\% for the second. There are four countries, Austria, Canada, Hungary and the USA, which do not differentiate spatial problems into two categories and 50\% of them use GIS.

Problems with multiple objectives use GIS in 65\% of DSS cases, whereas this percentage drops to $41 \%$ in problems with one objective. GIS are also related to the goods and services; in particular $42 \%$ of problems which involve only products use a GIS as part of the DSS, and in problems which involve both goods and services the percentage increases up to $70 \%$.

Many problems that involve only products have an information system (83\%) and almost all of them in other cases (96\%) (Table 2-10). Almost all problems that involve 
products and services have some information system (95\%). The remaining problems which focus on only products or only services also have an information system but the ratio is slightly reduced up to $84 \%$.

Table 2-10. Contingency table of problems only products dimension and information systems

\begin{tabular}{|l|l|c|c|c|}
\hline \multirow{2}{*}{ Only Products } & \multicolumn{2}{c|}{ Information Systems } & \multirow{2}{*}{ Total } \\
\cline { 3 - 4 } \multicolumn{2}{|c|}{\multirow{2}{*}{ No }} & No & Yes & \\
\hline & Count/(\% Products) & $3 /(4.4 \%)$ & $65 /(95.6 \%)$ & $68 /(100.0 \%)$ \\
\cline { 2 - 4 } & $\%$ Information Systems & $25.0 \%$ & $60.2 \%$ & $56.7 \%$ \\
\hline \multirow{2}{*}{ Yes } & Count/(\% Products) & $9 /(17.3 \%)$ & $43 /(82.7 \%)$ & $52 /(100.0 \%)$ \\
\cline { 2 - 4 } & $\%$ Information Systems & $75.0 \%$ & $39.8 \%$ & $43.3 \%$ \\
\hline \multirow{2}{*}{ Total } & Count/(\% Products) & $12 /(10.0 \%)$ & $108 /(90.0 \%)$ & $120 /(100.0 \%)$ \\
\hline
\end{tabular}

\subsection{Discussion}

This research provides an assessment of methods used in DSS for SFM, which have been described in the country reports and wiki of the FORSYS project. The results apply largely to European countries, with a smaller sample of countries from other continents. The in-depth analysis takes into account the main features of the problems, as well as the models and methods to analyse and solve them.

One of the most influential problem dimensions is the number of people involved in decision making. Whether the problem involves a single decision maker or more than one decision maker/stakeholder is related to the number of objectives, single or multiple, the spatial scale of the decision and the types of goods and services considered. For example, several decision makers or stakeholders were involved more frequently in regional or national planning issues than in forest or stand level planning, and this is also the case for forest problems with multiple objectives. At the same time, a single decision maker is associated more frequently with problems focused on 'only products'. In the cases of the DSS described in the country reports that involve goods and services, the highest percentage appears in multiple objectives problems and with more than one decision maker. This seems intuitive as the expert is the forester/planner using a DSS for solving problems of a technical nature and this professional role usually does not need to be shared with non-expert stakeholders, and as Reynolds (2005) has pointed out 
' 'the institutional perspective is at least as important as the technical one’'. Our results can be interpreted in the following way: problems that focus on "only product"' are mainly managed from a technical point of view, while those involving goods and services are less related with expert knowledge and more with stakeholder preferences.

The number of objectives has a significant influence on the distribution of forest problems by other characteristics, in addition to the number of decision makers involved in the process. In particular, multiple objectives are more frequently analysed in DSS involving strategic problems than in tactical and operational problems. Moreover, the percentage of problems with multiple objectives is much bigger in problems focused on products and services than single objective cases (Shang et al., 2012), although problems with a single objective are mainly focused on products (Binoti et al., 2012).

We found no significant relation between optimisation methods and problem dimensions, although this approach has been used in approximately 60\% of DSS developed for forest management. This suggests that optimisation models could be seen as general tools to deal with forest management problems, not related to their specific characteristics. In fact optimisation models have been used in the majority of published papers describing forest management DSS in the last decade, sometimes being solved by the commercial software CPLEX, or by means of metaheuristics algorithms, such as SA, TS, GA. In general, evolutionary algorithms are now becoming more popular as a tool to solve complex combinatorial optimisation problems, although their use has not been widespread in DSS until now. Metaheuristic methods require detailed studies to obtain the values of the parameters, which make them competitive in obtaining good solutions with less computing time. In addition, tuning parameters are linked to specific instances and many papers use artificial forests (Bettinger and Zhu, 2006; Boston and Bettinger, 2006; Pukkala and Heinonen, 2006; Hennigar et al., 2008). Thus there is an additional difficulty in applying these methods due to the gap between hypothetical and real forests and landscapes. DP is a conceptually smart idea to optimise a sequence of interrelated decisions in forest management. The main drawback for practitioners and DSS developers is that there is not a standard mathematical formulation for problems of DP, as there is for linear, integer and non-linear programming models. It is necessary to develop the particular equations for each problem when using DP. An interesting line of future research would be to develop DSS that are able to generate the required equations for common problems. 
Our analysis showed that statistical methods are not strongly related to problem features, and are applied to only $16 \%$ of problems solved by DSS for forest management. Statistical techniques can be seen as complementary tools to other approaches to inform decision making (Leskinen et al., 2006). In general, traditional approaches such as RA and multivariate models are used more frequently (Ren et al., 2011), although data mining and Artificial Neural Network (ANN) techniques are becoming more popular in recent DSS (Ficko et al., 2011). Recently, many authors have developed statistical spatial models as a more appropriate method to capture data from new sources (Newton et al., 2012), such as GIS.

In contrast to statistical methods, $63 \%$ of forest DSS have used simulation modeling methods and these are particularly related to the spatial scale and the number of people involved in making a decision. Simulation has been applied more successfully to problems involving a single decision maker working at a forest or landscape level. Muys et al. (2010) highlight a trend to integrate forest simulators with optimisation tools and also to involve stakeholders through participatory models, as can be we found in the literature review.

Our results show how closely MCDM are linked to problem types involving a number of objectives and the goods and services dimension. MCDM has the highest percentage use in the DSS concerned with multiple objective problems (73\%) and the least percentage in problems focused on only products (26\%). It highlights the percentage of problems with multiple objectives solved by MCDM, which is only 40\%. In addition, our data show no statistical evidence of the dependence or use of MCDM approaches on the temporal scale of problems, in contrast to what can be expected and had been said in other works (Muys et al., 2010). Thus, there seems to be a demonstrated interested to develop DSS with capabilities in MCDM, not just for long term problems, but for problem types with medium and short term temporal domains. MCDM tools are used to involve stakeholders in forest management and group decision making. Our results suggest that there is a great opportunity to improve the capabilities of DSS in this regard, but with difficulties to overcome often related to new types of data need by MCDM. DSS should be able to capture the preferences and judgements of decision makers/stakeholders periodically, providing quality data with low cost by using the latest technologies, and Menzel et al. (2012) provided a thorough review of DSS from this participatory perspective. 
Economic models have been found in approximately one out of four of the DSS described in the country reports, and these are related largely to temporal scale and goods and services. Economic models frequently address long term problems. Their use is also linked to problems focused on the forest products domain in which market values are more readily available. Their future use in the valuation of ESS that benefit people (Millennium Ecosystem Assessment, 2003) is likely to expand as CV, voting and other approaches to valuation become better developed (Bateman et al., 2011).

Nine out of ten DSS described for forest management have an associated information system, a database and/or a GIS. The dependency analysis of the problem dimension shows some important results. GIS are integrated into more than half of the DSS described. The percentage of problems using GIS is naturally higher in the DSS described in solving spatial problems, but also where multiple objectives and where products and services problem types are concerned. Brown and Reed (2009) evaluate a public participation GIS, as an example to collect non-traditional forest data. Eight out of ten DSS involved a database and this proportion increases when temporal scale is stretched, being used more commonly in long term problem types. If we consider DSS with whatever information system, the analysis shows dependence between this variable and the number of decision makers, having the highest value in cases where several decision makers/stakeholders are involved in the decision making process. Information systems show a high percentage of use and applicability in problems involving products and services. That is, in situations where more tools are needed to present complex information in a visual and intuitive way to support public involvement (Reynolds, 2005).

Almost all DSS for SFM have information systems; nevertheless information has not been properly exploited by classical or novel decision making methods. One reason may be the quantity and quality of data needed and the high cost to obtain and maintain these (Kaloudis et al., 2008). In addition, most of the DSS developed are used only in one country as it is often difficult to apply systems elsewhere (Cucchi et al., 2005; Muys et al., 2010). This fact may constitute a major constraint in the current application of DSS, accounting for inefficiency and overlap in development effort. It is hoped that one of the outcomes of the FORSYS COST Action will be to broaden the available DSS resources across the forest industry and policy makers. 


\subsection{Conclusions}

The analysis of DSS for forest management has shown the preferred approaches, models and methods, to deal with a particular problem, taking into account the nature of the decision problem. This can be characterized by the following six problem dimensions: temporal scale (strategic, tactical, operational), spatial context, spatial scale (stand, forest/landscape, regional/national), number of decision makers or stakeholders, objectives (single, multiple) and finally goods and services involved.

We found some general tools such as optimisation and statistical models and also some challenges to be solved in relation to these approaches. New trends include methods to provide advice to adapt traditional optimisation models, for example considering uneven-aged forests within different ecosystems. In addition, a new generation of evolutionary algorithms is gaining importance to help IP solvers, but they require tuning parameters to be competitive and their value is dependent on instance data. Regarding statistical methods there is a need to develop and integrate spatial models in GIS tools, which will be a requirement to tackle spatial problems and also to involve stakeholders in participatory processes, among other applications.

There is also a strong need to consider multiple objectives and to involve stakeholders in relevant phases of decision making in forestry. MCDM and group decision making should be developed further in DSS to provide a stronger stakeholder contribution to decision making. In this case, one of the challenges is non-traditional forest data, as lack of availability as input to models can limit their use in real problems. Additionally, the majority of DSS are focused on market products, alone or together with services. There are few DSS dealing only with services, and especially with non-market services. In this latter case, but also in general, we can say that quantity and quality of data required are a major issue to implement DSS in practice. New technologies to capture data will provide an opportunity to overcome this weakness, as well as a challenge to develop new models and methods that are really effective for practitioners.

Finally, DSS are mainly focused on technical and market economic objectives rather than social and environmental ones. We suggest that the future development of DSS for forest management should place stronger emphasis on economic models integrating the 
value of environmental services and collaborative decision making of multiple decision makers and stakeholders.

\section{Acknowledgments}

The authors acknowledge the support received from European Cooperation in Science and Technology (COST Action FP0804 - Forest Management Decision Support Systems “FORSYS'), the Ministry of Economy and Competitiveness through the research project "Multiple Criteria and Group Decision Making integrated into Sustainable Management”, Ref. ECO2011-27369 and Ministry of Education (Training Plan of University Teaching). We also thank the editor and reviewers for their suggestions to improve the paper. 


\title{
CHAPTER 3
}

\section{Sustainable Forest Management in a}

\section{Mediterranean region: Social}

\section{preferences}

Maroto, C., Segura, M., Ginestar, C., Uriol, J., \& Segura, B. (2013)

Forest Systems, 22(3), 546-558. http://doi.org/10.5424/fs/2013223-04135

\begin{abstract}
Multiple Criteria and Group Decision Making are the best decision making approaches to dealing with sustainable forest management. A literature review shows a lack of empirical research dealing with Mediterranean forest, one of the most vulnerable ecosystems. The main purpose of this chapter is to define the strategic criteria and objectives for sustainable forest management and to aggregate stakeholders' preferences in a particular Mediterranean region, using Analytic Hierarchy Process (AHP) and Goal Programming (GP) methods. Action plans of the public administration are also prioritised. Firstly, we identified forest stakeholders and structured a decision hierarchy. Then a workshop was carried out to test the proposed criteria, as well as a survey to
\end{abstract}


determine social preferences. In a second phase, another survey was conducted amongst experts, to determine the contribution of public action plans to the considered objectives. The results show a greater importance for environmental and social criteria and a lesser relevance for economic criteria, valid for both public and private Mediterranean forests. New products and services such as rural tourism, renewable energies, landscape, hydrological regulation and erosion control, biodiversity or climate change mitigation are also relevant. Finally, we prioritised action plans comparing them with the distribution of the administration budget.

\subsection{Introduction}

Forest management has been a source of numerous decision making problems related to principally industry in North America, Latin America, Scandinavia, Australia and New Zealand. Strategic forest planning has evolved from regulating the flow of industrial timber resources to its current focus on Sustainable Forest Management (SFM) (Martell et al., 1998). The current use of forests is oriented to multiple objectives, and in strategic planning the main idea is to define what is wanted from the forest and often involves numerous stakeholders. They could be the owners of the forests, people connected with tourism, recreation services or nature conservation, as well as forestry companies (Kangas et al., 2008). Nowadays, economic, social and environmental criteria are involved in practically all decision making situations. Within this context, the decision process should explore the conflicting nature of the criteria, the goals set by the decision makers, and the way in which these can be introduced into an appropriate decision model that takes into account the preferences of the stakeholders.

Multiple Criteria Decision Making (MCDM) methods have been widely applied to solving forest management problems over the past few decades and are a wellestablished paradigm for addressing many problems in this area. The applications can be classified into harvest scheduling, forest biodiversity conservation, forest sustainability, forestation, regional planning, forestry industry and risk and uncertainty (Diaz-Balteiro and Romero, 2008). The literature review of these authors points out an increasing interest in using group decision making methods with a multiple criteria approach. 
Ananda and Herath (2009) provide another recent review on forest management and planning using MCDM, confirming that published studies are only applied to cases in countries such as Finland, Canada, USA and Australia. These authors emphasize the importance of empirical applications and suggest areas for improvement in future research such as the process for selecting the decision criteria, as well as a clear definition of criteria.

Analyzing in depth the contributions in these areas over the last decade, we find several studies that focus on regional forest planning referring to the North East Victoria region (Australia). Ananda and Herath (2003a) used Multi-Attribute Value Theory (MAUT) to analyse stakeholder values. They considered a simplified model with 3 attributes (oldgrowth forest conservation, hardwood timber production and recreation intensity) and 3 hypothetical forest management options or strategies, constructed by taking the status quo as a basis. They interviewed 36 stakeholders from five groups (timber industry, environmentalists, farmers, recreationists and tour operators). Another paper shows that Analytic Hierarchy Process (AHP) can be a tool to formalize public participation in decision making with the same problem as an illustrative example, but they used hypothetical data and thus the results do not have any empirical validity (Ananda and Herath, 2003b). Later, Ananda (2007) and Ananda and Herath (2008) presented a real AHP application for a previous case study involving a greater number of stakeholders.

Kazana et al. (2003) used a multiple criteria approach to support decisions in forest management at a tactical level in a national forest park in Scotland. Hjortsø (2004) evaluated soft OR to enhance public participation in tactical forest planning with a case study in Denmark. Diaz-Balteiro et al. (2009) used Goal Programming (GP) to aggregate the preferences of forestry students, expressed through pairwise comparison matrices, referring to two public forests in Spain, to elicit weights for four objectives. Nordström et al. (2009) applied MCDM and group decision making in planning urban forest in Sweden. They designed a hierarchy with 4 stakeholder groups (timber producers, environmentalists, recreationists and reindeer herders), each of which have their own different objectives. GP models are used to aggregate stakeholder preferences and to obtain criteria weights to be used for ranking 12 forest management plans. In Nordström et al. (2010) another approach using AHP was applied to aggregate stakeholder preferences for the same urban forest, taking 3 plans into account. Hiltunen et al. (2009) tested the Mesta Internet-based decision-support application in strategic 
planning processes in Lapland (Finland). The main role of stakeholders in sustainable forest management has also been highlighted in other recent studies focused on regional forest programmes in Finland (Kangas et al., 2010).

Decision making and public opinion appears as one of the relevant themes for future research in natural resource management (Petrokofsky et al. 2010). In practice, MCDM methods have been implemented to inform decision problems and public participation and they will continue to be essential in forest and environmental management (Kangas and Kangas, 2005). Nevertheless, several reviews (Mendoza and Martins, 2006; Ananda and Herath, 2009) and an extensive analysis of the literature to date, show a lack of empirical research referring to Mediterranean forest, one of the most vulnerable ecosystems, according to the Intergovernmental Panel on Climate Change (2007).

We can differentiate two main forest zones in Spain: Atlantic and Mediterranean. Atlantic forests have a wood productivity as high as forests in central and northern Europe. In contrast, Mediterranean forests, in general, provide a low wood productivity and non-wood services. Valencian forest is a good example of the Mediterranean forest. Forest land is defined as those areas which present one or more uses which can be considered forestry use. Thus the Valencian Community has a total forest area of 1,323,465 hectares, representing $57 \%$ of the total land with the current trend increasing the forest area at a rate of about 3,300 ha/year, mostly through neglected agricultural areas and their subsequent colonisation by forest species. Forest woodlands now occupy 54\% of the forest land (PATFOR, 2011).

Management objectives are not always known or, in some cases, they can only be elicited through prior analysis (Schmoldt et al., 2001). This is the case in sustainable management of Mediterranean forest, so explicitly specifying all relevant objectives and quantifying their importance in its strategic and sustainable management are very interesting contributions towards developing public policies according to social preferences in Europe.

The decision maker in sustainable forest planning problem is the regional government, which distributes public funds to the different action plans. European public policies must reach a consensus through public participation. Public participation means that citizens are involved in natural resource decision making that has an effect on them. Public participation is also seen as part of sustainable development (COST, 2012). 
The objectives of this chapter are to define the strategic criteria for the sustainable management of Mediterranean forests, as well as to elicit and aggregate the stakeholders' preferences, using several methods to increase the objectivity and robustness of the results. Finally, we prioritise the action plans of the public administration, taking the social preferences we obtained into account.

In developing the decision hierarchy we tried to balance completeness with conciseness, two conflicting requirements in defining criteria and objectives for our problem. Another important aspect considered is that the information demands on the people involved should not be excessive, following the recommendation of Belton and Stewart (2002). Our hierarchy is logical and includes a complete set of fundamental objectives and has been validated by a large group of experts in a workshop (Saaty and Shih, 2009).

The rest of the chapter is organised as follows: The next section describes the public participation techniques and the methods used to aggregate the preferences for sustainable management of Mediterranean forests, in particular for the Valencian region. After that, the results are presented: the decision hierarchy, matrix consistency, social preferences of criteria and objectives as well as the global priorities of the action plans. Finally, the results are discussed and the main conclusions of this empirical research are pointed out.

\subsection{Material and Methods}

\subsubsection{The Analytic Hierarchy Process and Goal Programming models}

The method developed by Saaty, AHP, is undoubtedly one of those most commonly used to identify and prioritise objectives and alternatives in the field of forest management. Its approach is based on three principles: construction of the decision hierarchy, logical consistency and setting of priorities. The method allows us to incorporate qualitative aspects into the hierarchy definition and to use quantitative aspects to measure preferences and priorities. It also allows group participation in decision making. 
First, the decision hierarchy, for which all the actors involved in decision making have been identified, is designed. Second, the individual preferences are obtained by pairwise comparisons, i.e. comparing two elements of the same level of the hierarchy with respect to a criterion of a higher level. Comparisons are collected in a matrix that allows us to check the consistency of the preferences.

Each element of the comparison matrix $A, a_{i j}$ represents the relative importance of an element, i to another element, $\mathrm{j}$ with respect to a criterion in the upper level. The Saaty fundamental scale is set from 1 to 9 , where 1 indicates that the two elements are equally important, 3 moderate importance, 5 strong importance, 7 very strong importance and 9 extreme importance of the first element, i with regard to the second, $\mathrm{j}$. If we were to compare of the second element, $\mathrm{j}$ against the first, $\mathrm{i}$, the values would be given inversely $(1,1 / 2 \ldots 1 / 9)$. This matrix $A$ is consistent if $a_{i j}=a_{i k} a_{k j}$ for every element $i, j$ and $k$. That is, if element $\mathrm{i}$ has a relative importance of 2 compared to element $\mathrm{k}$ and element $\mathrm{k}$ has a relative importance of 2 compared to a third element, $\mathrm{j}$ then element $\mathrm{i}$ should have a relative importance of 4 compared to element $\mathrm{j}$ for a consistent response.

From this matrix A we obtain the associated eigenvector, which represents the individual weights $\mathrm{w}_{1}, \mathrm{w}_{2} \ldots \mathrm{w}_{\mathrm{n}}$ for each criterion (Saaty, 2008). To obtain the preferences of a group of people the geometric mean of all pairwise comparisons is used (Xu, 2000; Saaty and Peniwati, 2008).

The GP Models are an alternative method to AHP for aggregating stakeholder preferences from comparison matrices and obtaining weights of criteria. From individual stakeholder matrices we obtained a consensus matrix for each group using the extended GP model developed by González-Pachón and Romero (2007). In the second step, we derived the weights of the relative importance attached by the ith stakeholder group to the rth criterion from the consensus matrix using another GP model developed by González-Pachón and Romero (2004). Both models are presented in Annex IV.

\subsubsection{Experts, stakeholders, workshop and surveys}

In many real problems it is not easy to establish the goals that should inform decision making and this is particularly true when making government decisions which affect natural resource management and especially in forest management, where public 
participation is becoming increasingly important. The participation of qualified experts and stakeholders is of paramount importance in defining and selecting regional planning objectives. Expert interviews and workshops are suitable participatory techniques for strategic forest management. Structured surveys allow us to quantify the importance of the objectives and action plans, which can serve as indicators to inform formation and prioritisation of public policies.

From both the authors knowledge and exhaustive interviews with experts the following stakeholder groups have been identified: administration, professional engineering associations, people involved in forest research and education, hunting and fishing federations, forest owners (private and municipalities), companies and land stewardship, environmentalist and conservationist groups. Representatives of all these groups have been invited by the Regional Government to collaborate in developing new forest programmes in the Valencian Community.

After identifying the stakeholders, a decision hierarchy with sustainable management of Mediterranean forest as the decision goal at the first level was proposed. The second level consists of social, economic, and environmental criteria, the three basic pillars of the sustainability concept as well as the multifunctional forest. Each of these criteria is divided into specific objectives in the third level with enough detail to include all aspects which are currently relevant to the Valencian region. A decision hierarchy which considers several action plans was completed.

In the next phase, a workshop at the university (2010) was carried out, with representatives of stakeholders to test and validate the proposed decision hierarchy. Presidents of associations of public and private property, professional organisations and federations, managers of public forestry services, companies and land stewardship, environmentalist and conservationist groups took part, both directors and technical staff. Forestry researchers, teachers and students also participated in the all-day-workshop, which had almost 200 participants. In this workshop we held a round-table meeting with stakeholder's representatives, followed by a colloquium and general debate between all participants. Principal statistical data on Valencian forests and maps with public and private forest areas, as well as the decision hierarchy for strategic management of Mediterranean forests, in particular the forests of the Valencian Community, was presented following the recommendation from Sheppard and Meitner (2005). In the workshop Saaty's basic scale of comparisons between pairs of criteria (Saaty, 2008) 
was also explained, with the objective that stakeholders could respond to a questionnaire designed to elicit their preferences.

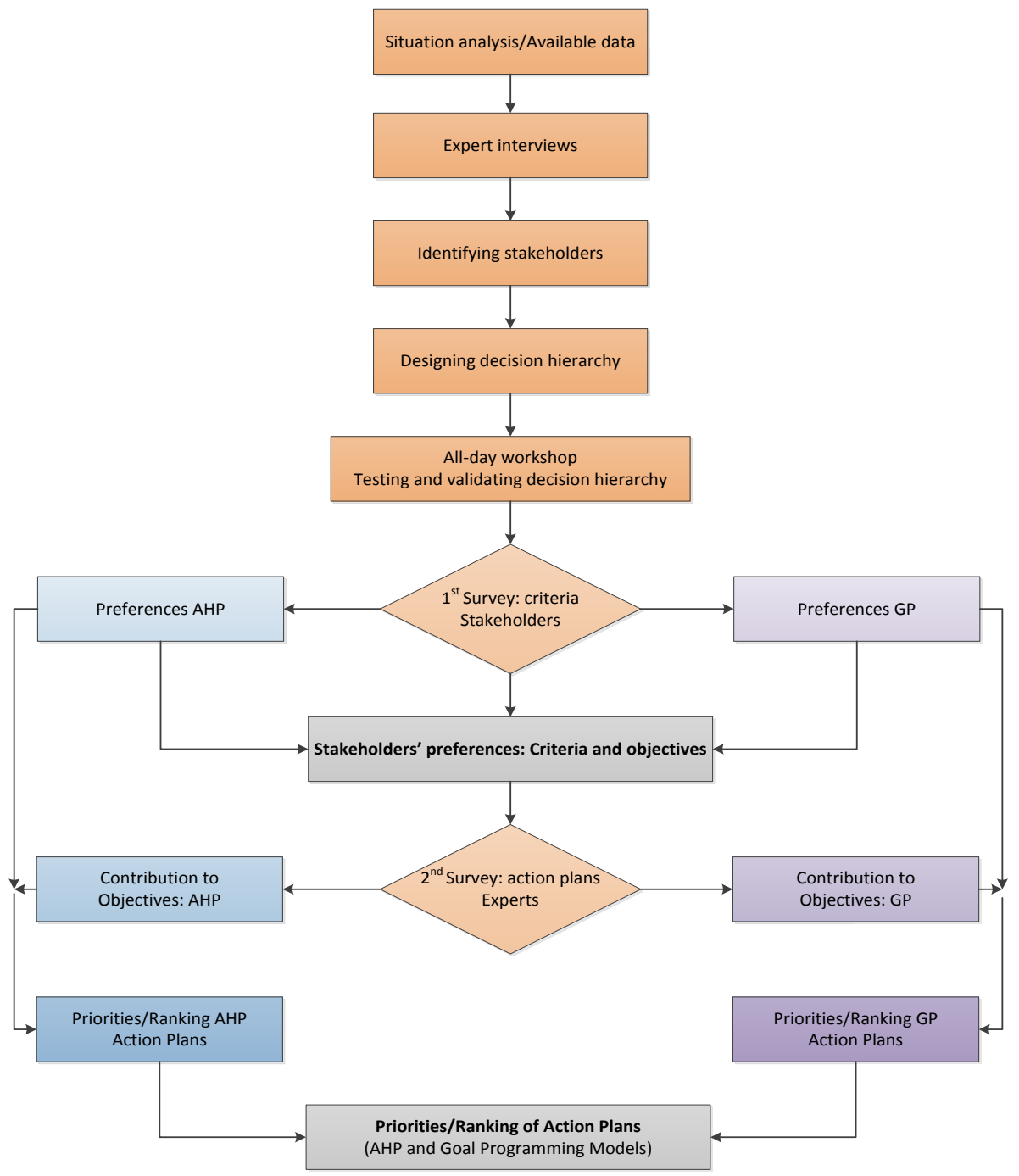

Figure 3-1. Flow-chart of process to obtain stakeholders' preferences and to prioritise action plans 
Then, two surveys were carried out, the first one amongst the stakeholders to determine their criteria and objective preferences (Annex II). Due to the lack of data, to quantify the contribution of the different action plans of the administration to the objectives included in the decision hierarchy, a second survey was carried out amongst experts (Annex III). These experts came from the administration, companies and researchers in the forest area. Finally, weights of criteria and objectives were obtained by aggregating stakeholder preferences, using two methods: AHP and GP models. For both methods, consensus matrices for stakeholder groups were derived. The weights of preferences of criteria and objectives and global priorities of action plans were then determined. The whole process has been represented in Figure 3-1.

\subsection{Results}

\subsubsection{Decision hierarchy}

Figure 3-2 synthesizes the criteria, objectives and action plans, adopted after the aforementioned workshop. The first level is the goal of the decision; the second level considers social, economic, and environmental criteria. Social criteria are divided into employment creation, educational and recreational activities and landscape. Environmental criteria have been grouped into hydrological regulation and erosion control, climate change mitigation and minimizing biodiversity loss. In economic criteria we find more traditional objectives, such as wood production, hunting and fishing, livestock and other production (truffles, mushrooms, cork, etc.) and mining. We also include other goods and services, such as renewable energies and rural tourism.

Finally, we completed the decision hierarchy with the following six action plans:

1. Fire prevention and extinction. Pest prevention.

2. Reforestation and forestry.

3. Hunting and fishing species management, including the maintenance of game reserves. 
4. Management of flora and fauna, conservation of flora micro-reserves, wildlife corridors and enhancement of the Nature 2000 Network, in order to preserve the biodiversity of the Valencian Community.

5. Trails and other recreational and tourism infrastructures (recreational areas, cabins, shelters, etc.).

6. Forest research, studies, education programmes, inventory and planning.

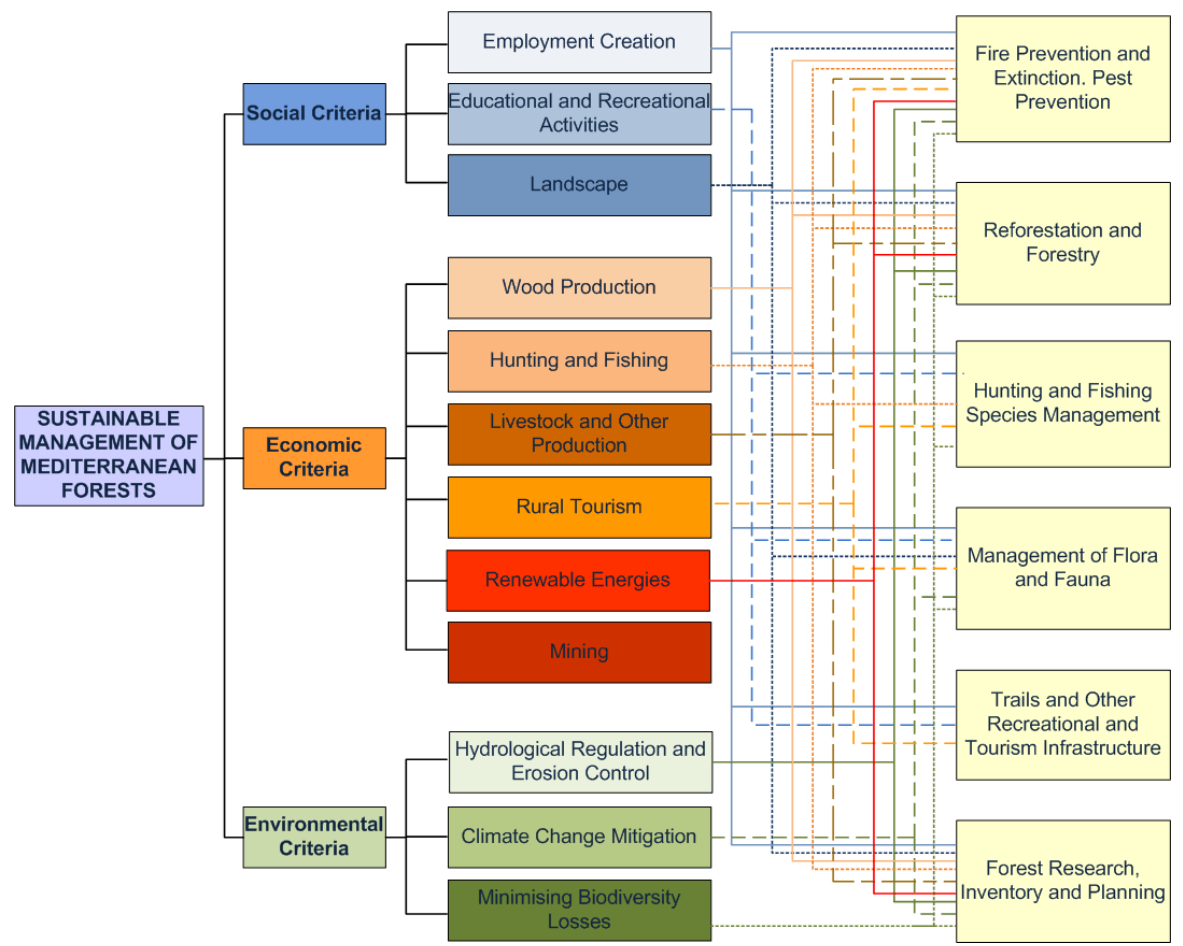

Figure 3-2. Decision hierarchy for strategic management of Mediterranean forests

Nowadays all action plans except for forest inventory and planning have an administration budget. These budgets are dedicated to financing both public and private forest (the latter through grants to the owners). Some stakeholders at the workshop 
suggested the inclusion of actions for forest inventory and planning, not considered previously. The action plans have been grouped into six categories due to the methodology of pairwise comparison. A greater number of plans would imply a greater number of questions (tedious surveys) and lesser consistency in the resulting matrices.

\subsubsection{Surveys and matrix consistency}

Mainly due to the large number of criteria and objectives under consideration two phases were planned. A first survey was carried out to gather the preferences of stakeholder groups for criteria and objectives. The second survey allowed us to determine the contribution of action plans to each objective which is a question of a technical nature, not of preferences. Thus, this second phase involved experts who participated in the first one. In both surveys we asked the stakeholders (first survey) or experts (second survey) to complete the top half of the comparison matrix and we assumed a reciprocal matrix.

Table 3-1 shows the distribution of the 46 questionnaires obtained from the stakeholder groups. Administration was the biggest one, because of the need to balance the different aspects and services involved such as forest management, fire prevention, hunting and fishing and biodiversity conservation.

The second survey asked about the relative contribution of each action plan to each objective, using the same money for each action plan being compared. In Figure 3-2 the links between nodes of third level and fourth level of the decision hierarchy represent the contribution of each action plan to objectives. For example, all six action plans contribute to employment creation, but only four of them contribute to rural tourism. In this second phase we obtained 17 questionnaires and their distribution amongst the groups of forestry experts is as shown in Table 3-1. We integrated all of them in just one group because the objective is to estimate the contribution of each action plan to each objective by providing expert judgments.

The matrix Inconsistency Index (II) was obtained using Superdecisions Software (2010). In our analysis only matrices having an II less than or equal to 0.1 , are used (Saaty, 2006). The percentage of consistent matrices is 67\% when stakeholders compare 3 criteria and 50\% when 6 criteria were involved in the pair comparisons. 
Table 3-1. Distribution of questionnaires among stakeholder groups (first survey) and the expert group (second survey)

\begin{tabular}{|l|c|c|}
\hline \multirow{2}{*}{ Stakeholder Groups } & \multicolumn{2}{c|}{ Number of questionnaires } \\
\cline { 2 - 4 } & First survey & Second survey \\
\hline Administration & 17 & 9 \\
\hline Professional engineering associations & 5 & 3 \\
\hline Forest research and education & 8 & 3 \\
\hline Hunting and fishing federations & 3 & - \\
\hline Forest owners & 4 & 2 \\
\hline Forestry companies & 6 & - \\
\hline Land stewardship, environmentalist and & 3 & \\
\hline conservationist groups & & \\
\hline TOTAL & 46 & \\
\hline
\end{tabular}

We have 17 experts who responded to the second questionnaire from each of whom we obtained 11 matrices of pairwise comparison. An interesting result of the study is that the consistency of these matrices referring to technical aspects is greater than in the first questionnaire (preferences) and does not depend so much on the number of strategies to be compared. The percentage of consistent matrices was between 71 and $82 \%$ with 3 , 4, 5 and 6 strategies to compare. Only in climate change (65\%) and renewable energies (53\%) did the percentage decrease, which would seem to be related to the newness of these criteria. 


\subsubsection{Preferences of stakeholder about criteria and objectives}

In this section the results of stakeholder preferences, obtained with AHP and GP are presented. In this latter case, preference results from the point of view of most of the people are represented in figures. After that, the differences when the opinions of minorities are incorporated into the model are discussed.

Figure 3-3 highlights the great importance of the environmental criterion in general, which is the most important for administration, forest research and education, hunting and fishing federations and forest owners. As the latter group is formed of private and public owners, we highlight that this result is due to the preferences of the people representing municipalities. Only engineering associations gave much more importance to social and economic criteria than environmental ones in sustainable management. On the contrary, economic criteria have less relevance in general, but they are the most important for forestry companies.

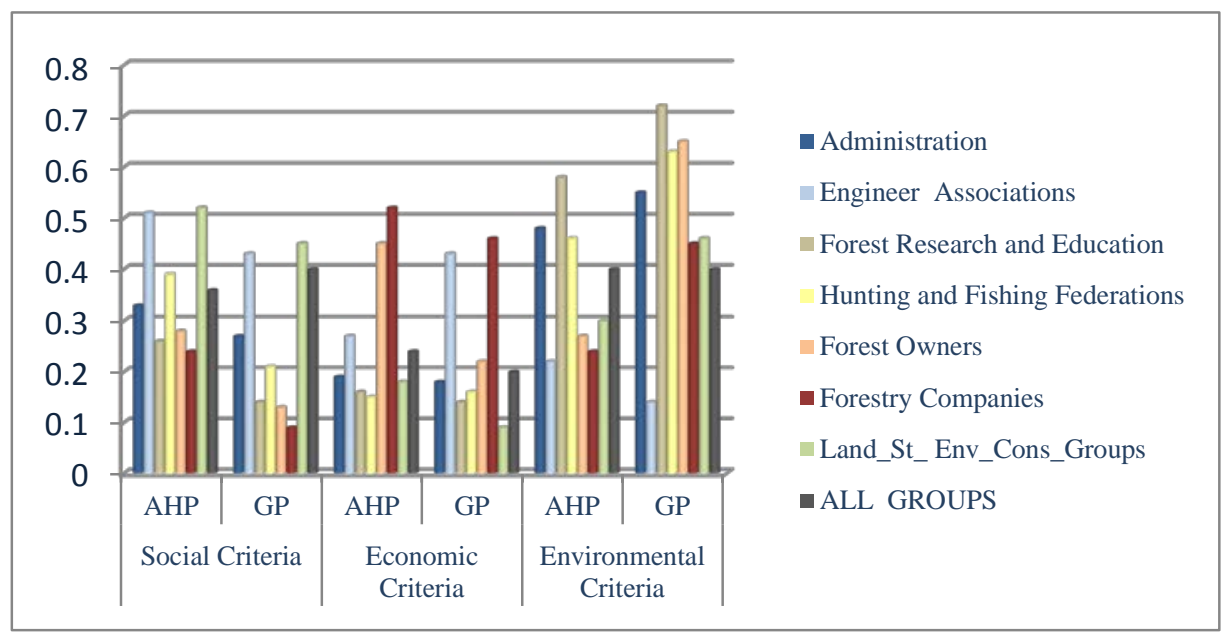

Figure 3-3. Priorities of social, economic and environmental criteria in sustainable management of Valencian forest by stakeholder groups 
Analysing the results with respect to public forest the answers highlight the lower relevance of economic criteria and the greater weight of social criteria compared to all the forests. A decrease in economic priorities is compensated mainly by an increase in the weights of social criteria. Stakeholders were also asked if they would change their opinion about the relative importance of the specific objectives (the third level of the hierarchy) for those public forests that are directly managed by the administration. A large majority said no and the percentages do not differ greatly from one stakeholder group to another. The percentage of stakeholders with a negative response is $65 \%, 28 \%$ said yes and $7 \%$ did not answer.

The objective contribution to social criteria can be seen in Figure 3-4. In general, the employment objective is in the first place, except in the case of land stewardship, environmentalist and conservationist groups. As it could be expected, recreational activities are more relevant for this last group. Results for hunting and fishing federations were not obtained due to the lack of consistent individual matrices.

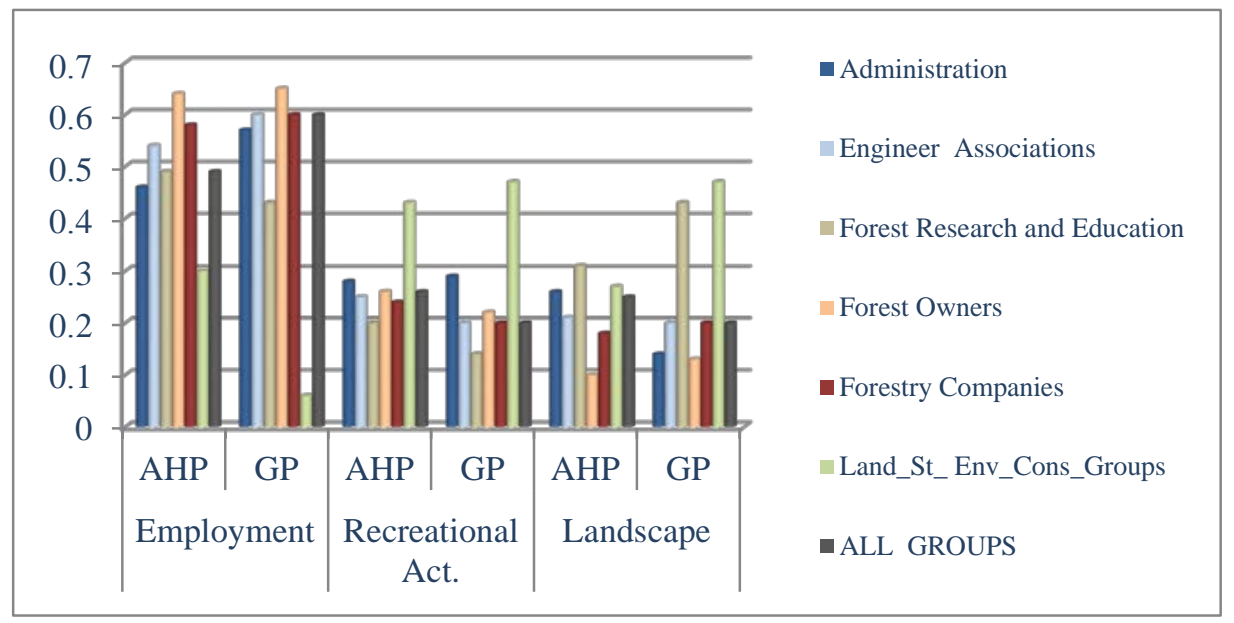

Figure 3-4. Priorities of social objectives of Valencian forest by stakeholder groups 
In Figure 3-5 the priorities for environmental objectives can be seen. Hydrological regulation and erosion control are very important to almost all groups. In this case, any individual matrix is consistent for land stewardship, environmental and conservationist group and we only have one from hunting and fishing federations.

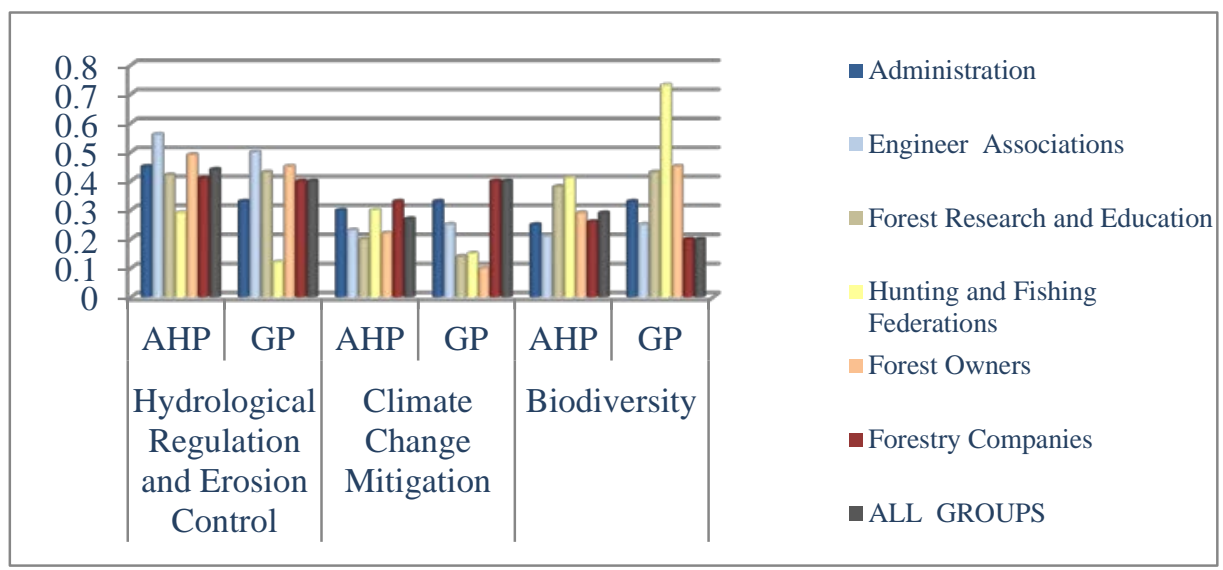

Figure 3-5. Priorities of environmental objectives of Valencian forest by stakeholder groups

Figure 3-6 displays the results of the weights of economic objectives from the stakeholders with consistent individual matrices. As it is well known, as the number of elements to compare increases, the difficulty of obtaining consistent matrices also increases. Nowadays, traditional forest products, such as wood production and livestock have less weight in Mediterranean forests, only hunting and fishing activities maintain some importance. New services and production, such as rural tourism and renewable energies are greater importance in general, with weights of between 15 and 40 per cent, depending on the stakeholder group under consideration. The industrial activity of mining (mainly quarries) is also an important source of income for some forest owners in the Mediterranean area.

Figures 3-3, 3-4, 3-5 and 3-6 represent the solution of GP models for control parameter $\lambda=1$, which shows the preferences of the majority. The model has also been solved for all stakeholders when $\lambda=0$. This solution generates the aggregated preferences when minimizing the maximum deviation of individual preferences regarding the consensus 
matrix. The model for intermediate values of the control parameter has also been solved as shown in Figure 3-7. As it can be seen, the priority of biodiversity varies between 17 and $25 \%$. The variation of preferences is greater in the other two objectives. In giving more weight to the minorities, the priority of hydrological regulation and control of erosion increases. This increase is compensated by lower values for the mitigation of climate change.

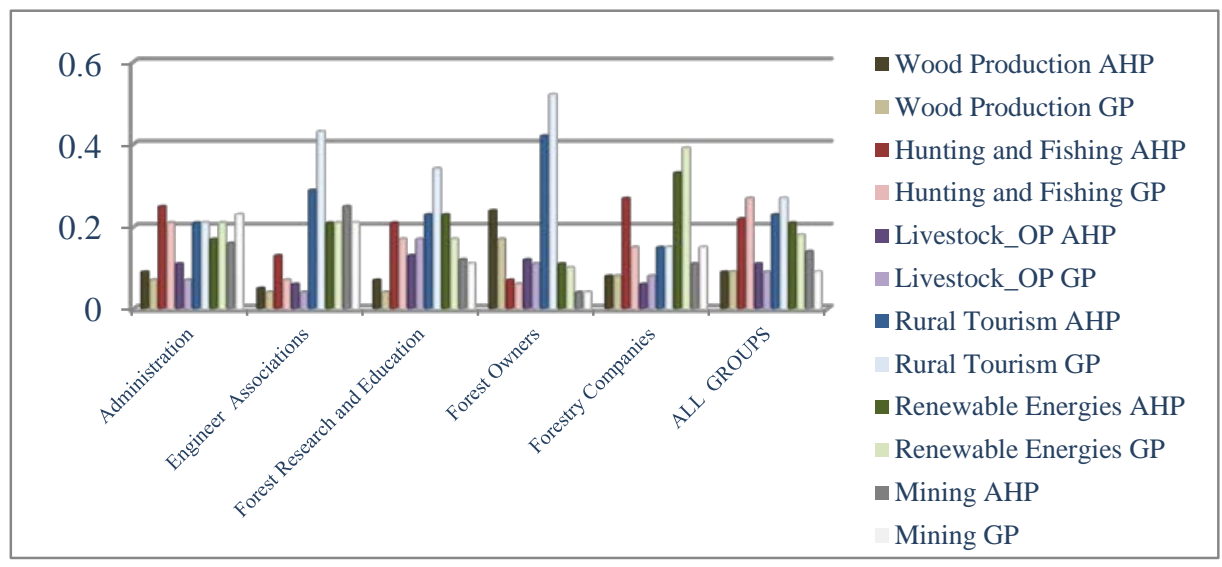

Figure 3-6. Priorities of economic objectives of Valencian forest by stakeholder groups

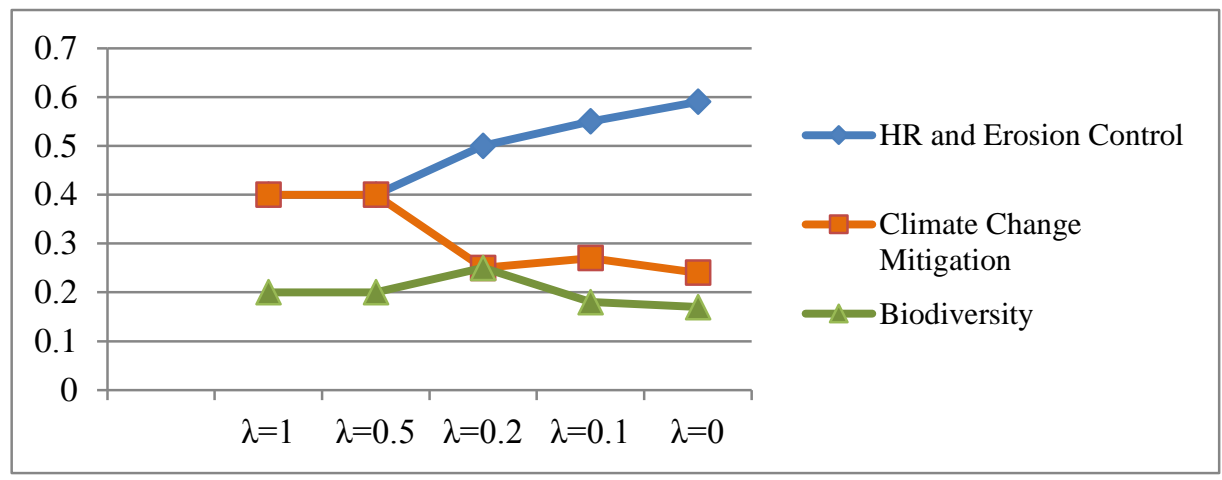

Figure 3-7. Priorities of environmental objectives when varying the control parameter in the extended Goal Programming model 
By varying the control parameter in the models of social and economic objectives, priorities are very similar for all values of $\lambda$. The same applies to the solution of the models that allow us to obtain the aggregated priority criteria, showing a greater preference for the environmental and social criteria than for the economic criteria in the Mediterranean forest, from the point of view of the majority and of the minority.

\subsubsection{Global priorities of action plans}

Table 3-2 shows the results of the global priorities of action plans (fourth level of decision hierarchy, Figure 3-2) for sustainable and participative management of Valencian forests. Enough questionnaires were obtained to balance the different areas of people's expertise and its distribution among administration, engineer associations, companies, research and education, to try to capture all relevant knowledge.

Due to action plans representing lines of public budget, how much these plans contributed to mining was not asked, because this is a profitable industrial activity and does not receive public funds from the forest administration. Nevertheless, this economic activity has to be included in the hierarchy because it affects the economic results of forests.

The weights or local priorities of the action plans were obtained from the second questionnaire. We calculated the consensus matrix from all the consistent individual matrices first by using a GP model with $\lambda=1$ (that is, aggregating majority judgments) and afterwards the local priorities by using the second model. All of the 11 consensus matrices obtained are consistent (II less than or equal to 0.10 ).

Finally, the global priority of each action plan was calculated, weighting the local priorities with the importance of the objectives and the criteria using distribute mode. The sum of all global priorities of action plans is equal to 1 (Saaty, 2006). These global priorities can be used as one of the possible indicators for taking decisions in the distribution of the public budget assigned for the management of the forest, both public and private. 
Table 3-2. Global priorities of action plans by stakeholder groups and public budget

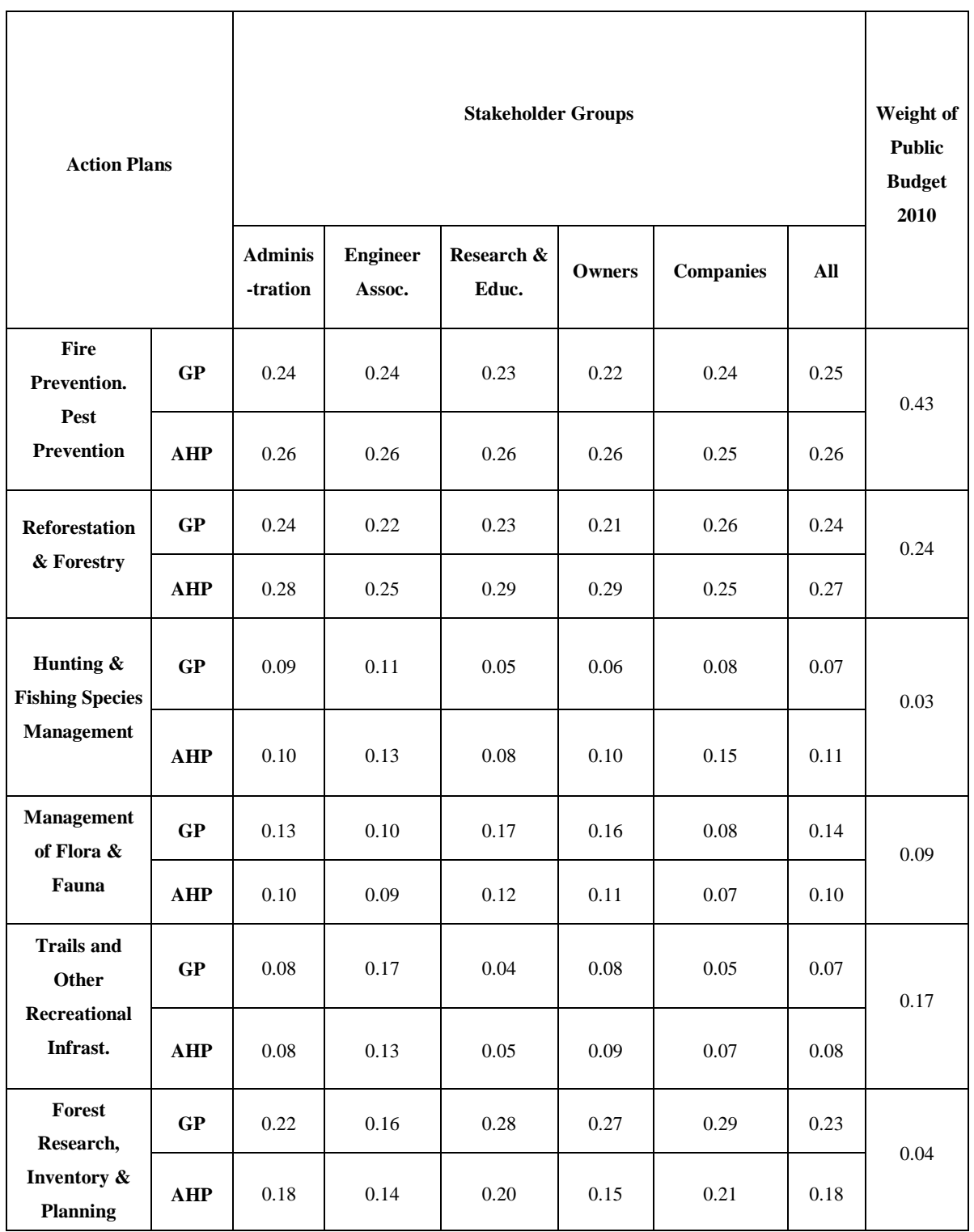


Fire prevention and extinction and reforestation and forestry have similar priorities, occupying the first or second place in all stakeholder groups. Forest research, inventory and planning are notable as they are the most relevant for the following three groups: forest research and education, forest owners and forestry companies (Table 3-2). These three action plans also occupy the first places for the hunting and fishing federation, with similar priorities. This group is not in Table 3-2 due to the lack of consistency in some matrices of the second level. The same situation happens with the land stewardship, environmentalist and conservationist groups. These groups are those with the fewest questionnaires. Nevertheless, from the available information from the land stewardship group, the strategy that occupies first place is trails and other recreational and tourist infrastructures. This line is the one that has the least importance for the other stakeholder groups being, globally, that with the lowest priority. Fourth place is occupied by flora and fauna management, followed by hunting and fishing species management. We would like to point out that the decision maker can derive priorities for all society by properly weighting stakeholder preferences. Priorities of all groups were obtained by integrating all stakeholder responses in one GP model to calculate a general consensus matrix and then using this matrix to derive global priorities.

The priorities of the strategies for the public forest are not very different from those for all forests. This is because there are no important differences between the weights of the objectives and criteria. In this case, forest research, inventory and planning have a slightly higher priority, occupying first place. The priority for the management of flora and fauna also increases slightly and those related to hunting and fishing and trails decrease.

\subsection{Discussion and conclusions}

First of all, we would like to emphasize that the principal results which were obtained from the two preference aggregation methods, geometric mean and eigenvalue and GP are along the same lines, even though each have its own strengths and weaknesses. The eigenvalue technique requires that the II be less than or equal to 0.1 , but this is not necessary in the GP method. However, in the analysis which we have made, only matrices which meet this requirement have been used so that we could compare the aggregated preferences and the global priorities using the same data. 
The geometric mean guarantees that the matrix which represents the preferences or judgements of various persons has an index of inconsistency no greater than that of the individual matrix with the greatest index of inconsistency. However, GP models do not assure that the consensus matrices resulting from consistent individual matrices are consistent themselves. In our case study, when the judgements of the experts from the second survey are aggregated, all the matrices obtained were consistent, but this was not the case in all the consensus matrices obtained from the first survey.

Expert responses are generally more consistent than the responses from the other people involved who have less technical knowledge about forestry. In the previous section we commented on the lack of consistent responses from some stakeholder groups where only a few people took part in the survey. Other empirical works revealed similar problems with matrix consistency and have included in their analyses matrices that have higher indexes of inconsistency, up to 0.30 (Nordström et al., 2010).

The investigation shows the greater importance of the environmental criteria over the economic and social criteria in the management of the Mediterranean forest. This result is the same regardless of which preference aggregation technique was used and takes into account the preferences of the majority of the stakeholders and also the minority opinions furthest from the consensus. The relevancy of the environmental criteria is valid for both public and private forest.

Although there were differences between the values of the priorities obtained using AHP and GP, these differences decrease as the number of stakeholder surveys taken into consideration increase and, in general, the relative order of the priorities remains.

Experts were involved during the first phase of the design of the decision hierarchy. This was later validated in consultation with the stakeholders. We can improve the legitimacy of the final decision when all the stakeholders are involved in the decision making (COST, 2012).

The public budget distribution during the last 5 years has been analysed. The greater part of the funds is destined for the prevention and extinction of fires, with an emphasis on extinction. It is of interest to note that the responsibility for extinction belongs to the fire service, not to the forest administration. Amongst the reasons for the great amount of budget dedicated to the extinction of forest fires are the high costs of this service, compared with other action plans. Additionally, this Mediterranean region is a high risk 
for forest fires, many of which present risks to housing and, above all, to human life. In summer, many people live in houses surrounded by forest. This has caused an increase in public spending to this end over the last few decades. For example, the budget was 112,421,579 Euro in 2010, distributed as 86,290,812.86 Euro for fire extinction, 24,785,508.12 Euro for fire prevention and the rest for pest prevention. If we remove the budget for fire extinction from the total, a close relation between the budget dedicated to the different action plans and its relative importance obtained from the stakeholder preferences can be seen (Table 3-2).

To our knowledge, this is the only proposal at a regional level for the Mediterranean forest. A large number of objectives have been included, taken into account all the relevant aspects of sustainable management. There is a noticeably greater representation of the social objectives in this proposal, compared to works published by other authors for other regions and other scales. Another difference is the use of several multiple criteria techniques to aggregate preferences. The use of several techniques reinforces the results of the work, making them more objective and useful when looking for consensus in strategic decisions.

The model that has been developed could be refined using Analytic Network Process (ANP), the AHP generalization which considers dependences between criteria, in order to include things such as the negative effect of mining on the landscape and erosion. It could also be improved by an analysis of sensitivity, weighting the importance of the different groups of stakeholders. The priorities of “All Groups” have been obtained giving all stakeholders an equal value, and so more importance was given to groups with more representatives, such as administration.

In conclusion, this empirical research contributes a model for sustainable regional planning of the Mediterranean forest using a multiple criteria and group decision methodology with a participative process including all stakeholder groups. Our decision hierarchy is a complete model with detailed social, economic and environmental objectives and has been validated by the stakeholders. We have quantified the lesser relevance of economic criteria and the greater importance of environmental criteria in sustainable and participative management of the Mediterranean forest. Social criteria are more important than economic criteria for all stakeholder groups, except for forest owners and forestry companies. It has been demonstrated that this tendency varies very 
slightly between private and public forest, showing the importance of the environmental forest services to society, regardless of who owns it.

Referring to action plans, fire prevention and extinction and reforestation and forestry have similar global priorities, occupying first or second place for all stakeholder groups. Forest research, inventory and planning occupy third place in the social preferences, although it is the highest priority strategy for people involved in forest research and education, forest owners and forestry companies. Management of flora and fauna is in fourth place, followed by hunting and fishing and finally trails and other recreational and tourism infrastructures.

Finally, our contribution could be a methodological reference for developing decision aid models for strategic forest planning in other regions, in particular the Mediterranean arc, as well as to inform public policies in that area. The model we have developed is a framework within which management models on a lesser scale can be developed, and can also be used to evaluate the environmental services which are provided. In future works it would be interesting to develop, evaluate and compare models and tools for participative multiple criteria decision making for the sustainable management of public forests and natural parks, using face-to-face and internet-based surveys, as well as small deliberation groups and workshops.

\section{Acknowledgments}

The authors acknowledge the support received from the Ministry of Science and Innovation through the research projects Ref. ECO2008-05895-C02-01/ECON and ECO2011-27369 and Ministry of Education (Training Plan of University Teaching), as well as the time and expert judgments from all the stakeholders involved in workshop and surveys we have carried out. 


\title{
CHAPTER 4
}

\section{A New Collaborative Methodology for}

\section{Assessment and Management of Ecosystem Services}

Segura, M., Maroto, C., Belton, V., \& Ginestar, C. (2015).

Forests, 6(5), 1696-1720. http://doi.org/10.3390/f6051696

\begin{abstract}
Collaborative management is a new framework to help implement programmes in protected areas. Within this context, the aim of this chapter is twofold. First, to propose a robust methodology to implement collaborative management focused on Ecosystem Services (ESS). Second, to develop indicators for the main functions of ESS. Decision makers, technical staff and other stakeholders are included in the process from the beginning, by identifying ESS and eliciting preferences using the Analytic Hierarchy Process (AHP). Qualitative and quantitative data are then integrated into a Preference Ranking Organisation Methods for Enrichment Evaluations (PROMETHEE) based method in order to obtain indicators for provisioning, maintenance and direct to citizens
\end{abstract}


services. This methodology, which has been applied in a forest area, provides a tool for exploiting available technical and social data in a continuous process, as well as providing easy to understand graphical results. This approach also overcomes the difficulties found in prioritising management objectives in a multiple criteria context with limited resources and facilitates consensus between all of the people involved. The new indicators define an innovative approach to assessing the ESS from the supply perspective and provide basic information to help establish payment systems for environmental services and compensation for natural disasters.

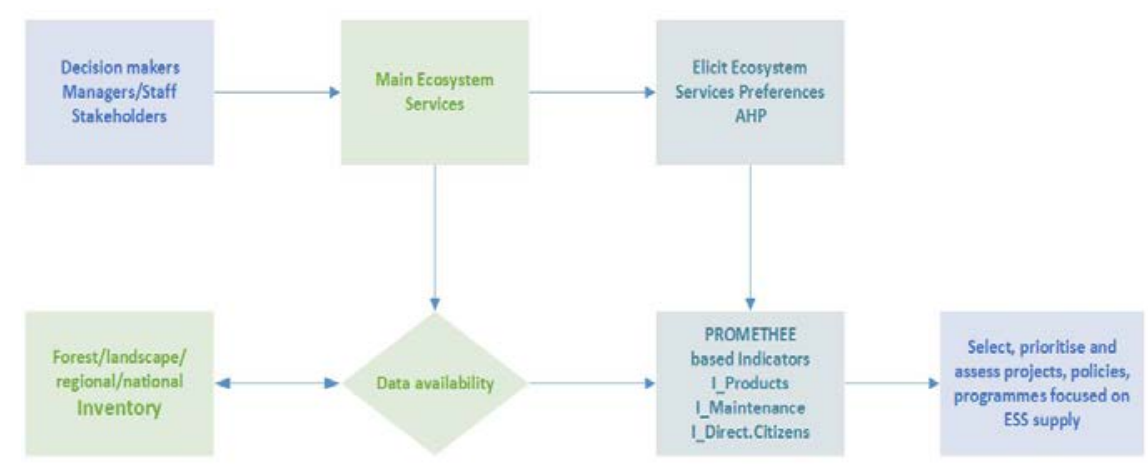

Illustration 4-1. Abstract graphic

\subsection{Introduction}

The vast majority of environmental services are free and can disappear due to poor management and a lack of economic incentive to preserve them. Designing protected areas has been a traditional mechanism worldwide for maintaining many important environmental services for humankind. The traditional paradigm of management in protected areas has been focused on conservation and recreation objectives and carried out by natural scientists or natural resource experts. An emerging paradigm includes 
social and economic objectives, as well as conservation and recreation (Lockwood et al., 2006).

In addition, the management of natural resources has evolved in such a way that public participation is seen as a basic element of modern conservation strategies in the governance of protected areas and all stakeholder values should be taken into account (Kijazi and Kant, 2011; Mustajoki et al., 2011; Fitzsimons et al., 2012). Published studies have involved stakeholders in the use of scenario analysis for ecosystem management (Tompkins et al., 2008; Palacios-Agundez et al., 2013), or have focused on social analysis to determine the attitudes and support of stakeholders and local communities (Liu et al., 2010; Apostolopoulou et al., 2012; Rees et al., 2013). Many authors advise engaging stakeholders in the decision making process as early as possible, although this may be a challenge due to their needs and priorities (Reed, 2008). Others highlight the strengths of multicriteria tools to deal with conflict and complex situations, taking into account stakeholder preferences in allocating limited resources (Mendoza and Martins, 2006; De Brucker et al., 2013).

Protected area categories, such as national parks, natural monuments or protected landscapes, define legal frameworks but do not provide tools for prioritising management alternatives which simultaneously consider the value of all Ecosystem Services (ESS). Primary and secondary objectives are defined for each category of protected area without providing tools or guidelines to weight their relevance in a specific context. Hockings et al. (2006) proposed an interesting framework to assess the management of protected areas based on the following evaluation criteria: context, planning, inputs, processes, outputs and outcomes. Nevertheless, this perspective does not provide tools to manage all ESS, including environmental, provisioning and cultural services. In particular, it is necessary to develop research focused on the non-market benefits of ESS, decision making and public opinion in natural resource management, as shown in previous studies (Petrokofsky et al., 2010; Maroto et al., 2013; Segura et al., 2014).

More multidisciplinary knowledge is needed to improve the management of ESS and to develop approaches to determine their value to society. Martinez-Harms et al. (2015), in a recent review on the management of ESS, conclude that ESS literature has been focused on quantifying and mapping their supply, without taking into account the corresponding decision making. The value of ESS is also related to the objectives which 
guide their management. Therefore, technical and economic concepts and the data used to measure these provide information about the state of the ESS and should be taken into account when assessing ESS together with the preferences of society. For instance, to manage the ESS of a protected area, it is necessary first to know the market and nonmarket services that are provided to society (Segura et al., 2014). Valuation techniques as Cost-Benefit Analysis (CBA) may be used to evaluate and make decisions based on market services (Sijtsma et al., 2013), however, this is not the case for non-market ecosystem services. Moreover, the problem becomes more complex when a balance is needed between market and non-market services, as in the case of protected areas. If the territory is both privately and publicly owned, the complexity increases even more.

Which projects are implemented in the next planning period in a scarce resource context? How are available funds distributed to manage a protected area? How can a mechanism for Payment for Ecosystem Services (PES) be established? Approaches which integrate economic, technical and social data in order to achieve an appropriate balance all ESS are needed to answer these questions.

This chapter proposes a methodology which integrates Multiple Criteria Decision Making (MCDM) with a formalised approach to support group decision making to provide support for decision making such as selecting and prioritising projects and to enable classification of the territory in homogeneous areas according to ESS contribution. The approach used here is based on the outranking method Preference Ranking Organisation Methods for Enrichment Evaluations (PROMETHEE) and the Analytic Hierarchy Process (AHP). The strengths of each method have been merged in a process to overcome their individual disadvantages, following the tendency in decision making of hybridizing several techniques when solving complex problems. For example, Macharis et al. (2004) proposed a method to obtain the weights of criteria that provides synergies between AHP and PROMETHEE, and also pointed out how the former could enhance the latter by structuring the problem and eliciting the weights. Recently, Fontana et al. (2013) has also used the AHP and PROMETHEE to compare land use alternatives considering ESS as criteria. To date, PROMETHEE has been more used in applied papers on sustainable decision in transport and logistic (Turcksin et al., 2011; Macharis et al., 2012), environmental management (for example, in ranking and selecting environmental projects), environmental impact assessment, ranking waste management alternatives and air quality/emissions problems (see the surveys by 
Behzadian et al. (2010) and Huang et al. (2011)) than in studies related to natural resource management (Ananda and Herath, 2009; Vacik et al., 2014).

An important requirement is to ascertain the importance of all stakeholders, including citizens, attribute to each ecosystem service. This information is essential to implementing a transparent and collaborative procedure in the evaluation of management alternatives and in the overall assessment of ESS. However, the question of how best to obtain information on social preferences is not easy to answer. In particular, the process and method adopted have to be transparent, understandable and equitable in order to effectively facilitate a process of collaborative decision making aimed at achieving consensus. If the inventory of protected areas included information about stakeholders' preferences, it would represent a step forward for implementing ESS collaborative management and assessing them.

Thus, our hypothesis is that, in order to manage and assess ESS, namely the overall benefits that ecosystems provide to society, it is necessary to adopt a management process which involves all stakeholders and makes use of an appropriate multicriteria evaluation methodology to permit the exploitation of the available data and also to incorporate new sources of information.

The objective of this chapter is twofold. First, to propose a methodology to implement collaborative and global ESS management which is capable of integrating available data in order to select and rank projects in protected areas. Second, to develop new indicators based on the main functions of ecosystems to classify the territory inside protected areas, in particular according to their contribution to the maintenance services and direct services to citizen. These new indicators, based on a hybrid multiple criteria method, define an innovative approach to assess the ESS supply and provide basic information to establish PES programmes and compensation for natural disasters. This methodology exploits all knowledge and data, qualitative and quantitative, to produce results that can be presented visually and which are simple for every stakeholder to understand.

The rest of the chapter is organised as follows. The next section synthesizes the methodological approach to reach the objectives, followed by the new procedure to manage ESS in protected areas and to classify the territory inside them. The proposed methodology is then illustrated using a case study focused on the natural park network 
of a Mediterranean region. Finally, the main results as well as a discussion and conclusions are presented.

\subsection{Methodological approach}

ESS are an important aspect of the territory in general, but especially in protected areas worldwide (agricultural, forest, wetlands or marine areas). The Millennium Ecosystem Assessment (MEA) (2003) defines ecosystem services as the benefits that people obtain from ecosystems indeed, they are aspects of ecosystems used to produce human wellbeing (Fisher and Turner, 2008). The MEA classifies ESS into four categories: provisioning services (wood, food, etc.), supporting services (soil formation, etc.), regulating services (climate regulation, water cycle, etc.) and cultural services (aesthetic, recreational, etc.). In short, the ESS concept integrates all that should be managed in protected areas.

The choice of criteria on which to base decisions is subjective so a first step is to make these and the process by which they are selected and prioritised explicit. This is particularly important for collaborative decision making processes which seek to engage a broad range of stakeholders, hence our proposal to utilise an approach which integrates MCDM within an appropriate and effective group process. MCDM is not only a means to evaluate alternatives, it also provides a robust approach to problem structuring (Keeney, 1992; Corner et al., 2001; Belton and Stewart, 2010) including the identification and structuring of objectives, as well as the creation of alternatives.

There are many different approaches to eliciting stakeholder views on the importance of criteria and associated challenges in ensuring that questions posed are appropriately interpreted by respondents. A simple approach is to directly assign a grade of importance using a qualitative (e.g., low, medium, high) or quantitative (e.g., 1-5) scale to each ESS. Other methods use comparison against an identified standard (e.g., the most important criterion) or, in order to ensure consistency of judgements, adopt a process of over-specification and reconciliation of judgements, for example AHP or Measuring Attractiveness by a Categorical Based Evaluation Technique (MACBETH) (Belton and Stewart, 2002). 
AHP is the most widely used MCDM method in natural resource planning, especially when the stakeholders are involved in the process (Marques-Pérez et al., 2014; Segura et al., 2014). We propose AHP as a method to elicit stakeholder views on the importance of ESS in the management of protected areas as we believe this provides a mechanism with good properties to elicit and aggregate preferences. It encourages differentiation between criteria to a greater extent than simple rating methods and highlights inconsistencies in responses. In addition, if we aggregate consistent individual preferences, the geometric mean provides consistent preferences for the group (Xu, 2000). This is not true for other methods, such as the arithmetic mean. Finally, AHP is not difficult to understand and is very easy to implement in a spreadsheet or by using professional software, for instance Expert Choice, SuperDecisions or D-Sight. These last strengths increase the possibility that MCDM is implemented in practice (Daellenbach et al., 2012), as verified by Segura et al. (2014).

To manage and assess ESS, we propose a procedure based on PROMETHEE which, in common with AHP and Multi-Attribute Utility Theory (MAUT), is a method that is primarily used to prioritise or select preferred alternatives. AHP and MAUT are compensatory methods while PROMETHEE is non-compensatory. Working with ESS, the hypothesis of a fixed trade-off rate between each pair of criteria is not realistic. It is not advisable to use a methodology that allows selecting an alternative in which very good ESS were able to compensate some others with unacceptable performances (Macharis et al., 2004).

PROMETHEE, as an outranking method, takes into account the differences in behaviour of the alternatives for each ESS and removes the scale effect when the ESS are measured in different units. This method also provides information about the conflicts between ESS and allows sensitivity analysis to see the impact of the weights on the solution. For practical purposes, the PROMETHEE II has been applied because it provides a complete ranking of alternatives. Thus, all alternatives are comparable. Our proposal does not calculate net flows for each alternative, but for each one of the three main functions of ESS. In this way, we compensate within the provisioning services, as well as within maintenance services and direct services to citizens. Nevertheless, we avoid compensating among the three main categories, because it is not appropriate when dealing with ESS. For example, profits from provisioning services would compensate for neither the lack of water for citizens nor high levels of erosion in Mediterranean 
areas. This is also the reason why we propose a simple graphical representation of the results, which is more useful than Geometrical Analysis for Interactive Aid (GAIA) plane. Although GAIA plane shows the discriminating power of the criteria, the conflicting aspects and the quality of the alternatives on different criteria which are useful to interpret the results in many decision problems, the solution shown in the GAIA plane compensates all ESS and our problem is more related to balanced solutions among the main groups of ESS.

To sum up, the nature of ESS which claims to balance them for meeting social preferences, together with the main properties of the method, make PROMETHEE one of the most suitable approaches to deal with ESS management and assessment. It can take tangible and intangible services into account, as well as analyse technical, economic and social data. Finally, their preference functions allow different perspectives and realities for ESS to be modelled.

\subsection{A collaborative process to manage and assess Ecosystem Services}

\subsubsection{Decision makers, technical staff and other stakeholders}

Figure 4-1 summarizes the methodology developed to deal with the problem about how to manage the territory and to assess all relevant ESS, taking stakeholder preferences into account. The involvement of stakeholders is important for implementing good governance and management, which is characterised by legitimacy as an attribute of quality in protected areas governance (Graham et al., 2003) and there is a wide consensus that the preferences of stakeholders should be taken into account in decision making related to the management of natural resources (Mendoza and Martins, 2006) and ESS (Martinez-Harms et al., 2015).

According to Belton and Stewart (2002), the first step in structuring a problem for multicriteria analysis is to identify relevant stakeholders. Banville et al. (1998) and Harrison and Qureshi (2000) focus on the inclusion of stakeholders in multiple criteria 
decision making. The latter also stress the importance of ensuring the representativeness of stakeholders over merely having many stakeholders. To effectively implement collaborative management of ESS, it is necessary to identify and distinguish three stakeholder groups: decision makers, who have the power to select the strategic alternatives; the technical staff who choose the technical solutions to implement selected alternatives; and a broad group of other stakeholders which includes all people with an interest in some aspects of ESS (for example: landowners, companies, municipalities, experts, environmentalists, citizens, etc.).

The role of technical staff is essential for the identification of ESS because they know the natural area, its weaknesses and strengths. Nevertheless, all points of view have to be taken into account for the complete identification of ESS and to secure the engagement of decision makers, technical staff and other stakeholders.

The role of technical staff is essential for the identification of ESS because they know the natural area, its weaknesses and strengths. Nevertheless, all points of view have to be taken into account for the complete identification of ESS and to secure the engagement of decision makers, technical staff and other stakeholders.

The next steps of a multicriteria analysis are the identification of criteria and alternatives for evaluation. The intention is that the views of these three stakeholder groups should inform the design of a hierarchical model which captures all relevant ESS classified by key functions. The hierarchy defines the criteria which provide the basis for the multicriteria evaluation of options. The nature of the options to be considered will depend on the specific context of the analysis; for example, this might be choosing between alternative strategies for conservation or assessing the ESS contribution of different regions or parts of territory.

Similarly, the consideration of key uncertainties is also part of problem structuring (Belton and Stewart, 2010) and the nature of the specific decision, in particular its timescale, will also determine whether or not this should be a key consideration in an analysis. Recent publications have explored the integration of MCDM and scenario analysis in water infrastructure planning (Scholten et al., 2014) and water resource planning (Miller and Belton, 2014). 


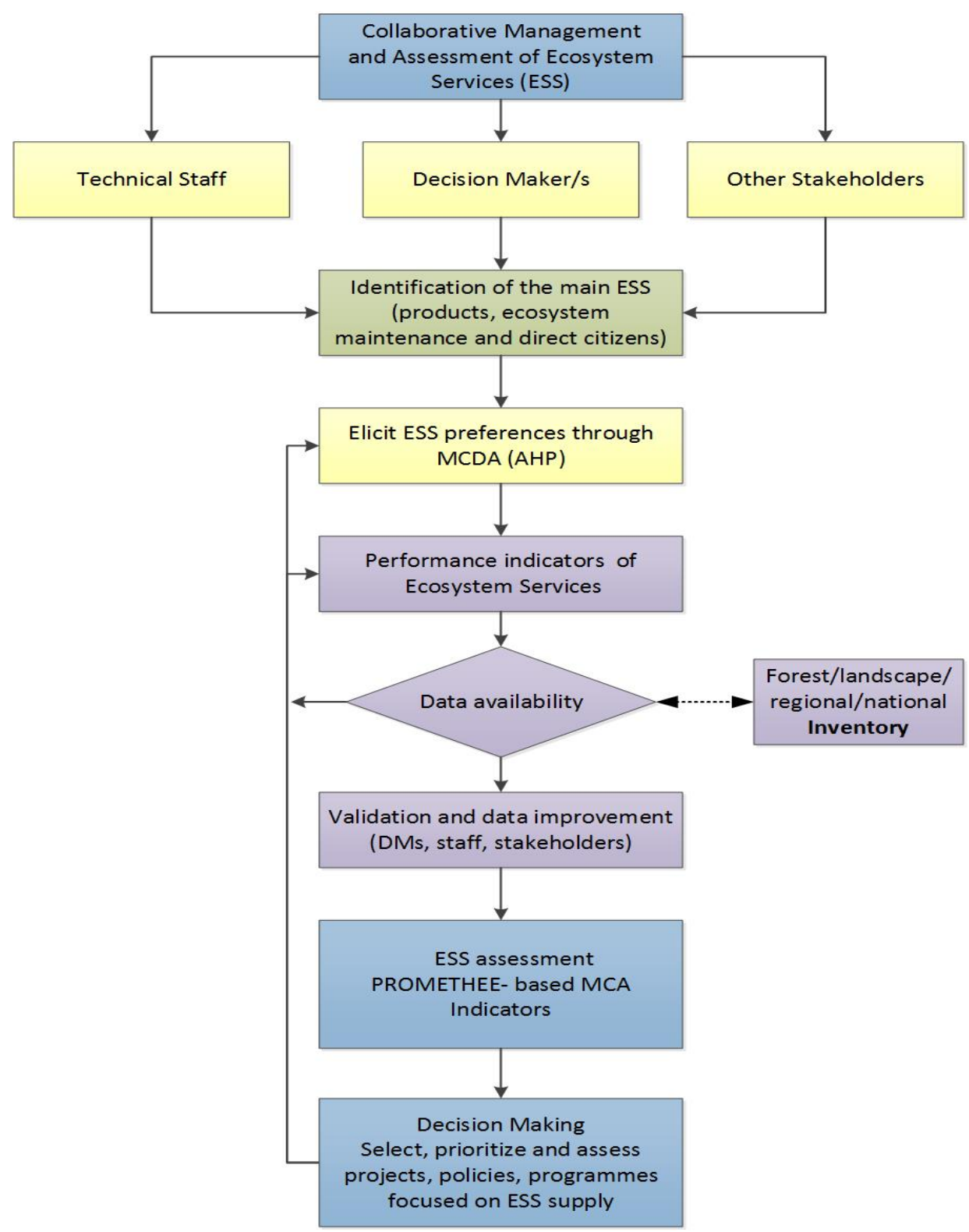

Figure 4-1. Methodology for implementing collaborative management and assessment Ecosystem Services 
Following this collaborative process of problem structuring, which has identified all ESS and specified appropriate alternatives for evaluation, the next steps of a multicriteria approach call for the assessment of the performance of alternatives with respect to each ESS and the elicitation of the different stakeholders' perceived importance of, or preference for, the given ESS.

\subsubsection{Performance measures for Ecosystem Services and elicitation of preferences}

Once the ESS to be considered have been identified by the participants in the collaborative process and structured as a criteria hierarchy, one of the next steps is to identify the best indicators to measure the performance against each ESS. The main problem at this point is the availability of data. We propose to start with the most reliable indicators. An iterative process begins, if necessary, in order to obtain useful indicators which are satisfactory for the majority of people.

The general goal is to assess ESS but the complexity of this task comes from the competing aspects and intangible nature of some of them. Improvement of provisioning services may reduce maintenance services and/or direct services to citizens. The multicriteria nature of the problem means that deriving a solution almost always implies the need for some subjective judgement. Accordingly, good multicriteria methods are needed to bring transparency and ensure the legitimacy of the process of decision making (Belton and Stewart, 2002).

It is expected that views on the importance of ESS, to be represented by weights in a multicriteria model, will differ across the identified stakeholder groups, and it is considered important that these are fully understood and captured in the analysis. Hence, the approach proposed for the elicitation of these preferences, AHP, initially seeks input from individual stakeholders rather than assuming a consensus or looking to facilitate a compromise. The global weights for all stakeholders can then be obtained by using the geometric mean. 


\subsubsection{Determining new indicators for assessing Ecosystem Services}

The last step of the methodology consists of applying an outranking-based method as a tool to generate new indicators to assess functions of ESS which are obtained from individual indicators and grouped into a single index (OECD, 2014).

Table 4-1 represents the evaluation table for $m$ alternatives which will be assessed by best available indicators of ecosystem. In general, there are $\mathrm{n}$ indicators for provisioning services, $\mathrm{p}$ for maintenance (supporting and regulating) services and $\mathrm{t}$ indicators to measure the direct services to citizens to evaluate all $\mathrm{m}$ alternatives. These indicators can be quantitative or qualitative in nature and may be organised by function, for example grouping all provisioning services in one category, another category for maintenance services and a third for direct services to citizens. We are interested in maximizing some of them, such as recreational use, and minimizing others such as soil erosion.

Table 4-1. Evaluation table of alternatives based on the Ecosystem Services

\begin{tabular}{|c|c|c|c|c|c|c|c|c|c|}
\hline \multirow{3}{*}{ Alternatives/Areas } & \multicolumn{9}{|c|}{ Evaluation Criteria: Indicators of the Ecosystem Services } \\
\hline & \multicolumn{3}{|c|}{ Provisioning Services } & \multicolumn{3}{|c|}{ Maintenance Services } & \multicolumn{3}{|c|}{ Direct Services to Citizens } \\
\hline & $\mathrm{I}_{\mathrm{ps} 1}$ & $\mathrm{I}_{\mathrm{psi}}$ & $\mathrm{I}_{\mathrm{psn}}$ & $\mathrm{I}_{\mathrm{rm} 1}$ & $\mathrm{I}_{\mathrm{rmj}}$ & $\mathrm{I}_{\mathrm{rmp}}$ & $\mathrm{I}_{\mathrm{dc} 1}$ & $\mathrm{I}_{\mathrm{dck}}$ & $\mathrm{I}_{\mathrm{dct}}$ \\
\hline $\mathrm{A}_{1}$ & $\mathrm{I}_{\mathrm{ps} 1}\left(\mathrm{~A}_{1}\right)$ & $\ldots$ & $\mathrm{I}_{\mathrm{psn}}\left(\mathrm{A}_{1}\right)$ & $\mathrm{I}_{\mathrm{rm} 1}\left(\mathrm{~A}_{1}\right)$ & $\ldots$ & $\mathrm{I}_{\mathrm{rmp}}\left(\mathrm{A}_{1}\right)$ & $\mathrm{I}_{\mathrm{dc} 1}\left(\mathrm{~A}_{1}\right)$ & $\ldots$ & $\mathrm{I}_{\mathrm{dct}}\left(\mathrm{A}_{1}\right)$ \\
\hline $\mathrm{A}_{2}$ & $\mathrm{I}_{\mathrm{ps} 1}\left(\mathrm{~A}_{2}\right)$ & $\ldots$ & $\mathrm{I}_{\mathrm{psn}}\left(\mathrm{A}_{2}\right)$ & $\mathrm{I}_{\mathrm{rm} 1}\left(\mathrm{~A}_{2}\right)$ & $\ldots$ & $\mathrm{I}_{\mathrm{rmp}}\left(\mathrm{A}_{2}\right)$ & $\mathrm{I}_{\mathrm{dc1}}\left(\mathrm{A}_{2}\right)$ & $\ldots$ & $\mathrm{I}_{\mathrm{dct}}\left(\mathrm{A}_{2}\right)$ \\
\hline$\cdots$ & $\cdots$ & $\cdots$ & $\cdots$ & $\cdots$ & $\cdots$ & $\cdots$ & $\cdots$ & $\cdots$ & $\cdots$ \\
\hline$A_{i}$ & $\mathrm{I}_{\mathrm{ps} 1}\left(\mathrm{~A}_{\mathrm{i}}\right)$ & $\ldots$ & $\mathrm{I}_{\mathrm{psn}}\left(\mathrm{A}_{\mathrm{i}}\right)$ & $\mathrm{I}_{\mathrm{rm} 1}\left(\mathrm{~A}_{\mathrm{i}}\right)$ & $\ldots$ & $\mathrm{I}_{\mathrm{rmp}}\left(\mathrm{A}_{\mathrm{i}}\right)$ & $\mathrm{I}_{\mathrm{dc} 1}\left(\mathrm{~A}_{\mathrm{i}}\right)$ & $\ldots$ & $\mathrm{I}_{\mathrm{dct}}\left(\mathrm{A}_{\mathrm{i}}\right)$ \\
\hline$\cdots$ & $\cdots$ & $\cdots$ & $\cdots$ & $\cdots$ & $\ldots$ & $\cdots$ & $\cdots$ & $\ldots$ & $\cdots$ \\
\hline $\mathrm{A}_{\mathrm{m}}$ & $\mathrm{I}_{\mathrm{ps} 1}\left(\mathrm{~A}_{\mathrm{m}}\right)$ & $\ldots$ & $\mathrm{I}_{\mathrm{psn}}\left(\mathrm{A}_{\mathrm{m}}\right)$ & $\mathrm{I}_{\mathrm{rm} 1}\left(\mathrm{~A}_{\mathrm{m}}\right)$ & $\ldots$ & $\mathrm{I}_{\mathrm{rmp}}\left(\mathrm{A}_{\mathrm{m}}\right)$ & $\mathrm{I}_{\mathrm{dc} 1}\left(\mathrm{~A}_{\mathrm{m}}\right)$ & $\ldots$ & $\mathrm{I}_{\mathrm{dct}}\left(\mathrm{A}_{\mathrm{m}}\right)$ \\
\hline
\end{tabular}

The PROMETHEE method requires information on the weights of the relative importance of the indicators, which is $\mathrm{w}_{1}, \mathrm{w}_{2} \ldots \mathrm{w}_{\mathrm{k}}$, normalised to sum to 1 . As PROMETHEE does not provide any mechanism to elicit them, we have proposed AHP to elicit individual weights and the geometric mean to determine an aggregate weight 
for a group of stakeholders. The PROMETHEE process for eliciting preferences with regard to alternatives is also based on pairwise comparisons, but of a different nature to those used in AHP. In this case, comparisons are based on the difference between the evaluations of two alternatives on a particular indicator. The larger the difference between evaluations of the alternatives, the greater is the preference (up to a limit) of the preferred alternative. When the difference is small, it can be considered to be negligible. These preferences are represented by real numbers between 0 and 1 and allow ESS measured in different units to be integrating. A different preference function can be proposed for each indicator. In ESS assessment, some preference functions with one or two parameters specifying an indifference threshold and a strict preference threshold are interesting. The former is the value of the largest deviation on an indicator that is considered to have a negligible impact on preference (i.e., a relative preference value of 0 ) when comparing two alternatives. The preference threshold is the smallest value of the deviation between alternatives to be considered as sufficient for a strict preference of one alternative to another (i.e., a preference value of 1). A detailed explanation of the method and preference functions can be found in Brans and Mareschal (2005).

The usefulness and relevance of this methodology, a novelty for collaborative decision making and assessment ESS, is illustrated in the case study. The proposal is based on PROMETHEE. This method is easy to use and permits the calculation of new indicators to assess ESS. A two dimensional visualisation that represents the three indicators facilitates the evaluation of the projects or programmes in natural parks, by showing the relationship between provisioning, maintenance and cultural services and the assessment of ESS, providing basic indices of their supply. The latter could complement the economic valuation from the viewpoint of ESS demand, such as Contingent Valuation (CV). 


\subsection{Case study}

\subsubsection{Natural park network in the Valencian Community}

The Valencian Community is an autonomous region, located in the East of Spain. It is part of Mediterranean basin, a biodiversity hotspot, representing key areas of the world chosen for their species richness and endemism. The natural park network of the Valencian Community has 22 parks with a total surface of 169,511.57 hectares, which have been grouped in two main types of protected areas: forests and wetlands. This network includes natural areas selected for the importance of their flora, fauna, ecosystem and/or landscape beauty, with ecological, educational, cultural, scientific or aesthetical values that must be preserved (Generalitat Valenciana, 2013). For every natural park of the network, there is a board of stakeholder representation that includes representatives of all agents linked to each protected area, such as public administrations (state, regional and local), owners, unions, universities, hunting, fishing, conservation and hiking associations, irrigation communities and drainage boards in wetlands. The board of stakeholders is advisory, while the decision makers constitute a board of directors that is formed by the director of the natural park and representatives of regional and local administrations. Both boards have regular meetings twice a year.

In general, ESS of protected areas differ not only in the type and number but also in importance in order to consider all relevant environmental, economic and social factors. Albufera and Serra d'Espadà are two of the most important natural parks by size and are of different environmental significance. Albufera natural park is a coastal wetland included in the list of RAMSAR wetlands of international importance with 21,120 hectares; two thirds are dedicated to rice production in small private fields (RAMSAR, 2013). Agriculture, fishing, hunting and public use have been the source of many conflicts among stakeholders of this protected area, which is located in the metropolitan area of Valencia, with high population density. On the contrary, Serra d'Espadà natural park is an inland Mediterranean forest site and another of the biggest natural parks of the region, characterised by low population density. 


\subsubsection{Network survey, data analysis and results}

As an exploratory study, a survey was designed and carried out in order to identify the importance of the main ESS provided by the natural park network, taking into account the points of view and preferences of decision makers, technical staff and other stakeholders. The questionnaire is based on a Likert-type scale, one of the most widely used approaches to obtain social preferences as it is easy to understand, and this scale has been used in research in protected areas (Liu et al., 2010; Apostolopoulou et al., 2012; Rees et al., 2013).

The ESS provided by each natural park are grouped in three categories. The first one includes provisioning services, which are raw materials, such as food, energy (firewood or biomass), genetic resources, industrial resources (timber) and other uses (e.g., pharmaceutical or textile). The second category, ecosystem maintenance, includes both regulating and supporting services. The services which maintain the ecosystem are soil formation, nutrient cycle, climate regulation and cycle/purification water and biodiversity. Finally, the third group includes the direct services to citizens for recreational, cultural and indirect uses, e.g., tranquility or inspiration (Costanza et al., 1998; De Groot et al., 2002; PATFOR, 2013). The survey offers four levels to measure the importance of ESS: null, low, medium and high.

A pilot survey was carried out to test a preliminary version of the questionnaire with several experts in protected area management from academia, government agencies and businesses. Firstly, the questionnaire (Annex V) was sent to all natural parks of the Valencian Community, to be answered by the decisions makers, technical staff and other stakeholders (October 2012). Secondly, the particular survey of the Albufera wetland was distributed among citizens using the social networks Facebook, LinkedIn and Twitter (December 2012). Citizens interested in conservation of protected areas are usually not involved in the decision making of natural parks, their involvement being a step forward in the management of protected areas. In both cases, the Survey Monkey platform was used for sending and collecting data.

The total number of questionnaires analysed was 56, 21 of them are from wetlands and 35 from forest parks. All of the directors of the natural parks answered the survey. The highest stakeholder participation appears in Serra d'Espadà and Albufera. In this latter park, 90 citizens also responded to the questionnaire through social networks. 
The data processing has been carried out through a descriptive analysis of the percentage of people that gave the highest valuation for each item in the questionnaire. This is a usual method in the assessment of the management of protected areas. A Pearson's Chisquared method was used for the significance test to analyse the observed differences in the data. To identify differences between wetlands and forest areas, a Mann-Whitney $\mathrm{U}$ test has been used. In the study, we accepted the statistical significance when P-value is less than 0.05. Statistical analyses were undertaken using EXCEL spreadsheet and statistical software SPSS 16.0. We assessed the internal consistency of the survey to determine whether several variables, which were proposed to measure the same general fact, produce similar scores. To that end, we have used Cronbach's alpha, a statistic calculated from the pairwise correlations between items, and it is known as a measure of internal consistency. If the Cronbach's alpha is greater than 0.7 , which was the case for our survey, it is considered a well-built survey.

Figure 4-2 shows the results of the ESS importance in the natural park network for decisions makers, technical staff and other stakeholders. Almost all respondents attribute some importance to ecosystem maintenance services, $90 \%$ or more to direct services to citizens, and there are fewer people who assign importance to provisioning services. In the latter case, it is interesting to distinguish between wetlands and forest. Goods provided by the ecosystems in forest natural parks in the Valencian Community do not have high importance for the majority of stakeholders. Most of the respondents consider that food, energy, and genetic resources have medium importance. The industrial resources and other uses such as pharmaceuticals and textiles have lowmedium importance. Nevertheless, in the Albufera wetland, more than half of the stakeholders consider that food raw materials have high importance, because the rice crop is very relevant in this protected area. Another product also has high importance, as there is an important salt industry in another wetland of the region. 
Maintenance ESS have high importance, especially because of biodiversity with $89 \%$ of the respondents expressing this opinion. According to the proportion of people, biodiversity is followed by water cycle with $70 \%$ while approximately $40 \%-50 \%$ of respondents assigned high importance to climate change regulation, nutrient cycle and soil formation. These numbers are similar for both forests and wetlands.

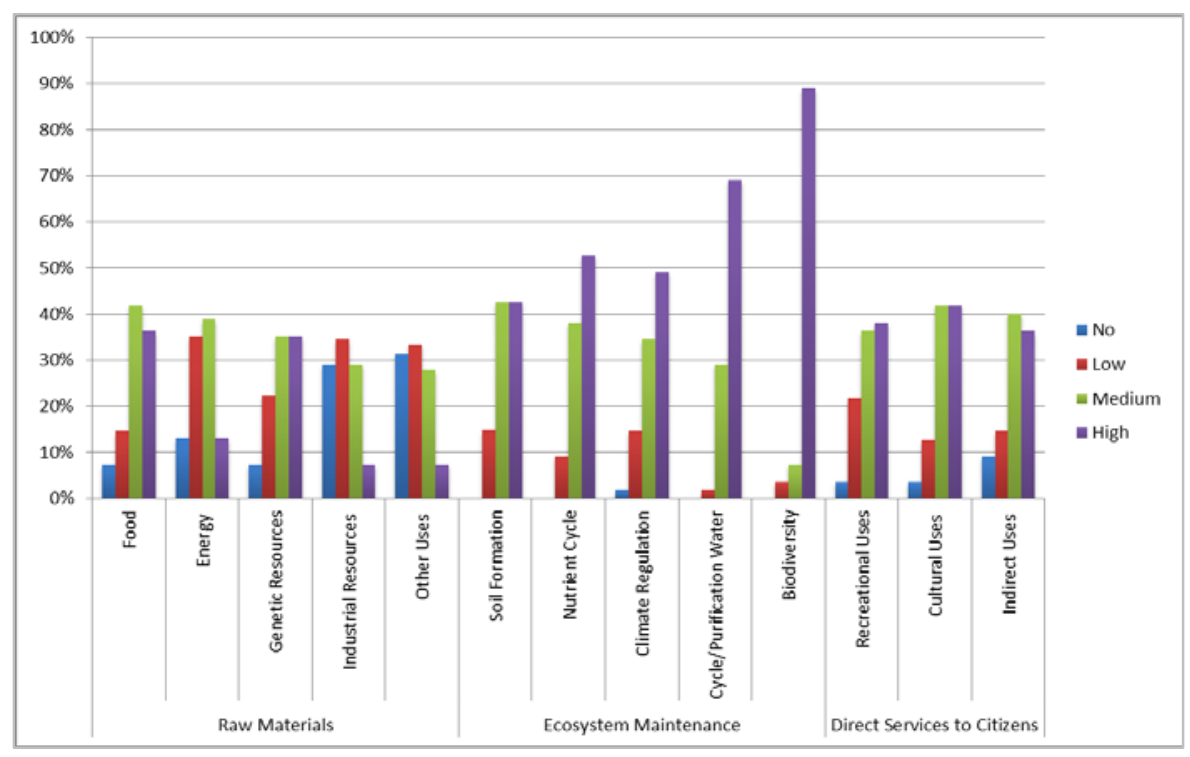

Figure 4-2. Percentage of decision makers, technical staff and other stakeholders by importance degree assigned to Ecosystem Services in the natural park network

More differences appear in the analysis of data from direct services to citizens. In this case, proportions of stakeholders with medium importance or high importance are approximately $50 \%$ for wetlands and less for forests. Recreational uses have significant differences. For more than half of the stakeholders, this service is very important in wetlands, but this percentage drops to $28 \%$ in forests.

The recreational use is also notable as since there are more people who assign low importance rather than high in the case of forests. That is, there is a consensus in medium-high importance of recreational uses in wetlands, but this is not the case in 
forest areas, as the opinions have a balanced distribution among low, medium and high relevance.

\subsubsection{Main Ecosystem Services hierarchy and preferences elicitation}

The survey results of the previous section show that decision makers, technical staff, other stakeholders and citizens have great difficulty in prioritising ESS using a grade scale. This is easy to understand, but not useful in the real context of limited resources, as many people assign high importance to the majority of ESS. However, as a result, their opinions are not useful to support management actions because some ESS conflict with others and this method cannot take into account these relationships. To overcome this pitfall, we can think of assigning weights directly, for example between zero and 10 , but the aggregation of these data to obtain group preferences also has drawbacks (Tofallis, 2014).

The proposed methodology elicits group preferences for ESS using a well-known collaborative multiple criteria technique because the prioritisation of ESS is necessary in order to manage natural areas with scarce resources and support decisions. This methodology was applied in the context of the Serra d'Espadà natural park.

First, we identified the ESS of the protected area and built the hierarchy with collaboration of decision makers and technical staff of Serra d'Espadà as can be seen in Figure 4-3 (December 2013). Second, a survey was designed to elicit the preferences of participants using the AHP method (Saaty and Vargas, 2001). The survey (Annex VI) was implemented in an Excel spreadsheet in order to the respondents to have access to the ESS weights resulting from their individual answers and also to be able to access their Inconsistency Index (II). If this index was greater than 0.10, the questionnaire indicated this and allowed the respondents to change their answers. The questionnaire was sent to the director, technical staff and board of stakeholders of the natural park. In some cases, we sent the survey on paper at the request of stakeholders. We received 14 answers, five from decision makers and technical staff, five from forest researchers and four from representatives of local administrations. One of them sent the answers on 
paper. Eleven percent of pairwise comparison matrices had an II greater than 0.10. These have been eliminated from the analysis.

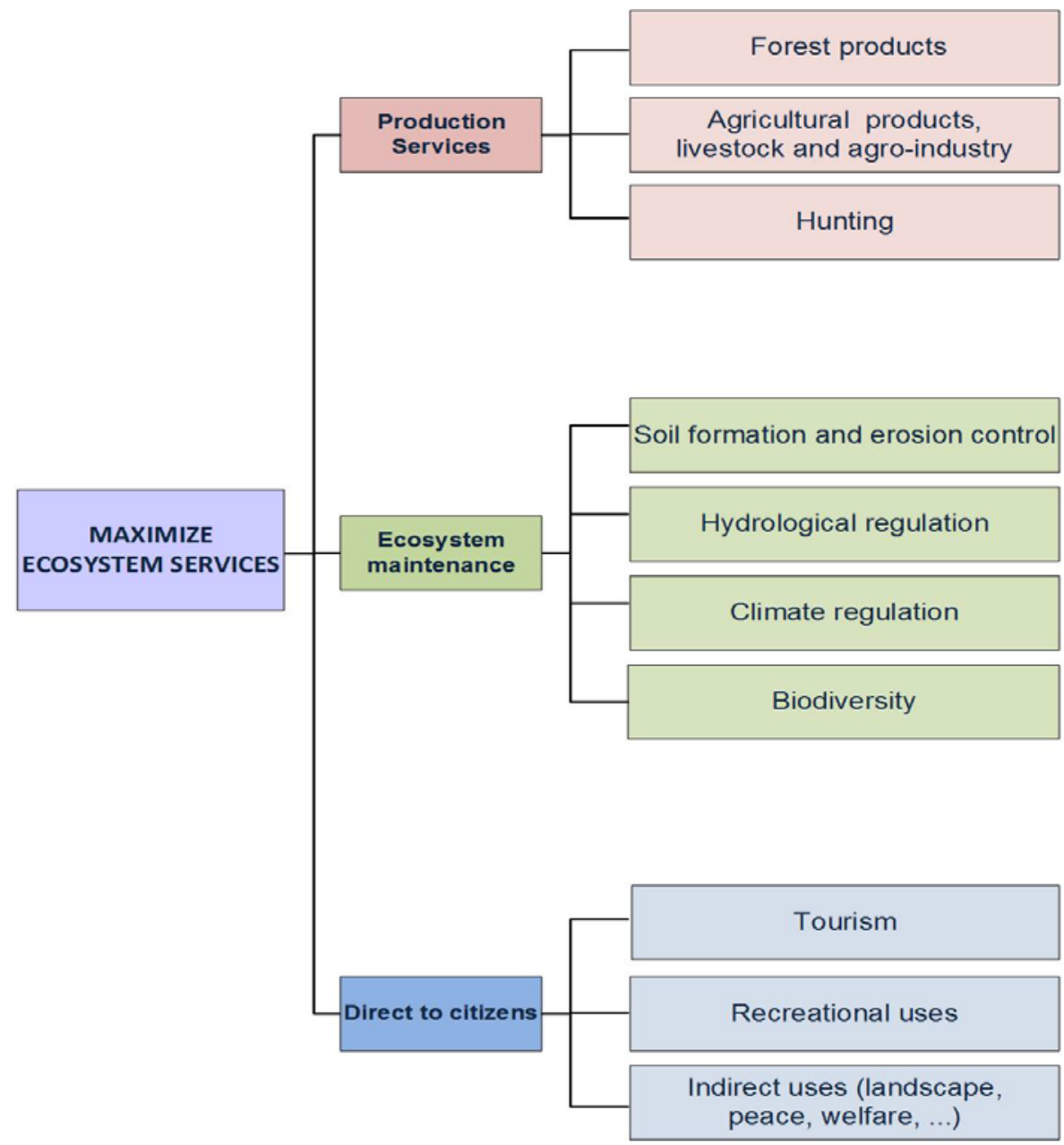

Figure 4-3. Ecosystem Services hierarchy of Serra d'Espadà natural park 
Table 4-2 shows the preferences for ESS grouped by functions and stakeholders. These have been calculated with the same weights for all respondents and using the geometric mean (Saaty and Peniwati, 2008). All stakeholders consider that the maintenance of ESS is the most important function of the natural park. Researchers give more importance to direct services to citizens than production services. However, the weight of production services is higher for decision makers/staff and especially for representatives of local administration.

Table 4-2. Preferences for Ecosystem Services by functions and group of stakeholders in percentage obtained by AHP method

\begin{tabular}{lccc}
\hline \multirow{2}{*}{ Stakeholders } & \multicolumn{3}{c}{ Ecosystem Services Weights in Percentage } \\
\cline { 2 - 4 } & Production Services & Ecosystem Maintenance & Direct to Citizens \\
\hline Decision maker/staff & 27.0 & 54.0 & 19.0 \\
Local administration & 32.1 & 48.1 & 19.8 \\
Researchers & 16.4 & 60.4 & 23.2 \\
Total & 25.4 & 54.3 & 20.3 \\
\hline
\end{tabular}

The global preferences for all ESS can be seen in Figure 4-4. Forest products (cork, timber, biomass, mushrooms...) are the most important provisioning services for all stakeholder groups. Agricultural products, livestock and agro-industry rank second in importance for all groups except for researchers. The latter give a little more importance to hunting.

The major differences between the preferences of stakeholders appear in the services of ecosystem maintenance. Forest researchers give more importance to soil formation and hydrological regulation, while biodiversity and climate regulation have less relative importance. Hydrological regulation presents the greatest weight for local administrations for whom all other ecosystem maintenance services are less important, whereas soil formation has higher value. On the other hand, biodiversity is the most important to decision makers/staff, followed by soil formation and hydrological regulation, and for this group climate regulation is the least important service. 
In direct services to citizens, decision makers/staff and local administrations give more importance to recreational uses and tourism. In addition, local administrations also assign the same importance to both. The indirect uses are the most important for researchers in comparison with other stakeholders. The weight of recreational uses is similar for all stakeholders, showing a great consensus on this aspect.

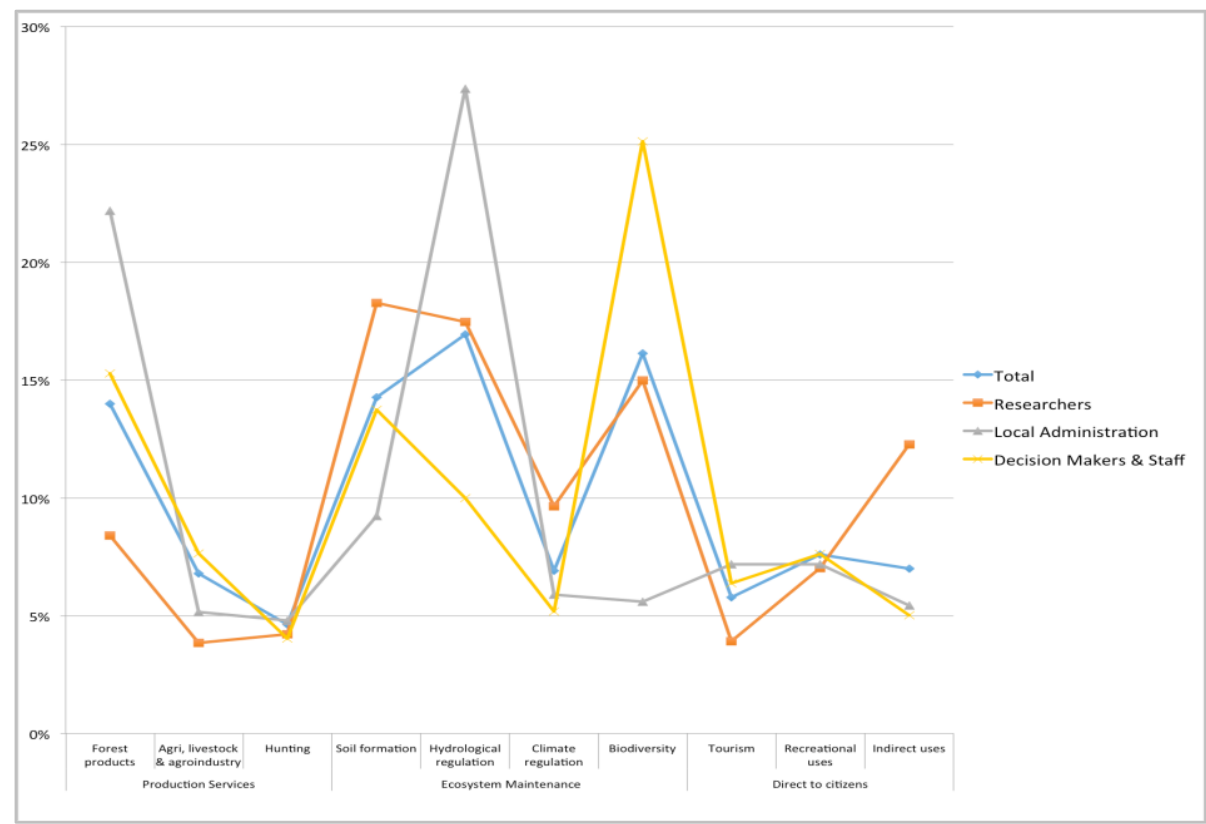

Figure 4-4. Ecosystem Services preferences (\%) by stakeholder groups in the Serra d'Espadà natural park

\subsubsection{Obtaining new indicators}

Each ESS represented in Figure 4-3 has to be measured using one or more indicators, such as economic value of products, hunters, degree of soil erosion, number of flora micro-reserves, number of fauna micro-reserves, number of endangered species, number of paths, number of areas of public use, landscape quality, etc. (Valls-Donderis et al., 2015). As an example, Table 4-3 represents the evaluation table for five zones of 
the natural park including one indicator for all ESS of the Serra d'Espadà natural park (Figure 4-3), except for biodiversity which has two indicators. These two indicators, which measure the biodiversity performance, have the same weight, each one $50 \%$. Although the numbers in Table 4-3 are hypothetical, the method based on PROMETHEE has been applied using the ESS weights obtained in the case study (Table 4-2). All ESS were maximized, except soil erosion and number of endangered species which were minimized. The example considers two types of PROMETHEE preference functions: usual and linear. The former attributes strict preference to the best zone and it was used for all five indicators of maintenance services. The linear preference function increases with the deviation between evaluations and it was used for all criteria related to provisioning services and direct services to citizens. We also consider several indifference and strict preference thresholds. Their values and criteria weights are shown in Table 4-4.

Table 4-3. Evaluation table for five zones of the Serra d'Espadà natural park

\begin{tabular}{lcccccccccccc}
\hline \multicolumn{1}{c}{ Evaluation Criteria: Indicators of the Ecosystem Services } \\
\hline \multicolumn{1}{c}{ Production Services } & \multicolumn{1}{c}{ Maintenance Services } & Direct Services to Citizens \\
\hline & IP11 & IP21 & IP31 & IM11 & IM21 & IM31 & IM41 & IM42 & IDC11 & IDC21 & IDC31 \\
\hline Zone 1 & 3000 & 1750 & 200 & 1 & 3 & 4 & 20 & 6 & 3000 & 10 & 4 \\
Zone 2 & 800 & 650 & 700 & 3 & 4 & 5 & 16 & 7 & 20 & 20 & 5 \\
Zone 3 & 150 & 3500 & 50 & 3 & 1 & 3 & 9 & 0 & 100 & 2 & 1 \\
Zone 4 & 10000 & 4000 & 1100 & 3 & 1 & 3 & 25 & 1 & 6000 & 5 & 3 \\
Zone 5 & 200 & 900 & 700 & 4 & 5 & 5 & 8 & 10 & 0 & 1 & 2 \\
\hline
\end{tabular}


Table 4-4. Preferences functions and parameters for Ecosystem Services indicators

\begin{tabular}{|c|c|c|c|c|c|c|}
\hline ESS & Criteria & Min/Max & Function & $\begin{array}{c}\text { Indifference } \\
\text { Threshold }\end{array}$ & $\begin{array}{l}\text { Preference } \\
\text { Threshold }\end{array}$ & Weight \\
\hline Forest Product & IP11 & Max & Linear & 200 & 2000 & $14.0 \%$ \\
\hline $\begin{array}{l}\text { Agri., livestock \& } \\
\text { Agroindustry }\end{array}$ & IP21 & Max & Linear & 200 & 3000 & $6.8 \%$ \\
\hline Hunting & IP31 & Max & Linear & 0 & 300 & $4.6 \%$ \\
\hline Soil formation & IM11 & Min & Usual & & & $14.3 \%$ \\
\hline $\begin{array}{l}\text { Hydrological } \\
\text { regulation }\end{array}$ & IM21 & Max & Usual & & & $16.9 \%$ \\
\hline Climate regulation & IM31 & Max & Usual & & & $6.9 \%$ \\
\hline \multirow{2}{*}{ Biodiversity } & IM41 & Min & Usual & & & $8.1 \%$ \\
\hline & IM42 & Max & Usual & & & $8.1 \%$ \\
\hline Tourism & IDC11 & Max & Linear & 50 & 3000 & $5.8 \%$ \\
\hline Recreational uses & IDC21 & Max & Linear & 0 & 5 & $7.6 \%$ \\
\hline Indirect uses & IDC31 & Max & Linear & 0 & 5 & $7.0 \%$ \\
\hline
\end{tabular}

PROMETHEE method requires information within criteria in addition to the information between criteria provided by their weights. The pairwise comparison of alternatives with respect to a criterion is based on a preference function that assigns a number between 0 and 1 to the deviation in the criterion value for the two alternatives. For example, when comparing two alternatives or zones with respect to soil erosion (AIM11), the usual function allocated a strict preference to the best option that means 1 as a value of preference. In this case, it is the option with the lower value because soil erosion should be minimized. Zone 1 is always preferred to any other (Table 4-3). Nevertheless, there are criteria, such as the economic value of forest products (AIP11), where the preference increases as the deviation between alternatives increases. In this 
case, we consider that a deviation up to 200 is negligible (i.e., equals 0), and then the preference value increases linearly up to 1 as the deviation increases from 200-2000, the preference threshold. For example when we compare zones 3 (A3IP11 = 150) and 5 (A5IP11 = 200), although zone 5 is better, PROMETHEE considers both zones equal as the indifference threshold is 200 for this criterion. In addition, since the preference threshold for the criteria AIP11 is 2000, we assign a value 1 for the best option when comparing zone 1 and zone 4, as well as if the comparison is between zones 3 and 4 (Table 4-4). The preference functions allow the aggregation of criteria measured in different units. This is made using the concepts of Aggregated Preference Indices (API) and net flows.

In short, to apply PROMETHEE we need to know the evaluation table, the weights of the criteria and the preference functions. We then calculate the API for each pair of alternatives $a$ and $b$. The API between $a$ and $b, \pi(a, b)$, is obtained by summing of all preference values multiplied by the weights of criteria. It expresses the degree to which alternative $a$ is preferred to $b$ and $\pi(b, a)$, the degree to which $b$ alternative is preferred to a. Finally, positive and negative outranking flows are defined after comparing an alternative with the others (x). The positive outranking flow is calculated by summing all API of an alternative $\pi(\mathrm{a}, \mathrm{x})$ and dividing by the number of alternatives minus one. It expresses to what extent an alternative outranks all the others and thereby the strength of the alternative. The higher the positive outranking flow, the better the alternative. Similarly, the method calculates negative outranking flow as the sum of all $\pi(x, a)$ and indicates to what extent an alternative is outranked by the others. It is an indicator of weakness and an alternative is better when its negative flow is smaller. These measures are used to define the dominance relations of PROMETHEE I, whereby an alternative is classified as preferred, indifferent or incomparable to another.

PROMETHEE II defines net flow for an alternative as the balance between positive and negative flows. Applying this method by using D-Sight software the new indicators are obtained and then represented in a bubble chart (Figure 4-5). Indicators of maintenance and direct services to citizens define the axes and the relative size of the bubble represents the provisioning indicator. The ideal situation would be if all zones appeared in the area with high values for both indicators and a big bubble. This graphic identifies four areas, the first with high social and environmental values, the second with high environmental value, the third with high social value and the fourth with low social and 
environmental values. The latter would require a further analysis about, for instance, how to improve the environmental and social performance. This visualisation provides an easy and effective means for decision makers and other stakeholders to understand where and how to focus efforts on new projects to improve the ESS, classified by their nature. This multidimensional representation is more useful than the global index, shown in Figure 4-6, which highlights the low performance of zone 3 but with relatively small differences between the other zones. Nevertheless, these differences are important from the point of view of ESS management and assessment, as shown in the blue bubbles from the case study (Figure 4-5). In our example, zones 1 and 2 have high performance from social and environmental perspectives, zone 4 has a high social value and also the greatest economic value derived from the products (size of the bubble), while zone 5 has a high environmental value and low provisioning services. Finally, zone 3 will need further analysis to determine the reasons for its low performances and how it can be improved.

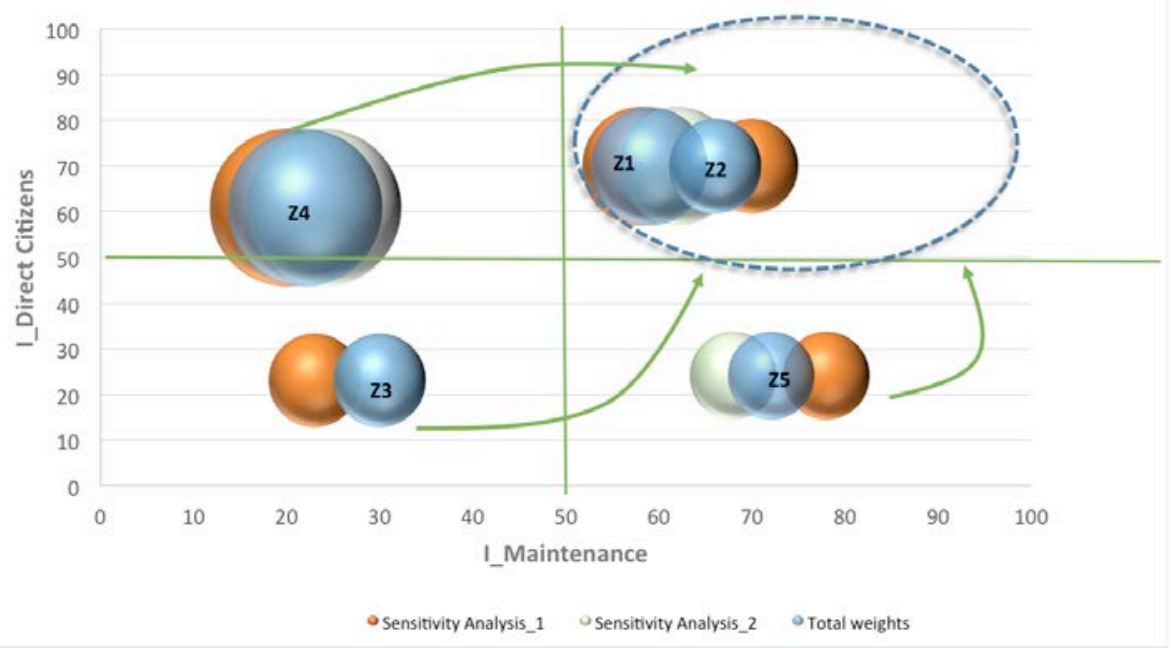

Figure 4-5. Visual classification of territory (Zones) by main categories of ESS in the Serra d'Espadà natural park 


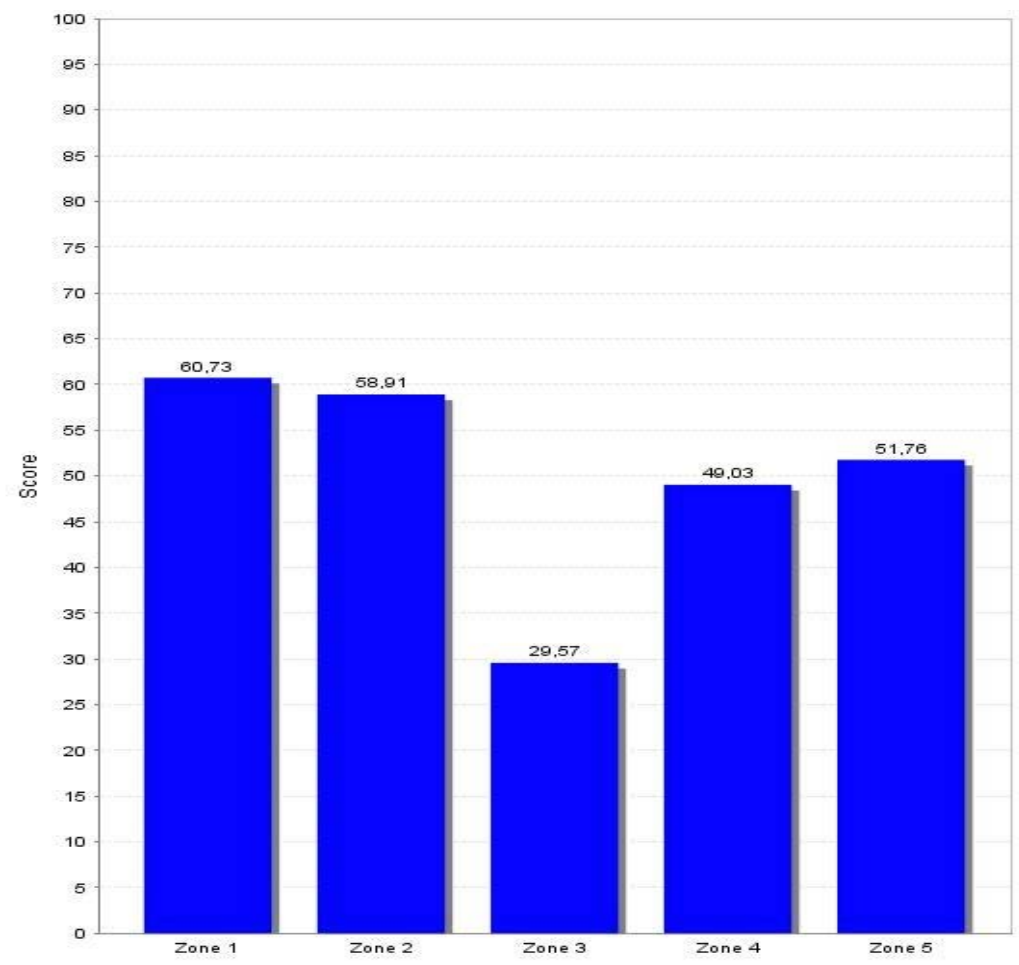

Figure 4-6. Global index by zones in the Serra d'Espadà natural park. D-Sight software

We also performed a sensitivity analysis of the weights of maintenance ESS to show the stability in the values of global indicators. The results of the sensitivity analysis determined a wide range of the weights which includes the preference values of the different stakeholders groups. The orange and grey bubbles represent the indicators obtained with extreme values, close to local administration and researchers' preferences, respectively. Therefore, this visual tool allows stakeholders to see and understand the influence of changing the ESS preferences. 


\subsection{Discussion}

According to the results of the survey based on a Likert-type scale, the most important ESS is biodiversity in the natural park network of the Valencian Community, in line with international agreements that include it as the main objective of protected areas. This result is also consistent with the regulation of protected areas in the Valencian Community, where the protection categories have been assigned according to their biological resources and values. Ecosystem maintenance is the priority function, being a result consistent with the previous regional studies. Products from forests, mainly timber, have little relevance due to the slow regenerative capacity of the Mediterranean forests (Maroto et al., 2013).

The responses to the survey indicate that over $40 \%$ of respondents (88\% in the case of biodiversity), attribute "high importance" to all ecosystem maintenance services and over $80 \%$ rate all as medium or high importance. These results are similar for all stakeholder groups and highlight the difficulty in prioritising ESS directly when decision making has multiple objectives. It was decided to apply AHP in order to focus attention on relative preferences through the use of pairwise comparisons and to achieve greater discrimination. The results of this study confirmed the perceived importance of maintenance services (54.2\% of total weight) over provisioning services such as timber, cork, mushrooms, etc. (25.4\% weight) and services direct to citizens such as tourism, recreational uses and indirect uses (20.4\%). Within maintenance services, biodiversity is important but does not have the highest priority, with hydrological regulation being rated as slightly more important. Hydrological regulation along with biodiversity and soil formation are the most relevant maintenance services. This can be interpreted as follows: the main goal is the sustainable use of resources, through a balance between products, recreation and environmental services, with more emphasis on the latter.

The involvement of stakeholders is a key aspect of the management and assessment of ESS in protected areas. Their collaboration may be difficult due to their lack of experience and/or knowledge about management and decision making techniques. It is important that the adopted methodology is well founded and easy to implement, but also easy for participating stakeholders to understand. This proposed process provides transparency and, through the engagement of relevant stakeholders, ensures legitimacy of the results obtained. Firstly, all stakeholders were involved in defining the relevant 
ESS. Secondly, their preferences for ESS are elicited using AHP method, and the geometric mean was used to aggregate individual pairwise comparisons. Thus, we use a method to obtain consistent preferences easily, and the stakeholders' preferences as a group are also consistent (Xu, 2000), as well as other properties in aggregating the rating of a panel (Tofallis, 2014). In addition, sending the questionnaires as an Excel file and offering the II immediately permitted a low value of inconsistent responses in comparison to other studies (Ananda, 2007). This method can be implemented smoothly in the website of protected areas as a mechanism to update preferences periodically. In this way, the stakeholders can be involved in collaborative management on an ongoing basis by participating in setting the weights they believe should be allocated to each ESS; sensitivity analysis shows the effect on decisions when these weights are changed. The second last step of the methodology, ESS assessment, has been carried out with hypothetical data in the case study. This is due to the lack of available real data.

In the analysis described here, we have used AHP as a method to obtain and aggregate preference (weightings) for ESS. AHP could also be useful to select and prioritise strategic alternatives in the management of ESS, by using pairwise comparison of the performance of alternatives in relation to every ESS. However, empirical studies have shown that only the most expert stakeholders are capable of meeting the consistency requirement of the method when comparing alternatives with respect to technical performances (Maroto et al., 2013). Thus, AHP is advisable for selecting and ranking alternatives when there are no data available for the indicators for ESS. Similarly, AHP alone is not a suitable approach to achieve our second objective of classifying zones in protected areas that would not only be able to inform the best actions, but also be a mechanism to zone the territory. A very relevant application of that approach would be the establishment of a system of PES and the distribution of European funds of Natura 2000 Network, the centrepiece of European Union nature and biodiversity policy, depending on the contribution of areas to ESS.

Our methodology proposed an approach based on PROMETHEE that compares alternatives taking technical data into account, which can be quantitative and qualitative. It is more credible in the specific context than a method based on expert judgements that would not be acceptable by stakeholders who do not have technical knowledge of ESS and may not be able to articulate consistent preferences. It could also have been appropriate to use a value function approach to incorporate technical measurements 
(Belton and Stewart, 2002). In addition, AHP has some disadvantages, such as 9-point scale, the number of evaluations needed and rank reversal problem, although the latter is also a weakness of PROMETHEE.

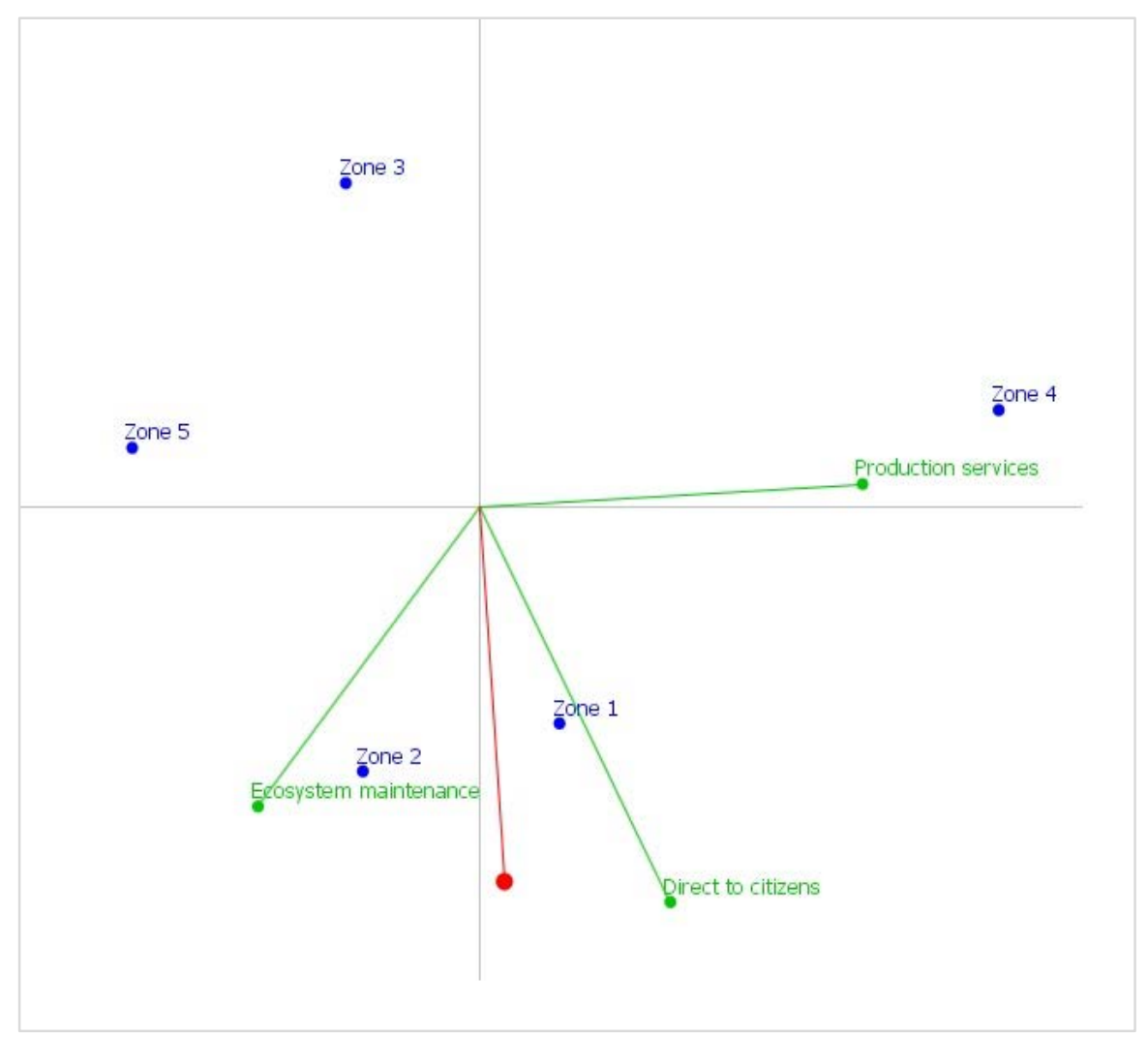

Figure 4-7. Global Visual Analysis for the Serra d'Espadà natural park. D-Sight software

Our methodology only compensates ESS inside the same function (provisioning, maintenance and direct to citizens), but not between them. Thus, we apply PROMETHEE to each of these three groups of ESS independently and then display the results as a bubble graph, which illustrates the relative value of maintenance services and direct services to citizens. The majority of these services do not have economic 
value in the market, but they have a high value for the society. Zones within protected areas can be classified based on the three new indicators. On the one hand, this classification can inform the identification of balanced management alternatives for improving the value of ESS. On the other hand, this approach permits the territory to be zoned, which would be a pillar for assessing ESS globally and useful for establishing payments for non-market ESS among other applications. The bubble graph is a more common representation of data and easy for stakeholders to understand without the need for explanation whereas GAIA is useful for the analyst to understand the "structure" of the data, as can be observed when comparing Figures 4-5 and 4-7.

Another important issue is how to involve stakeholders into collaborative management of ESS. The Group Decision Support System (GDSS) PROMETHEE (Macharis et al., 1998) is an interesting procedure that can be useful for strategic decisions in some contexts when there are not many decision makers or other stakeholders. It would be very difficult to implement this method in ESS management in protected areas due to the high number of people with very different expertise involved, and little time and funds available. Involving stakeholders in order to elicit the weights and look for consensus on indifference and preference thresholds would be more transparent and understandable than a more elaborate method, such as GDSS.

Vacik et al. (2014) provided an in-depth analysis of 43 collaborative methods to apply in the three phases of the Programme-based Planning Natural Resources (PBPNR). These phases are problem identification, problem modelling and problem solving. It is interesting to note that AHP is included in this study, this technique being one of the best performing for problem solving and for problem identification when it is combined with the Strengths, Weaknesses, Opportunities and Threats (SWOT) method. PROMETHEE was not included in this study, although the authors recognised that it could be improved by additional methods and also highlighted the need to identify techniques that complement each other.

The methodology based on MCDM techniques is a very different approach to the traditional methods of ESS valuation such as benefit transfer or CV, which is the most widely used method to assess non-market services. CV asks people directly how much they would pay to observe the environment and have access to it for recreation, their willingness to pay or their willingness to accept (Mendelsohn and Olmstead, 2009). Benefit transfer determines economic values by using existing values from studies 
already completed for another location or issue. There are two ways to transfer the values. The easiest approach is using simple unit transfer. Another way considers function transfer using meta-analysis or benefit transfer. The latter needs an econometric calibration (Wilson and Hoehn, 2006). Traditional valuation methods approach the ESS from the perspective of demand, which means they do not meet the requirements of some environmental regulations, which consider that the valuation of environmental impact must be made from the viewpoint of the supply. In addition, nonmarket based ESS such as soil formation and erosion control should be assessed from the supply perspective. If we want to establish a system of PES, in particular for maintenance ESS, it would be better to reward those areas more, which improve this type of ESS most.

The proposed methodology allows the natural areas to be assessed according to their ESS supply. This approach provides outputs that could be the basic inputs for an economic valuation of natural areas, with many potential applications in practice. For example, economic valuation is required for PES systems, for compensation due to the impacts of forest fires and other natural disasters (landslips, floods, etc.), for distribution of public aids such as Nature 2000 Network, and so on.

In summary, the proposed methodology combines two MCDM techniques to generate new indicators on which to base ESS assessment, in particular for intangible and nonmarket services. In this context, the advantages of each method can strengthen the integrated approach in order to deal with a complex problem. This allows decision makers to expand on the types of problems which can be addressed. For example, this can be used to reach consensus by identifying good options taking into account all ecosystem functions and showing reliable indicators in the inventory of ESS. Finally, it would be easy to implement Decision Support Systems (DSS) for managing and assessing ESS, whose necessity has been pointed out in a recent evaluation of DSS for forest management (Segura et al., 2014). 


\subsection{Conclusions}

In general, many decision makers, technical staff, other stakeholders and citizens consider natural areas as an asset that should be protected, where all environmental services have high importance. This perspective adds complexity to the management of the ESS, since in order to improve one of them it may be that the performance of other services can worsen and/or there can be competition for limited funds. Surveys based on a Likert-type scale are a first approach to knowing the attitudes of stakeholders on some issues and to establishing the decision making framework. However, they do not provide a transparent mechanism to transform opinions into priorities useful for management in a context of scarce resources. As this is the case in all protected areas around the world, it is valuable to explore the use of multiple criteria and group decision tools for ESS management and assessment.

The new methodology is based on the main ESS, grouped by functions (provisioning, maintenance and direct to citizens), considered as the objectives in the management process and it is therefore the basis for assessing them. In addition, it merges two MCDM techniques, incorporating all relevant points of view by involving decisions makers and other stakeholders from the very beginning of the process. This process starts with identifying the relevant ESS followed by an elicitation of stakeholder preferences, which define the weights to apply the PROMETHEE based method. This method allows new indicators for each group of relevant ESS to be obtained, deals with quantitative and qualitative data, enables sensitivity analysis and provides a tool for monitoring, assessing and improving ESS management in protected areas. These indicators can be presented visually as graphs, which are simple for every decision maker, stakeholder and citizen to understand. These advantages have been proposed as relevant criteria for the effective identification, modelling and solving of problems and for when selecting methods for natural resource management (Vacik et al., 2014).

The availability of reliable data is the main challenge to applying robust decision making techniques in practice. Therefore, it is necessary to design methodologies that take advantage of the best current information and also provide a way to highlight the lack of relevant data, as well as a mechanism to develop and improve their quality and quantity. This is facilitated by the methodology proposed in this research. In addition, reliable data together with suitable multicriteria tools are necessary to classify and 
prioritise the alternatives according to a new paradigm of management of protected areas, to help resolve conflicts among stakeholders as well as to establish a basis for new forms of financing, such as PES programmes. Thus, this methodology is also useful to evaluate free ESS, by integrating technical data with social values to assess mainly intangible, non-market services and public goods. Future research will seek to validate this approach by applying it to real technical data and different contexts, as well as evaluate other multicriteria and group decision making methods.

\section{Acknowledgments}

The authors acknowledge the support received from the Ministry of Economy and Competitiveness through the research project Ref. ECO2011-27369, as well as the time and expert judgments from all the decision makers, technical staff, other stakeholders and citizens involved in the surveys we have carried out. A special mention to the director and technical staff of the Serra d'Espadà natural park for all support and collaboration with this research. Marina Segura also thanks the Ministry of Education for support through the scholarship of Training Plan of University Teaching for developing her doctoral thesis. We also thank the reviewers for their suggestions to improve the paper. 



\section{CHAPTER 5}

\section{Valuing Ecosystem Services through} Multiple Criteria Decision Making and Bayesian Belief Networks

\subsection{Multiple Criteria Decision Making}

MCDM is a term that collects a range of approaches aimed at helping individuals and groups make decisions when it has to consider multiple criteria (Belton and Stewart, 2002). The application of MCDM techniques focuses on the conflict among criteria and conflict between stakeholders with different opinions and priorities.

There is no concept of "right answer " nor "optimal solution", traditional in Operations Research/Management Science. MCDM is an aid to the process of decision making, which may be divided into two areas: 1) integrate objective measures with value judgments, and 2) manage and control subjectivity.

According to Belton and Stewart (2002), MCDM is very useful in decision making and its main strengths are the following:

- MCDM takes into account the conflict among criteria in decision making.

- $\quad$ MCDM process helps structure the problem. 
- The models used provide a focus and a language for discussion among stakeholders.

- The decisions taken are justifiable and explainable after a transparent decision making process.

The applications have clearly grown in recent decades due to reasons such as:

- $\quad$ MCDM can deal with many different problem types.

- The time available to perform the analysis and the data to support are different for each type of problems.

- The analytical skills that help make decisions are not the same for each multicriteria tool.

- The requirements and necessities of organisations are different and their decisions also.

The MCDM process can be classified into the following three steps:

1. Problem identification and structuring.

2. Model building and use.

3. The development of action plans.

There are different techniques, most of which have the following features (Department for Communities and Local Government, 2009):

- $\quad$ Transparency.

- Internal consistency.

- $\quad$ Easy to use.

- $\quad$ Takes judgements into account.

- Does not require intensive manpower resource and time for the analysis process.

- $\quad$ Availability to monitor the process and sensitivity analysis.

- $\quad$ Software availability. 
The multicriteria techniques widely used are:

a) Analytic Hierarchy Process

As can be seen in Chapters 3 and 4 the first step in using this method is the construction of the hierarchy and the identification of criteria and alternatives. The second is to set the weights of the criteria and alternatives through pairwise comparisons. AHP has been widely applied in group decision making and to determine the criterion weights for other MCDM methods, as in this research.

b) Multi-Attribute Utility Theory

Multi-Attribute Utility Theory (MAUT) is a structured methodology designed to handle the trade-offs among multiple objectives. According to MAUT, the overall evaluation of an alternative a is defined as a weighted addition of its evaluation with respect to its relevant criteria. The common denominator of all these dimensions is the utility for the decision maker. MAUT tries to associate a unique number representing the overall strength of each alternative if all criteria are taken into account.

\section{c) Outranking Methods}

The outranking approaches differ from the utility/value function approaches in that there is no underlying aggregative function. The output of an analysis is an outranking relation on the set of alternatives and not a value for each alternative. An alternative a outranks alternative b, if taking into account all available information and decision maker's preferences, there is a strong reason to concluded that a is at least as good as b. Outranking methods thus focus on pairwise comparisons of alternatives. These MCDM methods try to associate a preference index to each pair of alternatives that is further exploited to rank alternatives in a descending order of preference. The most widely used outranking methods are PROMETHEE and ELimination and Choice Expressing REality (ELECTRE), the former being used in Chapter 4.

d) Other MCDM methods

There are many other MCDM methods which have not been widely applied or have not significantly contributed to group decision making (Department for Communities and Local Government, 2009). In their recent review Velasquez and Hester (2013) also 
include in their analysis other MCDM methods, such GP and Data Envelopment Analysis (DEA).

\subsection{Bayesian Belief Networks}

BBN are Directed Acyclic Graphs (DAG) that collect the probabilistic relationships among the variables of the model, based on the Bayes' theorem. The variables describe an attribute, characteristic or the hypothesis of an uncertain event with a set of values, which are discrete, mutual and collectively exclusive. BBN allow easy visualization among the relations of the model variables, represented by the graph nodes. They show the influences of particular variables (parent nodes) on other variables (child nodes), without which the nodes have influence on themselves (no closed loops). Relationships are defined as a cause-effect influence of one variable over another, represented in the graph by an arrow, and which utilise probabilistic relations, rather than deterministic terms (Sun and Müller, 2012).

Building BBN is divided into two steps. First, constructing the DAG which determine the nodes and the relationships between them. Second, setting the influences of parent nodes over child nodes from the Conditional Probability Tables (CPT). The complexity of the BBN relates to the number of nodes, as well as their characteristics and the attributes considered (Landuyt et al., 2013).

In a recent review Landuyt et al. (2013) analysed BBN applications in ESS modelling. The main applications have focused on genetic resources, water and climate regulation, fresh water and food provision, recreation and pest and wildfire prevention.

The most important strength of BBN is the ability of combining empirical data and information from experts, very important in environmental issues. The BBN can be used in participatory processes and can be adapted to changes in management or any other reason. BBN consider an explicit treatment of uncertainties and there are several methods for model validation, such as data driven, sensitivity analysis and expert/stakeholder evaluation.

On the contrary, BBN do not allow feedback, which limits the possibilities of problem modelling. As the software has not been widely developed, its capabilities are currently limited. In addition, the lack of data also makes it difficult to use BBN. 
The use of spatial data and valuation techniques, such as CV, have increased their utility and implementation with Geographical Information Systems (GIS) and people's willingness to pay in the BBN nodes have been effective.

\subsection{Multiple Criteria Decision Making and Bayesian Belief Networks: a comparative analysis}

MCDM directly involves the stakeholders facing a particular decision problem in order to elicit their own preferences and values regarding the decision criteria. Hence, the extracted values better reflect the priorities of the people concerned. BBN can also involve stakeholders, however, it is necessary to achieve a consensus, as there is no tool or method to integrate different preferences or opinions.

One of the main disadvantages of BBN techniques is the credibility of the models and public acceptance of these in ESS issues, hence the recommendations are that networks must be validated by experts and trained with data. However, MCDM have benefited from a greater acceptance among stakeholders and their applications in forestry issues, and ESS evaluation case studies are more widespread (Segura et al., 2014; Vacik et al., 2014).

One of the advantages of BBN compared to MCDM techniques is the ability to perform the results in both directions of the problem (Figure 5-1). The effects of variations can be shown by changing the independent variables (parent nodes) and dependent variables (child variables). However, the MCDM techniques such as MAUT, AHP, etc. only analyse the results in one direction. Both approaches, MCDM and BBN, can include and analyse quantitative and qualitative data.

Table 5-1 summarises some other advantages, disadvantages and applications of the methods analysed in this chapter. The literature shows that BBN and MCDM techniques are useful for many different issues. Both approaches (BBN and some MCDM methods) take uncertainty in consideration, but BBN provides a special focus on question of uncertainty. The most important disadvantage of BBN is that they do not allow feedback and this is a very important aspect in decision making related to collaborative management of natural resources. 
Table 5-1. Comparative analysis of BBN and MCDM methods

\begin{tabular}{|c|c|c|c|c|c|c|}
\hline 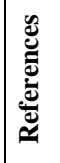 & 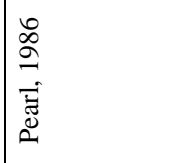 & & 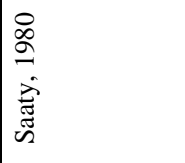 & 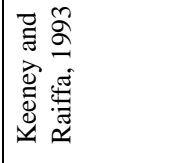 & 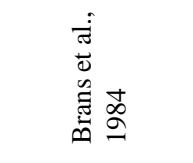 & 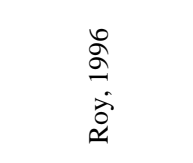 \\
\hline 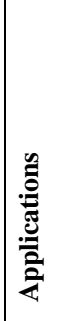 & 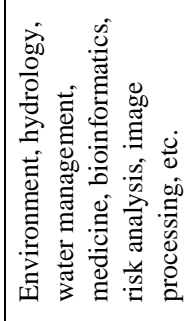 & & 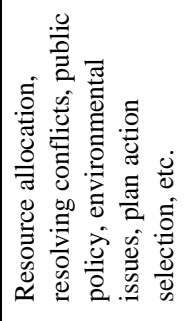 & 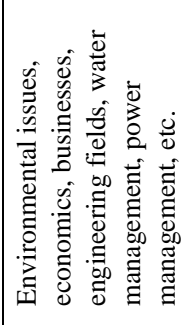 & 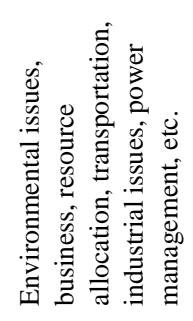 & 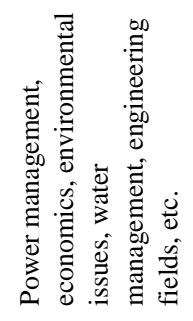 \\
\hline 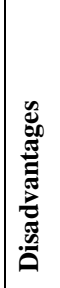 & 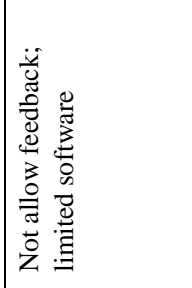 & & 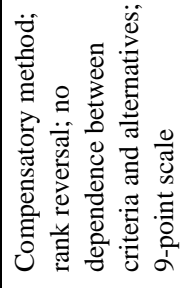 & 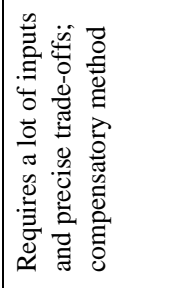 & 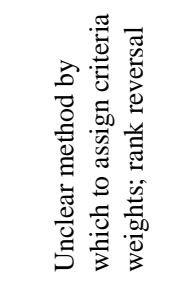 & 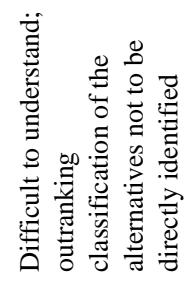 \\
\hline 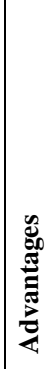 & 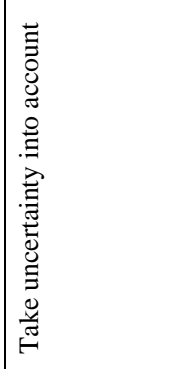 & & 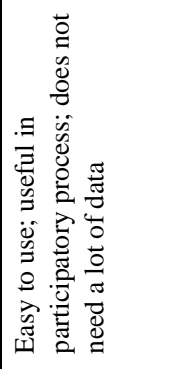 & 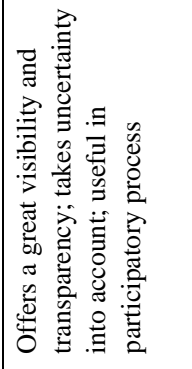 & 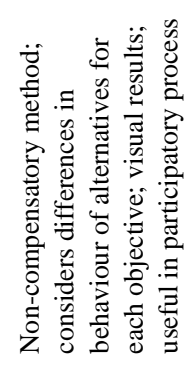 & 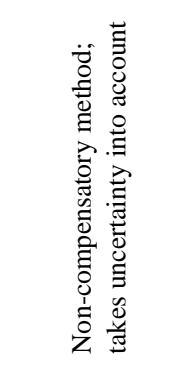 \\
\hline 窇 & 总 & 离 & 晏 & $\frac{5}{2}$ & 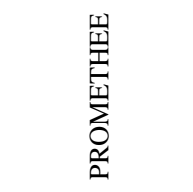 & 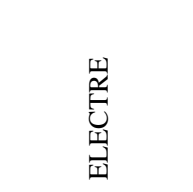 \\
\hline
\end{tabular}


MCDM methods have the disadvantage of solving problems with many criteria, and sometimes it is necessary to simplify the model to work with stakeholders. The MCDM methods can be classified in order to suit the aim of the problem. In addition, there are hybrid methods that combine several techniques to obtain a more robust tool (Macharis et al., 2004; Segura et al., 2014).

\subsection{The SIMWOOD project}

The SIMWOOD project aims to increase the mobilisation of wood from forests and woodlands in Europe. The project reaches out to stakeholders and regional initiatives with the aim of 'waking up' and mobilising forest owners, promoting collaborative forest management and ensuring sustainable forest functions (SIMWOOD, 2015).

The problem to be solved is to design and propose management strategies to increase the mobilisation of wood, analysing the impacts of such policies. The interventions, which are considered to achieve the objectives of the problem, are: training, organising people in cooperatives, subsidies and investment in infrastructure (e.g. forest roads). The highest priority is to find those approaches that increase the knowledge which enhances reaching the objectives of the SIMWOOD project, such as training.

Forest management alternatives are classified into ten categories. Five are alternatives where a certain management $(\mathrm{M})$ is applied in a specific area and other five, where there is no management $(\mathrm{U})$. Also the alternatives are classified on a scale of $1-5$, where 1 corresponds to conservation areas and 5 to intensive production areas.

The SIMWOOD general objective is to determine which interventions or activities are likely to increase wood mobilization and where to apply these. Figure 5-1 shows a conceptual model draft for SIMWOOD. The graph has two parts. The first is related to wood production, which is divided into costs and revenues. The costs are distributed on the following factors or variables: training costs, marketing costs, operation felling and thinning costs. The revenues for wood production consider the following variables: demand for wood, supply of wood and market structure for wood. With these variables it is possible to calculate the financial value of wood mobilization. Non-financial values of wood collect all the benefits that do not come from the market and the creation of cooperatives and rural development. 


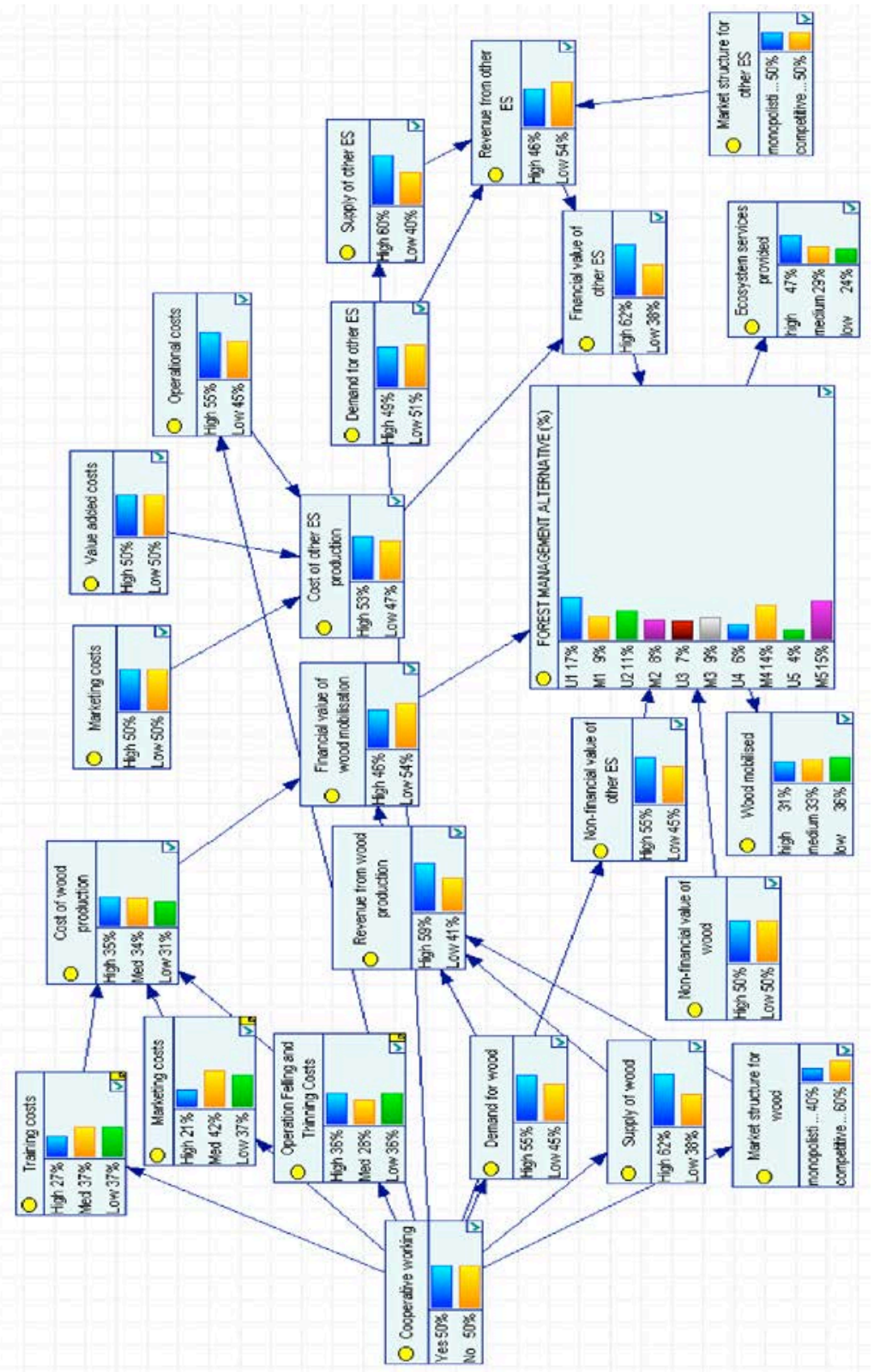

Figure 5-1. BBN conceptual model draft for SIMWOOD 


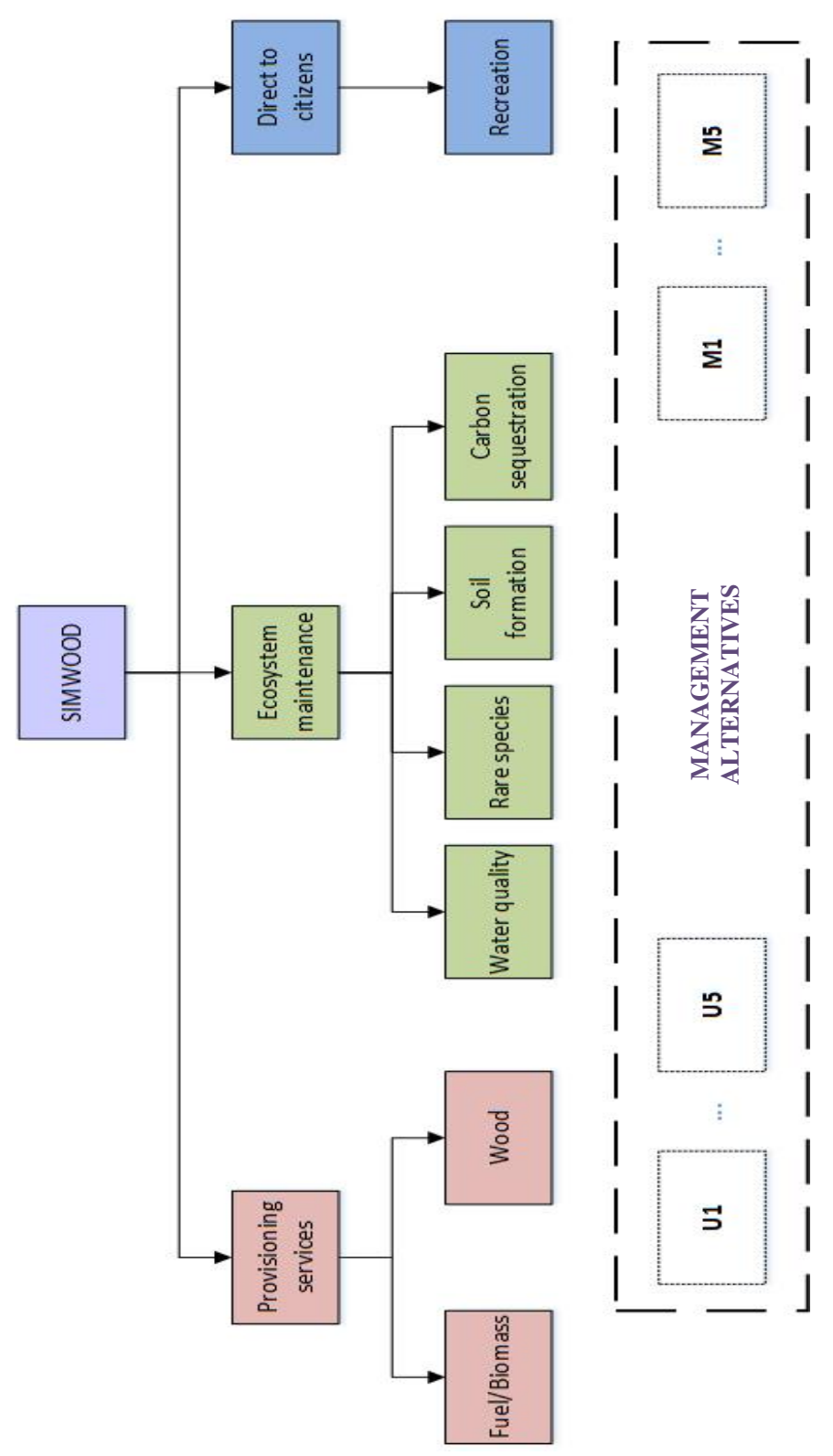

Figure 5-2. Decision hierarchy based on ecosystem services for SIMWOOD 
Another part of the model includes services other than wood production. In the same way the variables are divided into costs, revenues and non-financial values. The costs are classified into: marketing costs, value added costs and operational costs. The revenues have the following variables: demand for other ESS, supply of other ESS and market structure for other ESS. These variables determine the changes in the forest management alternatives and it is possible to calculate the wood mobilization and other ESS provision.

Figure 5-2 shows a multiple criteria approach of this problem with a decision hierarchy based on ESS for SIMWOOD. Three main groups of ESS functions have been included and disaggregated in cases of provisioning services and ecosystem maintenance, while recreation is the unique ESS specified for services direct to citizens. In the first phase of the decision making process, forest management alternatives are considered in the lowest level of hierarchy. In a second phase, management strategies such as training, organising people in cooperatives, subsidies, investment in infrastructure will be the alternatives of the decision hierarchy in order to achieve the SIMWOOD aim.

The combination of the BBN and MCDM methods are suitable for achieving the objectives of SIMWOOD project. BBN allow quantifying ESS derived from the selection of measures or interventions to be decided to increase the mobilization of wood. The multicriteria techniques, as decision making methods, allow reaching an agreement on measures to be taken in order to achieve the objectives. Forest management takes into account several criteria and involving many ESS. Therefore, these methods are complementary to the BBN and can integrate the process of decision making on the measures which should be implemented, and how the strategies should be carried out.

\subsection{Conclusions}

MCDM and BBN are different approaches to deal with the assessment and management of ESS, both with strengths and weaknesses, some of which are common. One of the main strengths of BBN is that expert knowledge can be combined with empirical data, turning it into a useful method for environmental issues as this is in case of MCDM. 
Expert/stakeholder evaluation and sensitivity analysis are ways to validate BBN and MCDM models, but data driven methods are only appropriate for the former. Both approaches allow the integration of qualitative and quantitative data, but availability of reliable data can represent an important challenge in both methodologies.

MCDM shows the conflicts between criteria and stakeholders, which are frequent in environmental issues and facilitate collaborative decision making, involving many stakeholders with different skills and priorities. As a statistical technique, BBN provide models which describe events and relationships among the factors responsible for them. In contrast MCDM is a prescriptive approach, using techniques that provide useful information to guide decision processes, based on a set of criteria and constraints.

On the one hand, BBN allow quantifying ESS based on expert knowledge, whose models can be validated with real data. On the other hand, MCDM can deal with collaborative decision making. Thus, combining MCDM and BBN is a promising approach to develop tools to handle assessment and management of ESS.

Finally, this proposal should be validated with case studies, such as SIMWOOD and other programmes/projects to improve ESS in Mediterranean areas. Another line of future research is to design and develop DSS, which integrate both techniques to provide insight about relations between relevant variables and data, as well as their direct use by MCDM tools, offering a multidisciplinary solution to assess ESS. 



\section{CHAPTER 6}

\section{General discussion of results}

This research provides an in-depth review of the models and methods used to solve forest management problems and an analysis of their pertinent DSS, which are in use worldwide. A strategic planning model was then developed for sustainable management of Mediterranean forests in the Valencian Community. Within this framework, a methodology has also been proposed in order to assess ecosystem services and applied to a case study in the natural park of Serra d' Espadà.

Forest management problems are characterized by a number of dimensions: temporal scale, spatial context, spatial scale, number of decision makers, number of objectives and goods and services involved. The analysis of forest DSS, taking into account the nature of the problems to be solved, has brought to light the relevant influence of the number of decision makers/stakeholders. For example, several people are involved in regional or national planning issues more frequently than in forest or stand level planning, and this is also the case for forest problems with multiple objectives, which occur mainly in large-scale problems.

On the one hand, a single decision maker is associated more frequently with problems which are focused on 'only products'. On the other hand, with problems that involve goods and services the highest percentage appears in those with multiple objectives and with more than one decision maker. These results are according to Reynolds (2005), who has pointed out that the problems of a technical nature do not require the opinion 
of the stakeholders and are usually solved by forest experts. Nevertheless, this author has also underlined that " the institutional perspective is at least as important as technical one'. This can be interpreted as follows: problems related to "only product" are mainly managed from a technical point of view, while those involving goods and services are less connected with expert knowledge and more with stakeholder preferences.

There is a lack of empirical studies on non-market services, whose integration in the DSS is small compared to the number of articles published on models and methods for management of non-market services. Such non-market services are the relevant services in the Mediterranean forests, which are characterized by low productivity in forest products, especially timber.

There are no relationships between the features that characterize forest problems and the optimisation and statistical methods. Optimisation methods, such as Linear Programming (LP) and Integer Programming (IP), have been widely used according to the analysis where $60 \%$ of the DSS implement them, as well as the articles of the literature review. The majority of published papers which describe forest management DSS in the last decade have optimisation models, which are solved by commercial software, such as CPLEX, or by means of metaheuristics algorithms.

The evolutionary algorithms are becoming more popular as a tool to solve complex combinatorial optimisation problems, although their use has not been widespread in DSS until now. Metaheuristic methods require detailed studies to obtain the values of the parameters, which make them competitive in obtaining good solutions with less computing time. In addition, tuning parameters are linked to specific instances, which make their utility in practice controversial as many papers use artificial forests (Bettinger and Zhu, 2006; Boston and Bettinger, 2006; Pukkala and Heinonen, 2006; Hennigar et al., 2008). Thus there is an additional difficulty in applying these methods due to the gap between hypothetical and real forests and landscapes.

The use of Dynamic Programming (DP) is less frequent than IP. In the former case the main drawback for practitioners and DSS developers is that there is not a standard mathematical formulation when problems are approached by DP. It would be an interesting line for future research, in particular to develop DSS that are able to generate the required equations for common problems. 
Statistical methods are not widely applied, representing $16 \%$ of problems solved by DSS for forest management. These techniques solve specific forest problems (pest, fire, etc.) and can be useful as complementary tools to other approaches to inform decision making (Leskinen et al., 2006). Traditional approaches such as Regression Analysis (RA) and multivariate models are used more frequently (Ren et al., 2011), although data mining and Artificial Neural Network (ANN) techniques are becoming more popular in the latest DSS (Ficko et al., 2011). Recently, many authors have developed statistical spatial models to capture data from new sources such as GIS (Newton et al., 2012).

Simulation models are related to some features of forestry problems, specifically with the spatial scale and the number of decision makers. Simulation models are widely used in the DSS (63\%) with a trend towards integrating forest simulators with optimisation tools and involving stakeholders in participatory models (Muys et al., 2010).

Multicriteria methods are related to the number of objectives and the goods and services dimension. Problems with multiple objectives represent $73 \%$ of the total, nevertheless it should be highlighted that the percentage of problems with multiple objectives solved by MCDM methods is only 40\%. In addition, MCDM techniques are used not just for long term problems, but also for medium and short term problems. These tools allow the involvement of stakeholders in participatory forest management, thus DSS should be able to capture the preferences and judgements of decision makers/stakeholders.

Economic models have been found in 25\% of the DSS and they are related to long term problems and to the forest products domain, in which market values are more readily available. There is a limitation in the DSS since many ecosystem services are not valued due to the lack of integration of non-market services valuation techniques, for example, CV or benefit transfer.

Almost all DSS for forest management have an information system, a database and/or a GIS. The integration of GIS is essential in DSS that deal with spatial problems. The percentage of systems with an information system increases as the time scale increases. That is, the percentage is higher in the long term problems than in the short term ones. Similarly, the percentage of DSS with any information systems are higher in cases where several decision makers/stakeholders are involved in the decision making process than a single decision maker. 
Reynolds (2005) has highlighted the necessity to design tools to present complex information in a visual and intuitive way to support public involvement. Nevertheless, the analysis carried out has revealed that the quantity and quality of data are some of the most important drawbacks in the implementation of DSS for forest management. Information has not been properly exploited by classical or novel decision making methods because of the high cost of obtaining and maintaining the information (Kaloudis et al., 2008). In addition, most of the DSS developed are used only in one country as it is often difficult to apply the systems elsewhere (Cucchi et al., 2005; Muys et al., 2010). This fact may constitute a major constraint in the current application of DSS, accounting for inefficiency and overlap in development effort.

A strategic model for sustainable forest management in Valencia region was developed due to the lack of studies which deal with Mediterranean forests as an extensive literature review pointed out. The Mediterranean forests, which are characterized by low timber productivity, should be managed from the multifunctional perspective of goods and services provided, taking into account environmental, social and economic criteria that are the pillars of sustainable forest management, together with public participation. The participatory model developed has been validated by stakeholders including representatives of public administration, forestry researchers, forest owners, forestry companies and conservation groups, among others.

The main results obtained from the regional forest management model are similar to the two preference aggregation methods used. Although there have been differences between the values of the priorities obtained using AHP and GP, these differences decrease as the number of stakeholders taken into consideration increases and, in general, the relative order of the priorities remains.

The research shows the greater importance of the environmental criteria over the economic and social criteria in the management of the Mediterranean forest for all groups of stakeholders, from perspectives of both the majority and the minority. The relevance of the environmental criteria is valid for both public and private forests. With regard to the action plans, there is a close relation between the public budget in the Valencian Community dedicated to the different action plans and its relative importance obtained from the stakeholder preferences. 
The use of several multicriteria techniques reinforces the results' robustness. AHP and GP are verified methods, although each one has its own strengths and weaknesses. AHP requires that the Index of Inconsistency (II) be less than or equal to 0.1, but guarantees that the matrix which represents the preferences/judgements of various decision makers/stakeholders/experts has an II no greater than that of the individual matrix with the greatest II. However, GP models do not assure that the consensus matrices resulting from consistent individual matrices are consistent themselves, as in the case of some consensus matrices obtained from the first survey.

The strategic forest management model developed for the Valencian Community region is the framework within which a management model on a smaller scale has been designed. In particular, a model for managing protected areas according to the proposed collaborative methodology, which is focused on the main ecosystem services.

Firstly, surveys based on a Likert-type scale were used to identify the most important ESS in the natural park network of the Valencian Community. Biodiversity has the highest priority, in line with international agreements that include it as the main objective of protected areas and the previous results of this research. In addition, $40 \%$ of stakeholders attribute "high importance" to all ecosystem maintenance services and over $80 \%$ rate all as medium or high important. Products from forests, mainly timber, have little relevance due to the slow regenerative capacity of the Mediterranean forests. However, such surveys cannot allow prioritising ESS, necessary in a context of limited resources.

As it is advisable that collaborative decision making is based on consistent judgements, it was decided to apply AHP in order to aggregate individual preferences of stakeholders. The results of the case study of a forest natural park confirmed the perceived importance of maintenance services (54.2\%) over provisioning services (25.4\%) and direct services to citizens (20.4\%). Hydrological regulation and biodiversity are the most relevant maintenance services.

The involvement of stakeholders is a key aspect of the management and assessment of ESS in protected areas, because it provides transparency and legitimacy. Their participation may be difficult due to their lack of experience and/or knowledge about management and decision making techniques. In this respect the AHP method is easy to understand, but it can produce inconsistent matrices. The regional strategic study had 
a lack of consistent responses from some stakeholder groups, as in other, previous empirical works (Nordström et al., 2010). To overcome this drawback, the methodology proposed the questionnaires as Excel files that immediately show the II and allow immediate modifications in order to elicit consistent responses.

The methodology combines two well-known MCDM methods. AHP as a method for obtaining and aggregating preferences (weightings) for ESS, and an approach based on PROMETHEE for classifying zones in protected areas. AHP would be able to select and prioritise strategic alternatives in the management of ESS where there are no data available for objective indicators of ESS.

Forest decision making must take into account all ecosystem functions. Our methodology only compensates ESS inside the same function (provisioning, maintenance and direct to citizens), but not between them. The bubble graph proposed illustrates the relative value of the protected area according to three indices, which represent the ecosystem functions. This classification would be useful in some complex forestry issues. First, it can inform the identification of balanced management alternatives for improving the value of ESS. Second, this approach permits the territory to be zoned, the establishment of a system of Payment for Ecosystem Services (PES) and the distribution of European funds of Natura 2000 Network, the centrepiece of European Union nature and biodiversity policy, depending on the contribution of areas to ESS.

Applications such as PES programs, Natura 2000 Network and compensations for natural disasters require economic valuation. Nevertheless, traditional methods, such as benefit transfer or $\mathrm{CV}$, assess the ESS from the perspective of demand, while some environmental regulations require that the natural areas should be assessed taking into account their ESS supply.

In summary, the proposed methodology combines two MCDM techniques to generate new indicators on which to base ESS assessment, in particular for intangible and nonmarket services. In the end, it will be easy to implement DSS for managing and assessing ESS, whose necessity has also been pointed out in the previous evaluation of them for forest management (Chapter 2).

Finally, the analysis of BBN and MCDM highlighted the usefulness of combining both methods to assess and manage ESS, in particular for achieving the objectives of 
SIMWOOD project. BBN as well as MCDM can integrate expert knowledge with quantitative and qualitative data. Nevertheless, the unavailability of the latter is one of the main challenges for future research and real applications, similar to other statistical and decision making techniques. BBN allow ESS to be quantified, pointing out the relationships between variables, while multicriteria techniques enable agreement to be reached on measures to be taken in order to achieve the objectives taking into account the preferences of stakeholders. The integration of both tools will guide the process of decision making on the measures which should be implemented, and how the strategies should be carried out. 



\section{CHAPTER 7}

\section{Conclusions}

Forests, which represent the dominant terrestrial ecosystem, have been the source of many decision making problems in order to improve their management, as the huge number of articles published during the last few decades has shown. Optimisation methods, such as LP and IP, have been used widely to maximise the objectives, for instance the volume of harvested timber, Net Present Value (NPV) and carbon sequestration, in the strategic and tactical problems. MCDM methods have been used for many purposes and in particular in participatory forest planning. In all cases, the role of software tools has been essential for applying these techniques, either by using general decision making software, such as CPLEX, Expert Choice and Super decisions, or DSS designed for forest management. Among the latter can be cited EMDS (Ecosystem Management Decision Support System) and Woodstock.

The main conclusions from the DSS assessment for forest management, taking into account their capabilities in models and methods and their relationships with the important features of forestry problems are the following:

Firstly, the methods used most in DSS for forest management are optimisation and simulation, with values of $60 \%$ and $63 \%$ respectively. In the latter case, the analysis showed significant relationships with characteristics of problems to be solved, as well as with DSS which integrate information systems, economic models and MCDM. Nevertheless, this is not the case for optimisation and statistics models. Therefore, optimisation and statistical models can be considered as general tools to deal with forest 
management problems, not being significantly affected by their characteristics, such as temporal and spatial scales, the spatial context, the number of objectives and decision makers or goods and services involved.

Secondly, although traditional optimisation methods are widely used, new trends are gaining importance, such as the incorporation of uneven-aged forests into models and different ecosystems or the generation of new evolutionary algorithms instead of IP solvers. Metaheuristics represent an opportunity and a challenge for future research, as they require tuning parameters to be competitive and their value is dependent on instance data.

Thirdly, there is a need to develop and integrate spatial statistical methods in GIS tools, which will be a requirement for tackling spatial problems and also to involve stakeholders in participatory processes, among other applications.

Fourthly, MCDM should be developed further in DSS due to the number of issues related to forest management and natural resources, as it involves multiple objectives in the decision making process. In addition, this conclusion is closely related to the lack of group decision making tools in the current DSS and the need to implement them, according to the emergent paradigm of natural resource management where stakeholders should participate in the decision making process to make it more transparent and have greater public acceptance.

Fifthly, quality and quantity of required data are a major issue to implement DSS in practice and these are really effective for practitioners. One of the challenges is the lack of non-traditional forest data, for example stakeholders' preferences, as their availability as input to models can limit their use in real problems, especially when dealing with non-market services.

Sixthly, the majority of DSS are focused on problems related to market products, alone or together with services, as well as problems whose objectives are technical and economic rather than social and environmental. There are few DSS dealing only with services, and fewer that deal with non-market services.

A model for sustainable management of Mediterranean forests has been developed by means of an empirical research for forests in the Valencian Community region. Decision makers, experts and stakeholders have been involved in defining and validating the 
strategic criteria to guide regional forest planning. The main conclusions can be summarized as follows.

The decision hierarchy represents a complete regional model, which includes all important social, economic and environmental objectives, validated by stakeholders in a workshop. In the first phase, social preferences have been elicited by using a survey, based on AHP method, of representatives of the following groups: administration, professional engineering associations, forest research and education, hunting and fishing federations, forest owners, forestry companies, land stewardship, environmentalist and conservationist groups. In a second phase, another survey this time of experts only, was undertaken in order to determine the contribution of action plans to each objective.

Individual preferences have been aggregated by AHP (geometric mean and eigen value) and GP models. Both approaches highlighted that environmental and social criteria have more importance than economic ones, only forest owners assign higher preference to economic criteria than social criteria. The results show that the variation between private and public forests is small, although the importance of environmental criteria in the latter slightly increases.

With regard to action plans, fire prevention and extinction and reforestation and forestry have similar global priorities, occupying first or second place for all stakeholder groups. Stakeholders involved in forest research and education, forest owners and companies have forest research, inventory and planning as a priority strategy and this is the third preferential action plan for rest of groups. Management of flora and fauna is in the fourth place, followed by hunting and fishing and finally trails and other recreational and tourism infrastructures.

The strategic model developed for the Valencian Community represents the framework and within this management models on a smaller scale should be developed, as it is the case of the model to assess the ESS provided by protected forest areas. In this context the information from surveys based on a Likert-type scale has limited value for decision making. This is because stakeholders and citizens assign high importance to all ESS, since they consider natural areas as an asset that should be protected. This procedure does not provide a transparent mechanism to transform opinions into useful priorities for management in a context of scarce resources. As this is the case in all protected areas 
around the world, it is valuable to explore the use of multiple criteria and group decision tools for ESS management and assessment.

The next paragraphs summarize the main conclusions from the collaborative methodology developed in this thesis for management and assessment ESS. Two MCDM techniques have been combined incorporating all relevant points of view of decision makers and other stakeholders from the very beginning of the process and considering the main ESS provided by the natural area.

ESS are grouped by ecosystems' functions that are provisioning services, maintenance services and direct services to citizens, and which are considered as the objectives in the management process and which is therefore the basis for assessing them. The decision making process starts by identifying the relevant ESS followed by an elicitation of stakeholder preferences using AHP.

A PROMETHEE based method is then applied, where the weights of ESS have been previously calculated with AHP. This method allows new indicators for each group of relevant ESS to be obtained, deals with quantitative and qualitative data, enables sensitivity analysis and provides a tool for monitoring, assessing and improving ESS management in protected areas.

The indicators obtained by this methodology can be presented visually as graphs, which are simple for every decision maker, stakeholder and citizen to understand. These advantages have been proposed by Vacik et al. (2014) as relevant criteria for the effective identification, modelling and solving of problems and when selecting methods for natural resource management.

This new methodology enables to overcome one of the challenges of natural resource management: the availability of reliable data. It takes advantage of the best current information and also provides a way to highlight the lack of relevant data, as well as a mechanism to develop and improve their quality and quantity.

The methodology also allows classifying and prioritising of the alternatives according to a new paradigm of management of protected areas, to help to solve conflicts among stakeholders as well as to establish a basis for new forms of financing, such as PES programmes. Thus, this methodology is useful to evaluate free ESS, by integrating technical data with social values to assess mainly intangible, non-market services and 
public goods. Thus, in addition to forests, the proposed methodology is appropriate for assessing different ecosystems relevant worldwide, such as wetlands, among others.

Finally, a comparative analysis of MCDM and BBN approaches has pointed out their complementary features and the great potential for combining these approaches in order to assess ESS and improve the tools for decision making. BBN allow the quantifying of ESS without providing mechanisms to reach agreements on measures to be taken in order to achieve the objectives, while this is an essential characteristic of the MCDM methods.

In future research it would be interesting to carry out empirical studies by applying BBN and the new collaborative methodology in case studies on forest ESS in Northern European countries as well as in Mediterranean areas, in order to validate the hybrid approach and find out the most appropriate management for ESS in Mediterranean and other types of forests.

Other future lines of research are the application of the methodology developed, based on multiple criteria, objective indicators and social preferences to design PES programmes, estimate compensations due to the impact of forest fires and other natural disasters, and for distribution of public aids, for instance in the Nature 2000 Network in Europe. This approach provides the assessment of ESS from the point of view of supply as a basic input for these programmes, meets the European regulations and complements the traditional methods of economic valuation. 



\section{References}

Ananda, J. (2007). Implementing participatory decision making in forest planning. Environmental Management, 39(4), 534-544. http://doi.org/10.1007/s00267-0060031-2

Ananda, J., \& Herath, G. (2003a). Incorporating stakeholder values into regional forest planning: a value function approach. Ecological Economics, 45(1), 75-90. http://doi.org/10.1016/S0921-8009(03)00004-1

Ananda, J., \& Herath, G. (2003b). The use of Analytic Hierarchy Process to incorporate stakeholder preferences into regional forest planning. Forest Policy and Economics, 5(1), 13-26. http://doi.org/10.1016/S1389-9341(02)00043-6

Ananda, J., \& Herath, G. (2008). Multi-attribute preference modelling and regional land-use planning. Ecological Economics, 65(2), 325-335. http://doi.org/10.1016/j. ecolecon.2007.06.024

Ananda, J., \& Herath, G. (2009). A critical review of multi-criteria decision making methods with special reference to forest management and planning. Ecological Economics, 68(10), 2535-2548. http://doi.org/10.1016/j.ecolecon.2009.05.010

Andersson, D., \& Eriksson, L. O. (2007). Effects of temporal aggregation in integrated strategic/tactical and strategic forest planning. Forest Policy and Economics, 9(8), 965-981. http://doi.org/10.1016/j.forpol.2006.09.002

Andersson, M., Dahlin, B., \& Mossberg, M. (2005). The Forest Time Machine - A multi-purpose forest management decision-support system. Computers and Electronics in Agriculture, 49(1), 114-128. http://doi.org/10.1016/j.compag.2005. 02.006

Apostolopoulou, E., Drakou, E. G., \& Pediaditi, K. (2012). Participation in the management of Greek Natura 2000 sites: evidence from a cross-level analysis. Journal of Environmental Management, 113, 308-18. http://doi.org/10.1016/j. jenvman.2012. 09. 006 
Backéus, S., Wikström, P., \& Lämås, T. (2005). A model for regional analysis of carbon sequestration and timber production. Forest Ecology and Management, 216(1-3), 28-40. http://doi.org/10.1016/j.foreco.2005.05.059

Banville, C., Landry, M., Martel, J. M., \& Boulaire, C. (1998). A stakeholder approach to MCDA. Systems Research and Behavioral Science, 15(1), 15-32. http://doi.org/ 10.1002/(SICI)1099-1743(199801/02)15:1<15::AID-SRES179>3.0.CO;2-B

Baskent, E. Z., \& Keles, S. (2005). Spatial forest planning: A review. Ecological Modelling, 188(2-4), 145-173. http://doi.org/10.1016/j.ecolmodel.2005.01.059

Bateman, I. J., Mace, G. M., Fezzi, C., Atkinson, G., \& Turner, K. (2011). Economic analysis for ecosystem service assessments. Environmental and Resource Economics, 48(2), 177-218. http://doi.org/10.1007/s10640-010-9418-x

Behzadian, M., Kazemzadeh, R. B., Albadvi, A., \& Aghdasi, M. (2010). PROMETHEE: A comprehensive literature review on methodologies and applications. European Journal of Operational Research, 200(1), 198-215. http://doi.org/10.1016/j.ejor. 2009.01.021

Belton, V., \& Stewart, T. J. (2002). Multiple criteria decision analysis: an integrated approach. Springer Science \& Business Media.

Belton, V., \& Stewart, T. J. (2010). Problem Structuring for Multiple Criteria Analysis. In New Trends in Multicriteria Decision Analysis. In S. Greco, R. J. Figuiera, \& M. Ehrgott (Eds.), Trends in Multiple Criteria Decision Analysis (Vol. 142, pp. 209240). New York, USA: Springer International Series in Operational Research and Management Science. http://doi.org/10.1007/978-1-4419-5904-1

Bettinger, P., Boston, K., Kim, Y. H., \& Zhu, J. (2007). Landscape-level optimization using tabu search and stand density-related forest management prescriptions. European Journal of Operational Research, 176(2), 1265-1282. http://doi.org/ 10.1016/j.ejor. 2005.09.025

Bettinger, P., \& Zhu, J. (2006). A new heuristic method for solving spatially constrained forest planning problems based on mitigation of infeasibilities radiating outward from a forced choice. Silva Fennica, 40(2), 315-333. 
Binoti, D. H. B., Binoti, M. L. M. da S., Leite, H. G., Gleriani, J. M., \& Campos, J. C. C. (2012). Regulation of even-aged forest with adjacency constraints. Forest Policy and Economics, 20, 49-57. http://doi.org/10.1016/j.forpol.2012.02.009

Borges, J. G., Nordström, E. M., Garcia Gonzalo, J., Hujala, T., \& Trasobares, A. (2014). Computer-based tools for supporting forest management. The experience and the expertise world-wide. Department of Forest Resource Management, Swedish University of Agricultural Sciences. Retrieved from http://pub.epsilon. slu.se/11417/7/ borges_jg_etal_140825.pdf

Boston, K., \& Bettinger, P. (2006). An economic and landscape evaluation of the greenup rules for California, Oregon, and Washington (USA). Forest Policy and Economics, 8(3), 251-266. http://doi.org/10.1016/j.forpol.2004.06.006

Brans, J. P., \& Mareschal, B. (2005). Promethee Methods. In R. J. Figuiera, S. Greco, \& M. Ehrgott (Eds.), Multiple Criteria Decision Analysis: State of the Art Surveys (Vol. 78, pp. 163-186). Springer International Series in Operational Research and Management Science. http://doi.org/10.1007/0-387-23081-5_5

Brans, J. P., Mareschal, B., \& Vincke, P. (1984). PROMETHEE: A new family of outranking methods in multiple criteria analysis. In J. P. Brans (Ed.), Operational Research, IFORS 84 (pp. 477-490). North Holland, Amsterdam

Brown, G., \& Reed, P. (2009). Public Participation GIS: A new method for use in national forest planning. Forest Science, 55(2), 166-182.

Chang, W. Y., Lantz, V. A., Hennigar, C. R., \& MacLean, D. A. (2012). Benefit-cost analysis of spruce budworm (Choristoneura fumiferana Clem.) control: incorporating market and non-market values. Journal of Environmental Management, 93(1), 104-12. http://doi.org/10.1016/j.jenvman.2011.08.022

Coleman, T. W., \& Rieske, L. K. (2006). Arthropod response to prescription burning at the soil-litter interface in oak-pine forests. Forest Ecology and Management, 233(1), 52-60. http://doi.org/10.1016/j.foreco.2006.06.001

Corner, J., Buchanan, J., \& Henig, M. (2001). Dynamic decision problem structuring. Journal of Multi-Criteria Decision Analysis, 10(3), 129-141. http://doi.org/10.1002 /mcda.295 
COST. (2012). Forest Management Decision Support Systems (COST Action FP0804 FORSYS). Retrieved March 1, 2012, from http://fp0804.emu.ee

Costa, A., Oliveira, A. C., Vidas, F., \& Borges, J. G. (2010). An approach to cork oak forest management planning: A case study in southwestern Portugal. European Journal of Forest Research, 129(2), 233-241. http://doi.org/10.1007/s10342-0090326-y

Costanza, R., D’Arge, R., de Groot, R. S., Farber, S., Grasso, M., Hannon, B., Limburg, K., Naeem, S., O'Neill, R. V., Paruelo, J., Raskin, R. G., Sutton, P., \& van den Belt, M. (1998). The value of the world's ecosystem services and natural capital. Ecological Economics, 25(1), 3-15. http://doi.org/10.1016/S0921-8009(98)000202

Couture, S., \& Reynaud, A. (2011). Forest management under fire risk when forest carbon sequestration has value. Ecological Economics, 70(11), 2002-2011. http://doi.org/10.1016/j.ecolecon.2011.05.016

Cucchi, V., Meredieu, C., Stokes, A., de Coligny, F., Suarez, J., \& Gardiner, B. A. (2005). Modelling the windthrow risk for simulated forest stands of Maritime pine (Pinus pinaster Ait.). Forest Ecology and Management, 213(1-3), 184-196. http://doi.org/10.1016/j.foreco.2005.03.019

D’Amours, S., Rönnqvist, M., \& Weintraub, A. (2008). Using Operational Research for Supply Chain Planning in the Forest Products Industry. INFOR: Information Systems and Operational Research, 46(4), 265-281. http://doi.org/10.3138/infor. 46.4.265

Daellenbach, H., McNickle, D., \& Dye, S. (2012). Management Science: Decisionmaking through systems thinking. New York, USA: Palgrave Macmillan. http://doi.org/10.1287/mnsc.1040.0218

Dai, L., Zheng, B., Shao, G., \& Zhou, L. (2006). The roles of a decision support system in applying forest ecosystem management in Northeast China. Science in China, Series E: Technological Sciences, 49(SUPPL. 1), 9-18. http://doi.org/10.1007/ s11431-006-8102-4 
De Brucker, K., Macharis, C., \& Verbeke, A. (2013). Multi-criteria analysis and the resolution of sustainable development dilemmas: A stakeholder management approach. European Journal of Operational Research, 224(1), 122-131. http://doi.org/10.1016/ j.ejor.2012.02.021

De Groot, R. S., Wilson, M. A., \& Boumans, R. M. (2002). A typology for the classification, description and valuation of ecosystem functions, goods and services. Ecological Economics, 41(3), 393-408. http://doi.org/10.1016/S09218009(02) 00089-7

Department for Communities and Local Government. (2009). Multi-criteria analysis: a manual. Communities and Local Government Publications. Retrieved May 10, 2013, from https:/www.gov.uk/government/uploads/system/uploads/attachment_ data/file/7612/ 1132618.pdf

Diamantopoulou, M. J., Milios, E., Doganos, D., \& Bistinas, I. (2009). Reforestation Design Through the Dominant Trees Bole-Volume Estimation. Natural Resource Modelling, 22(4), 511-543. http://doi.org/10.1111/j.1939-7445.2009.00051.x

Diaz-Balteiro, L., González-Pachón, J., \& Romero, C. (2009). Forest management with multiple criteria and multiple stakeholders: An application to two public forests in Spain. Scandinavian Journal of Forest Research, 24(1), 87-93. http://doi.org/10.10 80/02827580802687440

Diaz-Balteiro, L., \& Romero, C. (2008). Making forestry decisions with multiple criteria: A review and an assessment. Forest Ecology and Management, 255(8-9), 3222-3241. http://doi.org/10.1016/j.foreco.2008.01.038

Duchelle, A. E., Guariguata, M. R., Less, G., Albornoz, M. A., Chavez, A., \& Melo, T. (2012). Evaluating the opportunities and limitations to multiple use of Brazil nuts and timber in Western Amazonia. Forest Ecology and Management, 268, 39-48. http://doi.org/10.1016/j.foreco.2011.05.023

Eriksson, L. O., Backéus, S., \& Garcia, F. (2012). Implications of growth uncertainties associated with climate change for stand management. European Journal of Forest Research, 131(4), 1199-1209. http://doi.org/10.1007/s10342-011-0591-4 
Eyvindson, K., Kangas, A., Kurttila, M., \& Hujala, T. (2010). Using preference information in developing alternative forest plans. Canadian Journal of Forest Research, 40(12), 2398-2410. http://doi.org/10.1139/X10-179

Ficko, A., Poljanec, A., \& Boncina, A. (2011). Do changes in spatial distribution, structure and abundance of silver fir (Abies alba Mill.) indicate its decline? Forest Ecology and Management, 261(4), 844-854. http://doi.org/10.1016/j.foreco.2010. 12.014

Fisher, B., \& Turner, K. R. (2008). Ecosystem services: Classification for valuation. Biological Conservation, 141(5), 1167-1169. http://doi.org/10.1016/j.biocon.2008 .02 .019

Fitzsimons, J., Pearson, C. J., Lawson, C., \& Hill, M. J. (2012). Evaluation of land-use planning in greenbelts based on intrinsic characteristics and stakeholder values. Landscape and Urban Planning, 106(1), 23-34. http://doi.org/10.1016/j. landurbplan.2012.01.012

Fontana, V., Radtke, A., Bossi Fedrigotti, V., Tappeiner, U., Tasser, E., Zerbe, S., \& Buchholz, T. (2013). Comparing land-use alternatives: Using the ecosystem services concept to define a multi-criteria decision analysis. Ecological Economics, 93, 128136. http://doi.org/10.1016/j.ecolecon.2013.05.007

Gardiner, B. A., \& Quine, C. P. (2000). Management of forests to reduce the risk of abiotic damage - a review with particular reference to the effects of strong winds. Forest Ecology and Management, 135(1-3), 261-277. http://doi.org/10.1016/S03781127(00)00285-1

Gärtner, S., Reynolds, K. M., Hessburg, P. F., Hummel, S., \& Twery, M. (2008). Decision support for evaluating landscape departure and prioritizing forest management activities in a changing environment. Forest Ecology and Management, 256(10), 1666-1676. http://doi.org/10.1016/j.foreco.2008.05.053

Generalitat Valenciana. (2013). Parcs Naturals de la Comunitat Valenciana. Retrieved December 20, 2013, from http:/www.cma.gva.es/webdoc/documento.ashx?id= 141553 
Gilabert, H., \& McDill, M. E. (2010). Optimizing inventory and yield data collection for forest management planning. Forest Science, 56(6), 578-591.

González-Olabarria, J. R., \& Pukkala, T. (2011). Integrating fire risk considerations in landscape-level forest planning. Forest Ecology and Management, 261(2), 278-287. http://doi.org/10.1016/j.foreco.2010.10.017

González-Pachón, J., \& Romero, C. (2004). A method for dealing with inconsistencies in pairwise comparisons. European Journal of Operational Research, 158(2), 351361. http://doi.org/10.1016/j.ejor.2003.06.009

González-Pachón, J., \& Romero, C. (2007). Inferring consensus weights from pairwise comparison matrices without suitable properties. Annals of Operations Research, 154(1), 123-132. http://doi.org/10.1007/s10479-007-0182-4

Graham, J., Amos, B., \& Plumptre, T. (2003). Governance Principles for Protected Areas in the 21st Century. In The Fifth World Parks Congress Durban, South Africa (p. 50). Durban, South Africa.

Griesbauer, H. P., Green, D. S., \& O’Neill, G. A. (2011). Using a spatiotemporal climate model to assess population-level Douglas-fir growth sensitivity to climate change across large climatic gradients in British Columbia, Canada. Forest Ecology and Management, 261(3), 589-600. http://doi.org/10.1016/j.foreco.2010.11.012

Gutiérrez, V. H., Zapata, M., Sierra, C., Laguado, W., \& Santacruz, A. (2006). Maximizing the profitability of forestry projects under the Clean Development Mechanism using a forest management optimization model. Forest Ecology and Management, 226(1-3), 341-350. http://doi.org/10.1016/j.foreco.2006.02.002

Harrison, S. R., \& Qureshi, M. E. (2000). Choice of stakeholder groups and members in multicriteria decision models. Natural Resources Forum, 24, 11-19. http://doi.org/10.1111/j.1477-8947.2000.tb00925.x

Heinonen, T., Kurttila, M., \& Pukkala, T. (2007). Possibilities to aggregate raster cells through spatial optimization in forest planning. Silva Fennica, 41(1), 89-103.

Hennigar, C. R., \& MacLean, D. A. (2010). Spruce budworm and management effects on forest and wood product carbon for an intensively managed forest. Canadian Journal of Forest Research, 40(9), 1736-1750. http://doi.org/10.1139/X10-104 
Hennigar, C. R., MacLean, D. A., \& Amos-Binks, L. J. (2008). A novel approach to optimize management strategies for carbon stored in both forests and wood products. Forest Ecology and Management, 256(4), 786-797. http://doi.org/ 10.1016/j.foreco .2008.05.037

Hildebrandt, P., \& Knoke, T. (2011). Investment decisions under uncertainty-A methodological review on forest science studies. Forest Policy and Economics, 13(1), 1-15. http://doi.org/10.1016/j.forpol.2010.09.001

Hiltunen, V., Kurttila, M., Leskinen, P., Pasanen, K., \& Pykäläinen, J. (2009). Mesta: An internet-based decision-support application for participatory strategic-level natural resources planning. Forest Policy and Economics, 11(1), 1-9. http://doi.org/10.1016 /j.forpol.2008.07.004

Hjortsø, C. N. (2004). Enhancing public participation in natural resource management using Soft OR-an application of strategic option development and analysis in tactical forest planning. European Journal of Operational Research, 152(3), 667683. http://doi.org/10.1016/S0377-2217(03)00065-1

Hockings, M., Stolton, S., Dudley, N., Leverington, F., \& Courrau, J. (2006). Evaluating effectiveness: A framework for assessing management of protected areas. Cambrige: IUCN: Gland, Switzerland.

Holopainen, M., Mäkinen, A., Rasinmäki, J., Hyyppä, J., Hyyppä, H., Kaartinen, H., Viitala, R., Vastaranta, M., \& Kangas, A. (2010). Effect of tree-level airborne laserscanning measurement accuracy on the timing and expected value of harvest decisions. European Journal of Forest Research, 129(5), 899-907. http://doi.org/ 10.1007/s10342-009-0282-6

Holsapple, C. W. (2008). Decision and knowledge. In F. Burstein \& C. W. Holsapple (Eds.), Handbook on Decision Support System 1 (pp. 21-53). Springer. http://doi.org/ 10.1007/978-3-540-48713-5

Holsten, A., Dominic, A. R., Costa, L., \& Kropp, J. P. (2013). Evaluation of the performance of meteorological forest fire indices for German federal states. Forest Ecology and Management, 287, 123-131. http://doi.org/10.1016/j.foreco.2012.08. 035 
Huang, I. B., Keisler, J., \& Linkov, I. (2011). Multi-criteria decision analysis in environmental sciences: ten years of applications and trends. The Science of the Total Environment, 409(19), 3578-94. http://doi.org/10.1016/j.scitotenv.2011.06. 022

Hurst, J. M., Stewart, G. H., Perry, G. L. W., Wiser, S. K., \& Norton, D. A. (2012). Determinants of tree mortality in mixed old-growth Nothofagus forest. Forest Ecology and Management, 270, 189-199. http://doi.org/10.1016/j.foreco.2012.01. 029

Intergovernmental Panel on Climate Change. (2007). Climate Change 2007, the IPCC Fourth Assessment Report. Synthesis Report. Summary for Policymakers. Intergovernmental Panel on Climate Change. Core Writing Team IPCC. Retrieved from www.ipcc.ch.

Iqbal, J., Hennigar, C. R., \& MacLean, D. A. (2012). Modeling insecticide protection versus forest management approaches to reducing balsam fir sawfly and hemlock looper damage. Forest Ecology and Management, 265, 150-160. http://doi.org/ 10.1016/j. foreco.2011.10.029

Jalilova, G., Khadka, C., \& Vacik, H. (2012). Developing criteria and indicators for evaluating sustainable forest management: A case study in Kyrgyzstan. Forest Policy and Economics, 21, 32-43. http://doi.org/10.1016/j.forpol.2012.01.010

Kajanus, M., Leskinen, P., Kurttila, M., \& Kangas, J. (2012). Making use of MCDS methods in SWOT analysis-Lessons learnt in strategic natural resources management. Forest Policy and Economics, 20, 1-9. http://doi.org/10.1016/ j.forpol.2012.03.005

Kaloudis, S., Costopoulou, C. I., Lorentzos, N. A., Sideridis, A. B., \& Karteris, M. (2008). Design of forest management planning DSS for wildfire risk reduction. Ecological Informatics, 3(1), 122-133. http://doi.org/10.1016/j.ecoinf.2007.07.008

Kangas, A., Kangas, J., \& Kurttila, M. (2008). Decision Support for Forest Management. Springer Netherlands. http://doi.org/10.1007/978-1-4020-6787-7 
Kangas, A., Kangas, J., Lahdelma, R., \& Salminen, P. (2006). Using SMAA-2 method with dependent uncertainties for strategic forest planning. Forest Policy and Economics, 9(2), 113-125. http://doi.org/10.1016/j.forpol.2005.03.012

Kangas, A., Saarinen, N., Saarikoski, H., Leskinen, L. A., Hujala, T., \& Tikkanen, J. (2010). Stakeholder perspectives about proper participation for Regional Forest Programmes in Finland. Forest Policy and Economics, 12(3), 213-222. http://doi.org/10.1016/j.forpol.2009.10.006

Kangas, J., \& Kangas, A. (2005). Multiple criteria decision support in forest management - the approach, methods applied, and experiences gained. Forest Ecology and Management, 207(1-2), 133-143. http://doi.org/10.1016/j.foreco.2004. 10.023

Kazana, V., Fawcett, R. H., \& Mutch, W. E. S. (2003). A decision support modelling framework for multiple use forest management: The Queen Elizabeth Forest case study in Scotland. European Journal of Operational Research, 148(1), 102-115. http://doi.org/10.1016/S0377-2217(02)00348-X

Keeney, R. L. (1992). Value-Focused Thinking: A Path to Creative Decision Making. Cambridge, USA: Harvard University Press.

Keeney, R. L., \& Raiffa, H. (1993). Decisions with multiple objectives - preferences and value tradeoffs. Cambridge, USA: Cambridge University Press.

Kijazi, M. H., \& Kant, S. (2011). Social acceptability of alternative forest regimes in Mount Kilimanjaro, Tanzania, using stakeholder attitudes as metrics of uncertainty. Forest Policy and Economics, 13(4), 242-257. http://doi.org/10.1016/j.forpol.2010. 12.001

Kirilenko, A., Chivoiu, B., Crick, J., Ross-Davis, A., Schaaf, K., Shao, G., Singhania, V., \& Swihart, R. (2007). An Internet-based decision support tool for non-industrial private forest landowners. Environmental Modelling \& Software, 22(10), 14981508. http://doi.org/10.1016/j.envsoft.2006.11.001 
Kurttila, M., Muinonen, E., Leskinen, P., Kilpeläinen, H., \& Pykäläinen, J. (2009). An approach for examining the effects of preferential uncertainty on the contents of forest management plan at stand and holding level. European Journal of Forest Research, 128(1), 37-50. http://doi.org/10.1007/s10342-008-0237-3

Landuyt, D., Broekx, S., D’hondt, R., Engelen, G., Aertsens, J., \& Goethals, P. L. M. (2013). A review of Bayesian belief networks in ecosystem service modelling. Environmental Modelling and Software, 46, 1-11. http://doi.org/10.1016/j.envsoft. 2013.03.011

Larson, A. J., \& Churchill, D. (2012). Tree spatial patterns in fire-frequent forests of western North America, including mechanisms of pattern formation and implications for designing fuel reduction and restoration treatments. Forest Ecology and Management, 267, 74-92. http://doi.org/10.1016/j.foreco.2011.11.038

Leskinen, P., Viitanen, J., Kangas, A., \& Kangas, J. (2006). Alternatives to incorporate uncertainty and risk attitude in multicriteria evaluation of forest plans. Forest Science, 52(3), 304-312.

Liu, J., Ouyang, Z., \& Miao, H. (2010). Environmental attitudes of stakeholders and their perceptions regarding protected area-community conflicts: a case study in China. Journal of Environmental Management, 91(11), 2254-2262. http://doi.org/ 10.1016/j. jenvman. 2010.06.007

Lockwood, M., Worboys, G., \& Kothari, A. (2006). Managing Protected Areas: A Global Guide. London, UK: Earthscan.

Loudermilk, E. L., Cropper, J. P., Mitchell, R. J., \& Lee, H. (2011). Longleaf pine (Pinus palustris) and hardwood dynamics in a fire-maintained ecosystem: A simulation approach. Ecological Modelling, 222(15), 2733-2750. http://doi.org/10.1016/j. ecolmodel.2011.05.004

Macharis, C., Brans, J. P., \& Mareschal, B. (1998). The GDSS Promethee procedure. Journal of Decision Systems, 7, 283-307. 
Macharis, C., Springael, J., De Brucker, K., \& Verbeke, A. (2004). PROMETHEE and AHP: The design of operational synergies in multicriteria analysis. European Journal of Operational Research, 153(2), 307-317. http://doi.org/10.1016/S03772217(03)00153-X

Macharis, C., Turcksin, L., \& Lebeau, K. (2012). Multi Actor Multi Criteria Analysis (MAMCA) As a Tool to Support Sustainable Decisions: State of Use. Decision Support Systems, 54(1), 610-620. http://doi.org/10.1016/j.dss.2012.08.008

Maroto, C., Segura, M., Ginestar, C., Uriol, J., \& Segura, B. (2012). Aggregation of stakeholder preferences of in Sustainable Forest Management using AHP Mediterranean Forests in. In C. Luz \& F. Valente (Eds.), Proceedings of the 1st Internatinal Conference on Operations Research and Enterprise Systems (pp. 100 107). SciTePress. http://doi.org/10.5220/0003697401000107

Maroto, C., Segura, M., Ginestar, C., Uriol, J., \& Segura, B. (2013). Sustainable Forest Management in a Mediterranean region: Social preferences. Forest Systems, 22(3), 546-558. http://doi.org/10.5424/fs/2013223-04135

Marques-Pérez, I., Segura, B., \& Maroto, C. (2014). Evaluating the functionality of agricultural systems: social preferences for multifunctional peri-urban agriculture. The "Huerta de Valencia” as case study. Spanish Journal of Agricultural Research, 12(4), 889-901. http://doi.org/10.5424/sjar/2014124-6061

Martell, D. L., Gunn, E. A., \& Weintraub, A. (1998). Forest management challenges for operational researchers. European Journal of Operational Research, 104(1), 1-17. http://doi.org/10.1016/S0377-2217(97)00329-9

Martinez-Harms, M. J., Bryan, B. A., Balvanera, P., Law, E. A., Rhodes, J. R., Possingham, H. P., \& Wilson, K. A. (2015). Making decisions for managing ecosystem services. Biological Conservation, 184, 229-238. http://doi.org/10. 1016/j.biocon. 2015.01.024

Martins, H., \& Borges, J. G. (2007). Addressing collaborative planning methods and tools in forest management. Forest Ecology and Management, 248(1-2), 107-118. http://doi.org/10.1016/j.foreco.2007.02.039 
Mendelsohn, R., \& Olmstead, S. (2009). The Economic Valuation of Environmental Amenities and Disamenities: Methods and Applications. Annual Review of Environment and Resources, 34(1), 325-347. http://doi.org/10.1146/annurevenviron-011509-135201

Mendoza, G. A., \& Martins, H. (2006). Multi-criteria decision analysis in natural resource management: A critical review of methods and new modelling paradigms. Forest Ecology and Management, 230(1-3), 1-22. http://doi.org/10.1016/j.foreco. 2006.03.023

Menzel, S., Nordström, E. M., Buchecker, M., Marques, A., Saarikoski, H., \& Kangas, A. (2012). Decision support systems in forest management: requirements from a participatory planning perspective. European Journal of Forest Research, 131(5), 1367-1379. http://doi.org/10.1007/s10342-012-0604-y

Millennium Ecosystem Assessment. (2003). MA Conceptual Framework. In Ecosystems and human well-being: A Framework for Assessment (pp. 25-36). Island Press. Retrieved from http:/www.millenniumassessment.org/documents/ document.765.aspx.pdf

Miller, K. A., \& Belton, V. (2014). Water resource management and climate change adaptation: a holistic and multiple criteria perspective. Mitigation and Adaptation Strategies for Global Change, 19(3), 289-308. http://doi.org/10.1007/s11027-0139537-0

Moore, D. S. (1995). Estadística aplicada básica. Antoni Bosch.

Mustajoki, J., Saarikoski, H., Marttunen, M., Ahtikoski, A., Hallikainen, V., Helle, T., Hypponen, M., Jokinen, M., Naskali, A., Tuulentie, S., Varmola, M., Vatanen, E., \& Ylisirnio, A. L. (2011). Use of decision analysis interviews to support the sustainable use of the forests in Finnish Upper Lapland. Journal of Environmental Management, 92(6), 1550-1563. http://doi.org/10.1016/j.jenvman.2011.01.007

Muys, B., Hynynen, J., Palahí, M., Lexer, M. J., Fabrika, M., Pretzsch, H., Gillet, F., Briceño, E., Nabuurs, G. J., \& Kint, V. (2010). Simulation tools for decision support to adaptive forest management in Europe. Forest Systems, 19, 86-99. 
Newton, P., Peres, C. A., Desmoulière, S. J. M., \& Watkinson, A. R. (2012). Crossscale variation in the density and spatial distribution of an Amazonian non-timber forest resource. Forest Ecology and Management, 276, 41-51. http://doi.org/ 10.1016/j.foreco. 2012.03.020

Nordström, E. M., Eriksson, L. O., \& Öhman, K. (2010). Integrating multiple criteria decision analysis in participatory forest planning: Experience from a case study in northern Sweden. Forest Policy and Economics, 12(8), 562-574. http://doi.org/ 10.1016/j.forpol.2010.07.006

Nordström, E. M., Romero, C., Eriksson, L. O., \& Öhman, K. (2009). Aggregation of preferences in participatory forest planning with multiple criteria: an application to the urban forest in Lycksele, Sweden. Canadian Journal of Forest Research, 39(10), 1979-1992. http://doi.org/10.1139/X09-107

OECD. (2014). The OECD Glossary of Statistical Terms. Retrieved September 22, 2014, from http://stats.oecd.org/glossary/

Öhman, K., Edenius, L., \& Mikusiński, G. (2011). Optimizing spatial habitat suitability and timber revenue in long-term forest planning. Canadian Journal of Forest Research, 41(3), 543-551. http://doi.org/10.1139/X10-232

Öhman, K., \& Wikström, P. (2008). Incorporating aspects of habitat fragmentation into long-term forest planning using mixed integer programming. Forest Ecology and Management, 255(3-4), 440-446. http://doi.org/10.1016/j.foreco.2007.09.033

Ovando, P., Campos, P., Oviedo, J. L., \& Montero, G. (2010). Private net benefits from afforesting marginal cropland and shrubland with cork oaks in Spain. Forest Science, 56(6), 567-577.

Paffetti, D., Travaglini, D., Buonamici, A., Nocentini, S., Vendramin, G. G., Giannini, R., \& Vettori, C. (2012). The influence of forest management on beech (Fagus sylvatica L.) stand structure and genetic diversity. Forest Ecology and Management, 284, 34-44. http://doi.org/10.1016/j.foreco.2012.07.026 
Palacios-Agundez, I., Casado-Arzuaga, I., Madariaga, I., \& Onaindia, M. (2013). The Relevance of Local Participatory Scenario Planning for Ecosystem Management Policies in the Basque Country, Northern Spain. Ecology and Society, 18(3). http://doi.org/10.5751/ES-05619-180307

Pasqualini, V., Oberti, P., Vigetta, S., Riffard, O., Panaïotis, C., Cannac, M., \& Ferrat, L. (2011). A GIS-based multicriteria evaluation for aiding risk management Pinus pinaster Ait. Forests: A case study in Corsican island, western Mediterranean region. Environmental Management, 48(1), 38-56. http://doi.org/10.1007/s00267-0119674-8

PATFOR. (2011). Plan de acción territorial forestal de la Comunitat Valenciana. Retrieved December 10, 2013, from http://www.cma.gva.es/webdoc/documento. ashx ?id=144302

Pauwels, D., Lejeune, P., \& Rondeux, J. (2007). A Decision Support System to Simulate and Compare Silvicultural Scenarios for Pure Even-Aged Larch Stands. Annals of Forest Science, 64(3), 345-353. http://doi.org/10.1051/forest:2007011

Pearl, J. (1986). Fusion, propagation, and structuring in belief networks. Artificial Intelligence, 29(3), 241-288. http://doi.org/10.1016/0004-3702(86)90072-X

Petrokofsky, G., Brown, N. D., Hemery, G. E., Woodward, S., Wilson, E., Weatherall, A., Stokes, V., Smithers, R. J., Sangster, M., Russell, K., Pullin, A. S., Price, C., Morecroft, M., Malins, M., Lawrence, A., Kirby, K. J., Godbold, D., Charman, E., Boshier, D., Bosbeer, S., \& Arnold, J. E. M. (2010). A participatory process for identifying and prioritizing policy-relevant research questions in natural resource management: a case study from the UK forestry sector. Forestry, 83(4), 357-367. http://doi.org/10.1093/forestry/cpq018

Pukkala, T., \& Heinonen, T. (2006). Optimizing heuristic search in forest planning. Nonlinear Analysis: Real World Applications, 7(5), 1284-1297. http://doi.org/ 10.1016/j.nonrwa.2005.11.011

Pukkala, T., Lähde, E., \& Laiho, O. (2010). Optimizing the structure and management of uneven-sized stands of Finland. Forestry, 83(2), 129-142. http://doi.org/10.1093/ forestry/cpp037 
Pyatt, G., Ray, D., \& Fletcher, J. (2001). An Ecological Site Classification for forestryin Great. Forestry Commission Bulletin 124. Edinburgh. Retrieved from http://www.forestry.gov.uk/pdf/ESCBulletin.pdf/\$file/ESCBulletin.pdf

Quintero, M. A., Jerez, M., \& Ablan, M. (2011). Evaluación de tres técnicas heurísticas para resolver un modelo de planificación del aprovechamiento en plantaciones forestales industriales. Interciencia, 36(5), 348-355.

RAMSAR. (2013). The List of Wetlands of International Importance. Retrieved December 15, 2013, from http://www.ramsar.org/

Reed, M. S. (2008). Stakeholder participation for environmental management: A literature review. Biological Conservation, 141(10), 2417-2431. http://doi.org/ 10.1016 /j.biocon.2008.07.014

Rees, S. E., Attrill, M. J., Austen, M. C., Mangi, S. C., \& Rodwell, L. D. (2013). A thematic cost-benefit analysis of a marine protected area. Journal of Environmental Management, 114, 476-485. http://doi.org/10.1016/j.jenvman.2012.10.048

Reichhuber, A., \& Requate, T. (2012). Alternative use systems for the remaining Ethiopian cloud forest and the role of Arabica coffee - A cost-benefit analysis. Ecological Economics, 75, 102-113. http://doi.org/10.1016/j.ecolecon.2012.01.006

Ren, Y., Wei, X., Wei, X., Pan, J., Xie, P., Song, X., Peng, D., \& Zhao, J. (2011). Relationship between vegetation carbon storage and urbanization: A case study of Xiamen, China. Forest Ecology and Management, 261(7), 1214-1223. http://doi.org/10.1016/j.foreco. 2010.12.038

Rey, P. A., Muñoz, J. A., \& Weintraub, A. (2009). A Column Generation Model for Truck Routing in the Chilean Forest Industry. INFOR: Information Systems and Operational Research, 47(3), 215-221. http://doi.org/10.3138/infor.47.3.215

Reynolds, K. M. (2005). Integrated decision support for sustainable forest management in the United States: Fact or fiction? Computers and Electronics in Agriculture, 49(1), 6-23. http://doi.org/10.1016/j.compag.2005.02.002

Roy, B. (1996). Multicriteria Methodology for Decision Aiding. Springer US. http://doi.org/10.1007/978-1-4757-2500-1 
Ruiz, C. (2014). Valoración Económica de los Parques Naturales del sur de la provincia de Alicante. Thesis. Supervisor: Fernando Vidal Giménez. Universidad Miguel Hernández. Supervisor: Fernando Vidal Giménez

Saaty, T. L. (1980). The Analytic Hierarchy Process. New York: McGraw-Hill.

Saaty, T. L. (2006). Fundamentals of decision making and priority theory with the analytic hierarchy process. Pittsburgh: Rws Publications.

Saaty, T. L. (2008). Decision making with the analytic hierarchy process. International Journal of Services Sciences, 1(1), 83-98.

Saaty, T. L., \& Peniwati, K. (2008). Group decision making: drawing out and reconciling differences. Pittsburgh: RWS publications.

Saaty, T. L., \& Shih, H. S. (2009). Structures in decision making: On the subjective geometry of hierarchies and networks. European Journal of Operational Research, 199(3), 867-872. http://doi.org/10.1016/j.ejor.2009.01.064

Saaty, T. L., \& Vargas, L. G. (2001). Models, Methods, Concepts \& Applications of the Analytic Hierarchy Process. Kluwer Academic Publishers, The Netherlands

Savage, D. W., Martell, D. L., \& Wotton, B. M. (2011). Forest management strategies for dealing with fire-related uncertainty when managing two forest seral stages. Canadian Journal of Forest Research, 41(2), 309-320. http://doi.org/10.1139/X10212

Schmoldt, D. L., Mendoza, G. A., \& Kangas, J. (2001). Past Developments and Future Directions for the AHP in Natural Resources. In D. Schmoldt, J. Kangas, G. Mendoza, \& M. Pesonen (Eds.), The Analytic Hierarchy Process in Natural Resource and Environmental Decision Making SE - 18 (Vol. 3, pp. 289-305). Springer Netherlands. http://doi.org/10.1007/978-94-015-9799-9_18

Scholten, L., Scheidegger, A., Reichert, P., Mauer, M., \& Lienert, J. (2014). Strategic rehabilitation planning of piped water networks using multi-criteria decision analysis. Water Research, 49, 124-43. http://doi.org/10.1016/j.watres.2013.11.017 
Schou, E., Jacobsen, J. B., \& Kristensen, K. L. (2012). An economic evaluation of strategies for transforming even-aged into near-natural forestry in a coniferdominated forest in Denmark. Forest Policy and Economics, 20, 89-98. http://doi.org/10.1016/ j.forpol.2012.02.010

Segura, M., Ray, D., \& Maroto, C. (2014). Decision support systems for forest management: A comparative analysis and assessment. Computers and Electronics in Agriculture, 101, 55-67. http://doi.org/10.1016/j.compag.2013.12.005

Seidl, R., Fernandes, P. M., Fonseca, T. F., Gillet, F., Jönsson, A. M., Merganičová, K., Netherer, S., Arpaci, A., Bontemps, J. D., Bugmann, H., González-Olabarria, J. R., Lasch, P., Meredieu, C., Moreira, F., Schelhaas, M. J., \& Mohren, F. (2011). Modelling natural disturbances in forest ecosystems: a review. Ecological Modelling, 222(4), 903-924. http://doi.org/10.1016/j.ecolmodel.2010.09.040

Shang, Z., He, H. S., Xi, W., Shifley, S. R., \& Palik, B. J. (2012). Integrating LANDIS model and a multi-criteria decision-making approach to evaluate cumulative effects of forest management in the Missouri Ozarks, USA. Ecological Modelling, 229, 50 63. http://doi.org/10.1016/j.ecolmodel.2011.08.014

Shao, G., Wang, H., Dai, L., Wu, G., Li, Y., Lang, R., \& Song, B. (2005). Integrating stand and landscape decisions for multi-purposes of forest harvesting. Forest Ecology and Management, 207(1-2), 233-243. http://doi.org/10.1016/j.foreco. 2004.10.029

Sheppard, S. R. J., \& Meitner, M. (2005). Using multi-criteria analysis and visualisation for sustainable forest management planning with stakeholder groups. Forest Ecology and Management, 207(1-2), 171-187. http://doi.org/10.1016/j.foreco. 2004.10.032

Sijtsma, F. J., van der Heide, C. M., \& van Hinsberg, A. (2013). Beyond monetary measurement: How to evaluate projects and policies using the ecosystem services framework. Environmental Science \& Policy, 32, 14-25. http://doi.org/10.1016/ j.envsci.2012.06.016

SIMWOOD. (2015). Sustainable Innovative Mobilisation of Wood. Retrieved March 2, 2015, from http://simwood.efi.int/ 
Slaney, G. L., Lantz, V. A., \& MacLean, D. A. (2009). The economics of carbon sequestration through pest management: application to forested landbases in New Brunswick and Saskatchewan, Canada. Forest Policy and Economics, 11(7), 525534. http://doi.org/10.1016/j.forpol.2009.07.009

Spring, D. A., Kennedy, J., Lindenmayer, D. B., McCarthy, M. A., \& Nally, R. Mac. (2008). Optimal management of a flammable multi-stand forest for timber production and maintenance of nesting sites for wildlife. Forest Ecology and Management, 255(11), 3857-3865. http://doi.org/10.1016/j.foreco.2008.03.033

Streitberger, M., Hermann, G., Kraus, W., \& Fartmann, T. (2012). Modern forest management and the decline of the Woodland Brown (Lopinga achine) in Central Europe. Forest Ecology and Management, 269, 239-248. http://doi.org/10.1016/ j.foreco.2011.12.028

Strimbu, B. M., Innes, J. L., \& Strimbu, V. F. (2010). A deterministic harvest scheduler using perfect bin-packing theorem. European Journal of Forest Research, 129(5), 961-974. http://doi.org/10.1007/s10342-010-0405-0

Sun, Z., \& Müller, D. (2012). A framework for modeling payments for ecosystem services with agent-based models, Bayesian belief networks and opinion dynamics models. Environmental Modelling \& Software, 1-14. http://doi.org/10.1016/j. envsoft. 2012.06.007

SuperDecisions. (2010). Retrieved from http://www.superdecisions.com/

Thompson, D., Chartrand, D., Staznik, B., Leach, J., \& Hodgins, P. (2010). Integrating advanced technologies for optimization of aerial herbicide applications. New Forests, 40(1), 45-66. http://doi.org/10.1007/s11056-009-9181-4

Tofallis, C. (2014). Add or multiply? A tutorial on ranking and choosing with multiple criteria. INFORMS Transactions on Education, 144, 109-119. http://doi.org/ 10.1287 /ited.2013.0124

Toivanen, T., Liikanen, V., \& Kotiaho, J. S. (2009). Effects of forest restoration treatments on the abundance of bark beetles in Norway spruce forests of southern Finland. Forest Ecology and Management, 257(1), 117-125. http://doi.org/ 10.1016/j. foreco.2008.08.025 
Tompkins, E. L., Few, R., \& Brown, K. (2008). Scenario-based stakeholder engagement: incorporating stakeholders preferences into coastal planning for climate change. Journal of Environmental Management, 88(4), 1580-92. http://doi.org/10. 1016/j.jenvman.2007.07.025

Turcksin, L., Bernardini, A., \& Macharis, C. (2011). A combined AHP-PROMETHEE approach for selecting the most appropriate policy scenario to stimulate a clean vehicle fleet. Procedia - Social and Behavioral Sciences, 20, 954-965. http://doi.org/ 10.1016/j.sbspro.2011.08.104

Vacik, H., Kurttila, M., Hujala, T., Khadka, C., Haara, A., Pykäläinen, J., Honkakoski, P., Wolfslehner, B., \& Tikkanen, J. (2014). Evaluating collaborative planning methods supporting programme-based planning in natural resource management. Journal of Environmental Management, 144, 304-315. http://doi.org/10.1016/ j.jenvman.2014. 05.029

Vainikainen, N., Kangas, A., \& Kangas, J. (2008). Empirical study on voting power in participatory forest planning. Journal of Environmental Management, 88(1), 17380. http://doi.org/10.1016/j.jenvman.2007.02.004

Valls-Donderis, P., Vallés, M. C., \& Galiana, F. (2015). Criteria and indicators for sustainable forestry under Mediterranean conditions applicable in Spain at the forest management unit scale. Forest Systems, 24(1), 21. http://doi.org/10.5424/fs/ 2015241-05542

Velasquez, M., \& Hester, P. T. (2013). An analysis of multi-criteria decision making methods. International Journal of Operations Research, 10(2), 56-66.

Wang, J., Chen, J., Ju, W., \& Li, M. (2010). IA-SDSS: A GIS-based land use decision support system with consideration of carbon sequestration. Environmental Modelling \& Software, 25(4), 539-553. http://doi.org/10.1016/j.envsoft.2009.09 .010

Weintraub, A., \& Murray, A. T. (2006). Review of combinatorial problems induced by spatial forest harvesting planning. Discrete Applied Mathematics, 154(5), 867-879. http://doi.org/10.1016/j.dam.2005.05.025 
Wilson, M. A., \& Hoehn, J. P. (2006). Valuing environmental goods and services using benefit transfer: The state-of-the art and science. Ecological Economics, 60(2), 335342. http://doi.org/10.1016/j.ecolecon.2006.08.015

Wolfslehner, B., \& Vacik, H. (2011). Mapping indicator models: From intuitive problem structuring to quantified decision-making in sustainable forest management. Ecological Indicators, 11(2), 274-283. http://doi.org/10.1016/j. ecolind.2010.05.004

Xiaodan, W., Xianghao, Z., \& Pan, G. (2010). A GIS-based decision support system for regional eco-security assessment and its application on the Tibetan Plateau. Journal of Environmental Management, 91(10), 1981-90. http://doi.org/10.1016/ j.jenvman.2010. 05.006

$\mathrm{Xu}, \mathrm{Z}$. (2000). On consistency of the weighted geometric mean complex judgement matrix in AHP. European Journal of Operational Research, 126(3), 683-687. http://doi.org/10.1016/S0377-2217(99)00082-X

Young, J. A., Manen, F. T. van, \& Thatcher, C. A. (2011). Geographic profiling to assess the risk of rare plant poaching in natural areas. Environmental Management, 48(3), 577-587. http://doi.org/10.1007/s00267-011-9687-3

Zeng, H., Pukkala, T., \& Peltola, H. (2007a). The use of heuristic optimization in risk management of wind damage in forest planning. Forest Ecology and Management, 241(1-3), 189-199. http://doi.org/10.1016/j.foreco.2007.01.016

Zeng, H., Pukkala, T., Peltola, H., \& Kellomäki, S. (2007b). Application of ant colony optimization for the risk management of wind damage in forest planning. Silva Fennica, 41(2), 315-332. http://doi.org/10.1016/j.foreco.2007.01.016

Zhou, M., \& Buongiorno, J. (2011). Effects of stochastic interest rates in decision making under risk: A Markov decision process model for forest management. Forest Policy and Economics, 13(5), 402-410. http://doi.org/10.1016/j.forpol.2011.03.007 

Annexes 



\section{Annex I}

Glossary of abbreviations 



\section{Acronyms of Decision Support Systems}

4S Tool: Forest Stand Software Support System

ALS: Airborne Laser Scanning

EMDS: Ecosystem Management Decision Support System

ESC: Ecological Site Classification

ESDSS: Eco-Security assessment Decision Support System

FORESTAR: Forest Operation and Restoration for Enhancing Services in a Temperate Asian Region

ForestGALES: Geographic Analysis of the Losses and Effects of Storms in Forestry FTM: The Forest Time Machine

Geo-SIMA-HWIND: Forest growth SIMA and wind damage HWIND models integrated into GIS

GDSS: Group Decision Support System PROMETHEE

IA-SDSS: Integrated Assessment framework and a Spatial Decision Support System

LANDIS: LANdscape-scale, succession and DISturbance model

LMS: Landscape Management System

SBW: Spruce Budworm

SDSS: Silvicultural Decision Support System

Woodstock: Remsoft Spatial Planning System

WRR-DSS: Wildfire Risk Reduction DSS 


\section{Acronyms of Models and Methods}

ACO: Ant Colony Optimisation

AHP: Analytic Hierarchy Process

ANN: Artificial Neural Network

ANOVA: ANalysis Of VAriance

ANP: Analytic Network Process

BBN: Bayesian Belief Networks

BIP: Binary Integer Programming

CBA: Cost-Benefit Analysis

CM: Cognitive Mapping

CV: Contingent Valuation

DAG: Directed Acyclic Graphs

DEA: Data Envelopment Analysis

DP: Dynamic Programming

ELECTRE: ELimination and Choice Expressing REality

GA: Genetic Algorithms

GAIA: Geometrical Analysis for Interactive Aid

GIS: Geographic Information System

GLM: Generalized Linear Model

GM: Growth Model

GP: Goal Programing

IP: Integer Programming

LP: Linear Programming

LR: Logistic Regression 
MACBETH: Measuring Attractiveness by a Categorical Based Evaluation Technique MAUT: Multi-Attribute Utility Theory

MAV: Multi-Attribute Value

MC: Markov Chain

MCA: Multi-Criteria Analysis

MCDM: Multiple Criteria Decision Making

MCSM: Monte Carlo Simulation Method

MIP: Mix Integer Programming

MP: Mathematical Programming

NLP: Non-Linear Programming

NPV: Net Present Value

PCA: Principal Components Analysis

PROMETHEE: Preference Ranking Organisation METhod for Enrichment Evaluations

PSO: Particle Swarm Optimisation

RA: Regression Analysis

SA: Simulated Annealing algorithms

SFM: Sustainable Forest Management

SMAA: Stochastic Multicriteria Acceptability Analysis

SMART: Simple Multi-Attribute Rating Technique

SWOT: Strengths, Weaknesses, Opportunities and Threats

TA: Threshold Accepting

TS: Tabu Search 



\section{Annex II}

Questionnaire for the survey carried out to elicit the stakeholders' preferences about criteria and objectives for sustainable and participatory management of the forests of the Valencian Community 



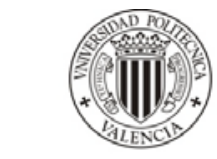

UNIVERSIDAD

POLITECNICA

DE VALENCIA

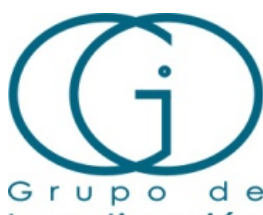

Investigación

Operativa

If you would like to contribute to the development of

\section{A MODEL FOR THE SUSTAINABLE AND} PARTICIPATORY MANAGEMENT OF THE FORESTS OF THE VALENCIAN COMMUNITY,

Please answer the questionnaire.

We recommend that you review the attached data and maps beforehand.

If you prefer to respond via electronic means, the questionnaire can be downloaded at www.upv.es/gio and sent to cmaroto@eio.upv.es 


\section{CRITERIA FOR SUSTAINABLE AND PARTICIPATORY MANAGEMENT OF THE FORESTS OF THE VALENCIAN COMMUNITY 1 \\ Block 1. Identification}

\begin{tabular}{|c|c|c|}
\hline \multicolumn{3}{|l|}{ SECTION 1 - IDENTIFICATION } \\
\hline \multicolumn{3}{|l|}{ 1. Name } \\
\hline \multirow{12}{*}{ 2. Organization } & \multicolumn{2}{|c|}{ Administration } \\
\hline & \multicolumn{2}{|c|}{ Forest Engineer Associations } \\
\hline & \multicolumn{2}{|l|}{ AMUFOR } \\
\hline & \multicolumn{2}{|l|}{ AFOVAL } \\
\hline & \multicolumn{2}{|c|}{ Forestry Company } \\
\hline & \multicolumn{2}{|c|}{ Hunting Federation } \\
\hline & \multicolumn{2}{|c|}{ Fishing Federation } \\
\hline & \multicolumn{2}{|c|}{ Mountain Sports Federation } \\
\hline & \multicolumn{2}{|c|}{ Shepherds Ligallo } \\
\hline & \multicolumn{2}{|l|}{ Avinença } \\
\hline & \multicolumn{2}{|c|}{ Friends of the "Serra Espadà" } \\
\hline & \multicolumn{2}{|c|}{ Other, please indicate } \\
\hline \multirow{2}{*}{ 3. Position } & \multicolumn{2}{|l|}{ Manager } \\
\hline & \multicolumn{2}{|c|}{ Technician } \\
\hline \multicolumn{3}{|l|}{$\begin{array}{l}\text { 4. Number of Members in the } \\
\text { organization }\end{array}$} \\
\hline \multirow{13}{*}{ 5. If Answering personally } & \multirow{5}{*}{ Professor } & Forestry/Forest Engineering \\
\hline & & Agricultural Engineer \\
\hline & & Environmental Sciences \\
\hline & & Business Administration \\
\hline & & Other qualifications \\
\hline & \multirow{5}{*}{ Student } & Forestry/Forest Engineering \\
\hline & & Agricultural Engineering \\
\hline & & Environmental Sciences \\
\hline & & Business Administration \\
\hline & & Other qualifications \\
\hline & \multicolumn{2}{|l|}{ Forester } \\
\hline & \multicolumn{2}{|c|}{ Wildlife expert } \\
\hline & \multicolumn{2}{|c|}{ Other, please indicate } \\
\hline
\end{tabular}

1 The authors acknowledge the support received from the Ministry of Science and Innovation through the research project Modelling and Optimisation Techniques for a Sustainable Development, Ref. EC02008-05895-C02-01/ECON 
Before answering the questionnaire you should understand the scales that are used to measure the comparisons between the criteria and objectives of forest management and which are explained on the next page.

\section{SUSTAINABLE FOREST MANAGEMENT:}

The management and use of forests and forest lands in a manner and at such a rate that they can maintain their biodiversity, productivity, regeneration capacity, vitality and the potential to fulfill, now and in the future, important ecological, economic and social functions at local, national and global levels without causing damage to other ecosystems (Ministerial Conference on the Protection of Forests in Europe,1993)

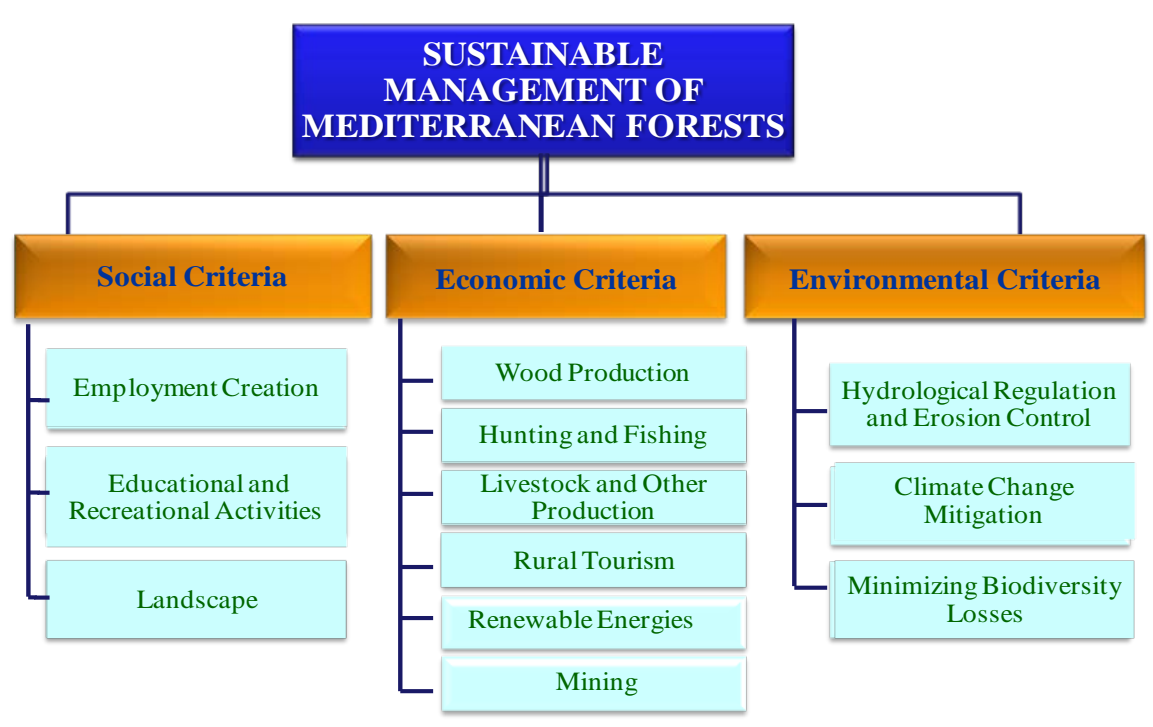


BASIC SCALE OF COMPARISONS BETWEEN PAIRS OF CRITERIA ${ }^{2}$

\begin{tabular}{|c|c|c|}
\hline $\begin{array}{l}\text { Importance or contribution } \\
\text { of one criterion versus } \\
\text { another }\end{array}$ & Definition & Explanation \\
\hline 1 & Equally important & $\begin{array}{l}\text { Two criteria contribute equally to the } \\
\text { objective }\end{array}$ \\
\hline 2 & Weak or slight & intermediate Importance between 1 and 3 \\
\hline 3 & Moderate Importance & $\begin{array}{l}\text { Experience and judgment slightly favour } \\
\text { the first criterion over the other }\end{array}$ \\
\hline 4 & Moderate/strong & Importance between 3 and 5 \\
\hline 5 & Strong importance & $\begin{array}{l}\text { Experience and judgment strongly favour } \\
\text { the first criterion over the other }\end{array}$ \\
\hline 6 & Strong/very strong & Importance between 5 and 7 \\
\hline 7 & $\begin{array}{l}\text { Very strong or } \\
\text { demonstrated } \\
\text { importance }\end{array}$ & $\begin{array}{l}\text { A criterion is favoured very strongly over } \\
\text { another; its dominance is demonstrated in } \\
\text { practice }\end{array}$ \\
\hline 8 & Very, very strong & Importance between 7 and 9 \\
\hline 9 & Extreme importance & $\begin{array}{l}\text { The evidence favouring one criterion over } \\
\text { another is of the highest possible order of } \\
\text { affirmation }\end{array}$ \\
\hline $1 / 21 / 3 \ldots 1 / 81 / 9$ & \multicolumn{2}{|c|}{$\begin{array}{l}\text { If the first criterion has a strong importance compared with a } \\
\text { second test it would be given a } 5 \text { on the scale. } \\
\text { If we were to do the comparison of the second test against the } \\
\text { first value that would be given } 1 / 5\end{array}$} \\
\hline
\end{tabular}

2. Source scale (Saaty, 2008) Decision making with the analytic hierarchy process. Int.J. Services Sciences. Vol. 1.No.1, pp 83-98 
Block 2. Relative Importance of Economic, Social and Environmental Criteria on the Sustainable Management of Forests

\begin{tabular}{|l|c|c|c|c|c|c|c|c|c|}
\hline BLOCK 2 \\
\hline $\begin{array}{l}\text { 6. What importance should social criteria have in } \\
\text { the sustainable management of the forest when } \\
\text { compared to economic criteria? }\end{array}$ & 1 & 2 & 3 & 4 & 5 & 6 & 7 & 8 & 9 \\
\hline $\begin{array}{l}\text { 7. What importance should social criteria have in } \\
\text { the sustainable management of the forest when } \\
\text { compared to environmental criteria? }\end{array}$ & 1 & 2 & 3 & 4 & 5 & 6 & 7 & 8 & 9 \\
\hline & $1 / 2$ & $1 / 3$ & $1 / 4$ & $1 / 5$ & $1 / 6$ & $1 / 7$ & $1 / 8$ & $1 / 9$ \\
\hline $\begin{array}{l}\text { 8. What importance should economic criteria have } \\
\text { in the sustainable management of the forest when } \\
\text { compared to environmental criteria? }\end{array}$ & 1 & 2 & 3 & 4 & 5 & 6 & 7 & 8 & 9 \\
\hline
\end{tabular}

Block 3. Relative contribution of the Objectives to the Social Function of Forests

\begin{tabular}{|c|c|c|c|c|c|c|c|c|c|}
\hline \multicolumn{10}{|l|}{ BLOCK 3} \\
\hline \multirow{2}{*}{$\begin{array}{l}\text { 9. What does employment creation contribute to } \\
\text { the social function of forests when compared to the } \\
\text { recreational and educational activities? }\end{array}$} & \multirow{2}{*}{1} & 2 & 3 & 4 & 5 & 6 & 7 & 8 & 9 \\
\hline & & $1 / 2$ & $1 / 3$ & $1 / 4$ & $1 / 5$ & $1 / 6$ & $1 / 7$ & $1 / 8$ & $1 / 9$ \\
\hline \multirow{2}{*}{$\begin{array}{l}\text { 10. What does employment creation contribute to } \\
\text { the social function of forests when compared to the } \\
\text { landscape? }\end{array}$} & \multirow{2}{*}{1} & 2 & 3 & 4 & 5 & 6 & 7 & 8 & 9 \\
\hline & & $1 / 2$ & $1 / 3$ & $1 / 4$ & $1 / 5$ & $1 / 6$ & $1 / 7$ & $1 / 8$ & $1 / 9$ \\
\hline \multirow{2}{*}{$\begin{array}{l}\text { 11. What do recreational and educational } \\
\text { activities contribute to the social function of forests } \\
\text { when compared with the landscape? }\end{array}$} & \multirow{2}{*}{1} & 2 & 3 & 4 & 5 & 6 & 7 & 8 & 9 \\
\hline & & $1 / 2$ & $1 / 3$ & $1 / 4$ & $1 / 5$ & $1 / 6$ & $1 / 7$ & $1 / 8$ & $1 / 9$ \\
\hline
\end{tabular}




\section{Block 4. Relative contribution of the Objectives to the Economic Function of Forests}

\begin{tabular}{|c|c|c|c|c|c|c|c|c|c|}
\hline \multicolumn{10}{|l|}{ BLOCK 4} \\
\hline \multirow{2}{*}{$\begin{array}{l}\text { 12. How much does wood production contribute to } \\
\text { the economic function of the forest when compared } \\
\text { to hunting and fishing activities? }\end{array}$} & \multirow{2}{*}{1} & 2 & 3 & 4 & 5 & 6 & 7 & 8 & 9 \\
\hline & & $1 / 2$ & $1 / 3$ & $1 / 4$ & $1 / 5$ & $1 / 6$ & $1 / 7$ & $1 / 8$ & $1 / 9$ \\
\hline \multirow{2}{*}{$\begin{array}{l}\text { 13. How much does wood production contribute to } \\
\text { the economic function of the forest when compared } \\
\text { with livestock and other land use (mushrooms, } \\
\text { truffles, beekeeping, aromatic plants, cork, etc.)? }\end{array}$} & \multirow{2}{*}{1} & 2 & 3 & 4 & 5 & 6 & 7 & 8 & 9 \\
\hline & & $1 / 2$ & $1 / 3$ & $1 / 4$ & $1 / 5$ & $1 / 6$ & $1 / 7$ & $1 / 8$ & $1 / 9$ \\
\hline \multirow{2}{*}{$\begin{array}{l}\text { 14. How much does wood production contribute to } \\
\text { the economic function of the forest when compared } \\
\text { with rural tourism? }\end{array}$} & \multirow{2}{*}{1} & 2 & 3 & 4 & 5 & 6 & 7 & 8 & 9 \\
\hline & & $1 / 2$ & $1 / 3$ & $1 / 4$ & $1 / 5$ & $1 / 6$ & $1 / 7$ & $1 / 8$ & $1 / 9$ \\
\hline \multirow{2}{*}{$\begin{array}{l}\text { 15. How much does wood production contribute to } \\
\text { the economic function of the forest when compared } \\
\text { with renewable energies (wind and biomass)? }\end{array}$} & \multirow{2}{*}{1} & 2 & 3 & 4 & 5 & 6 & 7 & 8 & 9 \\
\hline & & $1 / 2$ & $1 / 3$ & $1 / 4$ & $1 / 5$ & $1 / 6$ & $1 / 7$ & $1 / 8$ & $1 / 9$ \\
\hline \multirow{2}{*}{$\begin{array}{l}\text { 16. How much does wood production contribute to } \\
\text { the economic function of the forest when compared } \\
\text { with quarries? }\end{array}$} & \multirow{2}{*}{1} & 2 & 3 & 4 & 5 & 6 & 7 & 8 & 9 \\
\hline & & $1 / 2$ & $1 / 3$ & $1 / 4$ & $1 / 5$ & $1 / 6$ & $1 / 7$ & $1 / 8$ & $1 / 9$ \\
\hline \multirow{2}{*}{$\begin{array}{l}\text { 17. How much does hunting and fishing contribute } \\
\text { to the economic function of the forest when } \\
\text { compared with livestock and other uses } \\
\text { (mushrooms, truffles, beekeeping, aromatic plants, } \\
\text { cork, etc.)? }\end{array}$} & \multirow{2}{*}{1} & 2 & 3 & 4 & 5 & 6 & 7 & 8 & 9 \\
\hline & & $1 / 2$ & $1 / 3$ & $1 / 4$ & $1 / 5$ & $1 / 6$ & $1 / 7$ & $1 / 8$ & $1 / 9$ \\
\hline \multirow{2}{*}{$\begin{array}{l}\text { 18. How much does hunting and fishing contribute } \\
\text { to the economic function of the forest when } \\
\text { compared with rural tourism? }\end{array}$} & \multirow[b]{2}{*}{1} & 2 & 3 & 4 & 5 & 6 & 7 & 8 & 9 \\
\hline & & $1 / 2$ & $1 / 3$ & $1 / 4$ & $1 / 5$ & $1 / 6$ & $1 / 7$ & $1 / 8$ & $1 / 9$ \\
\hline \multirow{2}{*}{$\begin{array}{l}\text { 19. How much does hunting and fishing contribute } \\
\text { to the economic function of the forest when } \\
\text { compared with renewable energy (wind and } \\
\text { biomass)? }\end{array}$} & \multirow[b]{2}{*}{1} & 2 & 3 & 4 & 5 & 6 & 7 & 8 & 9 \\
\hline & & $1 / 2$ & $1 / 3$ & $1 / 4$ & $1 / 5$ & $1 / 6$ & $1 / 7$ & $1 / 8$ & $1 / 9$ \\
\hline \multirow{2}{*}{$\begin{array}{l}\text { 20. How much does hunting and fishing contribute } \\
\text { to the economic function of the forest when } \\
\text { compared with the quarries? }\end{array}$} & \multirow{2}{*}{1} & 2 & 3 & 4 & 5 & 6 & 7 & 8 & 9 \\
\hline & & $1 / 2$ & $1 / 3$ & $1 / 4$ & $1 / 5$ & $1 / 6$ & $1 / 7$ & $1 / 8$ & $1 / 9$ \\
\hline \multirow{2}{*}{$\begin{array}{l}\text { 21. How much does livestock and other uses } \\
\text { (mushrooms, truffles, beekeeping, aromatic plants, } \\
\text { cork, etc.) contribute to the economic function of the } \\
\text { forest when compared with rural tourism? }\end{array}$} & \multirow[b]{2}{*}{1} & 2 & 3 & 4 & 5 & 6 & 7 & 8 & 9 \\
\hline & & $1 / 2$ & $1 / 3$ & $1 / 4$ & $1 / 5$ & $1 / 6$ & $1 / 7$ & $1 / 8$ & $1 / 9$ \\
\hline
\end{tabular}




\begin{tabular}{|c|c|c|c|c|c|c|c|c|c|}
\hline \multirow{2}{*}{$\begin{array}{l}\text { 22. How much does livestock and other uses } \\
\text { (mushrooms, truffles, beekeeping, aromatic plants, } \\
\text { cork, etc.) contribute to the economic function of the } \\
\text { forest when compared with renewable energies } \\
\text { (wind and biomass)? }\end{array}$} & \multirow{2}{*}{1} & 2 & 3 & 4 & 5 & 6 & 7 & 8 & 9 \\
\hline & & $1 / 2$ & $1 / 3$ & $1 / 4$ & $1 / 5$ & $1 / 6$ & $1 / 7$ & $1 / 8$ & $1 / 9$ \\
\hline \multirow{2}{*}{$\begin{array}{l}\text { 23. How much does livestock and other uses } \\
\text { (mushrooms, truffles, beekeeping, aromatic plants, } \\
\text { cork, etc.) contribute to the economic function of the } \\
\text { forest when compared with quarries? }\end{array}$} & \multirow{2}{*}{1} & 2 & 3 & 4 & 5 & 6 & 7 & 8 & 9 \\
\hline & & $1 / 2$ & $1 / 3$ & $1 / 4$ & $1 / 5$ & $1 / 6$ & $1 / 7$ & $1 / 8$ & $1 / 9$ \\
\hline \multirow{2}{*}{$\begin{array}{l}\text { 24. How much does rural tourism contribute to the } \\
\text { economic function of the forest when compared with } \\
\text { renewable energy (wind and biomass)? }\end{array}$} & \multirow{2}{*}{1} & 2 & 3 & 4 & 5 & 6 & 7 & 8 & 9 \\
\hline & & $1 / 2$ & $1 / 3$ & $1 / 4$ & $1 / 5$ & $1 / 6$ & $1 / 7$ & $1 / 8$ & $1 / 9$ \\
\hline \multirow{2}{*}{$\begin{array}{l}\text { 25. How much does rural tourism contribute to the } \\
\text { economic function of the forest when compared with } \\
\text { quarries? }\end{array}$} & & 2 & 3 & 4 & 5 & 6 & 7 & 8 & 9 \\
\hline & & $1 / 2$ & $1 / 3$ & $1 / 4$ & $1 / 5$ & $1 / 6$ & $1 / 7$ & $1 / 8$ & $1 / 9$ \\
\hline \multirow{2}{*}{$\begin{array}{l}\text { 26. How much do renewables (wind and biomass) } \\
\text { contribute to the economic function of the forest } \\
\text { when compared with quarries? }\end{array}$} & \multirow{2}{*}{1} & 2 & 3 & 4 & 5 & 6 & 7 & 8 & 9 \\
\hline & & $1 / 2$ & $1 / 3$ & $1 / 4$ & $1 / 5$ & $1 / 6$ & $1 / 7$ & $1 / 8$ & $1 / 9$ \\
\hline
\end{tabular}


Block 5. Relative Contribution of the objectives to the Environmental function of the forest

\begin{tabular}{|c|c|c|c|c|c|c|c|c|c|}
\hline \multicolumn{10}{|l|}{ BLOCK 5} \\
\hline \multirow{2}{*}{$\begin{array}{l}\text { 27. How much does water regulation and erosion } \\
\text { control contribute to the environmental function of } \\
\text { the forest when compared to the mitigation of } \\
\text { climate change? }\end{array}$} & \multirow{2}{*}{1} & 2 & 3 & 4 & 5 & 6 & 7 & 8 & 9 \\
\hline & & $1 / 2$ & $1 / 3$ & $1 / 4$ & $1 / 5$ & $1 / 6$ & $1 / 7$ & $1 / 8$ & $1 / 9$ \\
\hline \multirow{2}{*}{$\begin{array}{l}\text { 28. How much does water regulation and erosion } \\
\text { control contribute to the environmental function of } \\
\text { the forest when compared to the minimization of } \\
\text { biodiversity loss? }\end{array}$} & \multirow[b]{2}{*}{1} & 2 & 3 & 4 & 5 & 6 & 7 & 8 & 9 \\
\hline & & $1 / 2$ & $1 / 3$ & $1 / 4$ & $1 / 5$ & $1 / 6$ & $1 / 7$ & $1 / 8$ & $1 / 9$ \\
\hline \multirow{2}{*}{$\begin{array}{l}\text { 29. How much does mitigation of climate change } \\
\text { contribute to the environmental function of the forest } \\
\text { when compared with the minimization of } \\
\text { biodiversity loss? }\end{array}$} & \multirow[b]{2}{*}{1} & 2 & 3 & 4 & 5 & 6 & 7 & 8 & 9 \\
\hline & & $1 / 2$ & $1 / 3$ & $1 / 4$ & $1 / 5$ & $1 / 6$ & $1 / 7$ & $1 / 8$ & $1 / 9$ \\
\hline
\end{tabular}

Block 6. Relative Importance of Social, Economic and Environment Criteria in the Sustainable Management of public forests when directly managed by the Forest Administration

\begin{tabular}{|l|l|l|l|l|l|l|l|l|l|}
\hline BLOCK 6 \\
\hline $\begin{array}{l}\text { 30. How much importance should social criteria } \\
\text { have in the sustained management of the Public } \\
\text { forests when compared to economic criteria? }\end{array}$ & 1 & 2 & 3 & 4 & 5 & 6 & 7 & 8 & 9 \\
\cline { 2 - 16 } & $1 / 2$ & $1 / 3$ & $1 / 4$ & $1 / 5$ & $1 / 6$ & $1 / 7$ & $1 / 8$ & $1 / 9$ \\
\hline $\begin{array}{l}\text { 31. How much importance should social criteria } \\
\text { have in the sustained management of the Public } \\
\text { forests when compared to environmental } \\
\text { criteria? }\end{array}$ & 1 & 2 & 3 & 4 & 5 & 6 & 7 & 8 & 9 \\
\hline $\begin{array}{l}\text { 32. How much importance should economic } \\
\text { criteria have in the sustained management of the } \\
\text { Public forests when compared to environmental } \\
\text { criteria? }\end{array}$ & 1 & 2 & 3 & 4 & 5 & 6 & 7 & 8 & 9 \\
\hline $\begin{array}{l}\text { 33. Would your opinion about the relative importance of the different objectives } \\
\text { change for those public forests that are directly managed by the Forest }\end{array}$ & & YES \\
\hline \begin{tabular}{l} 
Administration? \\
\hline
\end{tabular}
\end{tabular}




\section{Annex III}

Questionnaire for the survey carried out amongst forest experts to quantify the contribution of the action lines to different objectives for forest management in the Valencian Community 



\section{STRATEGIES FOR A SUSTAINABLE AND PARTICIPATORY \\ MANAGEMENT OF THE FOREST IN THE VALENCIAN COMUNITY REGION 2}

\section{Block 1. Identification}

\begin{tabular}{|c|c|c|}
\hline \multicolumn{3}{|c|}{ BLOCK 1 - IDENTIFICATION } \\
\hline 1. & Name & \\
\hline \multirow{7}{*}{2.} & \multirow{7}{*}{ Organisation for which you work } & Administration \\
\hline & & College of Forestry/forest engineering \\
\hline & & AMUFOR \\
\hline & & Public Company \\
\hline & & Private Company \\
\hline & & University \\
\hline & & Other, Please indicate \\
\hline \multirow{3}{*}{\multicolumn{2}{|c|}{ 3. Position }} & Directive position \\
\hline & & Technician \\
\hline & & $\begin{array}{l}\text { Other, } \\
\text { Please } \\
\text { indicate }\end{array}$ \\
\hline
\end{tabular}

Before answering the questionnaire you should understand the scales that are used to measure the relative contribution of the different strategies to reach the objectives of the sustainable management of the forest of the Valencian Comunity (see following page).

\footnotetext{
${ }^{2}$ The authors acknowledge the support received from the Ministry of Science and Innovation through the research project Modelling and Optimisation Techniques for a Sustainable Development, Ref. EC02008-05895-C02-01/ECON
} 


\section{SUSTAINABLE FOREST MANAGEMENT:}

The management and use of forests and forest lands in such a manner and at such a rate that they can maintain their biodiversity, productivity, regeneration capacity, vitality and the potential to fulfil, now and in the future, important ecological, economic and social functions at local, national and global levels without causing damage to other ecosystems (Ministerial Conference on the Protection of Forests in Europe,1993).

\section{BASIC SCALE OF COMPARISONS BETWEEN PAIRS OF CRITERIA ${ }^{2}$}

\begin{tabular}{|c|l|l|}
\hline $\begin{array}{l}\text { Importance or contribution } \\
\text { of one criterion versus } \\
\text { another }\end{array}$ & Definition & Explanation \\
\hline 1 & Equally important & $\begin{array}{l}\text { Two criteria contribute equally to the } \\
\text { bbjective }\end{array}$ \\
\hline 2 & Weak or slight & intermediate Importance between 1 and 3 \\
\hline 3 & Moderate Importance & $\begin{array}{l}\text { Experience and judgment slightly favour } \\
\text { the first criterion over the other }\end{array}$ \\
\hline 4 & Moderate/strong & Importance between 3 and 5 \\
\hline 5 & Strong importance & $\begin{array}{l}\text { Experience and judgment strongly favour } \\
\text { the first criterion over the other }\end{array}$ \\
\hline 6 & Strong/very strong & Importance between 5 and 7 \\
\hline 7 & $\begin{array}{l}\text { Very strong or } \\
\text { demonstrated } \\
\text { importance }\end{array}$ & $\begin{array}{l}\text { A criterion is favoured very strongly over } \\
\text { another; its dominance is demonstrated in } \\
\text { practice }\end{array}$ \\
\hline 8 & Very, very strong & Importance between 7 and 9 \\
\hline 9 & Extreme importance & $\begin{array}{l}\text { The evidence favouring one criterion over } \\
\text { another is of the highest possible order of } \\
\text { affirmation }\end{array}$ \\
\hline $1 / 21 / 3 \ldots 1 / 81 / 9$ & $\begin{array}{l}\text { If the first criterion has a strong importance compared with a } \\
\text { second test it would be given a } \mathbf{5} \text { on the scale. } \\
\text { If we were to do the comparison of the second test against the } \\
\text { first value that would be given } \mathbf{1 / 5}\end{array}$ \\
\hline
\end{tabular}

2. Source scale (Saaty, 2008) Decision making with the analytic hierarchy process. Int.J. Services Sciences. Vol. 1.No.1, pp 83-98 


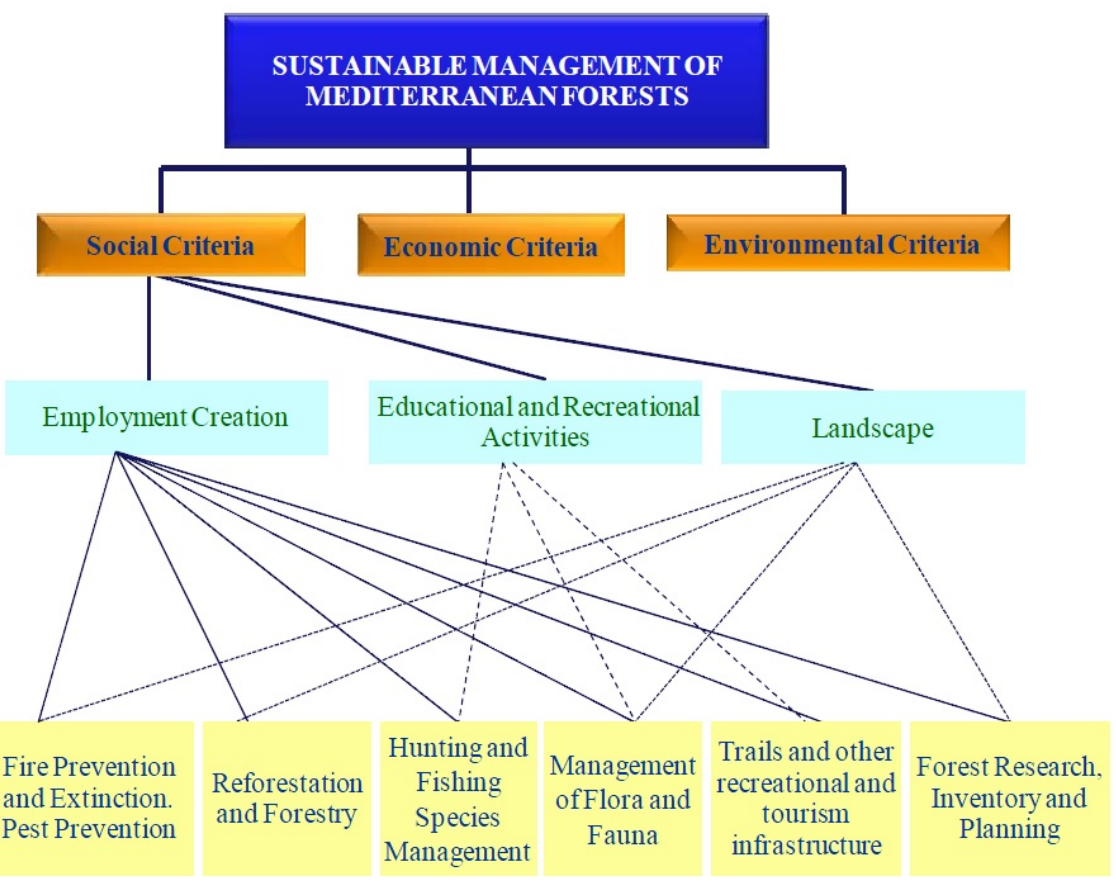

Block 2. Relative Contribution of strategies to achieve the Job Creation objective in the Sustainable Management of the Forest, if we spend the same amount of money on the two strategies compared for each question.

\begin{tabular}{|c|c|c|c|c|c|c|c|c|c|}
\hline \multicolumn{10}{|l|}{ BLOCK 2. OBJECTIVE JOB CREATION } \\
\hline $\begin{array}{l}\text { 4. How much does Prevention and } \\
\text { Firefighting contribute to the Job }\end{array}$ & & 2 & 3 & 4 & 5 & 6 & 7 & 8 & 9 \\
\hline $\begin{array}{l}\text { Creation objective compared with } \\
\text { Reforestation and Forestry? }\end{array}$ & 1 & $1 / 2$ & $1 / 3$ & $1 / 4$ & $1 / 5$ & $1 / 6$ & $1 / 7$ & $1 / 8$ & $1 / 9$ \\
\hline \multirow{2}{*}{$\begin{array}{l}\text { 5. How much does Prevention and } \\
\text { Firefighting contribute compared } \\
\text { with Management of Hunting and } \\
\text { Fishing on the Job Creation } \\
\text { objective? }\end{array}$} & \multirow[b]{2}{*}{1} & 2 & 3 & 4 & 5 & 6 & 7 & 8 & 9 \\
\hline & & $1 / 2$ & $1 / 3$ & $1 / 4$ & $1 / 5$ & $1 / 6$ & $1 / 7$ & $1 / 8$ & $1 / 9$ \\
\hline
\end{tabular}


6. How much does Prevention and Firefighting contribute to the Job Creation objective compared with Flora and Fauna Management?

7. How much does Prevention and Firefighting contribute to the Job Creation objective compared with Paths and other recreational facilities?

8. How much does Prevention and Firefighting contribute to the Job Creation objective compared with Planning, Research and Forest Inventory?

9. How much does Reforestation and Forestry contribute to the Job Creation objective compared with Management of Hunting and Fishing?

10. How much does Reforestation and Forestry contribute to the Job Creation objective compared with Flora and Fauna Management?

11. How much does Reforestation and Forestry contribute to the Job Creation objective compared with Pathways and other recreational infrastructures?

12. How much does Reforestation and Forestry contribute to the Job Creation objective compared with Planning, Research and Forest Inventory?

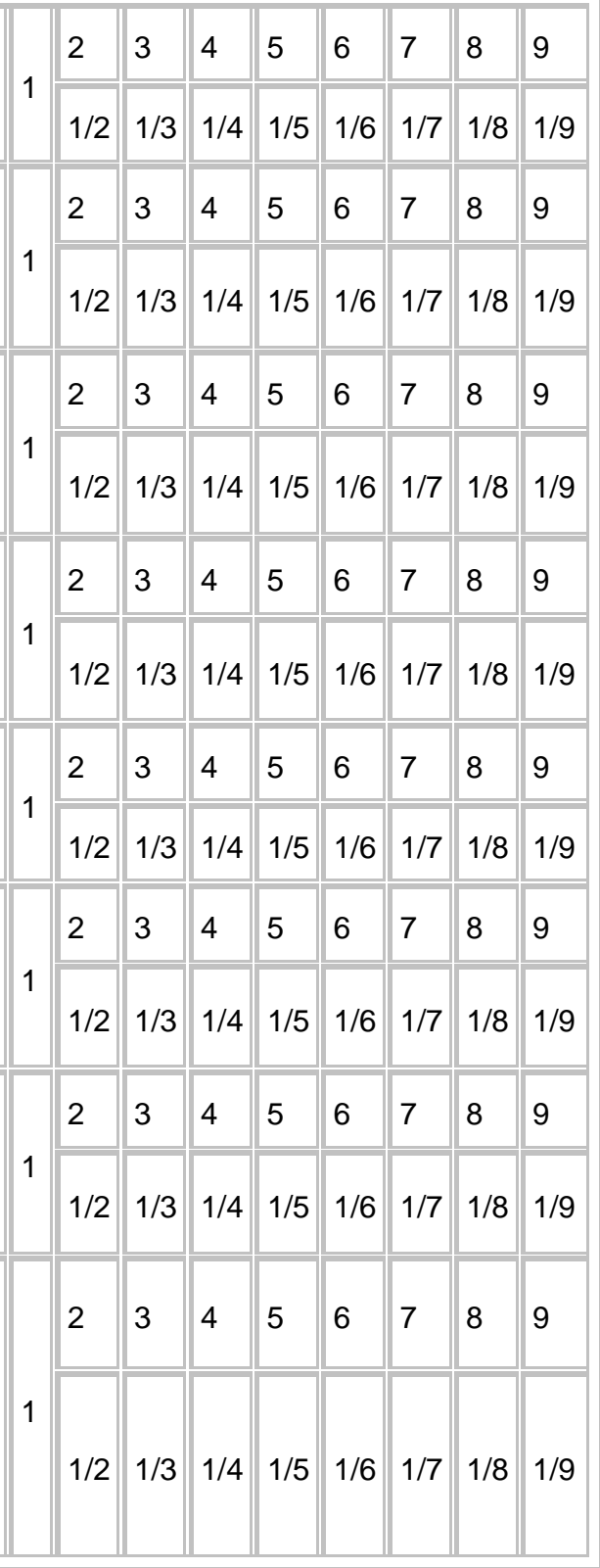

13. How much does Hunting and Fishing Management contribute to the Job Creation objective compared with Flora and Fauna Management? 
14. How much does Hunting and Fishing Management contribute to the Job Creation objective compared with Pathways and other recreational infrastructures?

15. How much does Hunting and Fishing Management contribute to the Job Creation objective compared with Planning, Research and Forest Inventory?

16. How much does Flora and Fauna Management contribute to the Job Creation objective compared with Pathways and other recreational infrastructures?

17. How much does Flora and Fauna Management contribute to the Job Creation objective compared with Planning, Research and Forest Inventory?

18. How much does Pathways and other recreational infrastructures contribute to the Job Creation objective compared with Planning, Research and Forest Inventory?

\begin{tabular}{|c|c|c|c|c|c|c|c|c|}
\hline \multirow{2}{*}{1} & 2 & 3 & 4 & 5 & 6 & 7 & 8 & 9 \\
\hline & $1 / 2$ & $1 / 3$ & $1 / 4$ & $1 / 5$ & $1 / 6$ & $1 / 7$ & $1 / 8$ & $1 / 9$ \\
\hline & 2 & 3 & 4 & 5 & 6 & 7 & 8 & 9 \\
\hline & $1 / 2$ & $1 / 3$ & $1 / 4$ & $1 / 5$ & $1 / 6$ & $1 / 7$ & $1 / 8$ & $1 / 9$ \\
\hline \multirow{2}{*}{1} & 2 & 3 & 4 & 5 & 6 & 7 & 8 & 9 \\
\hline & $1 / 2$ & $1 / 3$ & $1 / 4$ & $1 / 5$ & $1 / 6$ & $1 / 7$ & $1 / 8$ & $1 / 9$ \\
\hline \multirow{2}{*}{1} & 2 & 3 & 4 & 5 & 6 & 7 & 8 & 9 \\
\hline & $1 / 2$ & $1 / 3$ & $1 / 4$ & $1 / 5$ & $1 / 6$ & $1 / 7$ & $1 / 8$ & $1 / 9$ \\
\hline \multirow{2}{*}{1} & 2 & 3 & 4 & 5 & 6 & 7 & 8 & 9 \\
\hline & $1 / 2$ & $1 / 3$ & $1 / 4$ & $1 / 5$ & $1 / 6$ & $1 / 7$ & $1 / 8$ & $1 / 9$ \\
\hline
\end{tabular}

Block 3. Relative Contribution of strategies to achieve the Landscape objective in the Sustainable Management of the Forest, if we spend the same amount of money on the two strategies compared for each question.

BLOCK 3. LANDSCAPE OBJECTIVE

19. How much does Prevention and Firefighting contribute to the Landscape objective compared with the Reforestation and Forestry?

20. How much does Prevention and Firefighting contribute to the Landscape objective compared with Flora y Fauna Management?

\begin{tabular}{|c|c|c|c|c|c|c|c|c|}
\hline \multirow[b]{2}{*}{1} & 2 & 3 & 4 & 5 & 6 & 7 & 8 & 9 \\
\hline & $1 / 2$ & $1 / 3$ & $1 / 4$ & $1 / 5$ & $1 / 6$ & $1 / 7$ & $1 / 8$ & $1 / 9$ \\
\hline \multirow[b]{2}{*}{1} & 2 & 3 & 4 & 5 & 6 & 7 & 8 & 9 \\
\hline & $1 / 2$ & $1 / 3$ & $1 / 4$ & $1 / 5$ & $1 / 6$ & $1 / 7$ & $1 / 8$ & $1 / 9$ \\
\hline
\end{tabular}




\begin{tabular}{|c|c|c|c|c|c|c|c|c|c|c|}
\hline \multirow{2}{*}{\multicolumn{2}{|c|}{$\begin{array}{l}\text { 21. How much does Prevention and } \\
\text { Firefighting contribute to the Landscape } \\
\text { objective compared with Planning, } \\
\text { Research and Forest Inventory? }\end{array}$}} & \multirow[b]{2}{*}{1} & 2 & 3 & 4 & 5 & 6 & 7 & 8 & 9 \\
\hline & & & $1 / 2$ & $1 / 3$ & $1 / 4$ & $1 / 5$ & $1 / 6$ & $1 / 7$ & $1 / 8$ & $1 / 9$ \\
\hline & \multirow{2}{*}{$\begin{array}{l}\text { How much does Reforestation and } \\
\text { Forestry contribute to the Landscape } \\
\text { objective compared with Flora and } \\
\text { Fauna Management? }\end{array}$} & \multirow[b]{2}{*}{1} & 2 & 3 & 4 & 5 & 6 & 7 & 8 & 9 \\
\hline & & & $1 / 2$ & $1 / 3$ & $1 / 4$ & $1 / 5$ & $1 / 6$ & $1 / 7$ & $1 / 8$ & $1 / 9$ \\
\hline \multirow[t]{2}{*}{23.} & \multirow{2}{*}{$\begin{array}{l}\text { How much does Reforestation and } \\
\text { Forestry contribute to the Landscape } \\
\text { objective compared with Planning, } \\
\text { Research and Forest Inventory? }\end{array}$} & \multirow[b]{2}{*}{1} & 2 & 3 & 4 & 5 & 6 & 7 & 8 & 9 \\
\hline & & & $1 / 2$ & $1 / 3$ & $1 / 4$ & $1 / 5$ & $1 / 6$ & $1 / 7$ & $1 / 8$ & $1 / 9$ \\
\hline \multirow{2}{*}{\multicolumn{2}{|c|}{$\begin{array}{l}\text { 24. How much does Flora and Fauna } \\
\text { Management contribute to the Landscape } \\
\text { objective compared with Planning, } \\
\text { Research and Forest Inventory? }\end{array}$}} & \multirow{2}{*}{1} & 2 & 3 & 4 & 5 & 6 & 7 & 8 & 9 \\
\hline & & & $1 / 2$ & $1 / 3$ & $1 / 4$ & $1 / 5$ & $1 / 6$ & $1 / 7$ & $1 / 8$ & $1 / 9$ \\
\hline
\end{tabular}

Block 4. Relative Contribution of strategies to achieve the Educational and Recreational Activities objective in the Sustainable Management of the Forest, if we spend the same amount of money on the two strategies compared for each question.

\section{BLOCK 4. EDUCATIONAL AND RECREATIONAL ACTIVITIES OBJECTIVE}

25. How much does Hunting and Fishing Management contribute to the Educational and Recreational Activities objective compared with Flora and Fauna Management?

26. How much does Hunting and Fishing Management contribute to the Educational and Recreational Activities objective compared with Pathways and other infrastructures?

27. How much does Flora and Fauna Management contribute to the Educational and Recreational Activities objective compared with Pathways and other recreational infrastructures?

\begin{tabular}{|l|l|l|l|l|l|l|l|l|}
\hline 1 & 3 & 4 & 5 & 6 & 7 & 8 & 9 \\
\hline \hline 1 & $1 / 2$ & $1 / 3$ & $1 / 4$ & $1 / 5$ & $1 / 6$ & $1 / 7$ & $1 / 8$ & $1 / 9$ \\
\hline & 2 & 3 & 4 & 5 & 6 & 7 & 8 & 9 \\
\hline \hline 1 & $1 / 2$ & $1 / 3$ & $1 / 4$ & $1 / 5$ & $1 / 6$ & $1 / 7$ & $1 / 8$ & $1 / 9$ \\
\hline & 2 & 3 & 4 & 5 & 6 & 7 & 8 & 9 \\
\hline 1 & $1 / 2$ & $1 / 3$ & $1 / 4$ & $1 / 5$ & $1 / 6$ & $1 / 7$ & $1 / 8$ & $1 / 9$ \\
\hline
\end{tabular}




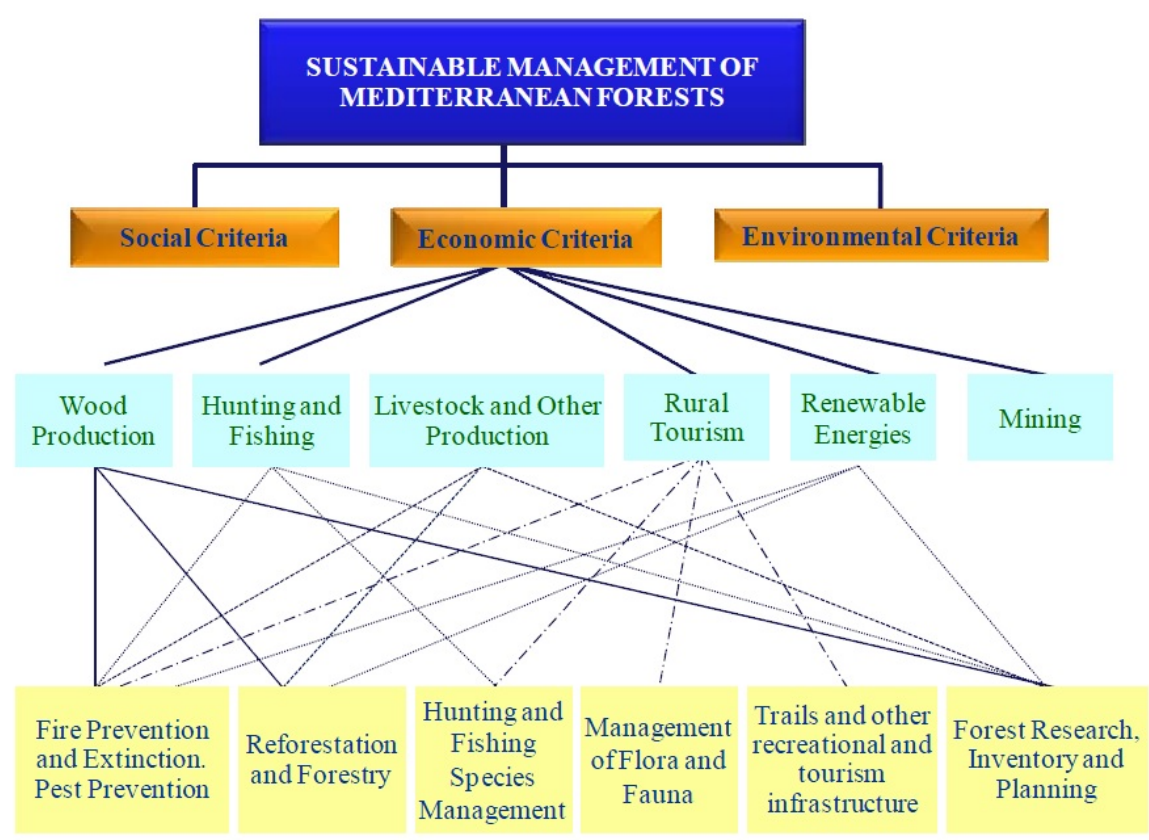

Block 5. Relative Contribution of strategies to achieve the Wood Production objective in the Sustainable Management of the Forest, if we spend the same amount of money on the two strategies compared for each question.

\section{BLOCK 5. WOOD PRODUCTION OBJECTIVE}

28. How much does Prevention and Firefighting contribute to the Wood Production objective compared with Reforestation and Forestry?

29. How much does Prevention and Firefighting contribute to the Wood Production objective compared with Planning, Research and Forestry Inventory?

30. How much does Reforestation and Forestry contribute to the Wood Production objective compared with Planning, Research and Forestry Inventory?

\begin{tabular}{|c|c|c|c|c|c|c|c|c|}
\hline \multirow{2}{*}{1} & 2 & 3 & 4 & 5 & 6 & 7 & 8 & 9 \\
\hline & $1 / 2$ & $1 / 3$ & $1 / 4$ & $1 / 5$ & $1 / 6$ & $1 / 7$ & $1 / 8$ & $1 / 9$ \\
\hline & 2 & 3 & 4 & 5 & 6 & 7 & 8 & 9 \\
\hline & $1 / 2$ & $1 / 3$ & $1 / 4$ & $1 / 5$ & $1 / 6$ & $1 / 7$ & $1 / 8$ & $1 / 9$ \\
\hline \multirow{2}{*}{1} & 2 & 3 & 4 & 5 & 6 & 7 & 8 & 9 \\
\hline & $1 / 2$ & $1 / 3$ & $1 / 4$ & $1 / 5$ & $1 / 6$ & $1 / 7$ & $1 / 8$ & $1 / 9$ \\
\hline
\end{tabular}


Block 6. Relative Contribution of strategies to achieve the Hunting and Fishing objective in the Sustainable Management of the Forest, if we spend the same amount of money on the two strategies compared for each question

\begin{tabular}{|c|c|c|c|c|c|c|c|c|c|}
\hline \multicolumn{10}{|l|}{ BLOCK 6. OBJECTIVE HUNTING AND FISHING } \\
\hline \multirow{2}{*}{$\begin{array}{l}\text { 31. How much does Prevention and } \\
\text { Firefighting contribute to the Hunting } \\
\text { and Fishing objective compared with } \\
\text { Reforestation and Forestry? }\end{array}$} & & 2 & 3 & 4 & 5 & 6 & 7 & 8 & 9 \\
\hline & & $1 / 2$ & $1 / 3$ & $1 / 4$ & $1 / 5$ & $1 / 6$ & $1 / 7$ & $1 / 8$ & $1 / 9$ \\
\hline \multirow{2}{*}{$\begin{array}{l}\text { 32. How much does Prevention and } \\
\text { Firefighting contribute to the Hunting } \\
\text { and Fishing objective compared with } \\
\text { Hunting and Fishing Species } \\
\text { Management? }\end{array}$} & \multirow[b]{2}{*}{1} & 2 & 3 & 4 & 5 & 6 & 7 & 8 & 9 \\
\hline & & $1 / 2$ & $1 / 3$ & $1 / 4$ & $1 / 5$ & $1 / 6$ & $1 / 7$ & $1 / 8$ & $1 / 9$ \\
\hline \multirow{2}{*}{$\begin{array}{l}\text { 33. How much does Prevention and } \\
\text { Firefighting contribute to the Hunting } \\
\text { and Fishing objective compared with } \\
\text { Planning, Research and Forestry } \\
\text { Inventory? }\end{array}$} & \multirow[b]{2}{*}{1} & 2 & 3 & 4 & 5 & 6 & 7 & 8 & 9 \\
\hline & & $1 / 2$ & $1 / 3$ & $1 / 4$ & $1 / 5$ & $1 / 6$ & $1 / 7$ & $1 / 8$ & $1 / 9$ \\
\hline \multirow{2}{*}{$\begin{array}{l}\text { 34. How much does Reforestation and } \\
\text { Forestry contribute to the Hunting and } \\
\text { Fishing objective compared with } \\
\text { Hunting and Fishing Species }\end{array}$} & \multirow[b]{2}{*}{1} & 2 & 3 & 4 & 5 & 6 & 7 & 8 & 9 \\
\hline & & $1 / 2$ & $1 / 3$ & $1 / 4$ & $1 / 5$ & $1 / 6$ & $1 / 7$ & $1 / 8$ & $1 / 9$ \\
\hline \multirow{2}{*}{$\begin{array}{l}\text { 35. How much does Reforestation and } \\
\text { Forestry contribute to the Hunting and } \\
\text { Fishing objective compared with } \\
\text { Planning, Research and Forestry } \\
\text { Inventory? }\end{array}$} & \multirow[b]{2}{*}{1} & 2 & 3 & 4 & 5 & 6 & 7 & 8 & 9 \\
\hline & & $1 / 2$ & $1 / 3$ & $1 / 4$ & $1 / 5$ & $1 / 6$ & $1 / 7$ & $1 / 8$ & $1 / 9$ \\
\hline \multirow{2}{*}{$\begin{array}{l}\text { 36. How much does Hunting and Fishing } \\
\text { Species Management contribute to } \\
\text { the Hunting and Fishing objective } \\
\text { compared with Planning, Research } \\
\text { and Forestry Inventory? }\end{array}$} & \multirow[b]{2}{*}{1} & 2 & 3 & 4 & 5 & 6 & 7 & 8 & 9 \\
\hline & & $1 / 2$ & $1 / 3$ & $1 / 4$ & $1 / 5$ & $1 / 6$ & $1 / 7$ & $1 / 8$ & $1 / 9$ \\
\hline
\end{tabular}


Block 7. Relative Contribution of strategies to achieve the Livestock and other Productions objective in the Sustainable Management of the Forest, if we spend the same amount of money on the two strategies compared for each question.

\begin{tabular}{|c|c|c|c|c|c|c|c|c|c|}
\hline \multicolumn{10}{|c|}{ BLOCK 7. LIVESTOCK AND OTHER PRODUCTIONS OBJECTIVE } \\
\hline \multirow{2}{*}{$\begin{array}{l}\text { 37. How much does Prevention and } \\
\text { Firefighting contribute to the Livestock } \\
\text { and other Productions objective } \\
\text { compared with Reforestation and } \\
\text { Forestry? }\end{array}$} & & 2 & 3 & 4 & 5 & 6 & 7 & 8 & 9 \\
\hline & 1 & $1 / 2$ & $1 / 3$ & $1 / 4$ & $1 / 5$ & $1 / 6$ & $1 / 7$ & $1 / 8$ & $1 / 9$ \\
\hline \multirow{2}{*}{$\begin{array}{l}\text { 38. How much does Prevention and } \\
\text { Firefighting contribute to the Livestock } \\
\text { and other Productions objective } \\
\text { compared with Planning, Research } \\
\text { and Forestry Inventory? }\end{array}$} & & 2 & 3 & 4 & 5 & 6 & 7 & 8 & 9 \\
\hline & 1 & $1 / 2$ & $1 / 3$ & $1 / 4$ & $1 / 5$ & $1 / 6$ & $1 / 7$ & $1 / 8$ & $1 / 9$ \\
\hline \multirow{2}{*}{$\begin{array}{l}\text { 39. How much does Reforestation and } \\
\text { Forestry contribute to the Livestock } \\
\text { and other Productions objective } \\
\text { compared with Planning, Research } \\
\text { and Forestry Inventory? }\end{array}$} & & 2 & 3 & 4 & 5 & 6 & 7 & 8 & 9 \\
\hline & 1 & $1 / 2$ & $1 / 3$ & $1 / 4$ & $1 / 5$ & $1 / 6$ & $1 / 7$ & $1 / 8$ & $1 / 9$ \\
\hline
\end{tabular}

Block 8. Relative Contribution of strategies to achieve the Rural Tourism objective in the Sustainable Management of the Forest, if we spend the same amount of money on the two strategies compared for each question.

\begin{tabular}{|c|c|c|c|c|c|c|c|c|c|}
\hline \multicolumn{10}{|l|}{ BLOCK 8. RURAL TOURISM OBJECTIVE } \\
\hline \multirow{2}{*}{$\begin{array}{l}\text { 40. How much does Prevention and } \\
\text { Firefighting contribute to the Rural } \\
\text { Tourism objective compared Hunting } \\
\text { and Fishing Species Management? }\end{array}$} & & 2 & 3 & 4 & 5 & 6 & 7 & 8 & 9 \\
\hline & 1 & $1 / 2$ & $1 / 3$ & $1 / 4$ & $1 / 5$ & $1 / 6$ & $1 / 7$ & $1 / 8$ & $1 / 9$ \\
\hline \multirow{2}{*}{$\begin{array}{l}\text { 41. How much does Prevention and } \\
\text { Firefighting contribute to the Rural } \\
\text { Tourism objective compared with Flora } \\
\text { and Fauna Management? }\end{array}$} & & 2 & 3 & 4 & 5 & 6 & 7 & 8 & 9 \\
\hline & 1 & $1 / 2$ & $1 / 3$ & $1 / 4$ & $1 / 5$ & $1 / 6$ & $1 / 7$ & $1 / 8$ & $1 / 9$ \\
\hline \multirow{2}{*}{$\begin{array}{l}\text { 42. How much does Prevention and } \\
\text { Firefighting contribute to the Rural } \\
\text { Tourism objective compared with } \\
\text { Pathways and other Recreational } \\
\text { Infrastructures? }\end{array}$} & & 2 & 3 & 4 & 5 & 6 & 7 & 8 & 9 \\
\hline & 1 & $1 / 2$ & $1 / 3$ & $1 / 4$ & $1 / 5$ & $1 / 6$ & $1 / 7$ & $1 / 8$ & $1 / 9$ \\
\hline \multirow{2}{*}{$\begin{array}{l}\text { 43. How much does Hunting and Fishing } \\
\text { Species Management contribute to } \\
\text { the Rural Tourism objective compared } \\
\text { with Flora and Fauna Management? }\end{array}$} & & 2 & 3 & 4 & 5 & 6 & 7 & 8 & 9 \\
\hline & 1 & $1 / 2$ & $1 / 3$ & $1 / 4$ & $1 / 5$ & $1 / 6$ & $1 / 7$ & $1 / 8$ & $1 / 9$ \\
\hline
\end{tabular}




\begin{tabular}{|c|c|c|c|c|c|c|c|c|c|c|}
\hline \multirow{2}{*}{\multicolumn{2}{|c|}{$\begin{array}{l}\text { 44. How much does Hunting and Fishing } \\
\text { Species Management contribute to } \\
\text { the Rural Tourism objective compared } \\
\text { with Pathways and other } \\
\text { Recreational Infrastructures? }\end{array}$}} & \multirow[b]{2}{*}{1} & 2 & 3 & 4 & 5 & 6 & 7 & 8 & 9 \\
\hline & & & $1 / 2$ & $1 / 3$ & $1 / 4$ & $1 / 5$ & $1 / 6$ & $1 / 7$ & $1 / 8$ & $1 / 9$ \\
\hline & $\begin{array}{l}\text { How much does Flora and Fauna } \\
\text { Species Management contribute to }\end{array}$ & \multirow[b]{2}{*}{1} & 2 & 3 & 4 & 5 & 6 & 7 & 8 & 9 \\
\hline & $\begin{array}{l}\text { with Pathways and other } \\
\text { Recreational } \\
\text { Management? }\end{array}$ & & $1 / 2$ & $1 / 3$ & $1 / 4$ & $1 / 5$ & $1 / 6$ & $1 / 7$ & $1 / 8$ & $1 / 9$ \\
\hline
\end{tabular}

Block 9. Relative Contribution of strategies to achieve the Renewable Energy objective in Sustainable Management of the Forest, if we spend the same amount of money on the two strategies compared for each question.

\begin{tabular}{|c|c|c|c|c|c|c|c|c|c|}
\hline \multicolumn{10}{|c|}{ BLOCK 9. RENEWABLE ENERGY OBJECTIVE (Biomass and Eolic Energy) } \\
\hline \multirow{2}{*}{$\begin{array}{l}\text { 46. How much does Prevention and } \\
\text { Firefighting contribute to the } \\
\text { Renewable Energy objective } \\
\text { compared to Reforestation and } \\
\text { Forestry? }\end{array}$} & \multirow[b]{2}{*}{1} & 2 & 3 & 4 & 5 & 6 & 7 & 8 & 9 \\
\hline & & $1 / 2$ & $1 / 3$ & $1 / 4$ & $1 / 5$ & $1 / 6$ & $1 / 7$ & $1 / 8$ & $1 / 9$ \\
\hline \multirow{2}{*}{$\begin{array}{l}\text { 47. How much does Prevention and } \\
\text { Firefighting contribute to the } \\
\text { Renewable Energy objective } \\
\text { compared to Planning, Research and } \\
\text { Forestry Inventory? }\end{array}$} & & 2 & 3 & 4 & 5 & 6 & 7 & 8 & 9 \\
\hline & 1 & $1 / 2$ & $1 / 3$ & $1 / 4$ & $1 / 5$ & $1 / 6$ & $1 / 7$ & $1 / 8$ & $1 / 9$ \\
\hline \multirow{2}{*}{$\begin{array}{l}\text { 48. How much does Reforestation and } \\
\text { Forestry contribute to the Renewable } \\
\text { Energy objective compared to } \\
\text { Planning, Research and Forestry } \\
\text { Inventory? }\end{array}$} & \multirow[b]{2}{*}{1} & 2 & 3 & 4 & 5 & 6 & 7 & 8 & 9 \\
\hline & & $1 / 2$ & $1 / 3$ & $1 / 4$ & $1 / 5$ & $1 / 6$ & $1 / 7$ & $1 / 8$ & $1 / 9$ \\
\hline
\end{tabular}




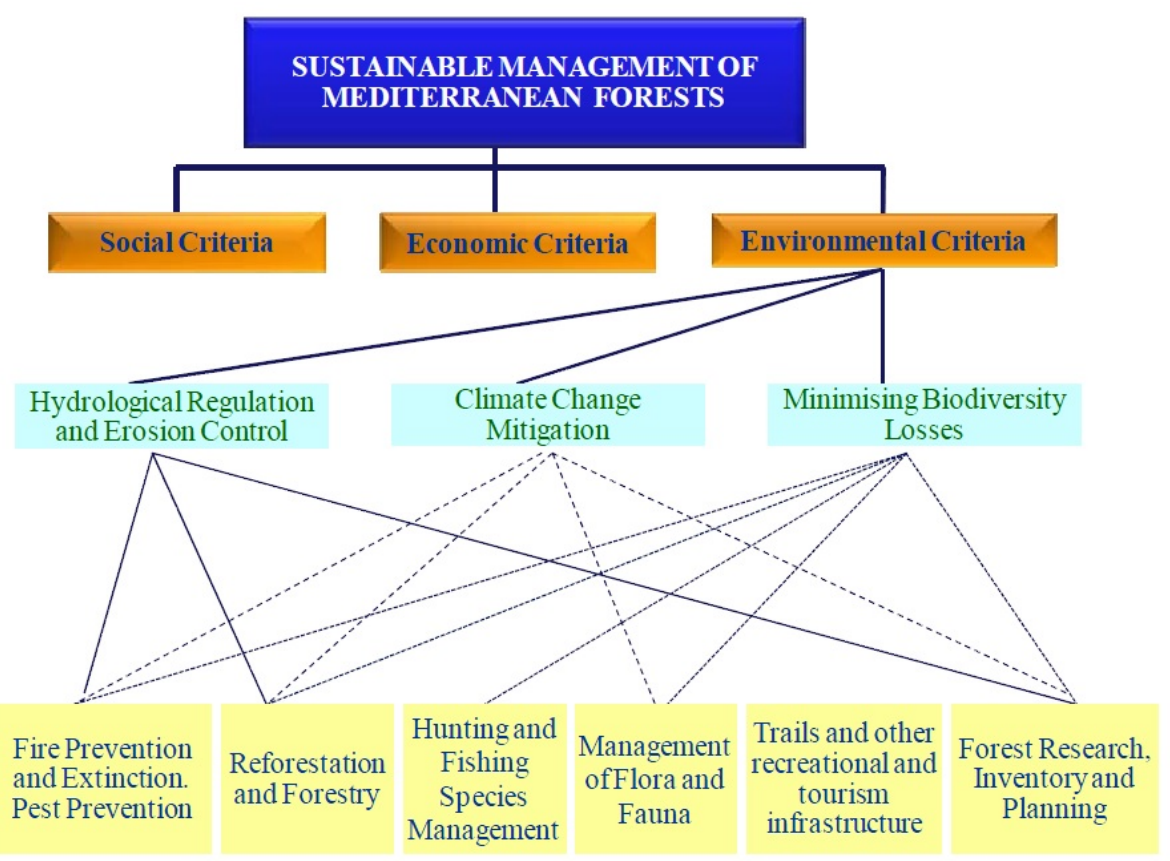

Block 10. Relative Contribution of strategies to achieve the Water Regulation and Erosion Control objective in Sustainable Management of the Forest, if we spend the same amount of money on the two strategies compared for each question.

\begin{tabular}{|c|c|c|c|c|c|c|c|c|c|}
\hline \multicolumn{10}{|c|}{ BLOCK 10. WATER REGULATION AND EROSION CONTROL OBJECTIVE } \\
\hline \multirow{2}{*}{$\begin{array}{l}\text { 49. How much does Prevention and } \\
\text { Firefighting contribute to the Water } \\
\text { Regulation and Erosion Control } \\
\text { objective compared to Reforestation } \\
\text { and Forestry? }\end{array}$} & & 2 & 3 & 4 & 5 & 6 & 7 & 8 & 9 \\
\hline & 1 & $1 / 2$ & $1 / 3$ & $1 / 4$ & $1 / 5$ & $1 / 6$ & $1 / 7$ & $1 / 8$ & $1 / 9$ \\
\hline \multirow{2}{*}{$\begin{array}{l}\text { 50. How much does Prevention and } \\
\text { Firefighting contribute to the Water } \\
\text { Regulation and Erosion Control } \\
\text { objective compared to Planning, } \\
\text { Research and Forestry Inventory? }\end{array}$} & & 2 & 3 & 4 & 5 & 6 & 7 & 8 & 9 \\
\hline & 1 & $1 / 2$ & $1 / 3$ & $1 / 4$ & $1 / 5$ & $1 / 6$ & $1 / 7$ & $1 / 8$ & $1 / 9$ \\
\hline \multirow{2}{*}{$\begin{array}{l}\text { 51. How much does Reforestation and } \\
\text { Forestry contribute to the Water } \\
\text { Regulation and Erosion Control } \\
\text { objective compared to Planning, } \\
\text { Research and Forestry Inventory? }\end{array}$} & \multirow[b]{2}{*}{1} & 2 & 3 & 4 & 5 & 6 & 7 & 8 & 9 \\
\hline & & $1 / 2$ & $1 / 3$ & $1 / 4$ & $1 / 5$ & $1 / 6$ & $1 / 7$ & $1 / 8$ & $1 / 9$ \\
\hline
\end{tabular}


Block 11. Relative Contribution of strategies to achieve the Climate Change Mitigation objective in Sustainable Management of the Forest, if we spend the same amount of money on the two strategies compared for each question.

\begin{tabular}{|c|c|c|c|c|c|c|c|c|c|}
\hline \multicolumn{10}{|c|}{ BLOCK 11. CLIMATE CHANGE MITIGATION OBJECTIVE } \\
\hline \multirow{2}{*}{$\begin{array}{l}\text { 52. How much does Prevention and } \\
\text { Firefighting contribute to the Climate } \\
\text { Change Mitigation objective compared } \\
\text { to Reforestation and Forestry? }\end{array}$} & & 2 & 3 & 4 & 5 & 6 & 7 & 8 & 9 \\
\hline & & $1 / 2$ & $1 / 3$ & $1 / 4$ & $1 / 5$ & $1 / 6$ & $1 / 7$ & $1 / 8$ & $1 / 9$ \\
\hline \multirow{2}{*}{$\begin{array}{l}\text { 53. How much does Prevention and } \\
\text { Firefighting contribute to the Climate } \\
\text { Change Mitigation objective compared } \\
\text { to Flora and Fauna Management? }\end{array}$} & \multirow[b]{2}{*}{1} & 2 & 3 & 4 & 5 & 6 & 7 & 8 & 9 \\
\hline & & $1 / 2$ & $1 / 3$ & $1 / 4$ & $1 / 5$ & $1 / 6$ & $1 / 7$ & $1 / 8$ & $1 / 9$ \\
\hline \multirow{2}{*}{$\begin{array}{l}\text { 54. How much does Prevention and } \\
\text { Firefighting contribute to the Climate } \\
\text { Change Mitigation objective compared } \\
\text { to Planning, Research and Forestry } \\
\text { Inventory? }\end{array}$} & \multirow[b]{2}{*}{1} & 2 & 3 & 4 & 5 & 6 & 7 & 8 & 9 \\
\hline & & $1 / 2$ & $1 / 3$ & $1 / 4$ & $1 / 5$ & $1 / 6$ & $1 / 7$ & $1 / 8$ & $1 / 9$ \\
\hline \multirow{2}{*}{$\begin{array}{l}\text { 55. How much does Reforestation and } \\
\text { Forestry contribute to the Climate } \\
\text { Change Mitigation objective compared } \\
\text { to Flora and Fauna Management? }\end{array}$} & \multirow[b]{2}{*}{1} & 2 & 3 & 4 & 5 & 6 & 7 & 8 & 9 \\
\hline & & $1 / 2$ & $1 / 3$ & $1 / 4$ & $1 / 5$ & $1 / 6$ & $1 / 7$ & $1 / 8$ & $1 / 9$ \\
\hline \multirow{2}{*}{$\begin{array}{l}\text { 56. How much does Reforestation and } \\
\text { Forestry contribute to the Climate } \\
\text { Change Mitigation objective compared } \\
\text { to Planning, Research and Forestry } \\
\text { Inventory? }\end{array}$} & & 2 & 3 & 4 & 5 & 6 & 7 & 8 & 9 \\
\hline & & $1 / 2$ & $1 / 3$ & $1 / 4$ & $1 / 5$ & $1 / 6$ & $1 / 7$ & $1 / 8$ & $1 / 9$ \\
\hline \multirow{2}{*}{$\begin{array}{l}\text { 57. How much does Flora and Fauna } \\
\text { Management contribute to the Climate } \\
\text { Change Mitigation objective compared } \\
\text { to Planning, Research and Forestry } \\
\text { Inventory? }\end{array}$} & \multirow[b]{2}{*}{1} & 2 & 3 & 4 & 5 & 6 & 7 & 8 & 9 \\
\hline & & $1 / 2$ & $1 / 3$ & $1 / 4$ & $1 / 5$ & $1 / 6$ & $1 / 7$ & $1 / 8$ & $1 / 9$ \\
\hline
\end{tabular}

Block 12. Relative Contribution of strategies to achieve the Biodiversity Loss Minimisation objective in Sustainable Management of the Forest, if we spend the same amount of money on the two strategies compared for each question.

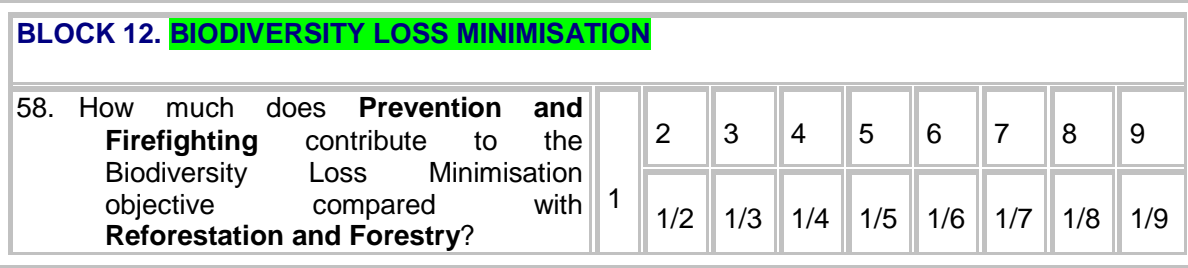




\begin{tabular}{|c|c|c|c|c|c|c|c|c|c|c|}
\hline \multicolumn{2}{|r|}{$\begin{array}{l}\text { 59. How much does Prevention and } \\
\text { Firefighting contribute to the } \\
\text { Biodiversity Loss Minimisation } \\
\text { objective compared with Hunting and } \\
\text { Fishing Species Management }\end{array}$} & 1 & 2 & $1 / 3$ & 4 & 5 & 6 & 7 & 8 & 9 \\
\hline 60. & $\begin{array}{l}\text { How much does Prevention and } \\
\text { Firefighting contribute to the }\end{array}$ & \multirow[b]{2}{*}{1} & 2 & 3 & 4 & 5 & 6 & 7 & 8 & 9 \\
\hline & $\begin{array}{l}\text { Biodiversity Loss Minimisation } \\
\text { objective compared with Flora and } \\
\text { Fauna Management? }\end{array}$ & & $1 / 2$ & $1 / 3$ & $1 / 4$ & $1 / 5$ & $1 / 6$ & $1 / 7$ & $1 / 8$ & $1 / 9$ \\
\hline \multirow[t]{2}{*}{61.} & $\begin{array}{l}\text { How much does Prevention and } \\
\text { Firefighting contribute to the }\end{array}$ & \multirow[b]{2}{*}{1} & 2 & 3 & 4 & 5 & 6 & 7 & 8 & 9 \\
\hline & $\begin{array}{l}\text { Biodiversity Loss Minimisation } \\
\text { objective compared with Planning, } \\
\text { Research and Forestry Inventory? }\end{array}$ & & $1 / 2$ & $1 / 3$ & $1 / 4$ & $1 / 5$ & $1 / 6$ & $1 / 7$ & $1 / 8$ & $1 / 9$ \\
\hline \multirow[t]{2}{*}{62.} & $\begin{array}{l}\text { How much does Reforestation and } \\
\text { Forestry contribute to the Biodiversity }\end{array}$ & \multirow{2}{*}{1} & 2 & 3 & 4 & 5 & 6 & 7 & 8 & 9 \\
\hline & $\begin{array}{l}\text { with Hunting and Fishing Species } \\
\text { Management? }\end{array}$ & & $1 / 2$ & $1 / 3$ & $1 / 4$ & $1 / 5$ & $1 / 6$ & $1 / 7$ & $1 / 8$ & $1 / 9$ \\
\hline \multirow[t]{2}{*}{63.} & $\begin{array}{l}\text { How much does Reforestation and } \\
\text { Forestry contribute to the Biodiversity }\end{array}$ & \multirow[b]{2}{*}{1} & 2 & 3 & 4 & 5 & 6 & 7 & 8 & 9 \\
\hline & $\begin{array}{l}\text { Loss Minimisation objective compared } \\
\text { with Flora and Fauna Management? }\end{array}$ & & || $1 / 2$ & $1 / 3$ & $1 / 4$ & $1 / 5$ & $1 / 6$ & $1 / 7$ & $1 / 8$ & $1 / 9$ \\
\hline \multirow[t]{2}{*}{64.} & $\begin{array}{l}\text { How much does Reforestation and } \\
\text { Forestry contribute to the Biodiversity }\end{array}$ & \multirow{2}{*}{1} & 2 & 3 & 4 & 5 & 6 & 7 & 8 & 9 \\
\hline & $\begin{array}{l}\text { Loss Minimisation objective compared } \\
\text { with Planning, Research and } \\
\text { Forestry Inventory? }\end{array}$ & & $1 / 2$ & $1 / 3$ & $1 / 4$ & $1 / 5$ & $1 / 6$ & $1 / 7$ & $1 / 8$ & $1 / 9$ \\
\hline \multirow[t]{2}{*}{65.} & $\begin{array}{l}\text { How much does Hunting and Fishing } \\
\text { Species Management contribute to }\end{array}$ & \multirow{2}{*}{1} & 2 & 3 & 4 & 5 & 6 & 7 & 8 & 9 \\
\hline & $\begin{array}{l}\text { the Biodiversity Loss Minimisation } \\
\text { objective compared with Flora and } \\
\text { Fauna Management? }\end{array}$ & & $1 / 2$ & $1 / 3$ & $1 / 4$ & $1 / 5$ & $1 / 6$ & $1 / 7$ & $1 / 8$ & $1 / 9$ \\
\hline \multirow[t]{2}{*}{66.} & $\begin{array}{l}\text { How much does Hunting and Fishing } \\
\text { Species Management contribute to }\end{array}$ & & 2 & 3 & 4 & 5 & 6 & 7 & 8 & 9 \\
\hline & $\begin{array}{l}\text { objective compared with Planning, } \\
\text { Research and Forestry Inventory? }\end{array}$ & & $1 / 2$ & $1 / 3$ & $1 / 4$ & $1 / 5$ & $1 / 6$ & $1 / 7$ & $1 / 8$ & $1 / 9$ \\
\hline \multirow[t]{3}{*}{67.} & $\begin{array}{l}\text { How much does Flora and Fauna } \\
\text { Management? contribute to the }\end{array}$ & \multirow{3}{*}{$\perp$} & 2 & 3 & 4 & 5 & 6 & 7 & 8 & 9 \\
\hline & $\begin{array}{l}\text { Biodiversity Loss Minimisation } \\
\text { objective compared with Planning, }\end{array}$ & & $1 / 2$ & $1 / 3$ & $1 / 4$ & $1 / 5$ & $1 / 6$ & $1 / 7$ & $1 / 8$ & $1 / 9$ \\
\hline & $h$ and Forestry & & $1 / 2$ & $1 / 3$ & $1 / 4$ & $1 / 5$ & $1 / 6$ & $1 / 7$ & $1 / 8$ & $1 / 9$ \\
\hline
\end{tabular}





\section{Annex IV}

Goal Programming models to aggregate stakeholders' preferences from comparison matrices and to obtain weights of criteria 

In this annex we summarise Goal Programming Models, an alternative method to AHP, to aggregate stakeholder preferences from comparison matrices and to obtain weights of criteria. From individual stakeholder matrices we have obtained a consensus matrix for each group using the Extended Goal Programming model developed by GonzálezPachón and Romero (2007). The decision variables of this model are the following:

$R_{i j}{ }^{C}=$ Consensus ratio value that quantifies the aggregated preference when the ith criterion is compared with the $j$ th criterion.

$N_{i j}{ }^{K}$ and $P_{i j}{ }^{K}$ Negative and Positive deviation variables of the goal when stakeholder $k$ is comparing criteria $i$ and $j$.

$D=$ Maximum disagreement of stakeholders with respect to the values of the consensus matrix.

Consensus ratio variables have lower and upper bounds (1), due to Saaty's scale which we have used.

$$
0.111 \leq R_{i j}{ }^{C} \leq 9 \quad i, j=1,2, \ldots n
$$

If the consensus ratio value between two criteria is different from a stakeholder $k$ value, this difference is the Negative or Positive deviation variables, as the model goals indicate (2).

$$
R_{i j}{ }^{C}+N_{i j}{ }^{K}=R_{i j}{ }^{K}+P_{i j}{ }^{K} \quad i, j=1,2, \ldots n \quad i \neq j \quad k=1,2, \ldots m
$$

The sum of all deviation variables of stakeholder $k$ is equal to or less than $D$, with as many restrictions as there are stakeholders (3).

$$
\sum_{j=1}^{n} \sum_{i=1}^{n}\left(N_{i j}^{k}+P_{i j}^{k}\right) \leq D \quad i, j=1,2, \ldots n \quad k=1,2, \ldots m
$$


The achievement function is the following:

$\operatorname{MIN}(1-\lambda) D+\lambda\left(\sum_{j=1}^{n} \sum_{i=1}^{n} \sum_{k=1}^{m}\left(N_{i j}^{k}+P_{i j}^{k}\right)\right) \quad i, j=1,2, \ldots n i \neq j \quad k=1,2, \ldots m$

where $\lambda$ is a control parameter. If $\lambda=1$ we find the consensus matrix that minimizes the sum of all deviations of all stakeholders and that can therefore be considered in order to obtain the best solution from the point of view of most people. If $\lambda=0$ we obtain the best solution from the point of view of the minority.

In the second step, we have derived the weights of the relative importance attached by the ith stakeholder group to the $r$ th criterion from the consensus matrix using another Goal Programming model developed by González-Pachón and Romero (2004). In this model decision variables $W_{r i}$ are the weights attached by the $i t h$ stakeholder group to the $r t h$ criterion. We also have Negative and Positive deviation variables of the goals and $i$ th stakeholder group $(i=1,2 \ldots \mathrm{m})$.

We have goals to link criterion weights with the ratio values of the consensus matrix (5) as follows

$$
W_{r}^{i}+N_{r s}^{i}=R_{r s}{ }^{C i} W_{s i}+P_{r s}{ }^{i} r, s=1,2, \ldots n \quad r \neq s \quad i=1,2, \ldots m
$$

We need to add constraints to reflect that the sum of all weights should be 1 for each stakeholder group i.

$$
\sum_{r=1}^{n} W_{r}^{i}=1 \quad r=1,2, \ldots n \quad i=1,2, \ldots m
$$

The achievement function is minimizing summation of all deviation variables for all criteria (7).

$$
\left.\operatorname{MIN} \sum_{r=1}^{n} \sum_{s=1}^{n}\left(N_{r s}^{i}+P_{r s}^{i}\right)\right) \quad r, s=1,2, \ldots n \quad r \neq s \quad i=1,2, \ldots m
$$




\section{Annex V}

Questionnaire for the survey to identify the preferences for Ecosystem Services in the natural park network of the Valencian Community 


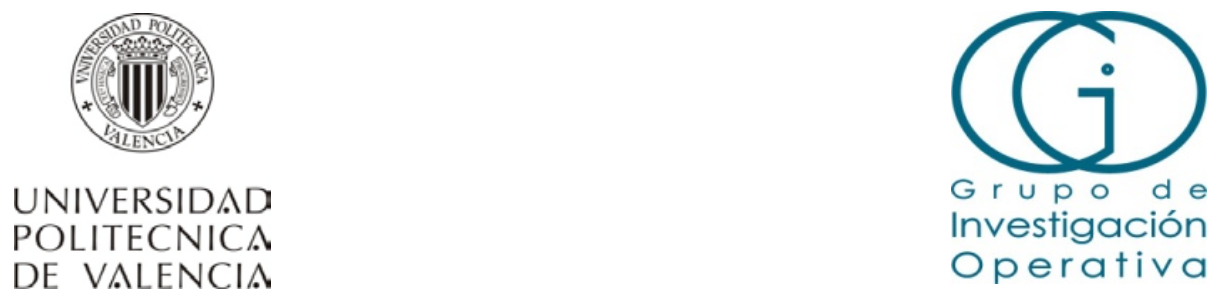

\section{NATURAL PARK NETWORK OF THE VALENCIAN COMMUNITY}

\section{SURVEY TO IDENTIFY PREFERENCES FOR ECOSYSTEM SERVICES}




\section{Block 1. Identification}

\begin{tabular}{|c|c|c|}
\hline 1. Name & & \\
\hline 2. Natural park & $\begin{array}{l}0 \\
0 \\
0 \\
0 \\
0 \\
0 \\
0 \\
0 \\
0 \\
0 \\
0 \\
0 \\
0 \\
0 \\
0 \\
0 \\
0 \\
0 \\
0 \\
0 \\
0 \\
0\end{array}$ & $\begin{array}{l}\text { Chera-Sot de Chera } \\
\text { Desert de les Palmes } \\
\text { El Fondo } \\
\text { El Montgó } \\
\text { Font Roja } \\
\text { Hoces del Cabriel } \\
\text { Illes Columbretes } \\
\text { Lagunas de la Mata Torrevieja } \\
\text { L'Albufera } \\
\text { Marjal de Pego Oliva } \\
\text { Penyagolosa } \\
\text { Penyal d'Ifac } \\
\text { Prat de Cabanes Torreblanca } \\
\text { Puebla de San Miguel } \\
\text { Salines de Santa Pola } \\
\text { Serra Calderona } \\
\text { Serra de Mariola } \\
\text { Serra d'Espadà } \\
\text { Serra d'Irta } \\
\text { Serra Gelada } \\
\text { Tinença de Benifassà } \\
\text { Túria }\end{array}$ \\
\hline 3. Position & $\begin{array}{l}0 \\
0 \\
0 \\
0 \\
0 \\
0 \\
0 \\
0 \\
0 \\
0 \\
0 \\
0 \\
0\end{array}$ & $\begin{array}{l}\text { Director of natural park } \\
\text { Staff of natural park } \\
\text { Administration of natural park } \\
\text { Local/regional government (please indicate) } \\
\text { Unions (please indicate) } \\
\text { Hydrologic confederation (please indicate) } \\
\text { Fishing/hunting federations } \\
\text { Farmer, rancher or shepherd } \\
\text { Sector Partnership company } \\
\text { Mountain sports federations (please indicate) } \\
\text { Local association (please indicate) } \\
\text { University representative (please indicate) } \\
\text { Others (please indicate) }\end{array}$ \\
\hline
\end{tabular}




\section{Block 2. WHAT IS YOUR OPINION ABOUT THE IMPORTANCE OF PRODUCTS AND \\ SERVICES PROVIDED BY THE NATURAL PARK?}

\begin{tabular}{|c|c|c|c|c|}
\hline \multicolumn{5}{|l|}{ A) Raw Materials } \\
\hline & $\begin{array}{c}\text { No } \\
\text { importance }\end{array}$ & $\begin{array}{c}\text { Low } \\
\text { importance }\end{array}$ & $\begin{array}{c}\text { Medium } \\
\text { importance }\end{array}$ & $\begin{array}{c}\text { High } \\
\text { importance }\end{array}$ \\
\hline \multicolumn{5}{|l|}{ 1. Food } \\
\hline \multicolumn{5}{|c|}{$\begin{array}{l}\text { 2. Energy (firewood, } \\
\text { biomass, ...) }\end{array}$} \\
\hline \multicolumn{5}{|c|}{ 3. Genetic Resources } \\
\hline \multicolumn{5}{|c|}{ 4. Industry (wood, ...) } \\
\hline $\begin{array}{l}\text { 5. Other uses } \\
\text { (pharmaceutical, } \\
\text { textile, ...) }\end{array}$ & & & & \\
\hline
\end{tabular}

\begin{tabular}{|l|c|c|c|c|}
\hline B) Services & $\begin{array}{c}\text { No } \\
\text { 1. Ecosystem maintenance }\end{array}$ & $\begin{array}{c}\text { Low } \\
\text { importance }\end{array}$ & $\begin{array}{c}\text { Medium } \\
\text { importance }\end{array}$ & $\begin{array}{c}\text { High } \\
\text { importance }\end{array}$ \\
\hline 1. Soil formation & & & & \\
\hline 2. Nutrient cycle & & & & \\
\hline 3. Climate regulation & & & & \\
\hline $\begin{array}{l}\text { 4. Water cycle/ } \\
\text { purification }\end{array}$ & & Low & $\begin{array}{c}\text { Medium } \\
\text { importance }\end{array}$ & $\begin{array}{c}\text { High } \\
\text { importance }\end{array}$ \\
\hline 5. Biodiversity & & & & \\
\hline 2. Direct to citizens & No & & & \\
\hline & importance & & & \\
\hline 1. Recreational uses & & & & \\
\hline 2. Cultural uses & & & & \\
\hline $\begin{array}{l}\text { 3. Indirect uses } \\
\text { (serenity, inspiration, } \\
\text {...) }\end{array}$ & & & & \\
\hline
\end{tabular}


Comments and/or recommendations: 


\section{Annex VI}

Questionnaire for the survey carried out amongst stakeholders to obtain the weights of the criteria for collaborative management and valuation of ecosystem services of the Serra d'Espadà natural park 



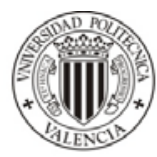

UNIVERSIDAD

POLITECNICA

DE VALENCIA

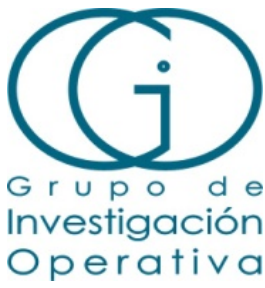

Criteria for collaborative management and valuation of ecosystem services of the Serra d'Espadà natural park

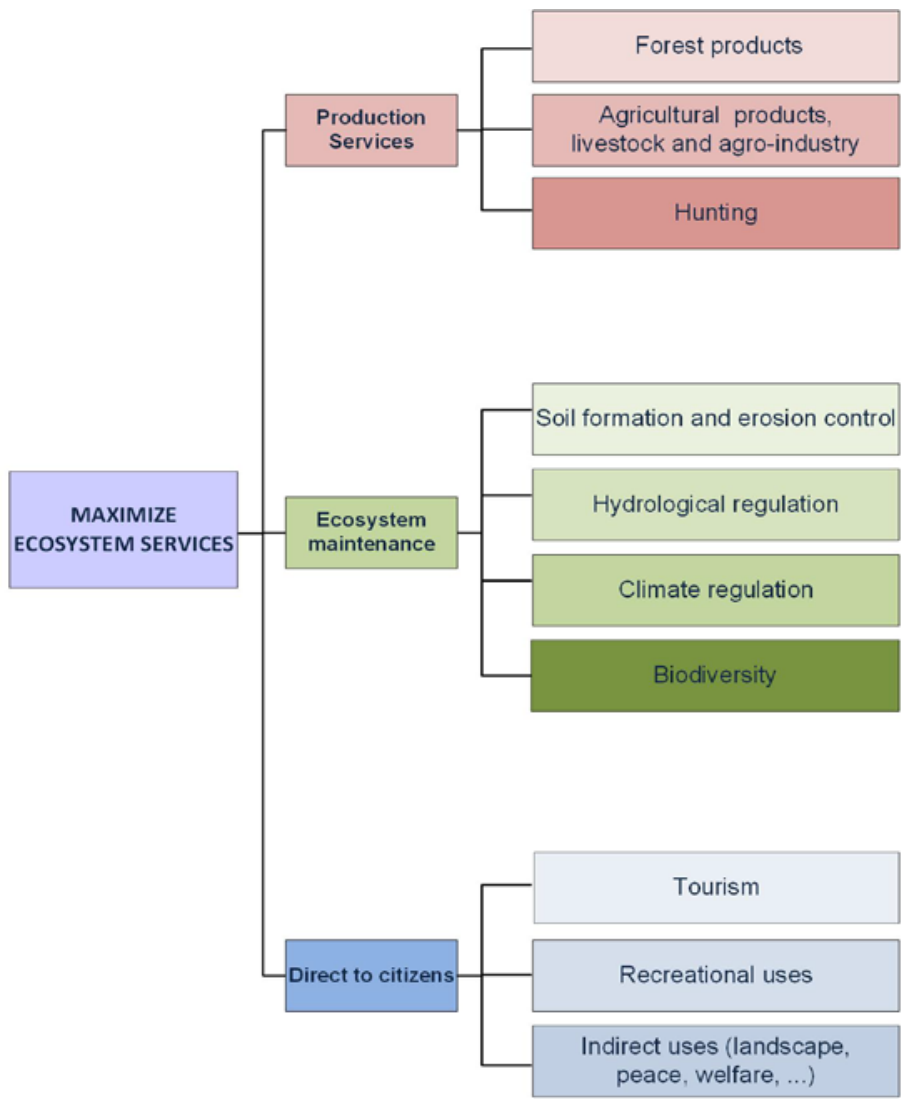


The survey was performed by pairwise comparison of the elements of the previous hierarchy. We will use the following scale of comparisons.

\begin{tabular}{|c|l|l|}
\hline $\begin{array}{c}\text { Importance or contribution } \\
\text { of one criterion versus } \\
\text { another }\end{array}$ & \multicolumn{1}{|c|}{ Definition } & \multicolumn{1}{|c|}{ Explanation } \\
\hline $\mathbf{1}$ & Equal importance & $\begin{array}{l}\text { Two activities equally contribute to the } \\
\text { objective. }\end{array}$ \\
\hline $\mathbf{2}$ & Weak importance & Intermediate importance between 1 and 3 \\
\hline $\mathbf{3}$ & Moderate importance & $\begin{array}{l}\text { Experience and judgement slightly in } \\
\text { favour of one activity over another }\end{array}$ \\
\hline $\mathbf{4}$ & Moderate/strong & Intermediate importance between 3 and 5 \\
\hline $\mathbf{5}$ & Strong importance & $\begin{array}{l}\text { Experience and judgement strongly in } \\
\text { favour one activity over another }\end{array}$ \\
\hline $\mathbf{6}$ & Strong/very strong & Intermediate importance between 5 and 7 \\
\hline 7 & $\begin{array}{l}\text { Very strong or } \\
\text { demonstrated } \\
\text { importance }\end{array}$ & $\begin{array}{l}\text { An activity is strongly favoured and its } \\
\text { dominance demonstrated in practice. }\end{array}$ \\
\hline $\mathbf{8}$ & Very, very strong & Intermediate importance between 7 and 9 \\
\hline $\mathbf{9}$ & Extreme importance & $\begin{array}{l}\text { The evidence favouring one activity over } \\
\text { another is of the highest possible order of } \\
\text { affirmation }\end{array}$ \\
\hline & \multicolumn{2}{|l}{} \\
\hline
\end{tabular}

With regard to the overall objective of maximizing ecosystem services, which one of the following objectives should be more important on a scale of 1 to 9 ?

\begin{tabular}{|c|c|c|c|c|}
\hline & $\begin{array}{l}\text { Production } \\
\text { Services }\end{array}$ & & & $\begin{array}{l}\text { Ecosystem } \\
\text { maintenance }\end{array}$ \\
\hline ० & 2 & & o & 2 \\
\hline$\circ$ & Moderate $=3$ & & $\circ$ & Moderate $=3$ \\
\hline$\circ$ & 4 & & $\circ$ & 4 \\
\hline$\circ$ & Strong $=5$ & & $\circ$ & Strong $=5$ \\
\hline ० & 6 & & ○ & 6 \\
\hline$\circ$ & Very strong $=7$ & & $\circ$ & Very strong $=7$ \\
\hline$\circ$ & 8 & & $\circ$ & 8 \\
\hline ○ & Extreme $=9$ & & o & Extreme $=9$ \\
\hline
\end{tabular}


With regard to the overall objective of maximizing ecosystem services, which one of the following objectives should be more important on a scale of 1 to 9 ?

\begin{tabular}{|c|c|c|c|c|}
\hline & $\begin{array}{l}\text { Bcosystem } \\
\text { maintenance }\end{array}$ & ○ Equal $=1$ & \multicolumn{2}{|r|}{$\begin{array}{l}\text { Direct to } \\
\text { citizens }\end{array}$} \\
\hline ० & 2 & & ○ & 2 \\
\hline o & Moderate $=3$ & & ○ & Moderate $=3$ \\
\hline o & 4 & & ○ & 4 \\
\hline ○ & Strong $=5$ & & ○ & Strong $=5$ \\
\hline ० & 6 & & ○ & 6 \\
\hline ० & Very strong $=7$ & & ○ & Very strong $=7$ \\
\hline$\circ$ & 8 & & $\circ$ & 8 \\
\hline 0 & Extreme $=9$ & & ○ & Extreme $=9$ \\
\hline
\end{tabular}

With regard to the overall objective of maximizing ecosystem services, which one of the following objectives should be more important on a scale of 1 to 9 ?

\begin{tabular}{|l|l|}
\hline $\begin{array}{c}\text { Production } \\
\text { Services }\end{array}$ & \multicolumn{1}{c|}{$\begin{array}{c}\text { Direct to } \\
\text { citirens }\end{array}$} \\
\hline 2 & $\circ$ Equal $=1$ \\
$\circ$ Moderate $=3$ & $\circ 2$ \\
$\circ 4$ & $\circ$ Moderate $=3$ \\
$\circ$ Strong $=5$ & $\circ 4$ \\
$\circ 6$ & $\circ$ Strong $=5$ \\
$\circ$ Very strong $=7$ & $\circ 6$ \\
$\circ 8$ & $\circ$ Very strong $=7$ \\
$\circ$ Extreme $=9$ & $\circ 8$ \\
& $\circ$ Extreme $=9$ \\
\hline
\end{tabular}


With regard to the objective of maximizing production services, which one of the following objectives should be more important on a scale of 1 to 9 ?

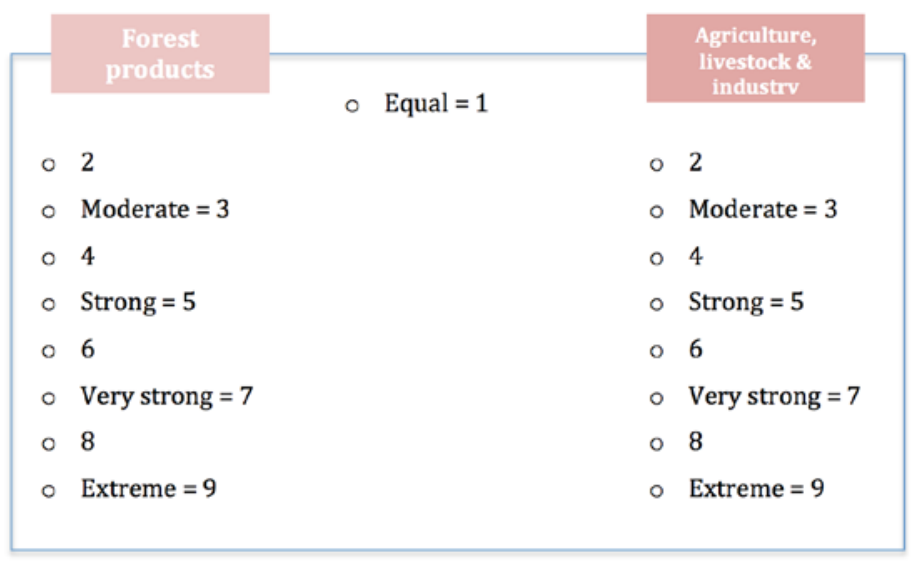

With regard to the objective of maximizing production services, which one of the following objectives should be more important on a scale of 1 to 9 ?

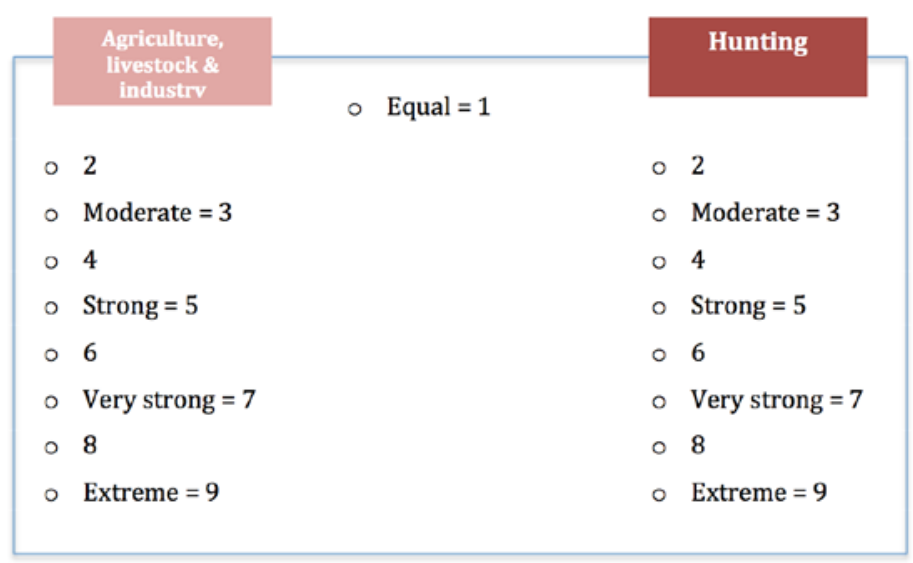


With regard to the objective of maximizing production services, which one of the following objectives should be more important on a scale of 1 to 9 ?

\begin{tabular}{|c|c|c|c|c|}
\hline \multicolumn{2}{|c|}{$\begin{array}{c}\text { Forest } \\
\text { products }\end{array}$} & Equal $=1$ & \multicolumn{2}{|r|}{ Hunting } \\
\hline ० & 2 & & $\circ$ & 2 \\
\hline$\circ$ & Moderate $=3$ & & $\circ$ & Moderate $=3$ \\
\hline ० & 4 & & 。 & 4 \\
\hline$\circ$ & Strong $=5$ & & $\circ$ & Strong $=5$ \\
\hline ० & 6 & & 。 & 6 \\
\hline$\circ$ & Very strong $=7$ & & $\circ$ & Very strong $=7$ \\
\hline ० & 8 & & 。 & 8 \\
\hline$\circ$ & Extreme $=9$ & & 。 & Extreme $=9$ \\
\hline
\end{tabular}

With regard to the objective of maximizing ecosystem maintenance services, which one of the following objectives should be more important on a scale of 1 to 9 ?

\begin{tabular}{|c|c|c|c|c|}
\hline \multirow{2}{*}{\multicolumn{2}{|c|}{$\begin{array}{l}\text { Soil formation } \\
\text { \& Erosion } \\
\text { Control }\end{array}$}} & \multirow{2}{*}{$\circ$ Equal $=1$} & \multirow{2}{*}{\multicolumn{2}{|c|}{$\begin{array}{l}\text { Hydrological } \\
\text { regulation }\end{array}$}} \\
\hline & & & & \\
\hline$\circ$ & 2 & & $\circ$ & 2 \\
\hline$\circ$ & Moderate $=3$ & & $\circ$ & Moderate $=3$ \\
\hline$\circ$ & 4 & & $\circ$ & 4 \\
\hline$\circ$ & Strong $=5$ & & $\circ$ & Strong $=5$ \\
\hline$\circ$ & 6 & & $\circ$ & 6 \\
\hline$\circ$ & Very strong $=7$ & & $\circ$ & Very strong $=7$ \\
\hline$\circ$ & 8 & & $\circ$ & 8 \\
\hline$\circ$ & Extreme $=9$ & & $\circ$ & Extreme $=9$ \\
\hline
\end{tabular}


With regard to the objective of maximizing ecosystem maintenance services, which one of the following objectives should be more important on a scale of 1 to 9 ?

\begin{tabular}{|c|c|c|c|c|}
\hline & $\begin{array}{l}\text { Hydrological } \\
\text { regulation }\end{array}$ & & & $\begin{array}{l}\text { Climate } \\
\text { regulation }\end{array}$ \\
\hline$\circ$ & 2 & & $\circ$ & 2 \\
\hline$\circ$ & Moderate $=3$ & & $\circ$ & Moderate $=3$ \\
\hline ○ & 4 & & $\circ$ & 4 \\
\hline o & Strong $=5$ & & o & Strong $=5$ \\
\hline$\circ$ & 6 & & $\circ$ & 6 \\
\hline$\circ$ & Very strong = 7 & & $\circ$ & Very strong $=7$ \\
\hline ० & 8 & & ○ & 8 \\
\hline ० & Extreme $=9$ & & ○ & Extreme $=9$ \\
\hline
\end{tabular}

With regard to the objective of maximizing ecosystem maintenance services, which one of the following objectives should be more important on a scale of 1 to 9 ?

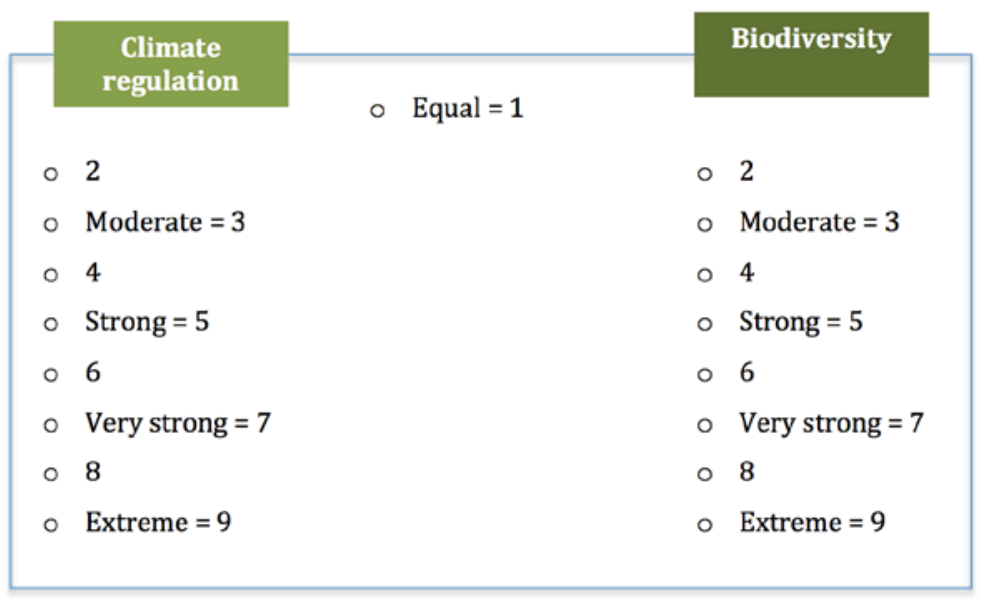


With regard to the objective of maximizing ecosystem maintenance services, which one of the following objectives should be more important on a scale of 1 to 9 ?

\begin{tabular}{|l|l|}
$\begin{array}{l}\text { Soil formation } \\
\text { \& Erosion } \\
\text { Control }\end{array}$ & \multicolumn{1}{c|}{$\begin{array}{c}\text { Climate } \\
\text { regulation }\end{array}$} \\
\hdashline$\quad 2$ & \\
$\circ \quad$ Moderate $=3$ & $\circ 2$ \\
$\circ 4$ & $\circ$ Moderate $=3$ \\
$\circ \quad$ Strong $=5$ & $\circ 4$ \\
$\circ 6$ & $\circ$ Strong $=5$ \\
$\circ \quad$ Very strong $=7$ & $\circ 6$ \\
$\circ 8$ & $\circ$ Very strong $=7$ \\
$\circ \quad$ Extreme $=9$ & $\circ 8$ \\
& $\circ$ Extreme $=9$ \\
\hline
\end{tabular}

With regard to the objective of maximizing ecosystem maintenance services, which one of the following objectives should be more important on a scale of 1 to 9 ?

\begin{tabular}{|c|c|c|c|c|}
\hline & $\begin{array}{l}\text { Hydrological } \\
\text { regulation }\end{array}$ & c Equal =1 & & Biodiversity \\
\hline$\circ$ & 2 & & ○ & 2 \\
\hline ○ & Moderate $=3$ & & $\circ$ & Moderate $=3$ \\
\hline ○ & 4 & & ○ & 4 \\
\hline ० & Strong $=5$ & & ○ & Strong $=5$ \\
\hline$\circ$ & 6 & & $\circ$ & 6 \\
\hline ○ & Very strong $=7$ & & ○ & Very strong $=7$ \\
\hline$\circ$ & 8 & & $\circ$ & 8 \\
\hline ○ & Extreme $=9$ & & ○ & Extreme $=9$ \\
\hline
\end{tabular}


With regard to the objective of maximizing ecosystem maintenance services, which one of the following objectives should be more important on a scale of 1 to 9 ?

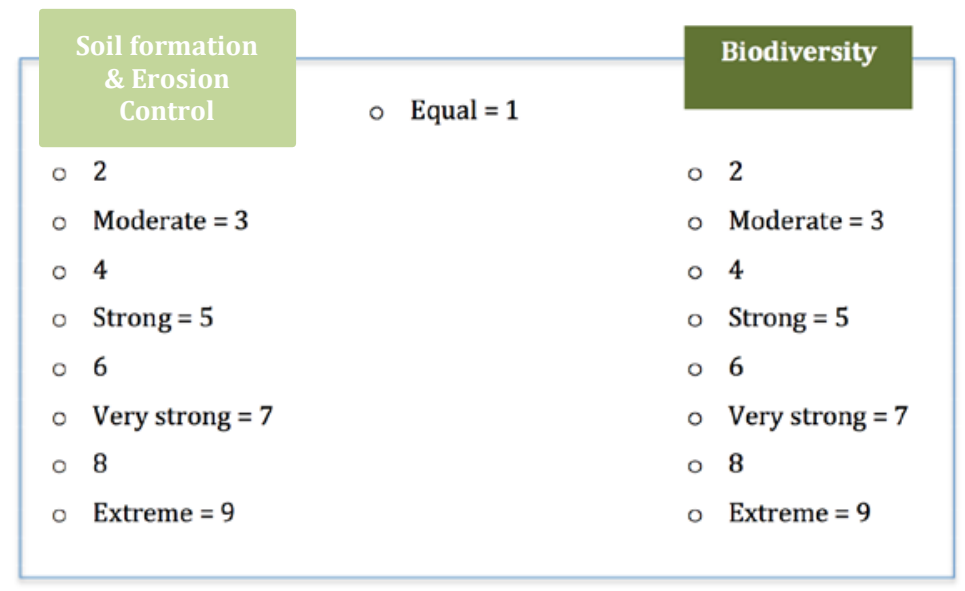

With regard to the objective of maximizing direct services to citizens, which one of the following objectives should be more important on a scale of 1 to 9 ?

\begin{tabular}{|c|c|c|c|c|}
\hline & Tourism & & \multicolumn{2}{|r|}{$\begin{array}{c}\text { Recreational } \\
\text { uses }\end{array}$} \\
\hline$\circ$ & 2 & & $\circ$ & 2 \\
\hline ० & Moderate $=3$ & & ० & Moderate $=3$ \\
\hline$\circ$ & 4 & & $\circ$ & 4 \\
\hline$\circ$ & Strong $=5$ & & $\circ$ & Strong $=5$ \\
\hline ० & 6 & & ○ & 6 \\
\hline o & Very strong $=7$ & & o & Very strong $=7$ \\
\hline$\circ$ & 8 & & $\circ$ & 8 \\
\hline 0 & Extreme $=9$ & & $\circ$ & Extreme $=9$ \\
\hline
\end{tabular}


With regard to the objective of maximizing direct services to citizens, which one of the following objectives should be more important on a scale of 1 to 9 ?

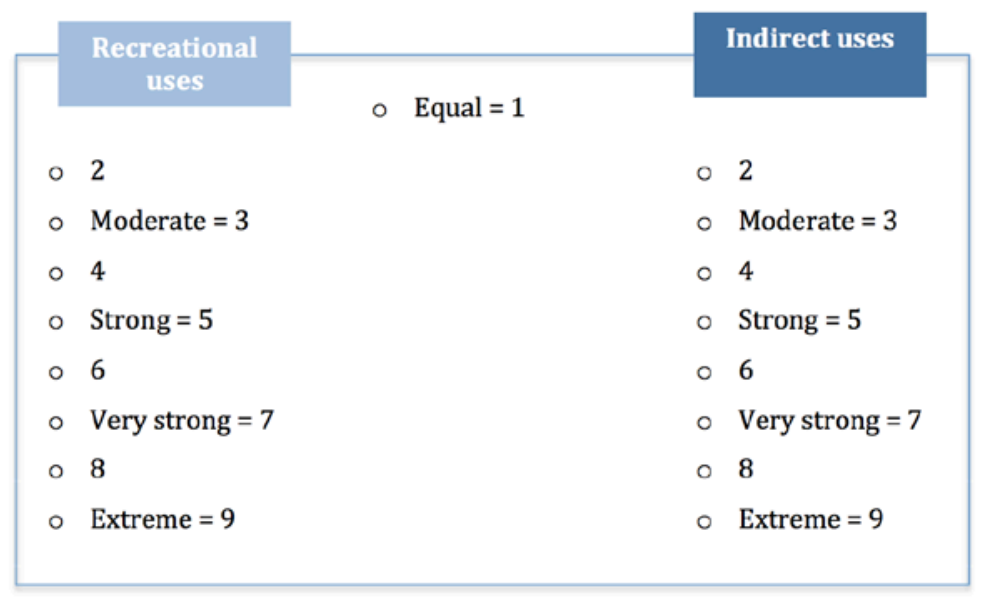

With regard to the objective of maximizing direct services to citizens, which one of the following objectives should be more important on a scale of 1 to 9 ?

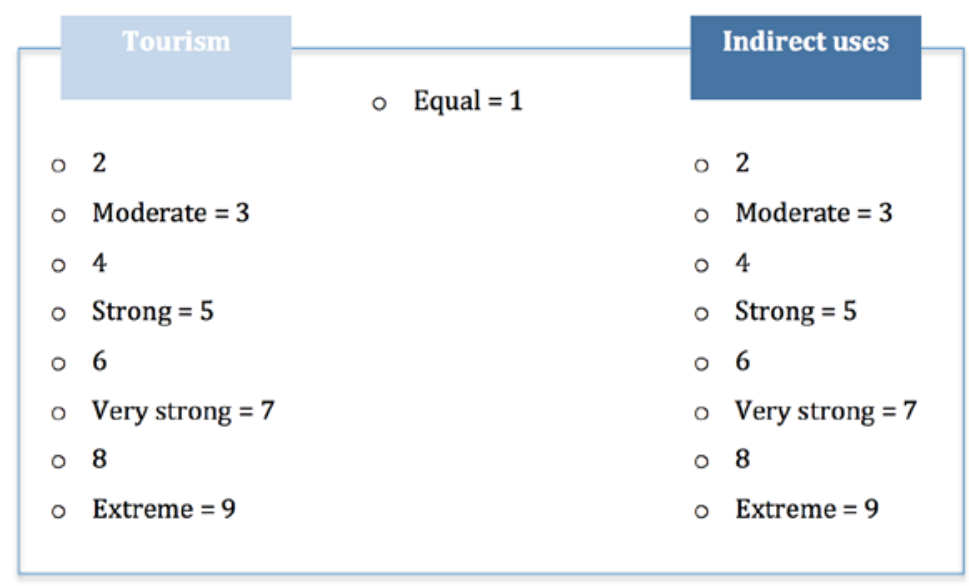


Comments and/or recommendations: 


$-$

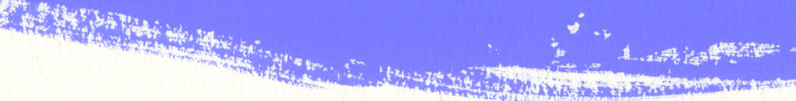

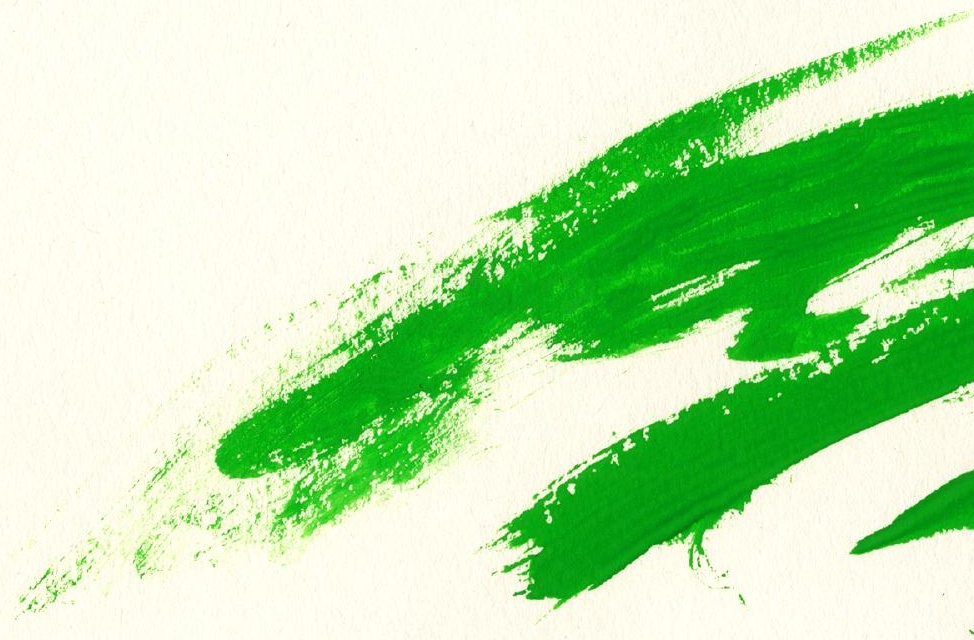

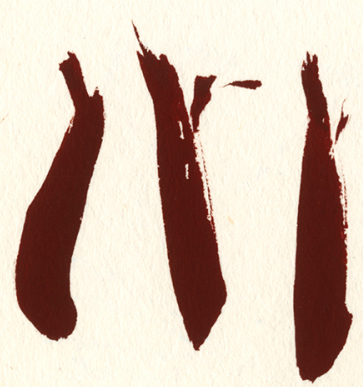
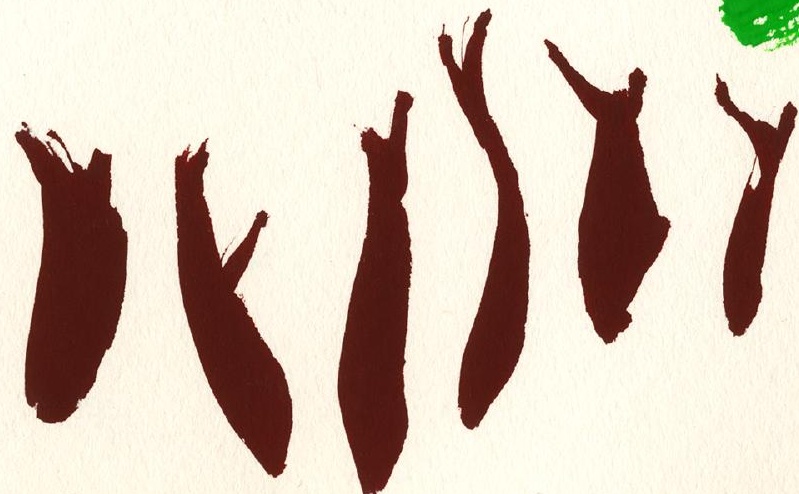